\title{
Beyond Access: Exploring Implementation of the Fair and Equitable Sharing Commitment in the CBD
}

ABS Series No. 2

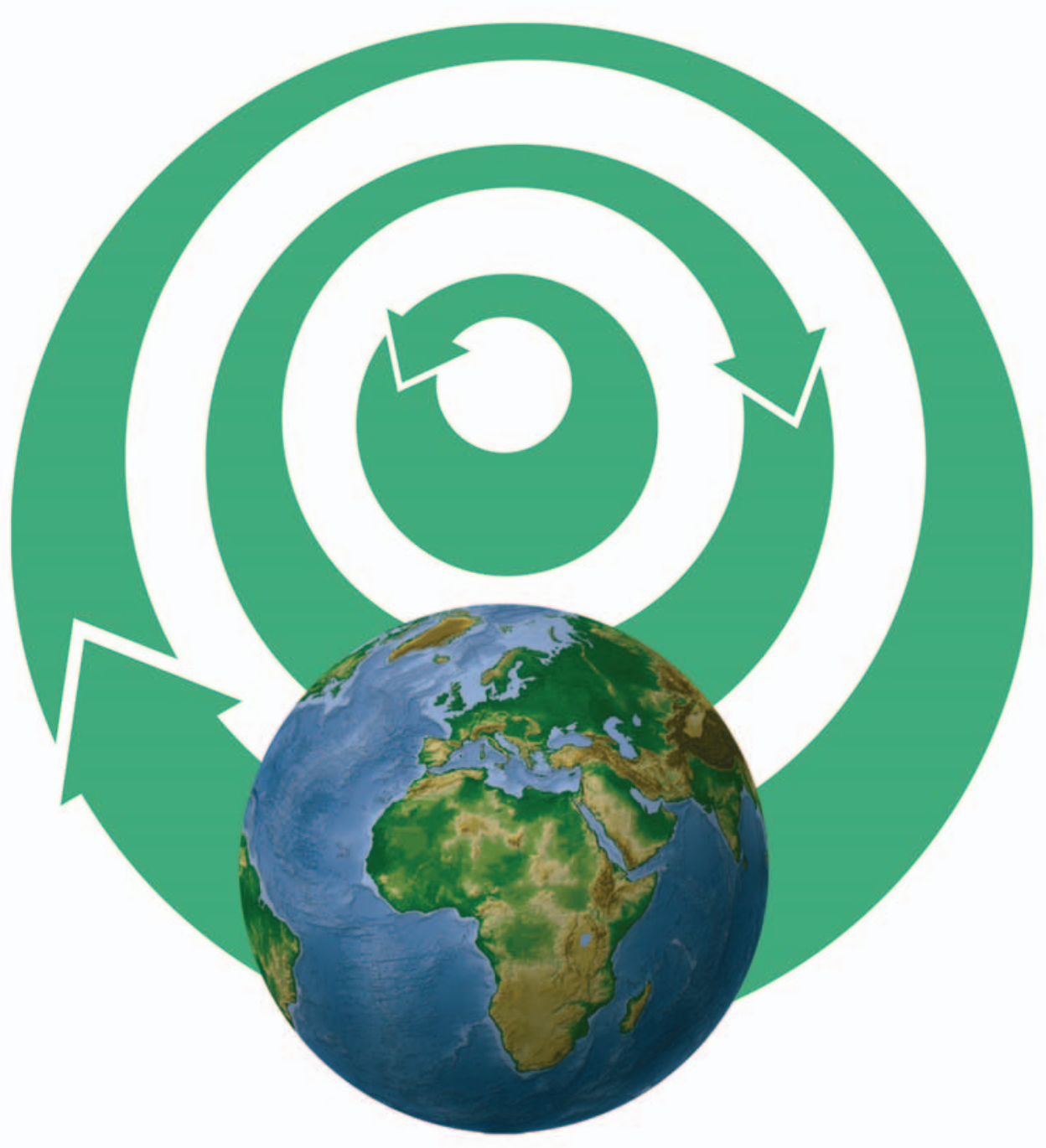





\section{Beyond Access:}

Exploring Implementation of the Fair and Equitable Sharing Commitment in the CBD 



\section{Beyond Access:}

Exploring Implementation of the Fair and Equitable Sharing Commitment in the CBD

Morten Walløe Tvedt and Tomme Young 
The designation of geographical entities in this book, and the presentation of the material, do not imply the expression of any opinion whatsoever on the part of IUCN or the German Federal Ministry for Economic Cooperation and Development (BMZ) concerning the legal status of any country, territory, or area, or of its authorities, or concerning the delimitation of its frontiers or boundaries.

The views expressed in this publication do not necessarily reflect those of IUCN or BMZ.

This publication has been made possible in part by funding from BMZ.

Published by:

IUCN, Gland, Switzerland in collaboration with the IUCN Environmental Law Centre, Bonn, Germany

Copyright:

(C) 2007 International Union for Conservation of Nature and Natural Resources Reproduction of this publication for educational or other non-commercial purposes is authorized without prior written permission from the copyright holder provided the source is fully acknowledged.

Reproduction of this publication for resale or other commercial purposes is prohibited without prior written permission of the copyright holder.

Citation: Tredt, Morten Walløe and Tomme Young (2007). Beyond Access: Exploring Implementation of the Fair and Equitable Sharing Commitment in the CBD. IUCN, Gland, Switzerland xx + 148 pp.

ISBN:

$978-2-8317-0980-2$

Cover design by: $\quad$ IUCN Environmental Law Centre

Cover image: $\quad$ Beverly Lorenc

Layout by: $\quad$ magoodesign $\cdot$ Markus Kahlenberg

Produced by: $\quad$ IUCN Environmental Law Centre

Printed by: $\quad$ medienHaus Plump, 53619 Rheinbreitbach, Germany

Available from: $\quad$ IUCN Publications Services

Rue Mauverney 28

1196 Gland

Switzerland

Tel: $\quad+41229990000$

Fax: +41229990002

E-mail: books@iucn.org www.iucn.org/publications

A catalogue of IUCN publications is also available.

The text of this book is printed on Novatech $90 \mathrm{~g} / \mathrm{m}^{2}$ paper made from raw materials originating from responsibly managed forests. 


\section{Table of Contents}

Foreword $\quad$ ix

Series Editor's Preface $\quad$ xi

About the Series $\quad$ xiii

Preface $\quad x v$

Acknowledgments $\quad$ xvii

Acronyms and Short Reference Names xix

Chapter 1 Introduction: Looking Beyond Access 1

1.1 Issues that need to be dealt with Beyond Access 2

1.2 Objective and approach 3

Chapter 2 The ABS Regime and the User 5

2.1 Overview: The ABS concept - CBD Article 15 and related decisions 6

2.2 CBD requirements applicable Beyond Access 8

2.3 Two sides of ABS measures - What is meant by "user measures"? $\quad 10$

2.4 Terminology of user and provider: Clarifying the concepts 12

2.4.1 Contract parties: "user" and "provider" and "middleman" 12

2.4.2 Understanding of the terms "user country," "provider country," "source country,"

2.5 "Access" and "benefit sharing" - exploring a link between these obligations 14

2.6 Conceptual deficit of ABS 15

2.7 Specific obstacles to ABS implementation $\quad 17$

$\begin{array}{lll}2.7 .1 & \text { Legal certainty } & 17\end{array}$

2.7.2 International provisions addressing private ABS actions 18

2.7.3 Applying conventional contractual law to a new concept of resource-based
ownership or rights

2.7.4 Lack of incentives in system construction 19

$2.8 \quad$ Legal and political importance of the ABS issue 19

Chapter 3 User Country Compliance with the Bonn Guidelines 21

$\begin{array}{lll}3.1 & \text { Functional approach } & 21\end{array}$

3.2 National "user measures" examined in this Chapter 23

3.2.1 Countries whose laws have been examined in greater detail 24

$\begin{array}{lll}3.2 .1 .1 & \text { Norway } & 24\end{array}$

3.2.1.2 United States 24

3.2.1.3 Costa Rica 25

3.2.1.4 Brazil 26

3.2.2 Other countries with specific measures and processes of interest 26

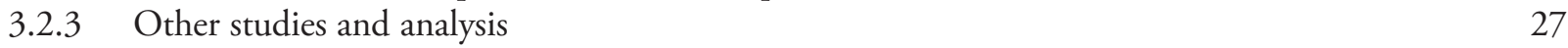

3.3 User-side legislative mandates 28

3.3.1 Requiring compliance with source country ABS law 29

3.3.1.1 The requirement as applied to ABS-compliant users 29

[a] Application of contract law to ABS situations 29

[b] Measures to assist source countries in overseeing ABS contracts and users 31

3.3.1.2 Users who have not complied with source-country ABS requirements 31

3.3.1.3 The roles of government, as user and advisor to users 33

$\begin{array}{lll}3.3 .1 .4 & \text { Disclosures in patent applications } & 34\end{array}$

3.3.2 Standards for determining performance 36

3.3.2.1 Identifying and applying the source country law 36

3.3.2.2 User measures where the source country is undisclosed 37

3.3.2.3 Practical problems: Applying source-country law 38 
[a] Description of the basic problems 38

[b] Current proposals for a partial solution - certificate of source, origin or legal provenance 38

3.3.2.4 "Equitable sharing" 39

3.3.2.5 Due process of law 39

3.3.3 Enforcing the rights of foreign providers under user country law 40

3.3.3.1 Source-country access to information about the utilization of genetic resources in the user country

$\begin{array}{lll}\text { 3.3.3.2 Disclosure as a step to enforcement } & 40\end{array}$

$\begin{array}{ll}\text { 3.3.3.3 Remedies and penalties in user countries } & 41\end{array}$

[a] Legal rights and remedies $\quad 41$

[b] Unadapted use of existing penal laws $\quad 43$

[c] Arbitration 44

3.3.3.4 Additional complications - undisclosed source $\quad 44$

3.4 User-side administrative responsibilities 44

3.5 Practical means of motivating compliance with user measures 45

3.5.1 Mandatory $\quad 46$

3.5.2 Non-mandatory provisions (voluntary measures and recommendations) 46

3.5.3 Incentive and motivation $\quad 47$

3.6 Summary - national adoption of user-side measures under the Bonn Guidelines 49

Chapter 4 Analyzing the "Building Blocks" of the ABS Concept on the User Side 51

4.1 Policy bases for benefits arising out of the utilization of genetic resources 53

4.1.1 The nature of "genetic resources"

4.1.1.1 "Containing functional units of heredity" $\quad 54$

4.1.1.2 "Of actual or potential value" 55

4.1.1.3 "Genetic resources" in international and national instruments 56

$\begin{array}{lll}\text { 4.1.1.4 Summary - biological versus genetic resources } & 57\end{array}$

4.1.2 The nature of activities that constitute "utilization of genetic resources" 58

4.1.2.1 The hidden issue 58

4.1.2.2 Defining "utilization of genetic resources"

4.1.2.3 Value of the concept

4.1.3 The nature of "benefits arising" from the utilization of genetic resources 60

4.1.3.1 What are "benefits" for Article 15.7 purposes? 60

$\begin{array}{lll}\text { 4.1.3.2 Whose benefits are considered? } & 61\end{array}$

4.1.3.3 Which benefits "arise out of" utilization of genetic resources? 61

4.2 The functional relationships - the three triggers of benefit sharing 62

4.2.1 The first trigger - "genetic resources" as a functional element 63

4.2.1.1 Option 1: "Genetic resources" as synonymous with "biological resources" 63

4.2.1.2 Option 2: "Genetic resources" as tangible "genetic material" 64

4.2.1.3 Option 3: "Genetic resources" refers to intangible "genetic information" 64

4.2.1.4 Option 4: "Genetic resources" combines physical and informational elements 65

4.2.1.5 Summing up - the genetic resource trigger 65

4.2.2 The second trigger: "Utilization of genetic resources" 65

4.2.2.1 Lists or categories of utilization of genetic resources 66

$\begin{array}{lll}\text { 4.2.2.2 Plant genetic resources as a particular category } & 67\end{array}$

$\begin{array}{lll}\text { 4.2.2.3 Further international development } & 68\end{array}$

4.2.2.4 Descriptive criteria for identifying utilization of genetic resources 69

4.2.3 The third trigger: "Benefits arising out of the utilization of genetic resources" 69

$\begin{array}{ll}\text { 4.2.3.1 Timing of "benefits arising" } & 69\end{array}$

$\begin{array}{ll}\text { 4.2.3.2 Operation of the benefit trigger } & 70\end{array}$

4.3 Applying the triggers - the CBD obligations to share benefits and research results 71

$\begin{array}{lll}\text { 4.3.1 Source-country agreement to benefit-sharing terms } & 71\end{array}$

$\begin{array}{ll}\text { 4.3.2 Sharing research results } & 72\end{array}$

4.4 Identifying an end point for the benefit-sharing obligation $\quad 73$

$\begin{array}{lll}\text { 4.4.1 Fulfillment of the ABS contract } & 73\end{array}$

$\begin{array}{lll}\text { 4.4.2 Transfers of genetic resources to third parties } & 73\end{array}$ 
Chapter 5 Applying Concepts of Valuation and Equity to Genetic Resources 75

5.1 Valuing "benefits arising" 75

5.2 Excludability and the value of genetic resources $\quad 76$

5.2.1 Genetic resources - as excludable or non-excludable goods?

$\begin{array}{ll}\text { 5.2.2 Excludability of the micro-physical element } & 78\end{array}$

$\begin{array}{ll}\text { 5.2.3 Accessibility of intangible or informational element } & 79\end{array}$

5.2.4 Patents as measures to convert non-excludable resources into excludable ones $\quad 80$

5.3 Approaches to valuing the contribution of genetic resources 80

5.3.1 Using prior contract data for valuation of genetic resources and negotiation of benefit share 81

5.3.2 Valuation using the "alternative value" method $\quad 82$

5.4 The fairness requirements - fair sharing and equity 83

5.4.1 Practical issues - legislation to ensure "fair sharing" $\quad 84$

$\begin{array}{ll}\text { 5.4.1.1 Determining a fair share } & 84\end{array}$

$\begin{array}{ll}\text { 5.4.1.2 "Sharing" intangible benefits } & 84\end{array}$

$\begin{array}{lll}\text { 5.4.1.3 Forms of payment } & 85\end{array}$

$\begin{array}{ll}\text { 5.4.2 Principles and objectives of equity } & 87\end{array}$

5.4.2.1 References to equity in the CBD and Bonn Guidelines 88

$\begin{array}{ll}\text { 5.4.2.2 Internationally recognized equitable principles } & 89\end{array}$

$\begin{array}{ll}\text { [a] Historic contribution } & 89\end{array}$

[b] Unjust enrichment - quantum meruit $\quad 90$

[c] "Clean hands" 90

5.4.3 Practical implications of equity in ABS 90

5.5 Broader equities - achievement of the Third Objective 92

5.5.1 Preserving diversity - recognizing the relationship between a genetic resource's uniqueness, its ecosystem and its value $\quad 92$

5.5.2 The CBD - an obligation to make genetic resources valuable 93

5.6 How economic, equitable and public interest principles inter-relate in ABS legislation 94

5.6.1 Reconciling value, equity and public interest in commercial ABS 95

5.6.2 How value, equity and public interest principles can be translated into practice 96

Chapter 6 Measures that Can Be Taken to Meet the User-side Commitment of the CBD Parties 99

6.1 User-side obligation: Achieving the benefit-sharing result, not simply adopting measures 99

6.1.1 Benefit sharing as the objective 99

$\begin{array}{ll}\text { 6.1.2 Binding/non-binding and voluntary/mandatory concepts } & 100\end{array}$

6.1.2.1 The term "legally binding" 100

6.1.2.2 "Voluntary" or non-binding measures 100

6.2 Using incentive and other motivation factors 102

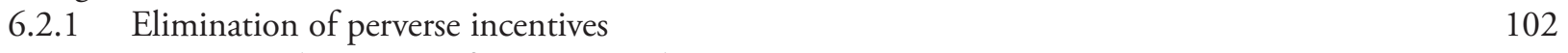

$\begin{array}{ll}\text { 6.2.2 Creating a disincentive for non-compliance } & 103\end{array}$

6.2.3 Removing disincentives for compliance 103

6.2.4 Positive incentives and motivators of compliance 104

6.3 Creating an international system for ABS 105

$\begin{array}{ll}\text { 6.3.1 Why national measures are not sufficient alone } & 106\end{array}$

6.3.2 Steps possible in unifying the "international regime" 106

6.3.2.1 Identifying the need for further international agreement 106

6.3.2.2 Questions to be addressed in the international regime negotiations 107

6.4 Practical implementation of ABS "Beyond Access" - adopting user-side measures 108

$\begin{array}{ll}\text { 6.4.1 Legislative justification } & 108\end{array}$

$\begin{array}{ll}\text { 6.4.2 Legislative objectives } & 109\end{array}$

6.4.3 The user-side legislative challenge: Relating to source-country law 109

$\begin{array}{lll}\text { 6.4.3.1 } \ldots \text { where there is an ABS contract } & 110\end{array}$

6.4.3.2 $\ldots$ in the absence of an ABS contract 110

6.4.4 Operative framework: user-side law relating to the benefit-sharing requirement 112 
6.4.4.1 Scoping and coverage - terms and triggers

[a] Definitions and scope for the triggers of the benefit-sharing obligation

[b] Stricter or different coverage

6.4.4.2 Provision imposing a direct benefit-sharing obligation 114

6.4.4.3 Oversight measures in user countries 114

[a] Clarification/specification of coverage questions $\quad 115$

[b] How the "triggers" function in practice 116

[c] What is required? A category approach 117

[d] Non-commercial benefits 117

[e] Transparency 118

[f] Benefit-sharing without an ABS contract $\quad 119$

[g] Confirmation of the data provided by the user $\quad 120$

6.5 Proposals for internationally accepted ABS measures and tools $\quad 120$

6.5.1 Source-country validation: Certificate proposals 121

6.5.2 Communication of user-side information to source countries - disclosure of origin 122

6.5.3 "Internationalized" mechanisms for benefit sharing 123

6.5.3.1 International fund and "standard payment" or tax system 124

6.5.3.2 The Fund under the International Treaty on Plant Genetic Resources 124

6.5.3.3 Special collections for genetic resource access and use of genetic resources 125

$\begin{array}{ll}\text { 6.5.4 Advantages and disadvantages of standard contracts } & 125\end{array}$

$\begin{array}{ll}\text { 6.5.5 Standard or "default" legislation } & 126\end{array}$

Chapter 7 Conclusions: User-side Measures - A Necessary Element of the International Regime on ABS

CODA: $\quad$ Beyond Beyond Access - Other User-side ABS Obligations in the CBD

CODA 1 Promoting "full source-country participation" in scientific research

CODA 1.2 Establishment of facilities and research activities in the source country 133

CODA 1.3 Creation of opportunities 134

CODA 2 Technology-transfer obligations in support of the third objective 135

CODA 2.1 Technology transfer and the sharing of less direct benefits 135

$\begin{array}{lll}\text { CODA 2.2 Technology transfer as an element of benefit-sharing } & 135\end{array}$

CODA 2.3 Comparing the "technology transfer" obligations 136

$\begin{array}{lll}\text { CODA } 3 & \text { Other genetic-resource-related responsibilities of user countries } & 136\end{array}$

$\begin{array}{ll}\text { References } & 139\end{array}$

$\begin{array}{ll}\text { About the Authors } & 145\end{array}$ 


\section{Foreword}

It is our pleasure to present this book Beyond Access: Exploring Implementation of the Fair and Equitable Sharing Commitment in the CBD, written by Morten Walløe Tvedt and Tomme Rosanne Young, which is published as IUCN Environmental Policy and Law Paper (EPLP) No. 67/2. This book represents an important contribution to the body of ABS literature currently available and is provided at a critical time in the development of $\mathrm{ABS}$ as a functional concept and international regime. The IUCN EPLP series dates back to 1972, and has through 35 years maintained a high standard of legal scholarship and quality outputs.

The Fridtjof Nansen Institute is renowned for its work in international law and policy, and has produced a number of publications addressing ownership and benefit sharing in the field of biodiversity and genetic resources. This book is well in line with FNI's previous and projected contributions to the literature in this field.

The ABS Series, which includes this book, is the first "sub-series" within the EPLP series, designed in this way to maximize the usefulness and accessibility of these writings to the broad range of participants addressing the ABS challenges at both national and international levels. We believe that this Series offers a substantial contribution that will enable progress on an issue which has, to now, been stymied both by its complexity and by its controversial nature. It is only through the understanding of those complexities that consensus and useful compromise can be attained that will resolve the controversies and enable a functional system for achieving the all-important equity objective of the Convention on Biological Diversity.

We are sincere in our hope and belief that this book also represents another milestone in enhancing collaboration between IUCN and the Fridtjof Nansen Institute.

\section{Dr. Alejandro Iza}

Director

IUCN Environmental Law Centre
Peter Johan Schei

Director

Fridtjof Nansen Institute

September, 2007 



\section{Series Editor's Preface}

In the course of The ABS Project, IUCN's Environmental Law Centre has taken a central position in promoting researched and balanced analysis of critical components of the current discussions of the international regime on access and benefit sharing under the CBD. The ABS Series provides the culmination of these efforts, enabling recognized experts to undertake intensive research and present detailed, balanced and reasonable analysis. It operates as a counterpoint to the growing numbers of authors whose work in ABS issues is sometimes more focused on advocacy than research. With this Series, we are trying to take a very different approach and to achieve a very different objective. Simply put, we hope to provide a deeper understanding of the legal, economic, practical and factual issues affecting the debate, and to build our analyses and recommendations on intensive legal research.

As a co-author of Beyond Access: Exploring Implementation of the Fair and Equitable Sharing Commitment in the $C B D$, I have little that can or should be said about the book in this preface, apart from expressing my individual gratitude for the opportunity it has given me to work with a fine legal mind and one of the most excellent collaborators it has been my pleasure to work with in my $20+$ years of legal research, analysis and redaction. It was truly a stroke of luck for The ABS Project to find such a lawyer who is both committed and able to address this complex issue with the highest level of legal scholarship and an undeniable desire to find solutions and alternatives that can help promote this issue. I hope that his careful and thoughtful insights and analysis on this and many other important issues will continue to be well recognized in future. I am very grateful to Peter Johan Schei, Director of the Fridtjof Nansen Institute, for many contributions of knowledge, experience and insight, as well as for enabling Morten to make this important contribution to international development of this critical issue.

This book and indeed the entire Project owe a great debt to our primary financial supporter, the German Federal Ministry for Economic Cooperation and Development (Bundesministerium für wirtschaftliche Zusammenarbeit und Entwicklung or $B M Z$ ), and especially to Julia Kaiser, Andrea Laux and Frank Schmiedchen - without whom this work could not have been completed. Numerous other partners and collaborators have also made important and sustaining commitments for which we are very grateful.

Finally, I express our gratitude for the support and foresight of Dr. Alejandro Iza and the IUCN Environmental Law Centre. It was through Dr. Iza’s efforts that The ABS Project became a reality, and his understanding of the difficulties in its implementation as well as his support and the unstinting assistance of the staff of the Environmental Law Centre, especially Legal Officer Daniel Klein, Project Assistant Ann DeVoy, Senior Information and Documentation Officer Anni Lukács, Documentation Officer Andrea Lesemann and Documentation Assistant Monica Pacheco-Fabig. Collectively, these individuals have been a primary reason that the Project could finish its work and that outputs throughout the term of the project have achieved the level of legal excellence expected of the IUCN Environmental Policy and Law Papers, among which The ABS Series has been included.

Tomme Rosanne Young

Series Editor and Project Manager, The ABS Project

September, 2007 



\section{About the Series}

The ABS Series represents a response to two realities: First, the ABS issue is controversial, and technically and legally complex. Because of the constant international concern over controversial policy and political issues, the primary focus of all writing on $A B S$ has been focused on political positions and advocacy, even where the expressed purpose of a particular document is "practical legal advice." Lack of a rigorous body of $\mathrm{ABS}$ analysis has been one part of this implementation problem. Many professional inputs are characterized by opinions that are unsupported, or supported only by citations to the opinions of other experts or random references to or excerpts from laws and policy instruments, taken out of context.

To IUCN's Environmental Law Centre, it has become clear that the complexity and the controversiality are linked problems. Solutions to the international ABS controversies are currently stymied by the lack of credible, non-biased technical analysis of the elements and issues of national implementation. Serious in-depth analyses are needed concerning not only the few ABS examples, but also the kinds of legal options that are available, and the manner in which they function. Simply put, one cannot build a structure without the right tools - and having the tools is meaningless without knowledge of what they can and cannot do.

The second "reality" faced by this project is the fact that, despite the long-extending international negotiations, genetic resources are being taken, studied, developed and utilized every day. Countries do not have the luxury of waiting for international negotiations to answer their questions, before taking action. It is consequently urgent for all parties (users, source countries, source communities and resource owners, user countries, researchers, middlemen and others) to have some basis for taking these actions. More important, they need to have some certainty that this basis will be robust enough to protect his/its rights, even after international negotiations provide some guidance or assistance to all or part of the ABS issue. Even where national laws and practices exist, they are proving inadequate to this objective, in some measure owing to the lack of technical help, as described above.

Consequently, The ABS Series focuses on national implementation and the legal and legislative issues that must be addressed, rather than advocating or addressing a particular side or position in the international negotiations. Through this process, The ABS Series seeks to create the best possible basis of researched information on the practical application issues. It is thus not only a tool for national decisionmakers but also for implementers. While it is not always possible to be certain that one has been unbiased, we have made an effort, at minimum, to note the existence of other credible positions on the issues discussed, and to give some reasons why these positions were not more fully expounded.

As of this writing, the international process for development of the ABS regime is ongoing. While not intended to "influence" that process, The ABS Series has been designed and written in the hope that a better knowledge of the realities of ABS will enable the negotiators to develop the regime as a functional and effective tool of conservation, equity and international development. As such, we believe that the books in this Series will continue to be primary works of scholarship and professional analysis on which the architects and implementers of the ABS regime will rely long after the negotiations have concluded. In addition, it is hoped that the authors in the Series (or a team of similarly qualified experts) will be engaged to update relevant books from the Series, when the time is right.

Target audiences: Writing for a broad audience can sometimes be challenging for lawyers. In The ABS Series, however, we recognize that our primary audience includes national decision-makers, NGOs and others, as well as lawyers and economists. We have endeavored to present our research in an accessible way, without doing harm to our absolute standard of legal correctness. Although many readers would like a "simplified" pamphlet-style analysis of the ABS issue, which can answer all of their questions in a few pages, 
this is not possible - the only simple fact about ABS is that it is not simple. The ABS Series provides summaries of the complexities in the issue that legal specialists must grapple with, but at the same time attempts to avoid "legalese" and its companion "econo-ese." In this way, we feel that The ABS Series provides both clarity and understandability for the non-lawyer, who may obtain a thorough grounding in the $\mathrm{ABS}$ issue through reading these books. For the legal or economics professional, however, these books also provide resources and information that will enable their deeper understanding of $\mathrm{ABS}$ issues.

The future: The ABS issue is still evolving. After the commencement of The ABS Project, the CBD entered on a groundbreaking process of re-evaluating $\mathrm{ABS}$ and attempting to develop the necessary tools, consensus and understanding (e.g., a clearer and more functional "international ABS regime") that will enable progress toward achieving the goals of the
CBD. With this decision, The ABS Project underwent its first evolution. It had begun as a project aimed at helping national governments to find some positive steps to enable them to try to achieve the fixed language of CBD Article 15. In 2004, it necessarily expanded that focus - embracing the goal of informing all participants and interested persons (at national, regional and international level) regarding the options, instruments, practices and processes that can enable the ABS regime to become a functional mechanism for achievement of the CBD third objective. Only time can decide how far the international negotiations will go toward assisting and supporting ABS implementation. The team of professionals who have worked to provide The ABS Series hope that a useful and innovative result is quickly obtained, and that we will all have the opportunity to extend the work of this Series and to guide, analyze and promote the new regime components that will be developed. 


\section{Preface}

The issue of "access and benefit sharing" under Article 15 of the Convention on Biological Diversity has, throughout the past 16 years, offered both a challenge and an opportunity. Of these, perhaps the most important is the opportunity - to find a way to promote long-term global objectives of conservation, sustainable use and social welfare through the use of modern technologies, markets and commercial incentives. The challenge, however, is massive - to develop and agree on legal mechanisms, methodologies, and specific policy approaches to concretize this amorphous concept and give it legal and practical reality, and most important enable it to achieve those objectives.

One of the greatest areas of disconnection in this process relates to the role of the so-called "user country" - that is, the country whose jurisdiction includes companies and other entities that are using genetic resources from another country. In each transaction, the user country has a particularly important role in the development of coordinated governmental (legislative, policy or administrative) measures to complement the law and practices of the "source country," as a means of ensuring, first, that benefit sharing occurs and, second, that it satisfies the letter and spirit of Article 15. The limited extent of "user measures" has been a source of controversy, with some OECD countries indicating that no additional legislation is needed, while many source countries and NGOs argue that without additional measures the $\mathrm{ABS}$ systems cannot function as a commercial mechanism.

This book is intended to offer a basis for evaluating and elaborating either of these views. It discusses:

- the role of user countries in the ABS processes;

- the existing user-oriented legislation currently in place;

- the manner in which ABS principles and concepts can be interpreted and applied to the development of the user side of ABS; and,

- (perhaps most important) a variety of recommendations and options about how user-oriented measures can promote $\mathrm{ABS}$ objectives, including by creating incentives and other features that make the system attractive to the users themselves.

All CBD Parties are required under Article 15.7 to adopt user-side measures - this is a basic principle underlying the work of this book. In the end, such measures are potentially of significant value to the user and to the country in which the user operates as well. The Bonn Guidelines negotiations were heavily laced with frequent and detailed comments about what users need and why users are not complying with $\mathrm{ABS}$ requirements. Ultimately, those guidelines are overwhelmingly focused on the "access" side of $\mathrm{ABS}$ and questions of what source countries and communities can/should expect from ABS. Consequently, they ignore a critical fact: It is not enough to say that the law must impose additional requirements on users. It is essential that all such measures must be integrated into existing commercial and industrial laws and institutional systems. In particular, the question of quid pro quo (i.e., what is given in exchange for what is received) at the transactional level has been ignored.

In the CBD negotiations, the quid pro quo between the negotiating countries was clear. Nationally, countries committed to enabling access to genetic resources (a commitment sought by developed countries on behalf of their research and industrial sectors), and in exchange for developing countries' agreement to this commitment, developed countries agreed to a second commitment - to develop a mechanism for sharing the benefits of the utilization of genetic resources with the country of origin. In essence, both groups received a desired objective, in exchange for committing to one for which they have less desire.

In national implementation, however, the idea that participation in this program should yield benefits has been ignored. At present, the provision of "access" has not yielded any significant benefits to the access provider at the level of national implementation; while the compliance of users with benefit shar- 
ing is infrequent, in part because users feel that they do not receive anything of value in return for their compliance. While provider countries, stakeholders and NGOs seek to impose stronger requirements, sanctions and other measures on access to genetic resources, users (especially researchers and others directly collecting resources in developing countries) bear the brunt of the failure. These user burdens include the possibility of high-profile claims of "biopiracy," but also less known burdens. For example, the provider country may impose limits on the materials that the user can confidently use. It is increasingly possible that other users may express doubts about the provenance of genetic materials at the time that materials and research are being transferred.

The expectation that source-country legislation can provide what the user needs (or protect the source's rights) seems to be misplaced, given that current approaches to ABS arrangements (i.e., ABS contracts and/or ABS permits), benefit sharing, and the other ABS implementation concepts are based on contractual, property and other commercial actions and legal constructions. Expecting the source country to develop measures that improve the situation for the user is essentially asking the seller to give up many negotiating points before he knows who the buyer is, which property is to be sold, what kind of sale it is, the terms of payment, etc.

User measures, including measures clarifying the relationship between the source/origin country and the user and user country, can enable the user country to address some of the user's concerns, and especially to find a way that ABS compliance can provide some positive result for users that will balance the costs of compliance (in the form of money, goods, services and opportunities paid in benefit sharing, but also in the additional time, manpower and money involved in complying with $\mathrm{ABS}$ regulations and requirements).

This volume addresses the balance in this quid pro quo of users and providers of genetic resources.

\author{
Morten Walløe Tvedt \\ and \\ Tomme Rosanne Young
}

August, 2007 


\section{Acknowledgments}

Through the long process of creating this book, we have been assisted in a variety of ways, both substantive and practical, by a number of knowledgeable and helpful sources. It is not possible to fully describe all such assistance; however, it is essential at least to recognize it and express our gratitude to those who made the most significant contributions of time and effort. Accordingly, we want to thank the following people for their active assistance: Ann DeVoy, Project Assistant of IUCN's Environmental Law Centre, who has provided a strong and supporting hand to our work from its inception, and her colleagues Anni Lukács, Monica Pacheco-Fabig, Jil Self, who also provided critical services quickly and cheerfully; Tiina Rajamets for proofreading and other advice; and Daniel Klein, who has served as the focal point of the
Project since he joined IUCN's Environmental Law Centre in August, 2006.

In terms of the legal and political substance of this book, we obtained information, advice and suggestions from many sources. We are particularly grateful for peer review provided by Manuel Ruiz and Fernando Casas, and for substantive input and comments from: Françoise Burhenne-Guilmin, Jorge Caillaux, Grethe H. Evjen, Ute Feit, John Herity, Sarah Hernandez, Timothy Hodges, Birthe Ivars, Olivier Jalvert, Veit Koester, Horst Korn, Ikechi Mgbeoji, Valerie Normand, Dan Ogolla, Maria Julia Oliva, François Pithoud, Peter Johan Schei, Sezanneh M. Seymour, Caroline Strulik and Seizo Sumida. 



\section{Acronyms and Short Reference Names}

ABS

AHWG-ABS

Bonn Guidelines

Cartagena Protocol

CBD

COP

DNA

GEF

IGC

ITPGRFA

MAT

MOP

MS

NFP

NPS

PIC

SMTA

TRIPS Agreement

UPOV

WIPO

WSSD

WTO "access to genetic resources and fair and equitably sharing the benefits arising from their utilization," as conceived under Articles 1 and 15 of the CBD, also known as "access and benefit sharing"

Ad hoc Open-ended Working Group on ABS, under the CBD-COP

Bonn Guidelines on Access to Genetic Resources and Fair and Equitable Sharing of the Benefits Arising out of Their Utilization (2002)

Cartagena Protocol on Biosafety to the Convention on Biological Diversity (Nairobi, 2000)

Convention on Biological Diversity (Rio, 1992)

Conference of the Parties (unless otherwise stated, "COP" when used alone, refers to the CBD COP)

deoxyribonucleic acid

Global Environment Facility

WIPO Intergovernmental Committee on Genetic Resources, Traditional Knowledge and Folklore

International Treaty on Plant Genetic Resources for Food and Agriculture (Rome, 2001)

Mutually Agreed Terms

Meeting of the Parties

Multilateral System

National Focal Point

National Parks Service (used herein in reference to the United States National Parks Service)

Prior Informed Consent

Standard Material Transfer Agreement

Trade-Related Intellectual Property Rights Agreement

International Union for the Protection of New Varieties of Plants (Union internationale pour la protection des obtentions végétales)

World Intellectual Property Organization

World Summit on Sustainable Development (Johannesburg, 2002)

World Trade Organization 



\section{Introduction: Looking Beyond Access}

For over 16 years, the international community has sought to create and implement "access and benefit sharing" or ABS - a mechanism to address the roles of commercial entities and other developers of genetic resources as well as the roles of the countries and communities from which the genetic resources had their origin - in promoting critical environmental and social welfare objectives. This work grew out of several recent antecedents. In particular, in the late 1980s, the concept of a "common heritage of mankind" began to evolve into a more complex model, which recognized the sovereign rights of countries over their living and inanimate natural resources. Over time, however, it was recognized that users of those resources were able to obtain great value from them without significant return to the source country. Pharmaceutical, genetic modification and biochemical activities were thought to yield enormous profits, but their commercial development and marketing has been based on few specimens. As a result, source countries could not realize income from this use through bulk harvesting and sale.
The quest for a system that would provide an equitable return to developing countries in these situations was focused and coalesced into ABS, within the negotiations of the Convention on Biological Diversity (CBD), ${ }^{1}$ where it served two purposes. First, it was perceived to be a possible source of additional funds always necessary for conservation. Second, it was seen as the quid pro quo of developing countries' acceptance of the Convention. Given that developing countries often bear the greatest burden in conventions relating to conservation, the equity component of the CBD was designed to place a balancing obligation on developed countries. Since 1992, the two elements of ABS, "access" and "benefit sharing," have been formal commitments of all Parties. For the succeeding decade, however, it was assumed by many that source-country legislation and "ABS contracts" would be sufficient to implement these commitments. ${ }^{2}$ It was troubling, ten years later, to find that fewer than $10 \%$ of CBD Parties had adopted ABS legislation, ${ }^{3}$ and that virtually none of those claimed that their ABS arrangements were functioning effectively. ${ }^{4}$

1 Preparatory Committee reports are no longer available in the CBD websites. For a discussion of the role of genetic resources as proposed at the time, see the Reports of the two meetings of the Intergovernmental Committee on the CBD (ICCBD), prior to its entry into force, see, "Report of the First ICCBD" (preserved as UNEP/CBD/COP/1/3, found online at http://www.biodiv.org/doc/meetings/cop/cop-01/official/cop-01-03-en.pdf), at paras 5,6 and 31 et passim, and "Report of the Second ICCBD" (preserved as UNEP/CBD/COP/1/4, found online at http://www.biodiv.org/doc/meetings/cop/cop-01/official/cop-01-04-en.pdf), especially at pages 49-58. It is useful to note that these reports also set a high priority on addressing the problems and needs of ABS, expressing that priority in ways that are nearly identically to more current statements of those needs.

2 See, e.g., Reid et al., 1993; Glowka et al., 1994; Glowka, 1998. All of these commentators noted confounding issues in ABS, but felt them to be surmountable obstacles.

3 The $10 \%$ statistic is drawn from the CBD's Database of ABS Measures, at http://www.biodiv.org/programmes/socio-eco/benefit/measures.aspx. A total of 29 countries and three regional bodies have submitted a total of 95 measures to the database, twenty-seven of which are either "strategy" or other non-binding instruments. Of the remaining 68 measures, two are drafts and 28 contain authorizations to regulate, but do not include specific regulations clarifying the process of obtaining access to genetic resources. The remaining 38 instruments come from one region and 19 countries. They contain adopted, implementable, legal, regulatory, or other measures that apply as law to ABS matters within their country. Some of these, however, are controls on access to "biological resources" - a much broader concept than "genetic resources," as discussed in 4.1.1. None of them require users in their country to share benefits arising from the use of genetic resources with origin in other countries.

4 The exception to this comment is Queensland, Australia, whose 2004 Biodiscovery Act is highly touted by its government as being an effective mechanism. (Geoff Burton, Presentation to the High-level Experts Meeting: Addressing the Access and Benefit-Sharing Challenges in the Context of the Convention on Biological Diversity (Tokyo, 8-9 February 2007) and other remarks in that meeting.) Like all other currently existing ABS legislation, however, this Act does not include "user-side" measures as discussed in this book. The inability of any country to claim a legally functional system was intensively discussed in the Global Biodiversity Forum 2000, in Nairobi, preceding CBD COP-5. Governmental representatives of the countries and region with the longest standing legislation - e.g., Costa Rica (whose ABS forerunner legislation was originally adopted before the Convention), the Philippines (1995), and the Andean Pact (1996) - have generally admitted that their legislation does not operate to impose mandatory controls nor to enable oversight or verification of any parts of their ABS permissions. In addition, the non-functionality of current legislation became a primary reason underlying the call for the "negotiation of an international regime on ABS" in the WSSD Plan of Implementation (2002). 
In 2003, the ABS landscape again began to change, when the Plan of Implementation of the World Summit on Sustainable Development (WSSD) in Johannesburg emphasized that the CBD is "...the key instrument for the conservation and sustainable use of biological diversity and the fair and equitable sharing of benefits arising from use of genetic resources." 5 The Plan specifically included ABS as one part of its call for "a significant reduction in the current rate of loss of biological diversity," calling on countries to:

\section{(o) Negotiate, within the framework of the Convention on Biological Diversity, bearing in mind the Bonn Guidelines, an international regime to promote and safeguard the fair and equitable sharing of benefits arising out of the utilization of genetic resources; ${ }^{6}$}

This political mandate was concretized by the seventh CBD Conference of the Parties (COP-7), when it mandated the Ad Hoc Working Group on Access and Benefit Sharing (the "AHWG-ABS") to -

\section{...elaborate and negotiate an international regime on access to genetic resources and benefit-sharing with the aim of adopting an instrument/instruments to effectively implement the provisions in Article 15 and Article $8(j)$ of the Convention on Biological Diversity and the three objectives of the Convention. ${ }^{7}$}

The commencement of negotiations opened a new stage in $\mathrm{ABS}$, giving the Parties a mandate to identify areas in which international decision-making can enable a functional ABS system. Thus, the goal is no longer to "make the best of what Article 15 says," but rather to determine how an ABS system can be designed to function effectively.

\subsection{Issues that need to be dealt with Beyond Access}

"Access and benefit sharing" or "ABS" is, by definition, the fusion of two concepts which are politically and (to a very limited extent) legally or contractually linked. In general, "access" is perceived to be primarily the responsibility of the source country, source community or individual, while "benefit sharing" is founded on the user (private company or entity) to be made legally effective by the country with jurisdiction over that user.

A critical element of $A B S$ is its trans-national nature. At least two countries are involved in every ABS transaction - a "source country" (from which genetic resources are obtained) and a "user country" (which has jurisdiction over the user). ${ }^{8}$ Even this statement is a severe oversimplification, as genetic resources often involve multiple uses, exchanges and activities - i.e., a particular utilization may involve many source countries and even many user countries. Article 15 does not include or even mention domestic access to or utilization of genetic resources; although, as a practical matter, it may be necessary for countries to regulate domestic utilization (at least in some aspect) in order to avoid gaps and "loopholes" in the regulation of external users. This means that there are a minimum of two distinct national legislative components ${ }^{9}$ to every $\mathrm{ABS}$ situation:

5 Johannesburg Plan of Implementation Article 42.

6 Johannesburg Plan of Implementation Article 42 (o).

7 Decision by the COP-7, UNEP/CBD/COP/7/21, VII/19 D p. 299.

8 The concept of the "user country" was not fully discussed in the CBD. The Bonn Guidelines consequently did not initially address the user countries, focusing instead on the "user" (company or individual) alone. As finally adopted, however, they include some references, using clearer terminology: "Contracting Parties with users of genetic resources under their jurisdiction." At para 16(d).

9 The CBD's provisions call for ABS to be implemented through national legislation. None of its provisions are written in a way that would allow them to be self-executing at the level of individual contracts, or to be adopted into national law by reference. Indeed, since international agreements between countries state what countries must do, they do not usually contain provisions that an individual or contract could rely on as law. They can only be applied through the law of a country. (This is so well understood in law, that most legal treatises do not state it. One source to review on this point might be Shany, 2003 at 29-74.) It is possible to create "self-executing conventions" - that is, conventions which do not need additional national law once the country accedes - but these are very different in nature. In essence, such a convention would include relevant code-style provisions directly, 
i. Source-country measures, ${ }^{10}$ including provisions asserting each country's sovereign rights over genetic resources, and the identification of access procedures and requirements; and

ii. User-country measures, by which each country addresses the responsibility of users under their jurisdiction who are utilizing genetic resources from other countries.

Up to now, however, even in countries with many users, most existing ABS legislation focuses on the provider side of the equation, given that "all countries

\subsection{Objective and approach}

This book, Beyond Access, seeks to analyze the application of ABS to genetic resources in the hands of users and researchers outside the provider country or country of origin. It considers a variety of measures and approaches, while keeping a focus on the CBD objectives - conservation and sustainable use - as the underlying rationale for development of this complex concept. ${ }^{12}$ It assumes that all Contracting Parties continue to support the objectives and obligations that they accepted in adopting and ratifying the CBD - focusing on achievement pursuance of the benefitsharing objective through the adoption of measures:

with the aim of sharing in a fair and equitable way the results of research and development and the benefits arising from the commercial and other utilization of genetic resources with the Contracting Party may be both users and providers." Few countries (developed or developing), however, have even considered adopting user-side measures. One impetus behind current "international regime" negotiations was the perception that users are not bound by ABS when they are outside the source country's jurisdiction. ${ }^{11}$

International guidance for user-side measures has so far been limited. To date, with the exception of a single sub-clause - paragraph 16(d) - among the 152 sub-clauses of the Bonn Guidelines, international ABS work has overwhelmingly focused on providerside measures. $\mathrm{ABS}$ implementation objectives require that we now focus on user-side measures.

\section{providing such resources. ${ }^{13}$}

Based on that assumption, we submit a technical legal analysis which presents and assesses the underlying policies and principles, as well as the obstacles, options and alternatives regarding the obligations of users and user countries, with the goal of creating a balanced and functional ABS system.

Chapter 2 discusses ABS commitments, focusing on user or "post-access" issues. Chapter 3 uses the Bonn Guidelines as a framework for considering the scarce body of existing measures on the "user side." Chapter 4 analyses legal concepts as applied to user measures and demonstrates the legislative framework of user measures that would be needed in order to create a mandatory ABS system; while Chapter 5

so that in becoming a party to the convention, a country automatically adopts the code contained in the law. (See, e.g., UNCITRAL's Convention on Contracts for the International Sale of Goods (Vienna, 1980), which is expressed in code form. Application of the UNCITRAL international contracts instruments is considered in Bhatti et al., 2007, the fourth book in this Series.) Normally, countries become party to self-executing conventions with difficulty, owing to underlying sovereignty problems. Most legislators and sovereigns are unwilling to allow foreign governments (individually or collectively) to dictate laws binding within their jurisdictions. Particularly with natural resources, given the rule of national sovereignty over natural resources, the international community has not yet adopted measures that can be "self-executing."

10 Source-country measures are described in another book in this Series - Cabrera and López, 2007.

11 These matters were discussed in detail in Johannesburg, where one primary element of the debate was whether the Plan of Implementation should call for a "binding regime" or, as ultimately decided, only call for negotiation of a "regime," leaving the question of its binding nature for further discussion.

12 The problems experienced in the first 16 years of the CBD demonstrate clearly that ABS would not have been adopted as a commercial measure alone. It must therefore be implemented as a component of the $C B D$ - i.e., in a manner that contributes to conservation of biological diversity and its sustainable use, while promoting equity.

13 CBD Article 15.7. 
considers the economic and social impacts. Based on the results of these analyses, Chapter 6 sets out options, approaches and recommendations; and Chapter 7 offers concluding remarks. 


\section{The ABS Regime and the User}

The CBD is necessarily the beginning point of any analysis of $A B S$, simply because the concepts underlying $\mathrm{ABS}$ - an ownable or devisable legal right or interest in genetic resources - did not exist prior to the CBD negotiations. ${ }^{14}$ In this very real sense, $A B S$ is one of the most novel and innovative legal concepts to be introduced to international law in the last century. As further examined in this chapter, however, the CBD creates only the policy concept - an outline of this novel idea. It does not provide any specific determinations of the requirements and interpretations needed for the implementation of ABS, nor any explanation of how they can be addressed through the use of existing and conventional legal mechanisms. Based on experience in other conventions (e.g., CITES) and in other sectors, we know that national legislative development to create an international system may take many years, even where the concepts are being enacted clearly defined or described in the relevant international instruments. It is, therefore, not surprising to legislative experts that the development of national implementing legislation in the concretization of this entirely new concept has been slow.

Added complications arise by virtue of the ABS system's multinational nature. Some kind of formal support (through formal documents embodying "agreed interpretations") appears necessary to help countries take the actions required under Article 15, in a more unified way. These interpretations must recognize the different needs of the provider country and user country, as well as the needs and requirements of the user, individual providers (if authorized under national law) and other affected parties. In this connection, one should note that the "user" is a person or entity, whereas "user country" refers to each country (or countries) with jurisdiction over any user. It is important not to stereotype these terms. Often "user country" is equated with "developed country," and "provider country" (referred to in this book as the "source country") with "developing country." However, a growing number of developing countries have technological capacity in genetic manipulation and synthesis of biological compounds, enabling them to be "users" by even the most technical definition. Similarly, numerous recent cases have been documented involving the acquisition and utilization of genetic resources taken from a developed country source. ${ }^{15}$ Thus, both the provider-side responsibilities and the obligation to develop and apply user measures apply to all countries. Not only must highly developed countries adopt userside measures, but so must developing countries. Similarly, the requirements relevant to countries as providers of genetic resources (increasingly including provider-side legislation) also apply to developed as well as developing countries.

14 The 1991 negotiations of the so-called INBio-Merck Agreement are widely thought of as the legal predecessor of ABS, but commenced long after the $\mathrm{CBD}$ negotiations had catalyzed discussions of $\mathrm{ABS}$ and the need to develop an equitable means for addressing the interests of developing/source countries in the utilization of their genetic resources. See Reid et al., 1993.

15 In 1985, a Swiss company patented the Taq Polymerase, a remarkably valuable discovery based on US genetic resources from Yellowstone National Park (both the acquisition and the utilization of this genetic resource, however, happened well before the CBD entered into force). To this day, Taq is cited by the US Government as one reason behind efforts to develop ABS legislation by a country not yet a Party to the CBD. See, UNITED STATES: National Park Service, September 2006, Servicewide Benefits-Sharing - Draft Environmental Impact Statement, Department of the Interior, at http://parkplanning.nps.gov/document.cfm?parkId=442\&projectId=12515\&documentID=16763 Similarly, in 1969, Cyclosporin A was found at Hardangervidda National Park (Norway) by a Swiss tourist who worked for Novartis. Cyclosporin proved to have an active compound that helps the human body not reject organs after a transplant. See, for example, Svarstad et al. 2000. In both instances, the company later developed a pharmaceutical product which is currently marketed, with no benefit-sharing. 


\subsection{Overview: The ABS concept - CBD Article 15 and related decisions}

"Access and benefit sharing" or "ABS" is a short-hand way of referring to a very particular concept - "the fair and equitable sharing of the benefits arising out of the utilization of genetic resources, including by appropriate access to genetic resources...". ${ }^{16}$ As one of the CBD's three primary objectives, ${ }^{17} \mathrm{ABS}$ is more than just a general goal. It is also the basis of at least 10 specific commitments of the CBD Parties, including obligations to

create conditions to facilitate access to genetic resources for environmentally sound uses [and to] take legislative, administrative or policy measures... with the aim of sharing in a fair and equitable way... the benefits arising from the commercial and other utilization of genetic resources with the Contracting Party providing such resources. ${ }^{18}$

ABS focuses on "genetic resources" (whether from wild, natural or human-developed sources) that may result in financial and other benefits. It is primarily intended to mandate the sharing of those benefits with the countries that were the sources of the genetic resources used. Several basic points seem to be clear from the outset, in Article 15:

- Each country (or its designee) may decide who has the right to obtain "access" to genetic resources found in that country, and may set conditions on that right.

- Implicit within the system is the idea that every genetic resource has a "source country" - the spe- cific country which originally provided those resources (or the material from which they were propagated).

- $\mathrm{ABS}$ as set out in the $\mathrm{CBD}$ is strictly international in nature, and only applies where the source country of the genetic resource is different from the country with jurisdiction over the user and/or his activities utilizing the genetic resources. ${ }^{19}$

- Some describe ABS as a system of individual transactions, in which "access" is given in return for "benefit sharing." 20 This trade-off is not reflected in the text of the Convention. The only quid pro quo was an international level at the time of negotiations, as described in Chapter 1. Countries agreed to adopt measures for "facilitated access" (desired by developed countries), in exchange for the reciprocal commitment to adopt benefit-sharing measures (desired by developing countries).

- Under the ABS system, the concept of "benefits" to be shared specifically includes non-commercial uses, ${ }^{21}$ (including financial benefits, research and data, technology, jobs, capacity, community improvement, and other benefits).

$\mathrm{ABS}$ is unique among legal concepts in several ways. Foremost, it envisions/mandates the creation of a new specific legal right in the genetic properties of naturally occurring species. No such right had ever existed in any

$16 \mathrm{CBD}$, Article 1. The acronym "ABS" is often used as a substitute for the words "access and benefit sharing" and is sometimes misunderstood by those who are not familiar with the context of the term, leading to inappropriate usage. The "benefit-sharing" aspect of ABS refers only to "...the fair and equitable sharing of the benefits arising out of the utilization of genetic resources."

17 The other two objectives are "conservation of biological diversity" (implemented through the provisions of Articles 8 and 9) and "sustainable use of its components" (implemented through Articles 6, 7, and 10). Id.

$18 \mathrm{CBD}$, Articles 15.2 and 15.7. Other ABS requirements are found in Articles 15, 16, 17, 19 and 20.

19 Article 15 is an international concept. This is unlike the implementation of the other two primary objectives, both of which focus primarily on the Contracting Parties' domestic activities. Nothing in Article 15 imposes any responsibilities, or even recommends any governmental action, relating to domestic use of the country's own genetic resources. While it is unlikely that the ABS system can function if domestic uses are entirely exempt, the choice of whether or how to regulate them is the country's sovereign choice.

20 Ten Kate and Laird, 1999.

21 Article 15.2 notes that access is permitted only for "environmentally sound uses" but does not characterize the uses that are included. More relevant, Article 15.7 specifically states that users must share "the benefits arising from commercial and other utilization of genetic resources." (emphasis added.) 
country as a separate type of transferable, legally-protectable interest. This right/interest underlies the Convention's text, but is included indirectly - it is embedded in the provisions of Article 15, which reiterate each country's sovereign rights in such resources and tells the Parties something about how those rights should be governed and their use controlled. It calls on countries and transactional parties to apply contractual and governmental provisions in realizing concepts such as "access to genetic resources" and "utilization of genetic resources." In so stating, Article 15 essentially says that there is some type of valued tangible or intangible commodity (known in law as a res) that can be owned, transferred, restricted or granted, and which can be legally tied to other responsibilities - i.e., to benefit sharing.

The detailed nature of that res is still not agreed. A legal right relating to genetic resources cannot be asserted or demonstrated in the same ways that property rights and other ownable legal interests are established in other areas. For example, the most basic way to establish and enforce a right over moveable tangible property is by possession. In the context of ABS, however, it is immediately clear that many people, communities, countries or entities may possess specimens of a given species (where each specimen contains DNA and other genetic material), but it would not be possible to consider everyone who possesses a sample to be an owner - i.e., to have the right to decide who may use or patent - of its genetic resources. Ownership of immoveable tangible property (e.g. land and buildings) is legally established by deed and/or registry, which identifies the property through a system that is clearly known, again based on the assumption that there can only be one valid chain of title ${ }^{22}$ to a particular property right. Genetic resources, however, are not easily identified by written description, nor can a single original owner be established from whose title other interests descend. In contrast, intangible rights in "intellectual property" are based on establishing the identity of one inventor and one specific description of what is includ- ed under the intellectual property right. In a patent (as the most applicable IPR) the invention is described in words which individualize and identify it. In the case of naturally occurring genetic resources, however, there is no single innovator, and consequently neither one owner nor one single subject matter can be identified. This means that the source's rights in its genetic resources is a legal res, but the nature and form of that right may be unclear, where the same genetic resource is independently owned/governed by others as well.

At the time of this writing, most of the current controversy in ABS discussions revolves around identifying the nature of that res (which is named either "genetic resources," "access to genetic resources," or "utilization of genetic resources.") Until those issues are decided, they remain serious obstacles to the development and application of user measures, as well as to the legal certainty and functionality of measures in source countries. ${ }^{23} \mathrm{Up}$ to now, some of the simplest analyses of the issue suppose that the res in ABS transactions is physical material (specimens obtained directly from the source country or in other ways). More detailed analyses suggest that the res may in some ways be more like an "intellectual property right" (i.e., the right to control the genetic information contained in the species); and others that it might be some other kind of vested permit or contractual right, or combination of the three. This question stands at the heart of the ABS challenge. It is examined in detail in Chapter 4, in the context of user countries and the development of user measures.

The difference between genetic resources, as res, and other categories of natural resources makes it difficult to think about ownership of genetic resources in the same terms as ownership of natural resources. The questions of holders and ownership are not currently clear - neither in Article 15, nor most of the small number of national laws that have been adopted to implement it. The CBD merely notes only that "the authority to determine access to genetic resources rests

22 The "chain of title" is the legal record of property ownership maintained in most countries through official records. See Pau Pedrón, 2002.

23 Source-country legislation is discussed in many books and articles, and comprehensively analyzed in Cabrera and López, 2007, Book 1 in this Series. Other books in this Series approach other aspects of these questions. Contractual issues of ABS arrangements between source countries (and source communities or individuals, where relevant) and users are discussed in Bhatti et al., 2007; and other work on legal certainty is found in Young et al., 2007, both in this Series. 
with the national governments and is subject to national legislation." ${ }^{24}$ Clearly, each country has the authority to regulate the ownership issue under domestic legislation, but has little available guidance for solving "the ownership question" with regard to genetic resources. As a consequence, very little has been done to address these issues legally.

Since the Convention's adoption, apart from the decision to "negotiate an international regime" on ABS (described in section 1.1), the primary international work on ABS has been the "Bonn Guidelines," ${ }^{25}$ which were adopted in 2002 after two rounds of negotiations. Much concern was expressed in the last stages of these negotiations, regarding the one-sided focus of the draft Guidelines. In the final draft that was submitted to the last round of negotiations (COP-6), the draft Guidelines discussed only the "provider countries" (governments) and "users" (companies, research institutes and entities), ${ }^{26}$ not mentioning the responsibilities of "user countries." Neither did they refer to processes and requirements the measures needed outside of the source country. After intensive negotiations, the final Guidelines were amended to include a brief specific mention of "user measures" - requirements imposed on "Contracting Parties with users of genetic resources under their jurisdiction." These measures were expressed as issues that "these countries should consider." 27

Based on experience with those negotiations, and a review of the legal and legislative function of $A B S$ at the time of this writing, there is a basic difference among the countries' positions on one question: Can $A B S$ can function as a contractual mechanism operating under national and international commercial law, or is more institutional and legal development needed at other levels (including international)? At present, the answer to this question lies in the hands of user countries, without whose active support, ABS cannot function effectively as an integrated and legally certain system.

\subsection{CBD requirements applicable Beyond Access}

Article 15.7 requires all countries that have or may have users within their respective jurisdictions to adopt

"legislative, administrative or policy measures... with the aim of sharing in a fair and equitable way ... the benefits arising from the commercial and other utilization of genetic resources with the Contracting Party providing such resources." 28

Unlike provisions for access which focus on specific legal processes (PIC and MAT), Article 15.7 on benefit sharing is expressed in terms of results. It states what the user-side measures should accomplish, rather than listing specific actions that will satisfy the requirement. The Convention provides several additional points of guidance regarding the obligations of the user. In fact, its provisions relating to user obligations outnumber its requirements relating to access. Specifically, in ratifying the $\mathrm{CBD}$, each Contracting Party committed to the following obligations relating to the use of genetic resources: ${ }^{29}$

- To carry out scientific research involving genetic

24 Article 15.2. It is notable that this provision applies only to "access" - the determination of the rights to enter and remove samples and other information. Benefit sharing is bound by the broader requirements of "equity" (discussed below), and cannot apparently be limited by national legislation.

25 Bonn Guidelines were first negotiated by the first AHWG-ABS-1, Bonn, 22-26 October, 2001. They were formally adopted by the $6^{\text {th }}$ CBDCOP in The Hague, 7-19 April, 2002. The documents of this meeting can be found online at http://www.biodiv.org.

26 About these entities, the Guidelines call on users to ensure compliance by persons to whom they have transferred any part of the genetic resources taken, and generally to share benefits, including by technology transfer, under CBD Article 16. Bonn Guidelines, para 16.b.ix.

27 Bonn Guidelines, para 16.d, discussed in Chapter 3.

28 CBD, Article 15.7.

29 The CBD is, of course, an agreement among sovereign nations. As such, as discussed in 1.1, it is not directly binding on individual companies, agencies, institutions and other users of genetic resources. 
resources in the source country; ${ }^{30}$

- To take measures with the aim of sharing results of genetic-resource research and development with the source country; ${ }^{31}$

- To take measures with the aim of sharing the benefits arising from genetic-resource utilization with the source country; ${ }^{32}$

- To provide the source country with access to and transfer of technology which makes use of its genetic resources (including technology protected by intellectual property rights); ${ }^{33}$

- To enable "effective participation" in biotechnological research by (and where possible within) developing countries, especially the source country of the genetic resources; ${ }^{34}$

- To "promote and advance priority access on a fair and equitable basis" by source countries, especially when they are developing countries, to the results and benefits arising from biotechnologies based upon the source country's genetic resources; $;^{35}$

- To provide "financial support and incentives in respect of those national activities which are intended to achieve the objectives of this Convention;"36 and

- To address the needs of developing countries through the exchange of information, which "shall where feasible, include repatriation of information." ${ }^{37}$

These requirements call upon the each Contracting Party to "endeavor to" take the actions listed. ${ }^{38}$ This "endeavor" language does not make the Convention's requirements (effectively or actually) voluntary. Rather, at law, it creates a requirement of "good faith" - all Contracting Parties must make all reasonable efforts to implement these obligations. ${ }^{39}$ If a country has made such an effort, but not yet been successful, it shall not be considered to have failed to meet its obligations; however, a country's failure to make the effort is a violation of its international obligations. The requirement of good faith suggests that, if the first effort is unsuccessful, reasonable efforts must continue, or the issue must be reconsidered, until a means of complying is found.

Taken together, the items in the above list emphasize the extent and importance of the commitments of user countries within the Convention, and

$30 \mathrm{CBD}$, Article 15.6. All of the provisions in this list assume that each research or development activity involves specific resources, with a specific, known source country. Hence, the discussion of the "country providing resources" appears to refer to the particular source country, from which the particular resources in use, or their progenitors, were taken.

31 CBD, Article 15.7.

32 CBD, Article 15.7.

33 CBD, Article 16.3.

34 CBD, Article 19.2.

35 CBD, Article 19.2.

36 CBD, Article 20.1.

$37 \mathrm{CBD}$, Article 17.1 and 17.2.

38 Article 15.7 (the benefit-sharing obligation) does not contain any of the limiting phrases, which are used in other parts of the CBD, such as "as far as possible," (which is found in requirements of CBD Arts. 5, 6(b), 7(chapeau); 8(chapeau); 9(chapeau); 10(chapeau); 11; 14.1(chapeau)), "in accordance with its particular conditions and capabilities," (Arts. 6(chapeau); and 20.1), "taking into account the special needs of developing countries," (CBD Arts. 12(chapeau); 17.1), "except where ... purely an internal matter," (CBD Art. 14.2) or "where necessary" (CBD Art. $8(\mathrm{~b})$ ). All these formulations suggest that, in some cases, a Party may not be able to take the action, or that the particular provision might not apply or be necessary in some situations or to some parties. Even where these words are used, international law requires the Parties to act in "good faith" to attempt to implement measures, before determining that it is not possible. See footnote 39.

39

Vienna Convention on the Law of Treaties, Arts. 26 and 27 applies the formal legal principle of pacta sunt servanda ("lawyers' Latin" meaning "pacts (or promises) shall be respected") to all binding treaties. This principle is stated very simply in Art 26: "Every treaty in force is binding upon the parties to it and must be performed by them in good faith." Art. 27 adds clarification: "A party may not invoke the provisions of its internal law as justification for its failure to perform a treaty." In general, a "duty of good faith" requires a clear effort, however, so that if it makes and continues making reasonable efforts which fail to produce compliance, the Party will not be in violation of international law. 
their relationship to the "great compromise" by which the CBD came into being. Moreover, the terminology of these provisions suggests that they are separate requirements and not a variety of restatements of the basic benefit-sharing requirements. That is, that the user will be required to take all of the listed measures that are relevant - it must not only provide a share of the "benefits of utilization of genetic resources," but also share research results, information developed and new technologies developed. The Convention appears to require, as an additional component, that the user country should enable source-country participation in the research and development wherever possible. Finally, developed countries are called upon generally to provide financial support and incentives that promote benefit sharing, as one of the objectives of the Convention.

The mandatory nature of these provisions has been somewhat tarnished by the (very few) user- focused provisions of the Bonn Guidelines. Specifically, in discussing the user country's obligations, the Guidelines provide only that "Contracting Parties with users of genetic resources under their jurisdiction should take appropriate legal, administrative, or policy measures, as appropriate, to support compliance with prior informed consent of the Contracting Party providing such resources and mutually agreed terms on which access was granted." 40 This statement is, of course, significantly weaker and less compelling than the CBD provisions. The Guidelines further state that Parties should "consider" a variety of possible options. The Bonn Guidelines are, according to their terms, non-binding. They are only "recommendations." They were not intended or adopted to change the CBD requirements. This fact was (and continues to be) underscored by almost all countries during their interventions in that meeting and all relevant CBD forums since that time. ${ }^{41}$

\subsection{Two sides of ABS measures - What is meant by "user measures"?}

As regularly stated in international ABS discussions, "all countries are both users and providers." 42 While true, this does not eliminate the need for user measures - rather it makes clear that they should be adopted by all Parties, not only the highly developed ones. Nevertheless, the most complex and potentially valuable forms of utilization of genetic resources usually occur in developed countries, while most developing countries utilize genetic resources primarily or exclu- sively for agricultural variety development. ${ }^{43}$

Clearly, the CBD recognizes two kinds of measures, which in the past have been called "access" measures and "benefit-sharing" measures. This terminology is not particularly helpful. Rather, what is needed are measures on the "provider-side" and measures on the "user-side" (Table 1).

40 Bonn Guidelines, Article 16(d).

41 The Bonn Guidelines were adopted by a COP Resolution, rather than any plenipotentiary body or process. They frequently state that they are non-binding, voluntary, and non-interpretative, offered only to assist the Parties with implementing their Article 15 responsibilities. The number of repetitions of "voluntariness" is evidence that the document would not have been adopted if it were intended to alter the Parties' Convention responsibilities and obligations.

42 Discussions in CBD COPs 5 (Nairobi, 2000), 6 (The Hague, 2002), 7 (Kuala Lumpur, 2004) and 8 (Curitiba, 2006), CBD-AHWG-ABS 1 (Bonn, 2002) and 2 (Montréal, 2003), and CBD Second Expert Panel on ABS-2 (Montréal, 2001). Based on the records and data of the Consultative Group on International Agricultural Resources (CGIAR), every country has been involved in the use of germplasm from one or more of the International Agricultural Resource Centres - a primary resource base providing germplasm from all countries for the development of new plant varieties in other countries. Fowler et al., 2001.

43 Nearly all countries have some government and/or private operations for the development of agricultural varieties by conventional means and a growing number of developing countries have at least some capacity to apply laboratory genetic techniques, used to modify crop varieties to address localized conditions and problems. See, generally, reports and analysis of the UNEP-GEF Biosafety Projects at http://www.unep.ch/biosafety/resources.htm. Information on the level of national GMO development capacity is not collated under the project, however another analysis (Hårstad et al., 2005) based on 18 in-depth evaluations in less developed countries noted the existence of operational genetic laboratories developing agricultural varieties in Cuba, Mexico, Guatemala, China, India, Indonesia and several European countries which have since entered the EU. 
Table 1

\begin{tabular}{|l|l|}
\hline Provider-side measures & User-side measures \\
$\begin{array}{l}\text { Generally: the measures in our country that apply } \\
\text { to ABS transactions involving genetic resources } \\
\text { that have their source in our country, or where our } \\
\text { country acquired the right to utilize those genetic } \\
\text { resources in accordance with the CBD. }\end{array}$ & $\begin{array}{l}\text { Generally: legislative, administrative or policy measures that } \\
\text { apply to the persons or entities under our countrys jurisdiction } \\
\text { cho are ung genetic resources that originated in another } \\
\text { country. }\end{array}$ \\
\hline $\begin{array}{l}\text { Controls and oversight of legal access to our } \\
\text { resources, and coordination with ecosystem } \\
\text { management and protection requirements. }\end{array}$ & $\begin{array}{l}\text { Requirements and incentives to ensure that our users of foreign } \\
\text { genetic resources comply with ABS requirements of those } \\
\text { other countries. }\end{array}$ \\
\hline $\begin{array}{l}\text { Procedures for Prior Informed Consent (PIC), } \\
\text { including which officer, agency or group gives that } \\
\text { consent. }\end{array}$ & $\begin{array}{l}\text { Mechanisms to ensure that providers of genetic resources } \\
\text { are aware of uses and able to verify compliance with } \\
\text { PIC/MAT. }\end{array}$ \\
\hline $\begin{array}{l}\text { Procedures for determining Mutually Agreed } \\
\text { Terms (MAT), including requirements regarding } \\
\text { both access and benefit sharing. }\end{array}$ & $\begin{array}{l}\text { Remedies and other procedures to enable providers } \\
\text { (individuals, communities and countries) to protect their } \\
\text { ABS rights and enforce their ABS laws against users in our } \\
\text { country who are violating those laws. }\end{array}$ \\
\hline etc. & etc. \\
\hline
\end{tabular}

Every CBD Party, being potentially both a provider country and a "country with users under its jurisdiction," will need to address both sides of the ABS issue eventually, although at present it seems most urgent that countries with a large number of users in their jurisdictions do so. Up to now, as described in Chapter 3, nearly all ABS legislation that has been adopted consists only of "provider-side" measures, and most (but not all) of it is found in developing countries. Even where developed countries have adopted some ABS law, however, the overwhelming bulk of such measures are focused on the providerside (access to and use of the country's own genetic resources). When this book speaks of "user measures" or "user-side" it is referring only to the measures described as "user-side measures" in Table 1. It focuses on these measures as an obligation of all countries (not singling out developed countries). 


\subsection{Terminology of user and provider: Clarifying the concepts}

As with virtually all aspects of the ABS issue, terminology problems are adding to the controversy in the area of user-side obligations. ABS terminology is not clear, even with regard to terms such as "user," "provider," "source" and "origin." In this book, however, it is obviously necessary to use these terms in very specific ways. Recognizing that many terminology questions will ultimately be resolved through the current international negotiations, we also realize that our publication deadline will not allow us to wait for that result. Accordingly, the following are the general interpretations of the terminology regarding use and provision of genetic resources which will be employed in this book.

\subsubsection{Contract parties: "user" and "provider" and "middleman"}

In this book, we use the terms "user" and "provider" on an individualized basis, referring to particular situations. In developing these terms, however, it is quickly noticed that there may be other participants in the process between the time of collection of genetic resources to the time that they are utilized and benefits arise. We use the term "middleman" to refer to these. Table 2 shows how we use these terms:

Table 2: Categories/terminology of parties to ABS transactions, as used in this book

\begin{tabular}{|c|c|}
\hline Term/category & Description/definition \\
\hline User & $\begin{array}{l}\text { A user is an individual, company, university, agency, government or other entity which is "uti- } \\
\text { lizing genetic resources," } 4 \text { acquiring genetic resources with the intention to utilize them or gen- } \\
\text { erating benefits from that utilization. }\end{array}$ \\
\hline Provider & $\begin{array}{l}\text { A provider is one who provides those resources to the user by giving him the legal right to utilize } \\
\text { them. The exact nature of the provider depends on national law. In some countries, the provider } \\
\text { will be any individual which can legally collect/sell/give anyone biological material including its } \\
\text { genetic resources. }{ }^{45} \text { In other countries, rights in biological material are separate from rights to } \\
\text { genetic resources within it, suggesting that the government is the provider of the genetic } \\
\text { resources, even if an individual owner provides the biological material. }\end{array}$ \\
\hline Middleman & $\begin{array}{l}\text { The term middleman refers to every person who is not a provider, but who is passing on genet- } \\
\text { ic resources to a user or another middleman. A user who sells or otherwise transfers his materi- } \\
\text { als and/or results to another user may also be a middleman. It is not clear whether middlemen } \\
\text { should be considered to be "users" or "providers." Some middlemen generate (monetary or non- } \\
\text { monetary) benefits, which are not currently captured by the ABS system. }\end{array}$ \\
\hline
\end{tabular}

44 The meaning and relevance of the concept of "utilization of genetic resources" is analyzed in Chapter 4.

45 See e.g., AUSTRALIA: Environment Protection and Biodiversity Conservation Regulations 2000, $\$ 8$ A.04. This approach is determined by the general approach of all ABS-related Australian Commonwealth Law, which does not distinguish between access to biological resources (a concept not addressed in the $\mathrm{CBD}$ ) and "access to genetic resources" under CBD Art. 15. Thus the owner of the land from which an individual specimen of a tree or animal is taken has the right to control physical access to that specimen. Therefore, under Australian law, that person also has the right to grant access (and obtain all benefit sharing relating to) the genetic resources of the entire species, even where the user then patents the isolated genes of that species, excluding all others from either utilizing or obtaining an access/benefit-sharing right to it in connection with specimens they own. 


\subsubsection{Understanding of the terms "user country," "provider country," "source country," "country of origin"}

The terminology of national jurisdictional roles is also very unclear in current discussions. Terms like "provider country," "user country" etc., are used very differently by many different delegations and national laws. The CBD contains two country-related terms - "country of origin" and "country providing the

genetic resources," however there appear to be about five possible roles a country could play in an ABS situation. (Given that the term "provider country" is used by different laws and authors to mean different - conflicting - things, this book will not use that term.) In our analysis, we use the following terms:

Table 3: Categories/terminology of countries involved in an ABS transaction, as used in this book

\begin{tabular}{|c|c|}
\hline Term/category & Description/definition \\
\hline User country ${ }^{46}$ & $\begin{array}{l}\text { The country with jurisdiction over a user in a given ABS transaction, whether such } \\
\text { jurisdiction is due to nationality of the user or because the user's activities (utiliz- } \\
\text { ing the genetic resources) are occurring within that country's jurisdiction. In an } \\
\text { ABS transaction, there may be more than one user country. }\end{array}$ \\
\hline $\begin{array}{l}\text { Source country }{ }^{47} \\
\text { (in some legislation and } \\
\text { discussions these countries } \\
\text { are called "provider } \\
\text { countries") }\end{array}$ & $\begin{array}{l}\text { The country in which the genetic resources in question were originally taken from } \\
\text { in-situ conditions (or if the genetic resources are agricultural varieties - where their } \\
\text { unique properties were developed). In theory at least, this is a simple question of fact. } \\
\text { Even where the original specimens have since died or disappeared, their progeny can } \\
\text { usually be traced back to an original source. }\end{array}$ \\
\hline Country of origin ${ }^{48}$ & $\begin{array}{l}\text { Any country in which the specific genetic resources in question can be found in-situ. } \\
\text { It is frequently noted that many species are found in-situ in more than one country, } \\
\text { meaning that each has, potentially, many countries of origin. Where the origin is } \\
\text { determinable, however, only one of these countries will be the source } \\
\text { country. This concept can also be important where a user does not know or will not } \\
\text { disclose the specific country that is the source of genetic material he is using. }\end{array}$ \\
\hline Secondary source ${ }^{49}$ & $\begin{array}{l}\text { A country that has acquired the genetic resources from a country of origin "in } \\
\text { accordance with the Convention," as discussed below. }\end{array}$ \\
\hline $\begin{array}{l}\text { Intermediate country } \\
\text { (in some legislation, these } \\
\text { countries are called the } \\
\text { "provider countries") }\end{array}$ & $\begin{array}{l}\text { The country with jurisdiction over a user or middleman, who is transferring genetic } \\
\text { resources that were previously removed from another country, which is the "source coun- } \\
\text { try," as defined above. It should be noted that ABS calls for benefit sharing with a provider } \\
\text { only where that provider country is either (i) a country of origin, or (ii) a secondary } \\
\text { source. This suggests that an intermediate country's role might be in ensuring that the } \\
\text { duties of benefit-sharing are passed through to the user country, along with the material. }\end{array}$ \\
\hline
\end{tabular}

46 The term "user country" does not appear in the CBD. The Bonn Guidelines call these "countries with users under their jurisdiction," which appears to ignore the fact, noted above, that "all countries are both users and providers."

47 The term "source country" does not appear in the CBD or in the Bonn Guidelines. However, in the CBD, the term "country providing genetic resources" appears to describe this category. CBD, Art. 2.

48 CBD Art. 2.

49 These following two additional categories ("secondary source," and "intermediate country") seem to be useful when discussing countries which are not a country of origin, but which are asserting rights on the provider-side of the transaction.

50 See NORWAY: Draft Nature Diversity Act, at $₫ 60$. 
According to Article 15.3, the rights of the "country providing resources" are applicable only to one country in each ABS transaction. That country must be either (i) the "country of origin" (where the species was found in-situ, or where the traditional agricultural variety developed its unique properties ${ }^{51}$ ) or (ii) some other country that "acquired the genetic resources in accordance with the Convention." This means that a country that is not a country of origin but which formally acquired genetic resources in accordance with the CBD, would be (i) bound to provide access to those resources, and (2) entitled to receive a share in the benefits arising from their utilization.
At least in theory, the "source country" (as defined in the above taxonomy) can be factually identified by asking "Where were the resources (or their progenitors) first taken from in-situ conditions?" By contrast, the "secondary source" (as above) is a legal determination. Hence the question is "Has the country "acquired the resources in accordance with the CBD?" The CBD does not explain the meaning of the phrase in italics (which been interpreted by some as a complete exemption for any biological specimens collected before 1992). Consequently, it is not clear whether any country or institution acquired "genetic resources in accordance with the CBD" prior to 1993.

\section{5 "Access" and "benefit sharing" - exploring a link between these obligations}

One of the most difficult conceptual problems inherent in the current ABS ambiguities arises when one asks a simple question - Is there a link between "access" and "benefit sharing" and if so, what is that link? As with virtually all aspects of $\mathrm{ABS}$, no simple answer is possible until the basic concepts of "access" and "benefit sharing" are clarified.

One primary problem is the term "access" which is completely undefined in the CBD. Unfortunately, this word is used (including by the authors of this book) as if it had a definite meaning; however, the assumed meanings differ from person to person. For some, "access" means only the right to obtain samples. This parallels the Convention negotiations, under which the developing countries agreed to facilitate researchers' desires to obtain samples (gain access to sites and the right to take samples legally), and in exchange the developed countries agreed to include the concept of "equitable benefit sharing." Under this definition of "access," there is no mandatory link between "access" and "benefit sharing," because thousands of people may obtain "access" (i.e., be allowed to collect samples), but only those who "utilize genetic resources" must engage in benefit sharing. The intersection of these concepts is expressed in the text of the CBD, where clauses 15.2 - 15.5 deal with access, and 15.6 and 15.7 deal with benefit sharing.

A second perspective is expressed by those who would link "access" to "benefit sharing." They assume that $A B S$ applies only to specimens which the user collected in their country of origin and is now utilizing its genetic resources, leaving other situations unaddressed. For instance, where material is acquired indirectly (from collectors, researchers or other users) after the material has left the source country, this "second perspective" would claim that no "access" has been obtained, and therefore no benefit sharing must be given in return. As analyzed in Chapter 4, this approach is one source of most of the conceptual problems of ABS, because it creates large loopholes, which can essentially swallow the entire ABS process.

51 CBD, Arts. 2 (definitions of "country of origin of genetic resources," "country providing genetic resources" and "in-situ conditions") and 15.3, noting that for ABS, a country providing genetic resources must be a country of origin or one that acquired genetic resources in accordance with the CBD (which came into existence in 1992, and entered into force in 1993). 


\subsection{Conceptual deficit of ABS}

As detailed and analyzed in Chapters 3 and 4, there are many fundamental problems with the ABS system as currently conceptualized. ABS concepts are new in international law, as well as in domestic legislation. The uniqueness of ABS, combined with the global lack of experience in the implementation of any system which is similar, has made it difficult to develop any consistency within the global "regime" on ABS. Therefore, there is a pressing need to identify and clarify core issues of such a regime. One such core concept is the subject matter of the ABS contract or permit - the res - in addition to defining the activities that should trigger the benefit-sharing mechanisms of the system.

This issue is at the heart of the ABS conceptual gap, because it has not yet been explained in detail in any official document, accepted interpretation, or agreed text. Owing to looming deadlines, ${ }^{52}$ the Parties negotiating the CBD swept this and many other questions aside. The negotiators concluded that most ABS matters would be addressed by legislation at the national level, with each country making its own system, and all of those systems linking up horizontally to cover the globe. If that had indeed been possible, then Article 15 would have needed only to provide a general policy mandate.
Based on this assumption, then, the Convention's guidance is very limited..$^{53}$ Article 15 consists of seven sentences, a total of 275 words (for purposes of comparison this paragraph contains 197 words). Adding every other CBD provision which directly addresses benefit sharing or its component parts (as listed in the benefit-sharing objective ${ }^{54}$ ) there are still only 18 sentences in the CBD addressing ABS. As noted above, only a few countries have adopted any ABS legislation, and many of them have adopted only a single paragraph or sentence (calling for further regulation). This miserly guidance, compared to the volume of guidance and interpretation available regarding the governmental regulation of other commercially valuable interests (real property, moveable property, intangible property rights, intellectual property rights, legally vested permit rights, etc.), may explain why ABS is not yet legally functional.

Many commenters and negotiators complain that the ABS concept is "flawed" or "impossible." A more correct statement might be that the ABS concept is not yet known or sufficiently developed to enable implementation.

52 The CBD was scheduled for adoption at the UN Conference on the Environment and Development (UNCED) in Rio, 1992. It has been suggested that this deadline was one reason for the urgency which impelled negotiators to find a "quick solution" to ABS that would enable the countries to adopt the CBD on schedule. As a result, many issues were left undecided, including most prominently, the remaining controversies over biosafety (article 19), ABS (Article 15), and the financial mechanism (Article 21). The biosafety issue was most directly left for further plenipotentiary negotiations, as the Convention stated specifically that "The Parties shall consider the need for and modalities of a protocol setting out appropriate procedures, ... in the field of the safe transfer, handling and use of any living modified organism resulting from biotechnology that may have adverse effect on the conservation and sustainable use of biological diversity." Article 19.3. As to the financial mechanism, its primary political concerns were decided through the addition of Article 39, when it was generally agreed that the GEF would fill this role, but left the issue slightly open, calling for some considerations and restructuring. This decision still affects the operations of the Convention, as demonstrated by the controversies and political negotiations underlying the 2005 adoption of the GEF Resource Allocation Framework, and its relationship to the Fourth Replenishment. In the ABS context, the choice made by the negotiators was to assume that national contract and property law would resolve ABS measures, as a way of enabling completion of the convention in time for UNCED. Unfortunately, they also consciously ignored the fact that there was, at the time, no national law which imposed any control on the utilization of genetic resources, or defined them as a right or type of property, or exerted any sovereign control over them.

53 Even direct negotiation of ABS arrangements (ABS contracts with providers and source countries and ABS permits) was incomplete, for this reason. The situation of the Costa Rica/Merck arrangement was recognized, even by its participants, to be a highly individualized situation, rather than providing a model or standard of practice. See, e.g., Reid, 1993. Moreover it specifically left the issue of "benefit sharing" for future determination, only after benefits have arisen.

54 As noted in Article 1, the objective of "fair and equitable sharing of the benefits arising out of the utilization of genetic resources," includes "access to genetic resources... transfer of relevant technologies... and appropriate funding." 
A number of problem areas arise consistently, across the entire range of $A B S$ discussions and negotiations as well as in attempts at legislative implementation. To find solutions for any aspect of the regime, one must be aware of, and directly address, the underlying sources of problems encountered. For many, the systemic problem is simply this - fewer than $10 \%$ of CBD Parties having adopted any kind of legislative, administrative or other ABS measures. ${ }^{55}$ Various commentators have cited many reasons for these deficiencies, including the following four:

- The "complexity" theory: Legal and practical problems encountered in attempting to adopt ABS legislation have proven to be insurmountable by national legislative/administrative experts; ${ }^{56}$ and

- The "user failure" theory: One-sided implementation cannot be effective - i.e., source-country law cannot be enforced after the genetic resources or users have been taken outside the source country. The source country has no jurisdiction to regulate in the user country, even as to use of its own genetic resources. ${ }^{57}$

- The "lack of interest" theory: "Source countries have concluded that ABS benefits are not worth the effort of adopting and implementing ABS laws." ${ }^{8}$

- The "cost" theory: ABS implementation systems will result in enormous costs and create legal uncertainty primarily to users and industry. ${ }^{59}$
Each of these theories, while strongly advocated by some, is also is strongly opposed. In support of the first three bullet points above, it is notable that a great many (at least 50 and possibly as many as 90) (00 $^{60}$ developing countries have attempted to develop ABS legislation, but few have yet adopted substantive measures on either the provider- or user-side. None of these, however, has formally decided to drop the ABS issue or their $A B S$ rights, and none has announced that $A B S$ is not worth the effort. Reportedly, several countries have indicated that legal inconsistencies within the international framework have been an obstacle to developing functional ABS legislation. ${ }^{61}$ Many countries seem to be waiting for the international negotiations to define the scope and practices of ABS. As noted elsewhere in this book, the authors perceive that there is one fairly indisputable fact - that it will be either legally impossible or prohibitively expensive to impose $\mathrm{ABS}$ controls using provider-side laws alone.

With regard to the fourth bullet point, there are many who claim that ABS documentation will be prohibitively expensive, ${ }^{62}$ and others that under new national "access" laws, administrative approval and benefit sharing have increased the time and cost of species collection and other bioprospecting activities. ${ }^{63}$ To date, however, "transaction cost" analyses have not been well documented. Often, they have been based on unsupported assumptions - reasoning by analogy, for example, beginning with the fact that a particular company once spent a specific amount of

55 See footnote 3 (Chapter 1) above. Nearly all such measures address provider-side issues only.

56 Young, 2004, “Options and Processes....”; Cabrera and López, 2007; Lettington and Didery, 2007; Wynberg, 2004.

57 Tvedt, 2006; Cabrera and López, 2007.

58 Scott, P., Presentation to the International Expert Workshop on Access to Genetic Resources and Benefit Sharing, Cuernavaca (24-27 October 2005.)

59 See, e.g., Finston, 2005, pp. 141-155; Wolfe and Zycher, 2005. To some, this claim is a better indication of industry position (opposed to any $\mathrm{ABS}$ ), than industry spokesmen's more generic statements that they support ABS, but only wish to see it rationally applied. Certainly, there is no single "industry position," although most industrial groups are suspicious of any proposal to add administrative requirements and paperwork (as well as mandatory "benefit sharing") which will cost them money.

60 Since 1999, it has commonly been noted that upwards of 50 countries were at the time developing national ABS legislation. Many if not all of these authors quote the one-time count of 50, found in Glowka, 1998. Since that time, however, many of those originally counted 50 countries have given up on their attempt, and others have taken up the challenge. As noted in footnote 3 , only around 32 have adopted even a single line on ABS.

61 Personal communications Ridwana Jooma (South Africa), Nancy Kgengenyane (Botswana), Leonard Hirsch (United States), and others.

62 See, e.g., Wolfe and Zycher, 2005.

63 This was asserted by a large number of users (but not all) in the recent user studies in Europe. See, Latorre, 2005; Holm-Müller et al., 2005. 
US dollars on one particular negotiation, then multiplying that number by all of the companies and products which use natural ingredients to arrive at the total cost of ABS to companies. These simplistic approaches do not consider the fact that other companies have spent very little, or that, when the system has been developed and unified, collaboration with national $\mathrm{ABS}$ authorities will actually make it easier to acquire and export samples. Some cost estimates are based on assumptions about the need for new forms and requirements. Others assume that IPRs will be filed on every species studied. ${ }^{64}$ Indisputably, many applicants have incurred substantial costs, including the costs of defending against challenges (lawsuits and other claims) by communities and others objecting to access. ${ }^{65}$ It is also undisputed, however, that current legal uncertainties and the resulting atmosphere of distrust are other important factors which, if ameliorated, would undoubtedly reduce costs and problems.

\subsection{Specific obstacles to ABS implementation}

Four basic categories of specific legal/practical problems lie beneath the user side of the ABS regime.

\subsubsection{Legal certainty}

The users of genetic resources (foreign researchers, companies seeking to develop products, and others) often focus their position on the problem of "legal certainty." Although uncertainties exist in all fields of endeavor, companies and individuals in developed countries generally must have certain minimum types and levels of "legal certainty" as to any action, right, or property in which they will invest time, money or other value. Specifically, before investing in any kind of bioprospecting or other species-collecting activity, a company or researcher will want to be certain that he has a clear legal right to remove the specimens, to study/analyze them, and to use the results of this analysis (including in some cases the right to commercialize a product). Similarly, before entering into an ABS contract or other ABS arrangement, the company will usually want to be certain, first, that the final contract will be valid and binding - i.e., that the official signing the ABS arrangement is authorized to do so, and that all relevant laws and restrictions have been satisfied. It will also want some certainty that the contract will not be changed, invalidated or rescinded in future without cause. The lack of legal certainty has not, so far, led to a decline in industrial, commercial and research interest in biological and genetic material. ${ }^{66}$ The warning from industry regarding their ABS problems should be seen as a major indication that the sector has not yet accepted the ABS concept, however, suggesting the need to demonstrate (create) the value of accepting and participating in the concept, rather than allowing it to be molded without practical inputs from the users.

Legal certainty is a "two-way street," however. Source countries and providers of genetic resources also need certainty - regarding the actions and commitments made by users. For this, they need to be able to confidently depend on the "other half" of the system (effective or enforceable laws governing the user's actions and benefit-sharing, adopted in user countries). Much of the complexity and demand in provider-side laws arises out of the perception that the source country's rights will have no support from user countries. The more restrictive elements of national access requirements can be understood in the light of the source country's uncertainty about its rights on the user side after the material has left the country.

\footnotetext{
64 In addition, for purposes of discussion, unsupported guesses about various costs have been used, and in later discussion the resulting numbers have been cited as if they were research conclusions. The primary document alleging billion-dollar level costs of the system internationally (Wolfe and Zycher, 2005) has been widely challenged on these points.

65 Young, 2005.

66 See, e.g., Latorre, 2005; Holm-Müller et al., 2005; and Oldam, 2005. To date, claims of decreasing industrial interest in genetic resources are seldom coupled with supporting statistics or other impartial or credible evidence. Such claims continue to be made, however. See e.g., Finston, 2005, pp. 141-155.
} 
Arguably, these issues can be better resolved through the development of an integrated system whether through widespread adoption of user measures at the national level or through the creation and implementation of such measures in an international regime. Either way, such a system must clarify key $\mathrm{ABS}$ issues, enabling provider countries to feel confident of systemic functionality. On the basis of that confidence, source countries can adopt more streamlined legislation and effectively reduce the bureaucracy. This, in turn, will increase user certainty and decrease the costs of administrative compliance.

\subsubsection{International provisions addressing private ABS actions}

Under general principles of law, private persons or companies are not directly governed by international law (that is, by agreements between governments). Rather, they are bound by the laws of the (various) countries that have jurisdiction over them and/or their actions. Until the COP-7, international ABS discussions focused primarily on provider-side access legislation in developing countries. The Bonn Guidelines illustrate this by focusing intensively on measures to be taken in or by the "provider country." ${ }^{7}$ Since then, common understanding has expanded to realize that perhaps access legislation in providing countries is not the only element needed to achieve fair and equitable benefit sharing. Value in biotechnology is often created by private users (including academic institutions, other governments, parastatal bodies, joint ventures, etc.). In most transactions, it is likely that the bulk of this work will be done in the user country, particularly in the last stages when the activity is about to produce benefits. An international decision or instrument cannot govern action by a private user or company, unless the country with jurisdiction over that user or activity adopts relevant law applying that decision or instrument to persons and activities under its jurisdiction. ${ }^{68}$ What international law can do is to develop the concept to a level of clarity and agreement that will enable countries to adopt legislation that is mutually interactive.

\subsubsection{Applying conventional contractual law to a new concept of resource-based ownership or rights}

Some authors and negotiators have claimed that the use of private contracts and contract law is the solution to the cross-border jurisdiction issue. ${ }^{69}$ Those commenters appear to assume that $\mathrm{ABS}$ is solely a matter of contractual enforcement - i.e., that the only "user measures" needed are the laws that allow private parties to make contracts and enforce contractual rights, and that these laws can apply to $\mathrm{ABS}$ arrangements with no additional refinement.

This assumption is not legally supportable. While ABS does use a contractual mechanism, it is

using that mechanism to facilitate the achievement of ABS obligations and objectives, which are not considered or supported by contract law. And it is applying that mechanism to a new order of legal rights - sovereign and individual rights in genetic resources - which have not been fully understood or enabled in any country. While some aspects of contract law are easily applied to ABS, a great many contractual concepts and practices have not yet been adapted to this area, especially the question of what happens when geneticresource rights are taken or used by persons who have not obtained an ABS contract or permit. ${ }^{70}$

67 Bonn Guidelines, CBD-COP Decision VI-24. Of 61 sections, only clause 16(d) discusses user measures.

68 Since the adoption of the Convention, implementation of ABS has been recognized to be a serious challenge and problem. See, Hendrickx et al., 1993; Glowka et al., 1997. More recent commentators do not appear to notice improvement. For example, Barber (2005) describes implementation as a main obstacle for benefit sharing.

69 See, e.g., Scott, 2005.

70 "Mutually agreed terms" in Article 15.4 and 15.7 are parallel (virtually identical) to the primary prerequisite of any contract - that is, that the parties to the contract come to a "mutual agreement" (sometimes called a "meeting of the minds") as to exactly what actions, forbearance, conditions, restrictions, and other elements are included in the contract, and what they require. Similarly, "prior informed consent," as described in Article 15.5, is exactly parallel to another general requirement of contract law - that a convention is only valid where the parties are fully 


\subsubsection{Lack of incentives in system construction}

As a practical matter, most "genetic resources" are found within biological material, and most biological material may be moved across national boundaries legally. ${ }^{71}$ The current lack of clarity in the ABS regime has caused many companies and researchers to assume that, if the particular sample from which they obtain a genetic resource has already been removed from the source country, then that material may be used without ABS compliance. $^{72}$

This assumption (wrong or right) may create a selffulfilling situation. Once they have the specimen or sample, their use of that sample is generally private and cannot be perceived by external or government observers. As discussed in Chapter 3, this lack of "observability" does not excuse companies from the need to comply with the benefit-sharing obligation, but may create a de facto incentive for them to keep quiet about it. To address the activities of a private user, userside measures must either impose controls (command and control), or construct ABS laws that provide an incentive or other motivation for compliance.

Although the practical ability to impose and oversee mandatory controls is limited, the ABS system currently does not offer many incentives. Without them, since most utilization of genetic resources happens in developed countries, the burden of control may be placed on developed countries, along with the blame, if the system does not function.

\subsection{Legal and political importance of the ABS issue}

The CBD was created as a platform from which national laws and practices for conservation and sustainable use could be integrated to ensure protection of the global web of life on earth. It recognized that this objective places a critical regulatory burden on developing countries, whose level of diversity ("megadiversity") is greatest, per capita and per hectare. ${ }^{73}$ To balance that burden, the obligation of all countries to share the burdens of conservation, with particular attention to financial responsibility, is repeatedly supported by binding provisions throughout the CBD. Benefit sharing is meant to be a manner of imposing a part of the conservation/sustainable use burden upon those private parties who derive benefits from their utilization of genetic resources.

Beyond the cost of conservation and sustainability, developing countries bear an additional burden, which can only be answered through the concept of equity (discussed in Chapter 5). While pressures for development (including the need for poverty alleviation, livelihood security, and social welfare) have continually

aware of all relevant facts, and freely consent to be bound by the contract. (For a general discussion of internationally recognized principles of the law of contracts, see the UNCITRAL (undated), which is discussed in Book 4 of this Series.) The legal concepts of PIC and MAT have been addressed extensively both in the ABS context and more generally. See Swiderska, 2001, for an excellent treatment of these issues and their relationship to public participation.

71 There are limits, of course. Some species are thought to be dangerous, and their international movement is prohibited. Even as to these specimens, often it will not be illegal to possess them in the user country, once they have successfully crossed the border. In addition, international movement of specimens of some species may be illegal under the Convention on International Trade in Endangered Species of Fauna and Flora (Washington DC, 1973) which has been widely implemented. Some foreign biological materials are prohibited or controlled in the user country as well (narcotic substances, bacterial weapons etc.). However, these controls apply to a small fraction of the total number of species and varieties on the planet. Most of the genetic resources that have been utilized commercially or subject of research are not listed or controlled in any of these ways. In some cases, however, it has been asserted that genetic-resource-oriented research has affected the conservation status of such species, suggesting a need for better coordination between ABS and CITES implementing officials. See, Mgbeoji, 2006.

72 See, e.g., Henkel, Thomas, "A Perspective from Pharmaceutical Industry," Presentation to High-level Experts Meeting - Addressing the Access and Benefit-Sharing (ABS) Challenges in the Context of the Convention on Biological Diversity (Tokyo, 8-9 February 2007) and other remarks in that meeting.

73 It is worth remembering that the CBD addresses the conservation and sustainability of the integrated web of life that sustains the earth, rather than focusing on particular species that are rare, endangered or narrowly endemic. (Discussed in detail in CBD COP-5 and subsequent SBSTTA meetings, relevant to the adoption and implementation of the "Ecosystem approach" (UNEP/CBD/5/6)). One of its great challenges is embodied in the need to ensure that conservation measures do not focus only on the special, because this focus often enables the destruction of species that are shared across many countries, of which no one country will willingly shoulder the entire burden of conservation. 
increased, environmental restrictions on development have intensified. Those pressures were generally not present during the development phases of countries in North America and Europe, and those countries benefited from their natural bounty in a way that modern developing countries cannot.

The equity objective of the Convention grew out of the concern that further environmental limitations would constitute a socio-economic inhibition on improvement of critical indicators (livelihood and wellbeing) in countries whose development was already a critical global priority. ${ }^{74}$ This priority was heightened recently, with the adoption of the UN's Millennium Development Goals. ${ }^{75}$ Politically speaking, these negotiations strongly demonstrate a paradigm shift. The international environmental agenda is increasingly controlled and directed by the countries whose development and socio-economic future is most directly impacted by environmental obligations. Their decisions may have the greatest impact on biodiversity conservation, given their national sovereignty over the biodiversity hotspots, rare species and critical ecosystems. Overall, the most critical importance of the ABS system may be as a demonstration that international legal process is a fair exchange by which the issues and concerns of all participants are recognized, negotiated, and implemented as binding instruments.

In the end, however, each country must still adopt the necessary legislation. And national legislative processes must and do concentrate on national interests. A national legislature is, by definition, focused on the perspectives and desires of the electorate to which the legislators must be accountable. Often, to national citizens and parliaments, the value of international governance is less recognized than that of domestic wellbeing and industrial cost, particularly in countries that include a large number of users of genetic resources. It may be difficult politically for governments to adopt measures which, in essence, call on their companies to pay money to other countries. Such provisions are likely to be opposed in the same spirit that tax increases are opposed - as limitations on profitability and commercial development. They can be more strongly opposed than other taxes because the amount assessed is not predictable or based on any calculable standard. Despite these difficulties, all OECD countries willingly signed the CBD and all but one have since ratified it. ${ }^{76}$

To build domestic political support for the implementation of benefit sharing one must begin with a simple question - What interests of user countries are promoted by benefit-sharing obligations? At present, the answers are limited:

- General: to meet the country's national commitments (operating in "good faith");

- Environmental: to promote the conservation and sustainable use of biological diversity, through a financial incentive tied to genetic resources;

- Socio-ethical: to promote the wellbeing of poorer countries, minimize poverty, and decrease the disparity between developed and developing countries;

- Functional: to protect the country's interest in access to the genetic resources found in other countries (the quid pro quo); and

- Commercial: to enable full participation by the country's research and industrial sectors in the development of genetic-resource-based products.

While the first three of these interests are of longestterm importance, the fourth and fifth provide, perhaps, the strongest incentives based on the commercial, financial and related interests within national constituencies.

74 It is not coincidental that the CBD was adopted in the second major international plenipotentiary conference on the environment, nor that the title of that conference was the United Nations Conference on Environment and Development.

75 Millennium Declaration, UNGA, 2000, Doc. A/55/L.2.

76 The 29 OECD members that are Parties to the CBD are Australia, Austria, Belgium, Canada, Czech Republic, Denmark, Finland, France, Germany, Greece, Hungary, Iceland, Ireland, Italy, Japan, Luxembourg, Mexico, Netherlands, New Zealand, Norway, Poland, Portugal, Slovak Republic, South Korea, Spain, Sweden, Switzerland, Turkey, and the United Kingdom. The Commission of the European Community also takes part in the OECD's agenda. The only OECD member who is not also a party to the CBD is the United States of America. 


\section{User Country Compliance with the 3 Bonn Guidelines}

The critical question to which the remainder of this book is directed is What measures are needed to fulfill the obligations of Article 15.7? These measures must address more than just the nature of benefit sharing but the full range of user-side responsibilities necessary to make the system function. Such measures must be adopted by all countries that have or may have users

\subsection{Functional approach}

Legislation must begin from a functional understanding of the commercial and physical activities to be regulated. The basic flow of the benefit-sharing concept is as follows:

- The user gains or has gained access (whether by direct collection in a source country or indirectly) to genetic resources that have their origin in the source country. Access should occur only with permission, gained through the source country's processes for prior informed consent (PIC) and on the basis of mutually agreed terms (MAT) for access;

- The user utilizes these resources in a manner that produces benefits of some sort;

- The user shares these "benefits arising from the utilization of genetic resources" with the source country. This benefit-sharing process has two practical steps: First, the user and source country come to mutually agreed terms (MAT) regarding the sharing of benefits; and second, the user complies with these terms.

None of these steps is entirely under the oversight of either the source country or the user country. Thus, all of genetic resources under their jurisdiction - i.e., probably all countries. ${ }^{77}$ This chapter identifies the laws and practices that appear to be needed to satisfy Article 15.7 through a mandatory system. Its discussion is illustrated by examples from various countries with users under their jurisdiction.

three must be addressed or considered by both provider-side and user-side measures. In many cases, for example, the user obtains access to genetic resources from material that is already outside the source country. It may be obtained from an ex-situ collection, for example, or in the form of results of genetic research transferred by a middleman (researcher or another company). The application of ABS to these situations has not yet been clarified.

Similarly, benefit-sharing law can only function where the meaning of legislation and/or the ABS contract is clear, in both the source and user country. This underscores our earlier statement that under Article 15 all countries must consider themselves as both providers and users of genetic resources, and must legislate accordingly.

On the provider side, as described elsewhere, ${ }^{78}$ source countries are expected to adopt legislation in five areas:

- administrative measures (national focal points and competent authorities);

- the negotiation process through which ABS contracts are approved, applying the process of prior

\footnotetext{
77 Depending on how the term "utilization of genetic resources" is ultimately defined, this may include virtually all countries. For example, if "utilization of genetic resources" includes conventional plant breeding activities, virtually all countries will be "user countries" since most plant breeders utilize varieties from around the world. This is the source of the separate development of the International Treaty on Plant Genetic Resources for Food and Agriculture (ITPGRFA), which as adopted is narrower than this original objective. It does not eliminate the need to apply national ABS legislation to agricultural variety development. See Moore and Tymowsky, 2003.

78 Including especially Cabrera and López, 2007, Book 1 in this Series.
} 
informed consent (PIC) and agreement on mutually agreed terms (MAT);

- the requirements applied where a user obtains access to genetic resources

- by direct collection in that country,

- from a collection or other institution, or

- from another source;

- the nature and scope of the rights granted to the user - including the activities required or allowed, reporting/milestones, transfer of the genetic resource, etc.; and

- how the benefits to be received shall be used or distributed.

The last element is not mentioned in the CBD, but is often listed as an obligation in many articles and nonbinding documents, including the Bonn Guidelines. ${ }^{79}$ The Convention recognizes each country's sovereign discretion regarding how it will use and distribute benefits, ${ }^{80}$ but many experts suggest that the link between ABS and conservation means the user country has an interest in how benefits are distributed. In some countries' ABS laws, some or all benefits must be used for conservation; in others, distributed to private holders. ${ }^{81}$ The Bonn Guidelines provide additional guidance for the implementation of these concepts.

Article 15's requirements for provider-side measures include a specific description of particular measures. On the user side, by contrast, the CBD does not identify any specific type of measures that should be used for implementing the user-side of ABS, rather it focuses on the results to be sought, asking countries to adopt measures

with the aim of sharing in a fair and equitable way the results of research and development and the benefits arising from the commercial and other utilization of genetic resources with the Contracting Party providing such resources. ${ }^{82}$

The Bonn Guidelines recommend six "user measures," and four primary administrative requirements applicable to the user side. ${ }^{83}$ They also include a few provisions regarding other potential approaches. Those measures are as follows:

- Options for implementing user-side legislative obligations (discussed in 3.3)

- "Measures aimed at preventing the use of genetic resources obtained without the prior informed consent of the Contracting Party providing such resources;"

- "Other measures that encourage users to comply with [mutually agreed terms];" ${ }^{4}$

- "Cooperation between Contracting Parties to address alleged infringements of access and benefit-sharing agreements;"

- "Measures discouraging unfair trade practices;"

- "Measures to encourage the disclosure of the

79 See Swiderska, 2001. Bonn Guidelines, Art 48. The latter specifically focuses on how benefits should be distributed - a matter solely within the source country's discretion: "benefits should be shared fairly and equitably with all those who have been identified as having contributed to the resource management, scientific andlor commercial process, including governmental, non-governmental or academic institutions and indigenous and local communities. Benefits should be directed so as to promote conservation and sustainable use of biological diversity."

80 See e.g., EC, 2003.

81 Compare COSTA RICA, in which a percentage of benefits is distributed to the protected areas agency (per Reid et al., 1993) and similar provisions in the USA proposal, on one hand, with AUSTRALIA: Environment Protection and Biodiversity Conservation Regulations 2000, $\$$ 8A.04, whose approach may be intended to provide an incentive for private conservation. The Costa Rican law considers other distribution to be a part of the ABS contract. Normas Generales para el Acceso a los Elementos y Recursos Genéticos y Bioquímicos de la Biodiversidad, art. 7.

82 CBD Art.15.7.

83 Bonn Guidelines, at paras 16(d), and 13. Although constituting less than one-half page in the 19 pages of the Bonn Guidelines, these few lines may be the most important for countries with large numbers of users and, with Article 15.7, is indeed the lynchpin of the entire ABS framework.

84 This paragraph actually refers to compliance with Bonn Guideline 16(b), which in turn addresses compliance with MAT. 
country of origin of the genetic resources and of the origin of traditional knowledge, innovations and practices of indigenous and local communities in applications for intellectual property rights." ${ }^{25}$

\section{- Administrative measures to enable integration with} the international system (discussed in 3.4)

- "Designation of "one national focal point for access and benefit sharing;"

- "Mechanisms to provide information to potential users on their obligations regarding access to genetic resources;"

_ "Responsib[ility] for monitoring and evaluation of access and benefit-sharing agreements;"

- "Responsib[ility] for implementation/enforcement of access and benefit-sharing agreements." 86

- Voluntary, mandatory and permissive approach (discussed in 3.5)

- "Voluntary certification for institutions abiding by rules on access and benefit sharing" and other general legal requirements (monitoring, dispute settlement, remedies, etc.). ${ }^{87}$

Before turning to those discussions, section 3.2 describes national laws that have been examined to provide a practical basis for this analysis.

\subsection{National "user measures" examined in this Chapter}

For this book, it was initially expected that case studies or researched analysis would consider the user measures of many types in many countries. Ultimately, however, this analysis uncovered very few "user measures" as that term is understood and explained in 2.3. The study set out to learn from current user-side experience with legislation, but the lesson we learned was of the general absence of such experience. Given this result, information regarding existing user measures has ultimately comprised only a small part of the research and analysis that was done for this book. Rather than detailed case studies, the analysis includes only particular details and provisions that are useful to illustrate key points. The following is a brief description of the ABS laws and other instruments reviewed for this book.
Our in-depth analysis was limited to Norway and the United States. ${ }^{88}$ In both of these countries, our analysis attempted to include all relevant laws and not stopping with those that are specifically identified as "ABS laws." ${ }^{\circ 9}$ In several other countries, we considered ABS laws and instruments only. From Japan, for example, we noted important soft law developments. In Canada, Australia, The Netherlands and the EU, (as well as the countries mentioned above) we examined ABS laws and other instruments, which although not meeting the definition of "user-side measures," provide insights into what those countries will expect from foreign users, based on their regulation of domestic users of their genetic resources. ${ }^{90}$ We have also noted an increasing number of developed countries are adopting "provider-side measures" regarding the use of their own resources, and have attempted to draw some user-side lessons from these. ${ }^{91}$

85 Bonn Guidelines at 16(d)(iii), (vii), (iv), (vi) and (ii), in the order presented here.

86 Bonn Guidelines at 13, 16(d)(i), 14(c) and 14(d), in the order presented here.

87 Bonn Guidelines at 16(d)(v). Paragraphs 51 through 61 also make general statements regarding incentives, accountability, monitoring/reporting, verification, disputes and remedies, which are phrased in very generic terms. Where relevant, these are discussed in the following sections.

88 Unfortunately, budgetary constraints have meant that we were also limited linguistically to countries which provided their laws (or a detailed analysis of their laws) in English, Norwegian, Spanish, or Portuguese.

89 The authors' underlying case study may not be a complete analysis, owing to the large number of potentially relevant laws, and the fact that some documents and reports could not be found or obtained. It was not possible, within the budget of this project, to undertake a full evaluation of the laws of the 50 US States.

90 The parallel may not be complete, however, and has not been recognized as such by any of these governments.

91 See for example the US, Norwegian, Australian and Canadian examples, discussed below. 


\subsubsection{Countries whose laws have been examined in greater detail}

Having accessed the full body of national laws in Norway and the US, and noting that the two offer important and very different examples, we examined national law in these countries in greater detail. In addition, we examined the legislation available from Brazil and Costa Rica, both of which have adopted detailed ABS laws. In these latter two countries, however, our research was limited to specific laws which were presented through the CHM as "ABS measures." Neither of these countries has actually adopted "userside measures" within the understanding of this book.

\subsubsection{Norway}

Norway became a Contracting Party to the CBD in 1993 and has been a primary supporter of the Convention. Unsurprisingly, it is one of the few countries that has made a concerted attempt to adopt user measures in addition to measures which govern the use of Norwegian genetic resources (provider measures), and has worked at bridging the gap between developing and developed countries in the $\mathrm{CBD}$, the FAO, the WTO/TRIPS Council and in the WIPO. Norway has experience as both a provider country and user country, and has engaged in ongoing governmental and other discussions of the need for specific ABS legislation. These discussions have evolved over time. In 1993, it was felt that Norwegian legislation was already compliant with CBD obligations and that no further legislative measures were needed. ${ }^{92}$ In the ensuing 14 years, five major legal debates have arisen in Norway regarding the $\mathrm{CBD}$, giving rise to five specific measures, of which two are directly analyzed in this book:

- The implementation of the EU Directive on Patents in Biotechnology (EC/98/44), ${ }^{93}$ which implements $\mathrm{ABS}$ disclosure requirements in patent applications; ${ }^{94}$

- The first draft Nature Diversity Act, ${ }^{95}$ which regulates practically all aspects of nature diversity, including dealing with the rights to genetic resources in Norway, and a short provision for one user-side measure (a general disclosure requirement);

- The draft Act on Marine Resources, ${ }^{96}$ which suggests that marine genetic resources should be the property of the state;

- Withdrawal of a plant variety protection act that was stricter than required by the UPOV-91;

- The Decision to become a full member of the European Patent Organization, ${ }^{97}$ which could potentially create a loophole in the disclosure requirements described above.

Provisions from the first draft Nature Diversity Act and the Patent Act are referenced throughout the next chapters. Although not yet in force, the draft Act demonstrates a significant effort to meet the user-side obligation (one of the only such efforts in the world), and exemplifies challenges faced by experts developing "user measures."

\subsubsection{United States}

The United States signed the CBD in June 1993, but has never ratified it. Although a non-party, it is an active participant in CBD policy forums (COP, SBSTTA and other meetings). Numerous authors have asserted that the US has within its jurisdiction more genetic resource users than any other country. ${ }^{98}$ As such, it has a strong interest in the ABS framework.

92 St. prp. Nr. 56 1992-93

93 Norway is formally an "associate country" with regard to the European Union (EU), and bound to implement new EU Directives in a number of legislative fields. It is a member of the European Free Trade Agreement (Iceland, Liechtenstein and Norway).

94 See Tvedt, 2007 (forthcoming).

95 NORWAY: NOU 2004:28 http://www.regjeringen.no/nb/dep/md/NOU-2004-28.html?id=388846.

96 NORWAY: NOU 2005:10 http://www.regjeringen.no/Rpub/NOU/20052005/010/PDFS/NOU200520050010000DDDPDFS.pdf.

97 June 2007.

98 See, e.g., Vogel, J., "Reflecting Financial and other Incentives of the TMOIFGR: The Biodiversity Cartel,” Chapter 3, in Ruiz and Lapeña, 2007, Book 3 of this Series. 
In addition, the US is a country of origin of a large number of species, and thus a potential provider of genetic resources. A recent US government analysis on ABS cited the 1969 discovery of the species used to create the TAQ Polymerase (patented by a Swiss company in 1985) as one justification for current legislative proposals as mentioned below. Although not a CBD Party, the US has designated a national ABS focal point, and undertaken some analysis of ABS issues. ${ }^{99}$

US delegates in CBD processes have indicated that the government believes that no new legislation would be needed in order to satisfy Article 15.7, if the US were a Party. No report of the basis of these conclusions has been made available. Although it has no plans to adopt user-side measures, the US has recently begun processes for development of a regulatory program ${ }^{100}$ governing the process for granting rights to use specimens from US national parks. ${ }^{101}$ It has stated that it considers these measures to be ABS principles. This proposal provides useful insight into the US's view of the ABS process. ${ }^{102}$ In addition to documents relating to this process, the current study reviewed the following instruments, which have been reported to be the primary basis of user measures in the US at present: the Lacey Act, ${ }^{103}$ the Stolen Property Act (NSPA), ${ }^{104}$ the Federal Technology Transfer Act of 1986 (FTTA). ${ }^{105}$ These instruments have been identified by some official commentators as measures which are sufficient to address Article 15.7..$^{106}$

Two more direct US programs addressing ABSrelated materials focus only on particular smaller groups or sectors. Of these, the most direct legislative relevance is the work of the National Institutes of Health, which has imposed specific benefit-sharing practices and requirements on partners and funded projects, as a condition of funding. ${ }^{107}$ The other such program with similar focus (but not referring to ABS) is the National Cancer Institute's research processes. ${ }^{108}$

\subsubsection{Costa Rica}

Costa Rica is primarily seen as a "provider country." That is, the country assumes that its genetic resources are utilized by both domestic and foreign users, but that Costa Rica's domestic users do not utilize genetic resources from any other country. ${ }^{109}$ It has been notable as one of the first countries to adopt an institutional and legislative system for access and

99 As a non-party, the US is not specifically bound by the commitments made by all Contracting Parties to the CBD; however, it has made some serious efforts to comply with them including identification and monitoring under Article 7, and submitting one national thematic report (a Voluntary Report on Implementation of Expanded Program of Work on Forests, dated Feb. 2004 at http://www.biodiv.org/doc/world/us/us-nr-vfe-en.pdf).

100 This proposal is still in a preliminary (environmental impact review) stage. See, UNITED STATES National Park Service, September 2006, Servicewide Benefits-Sharing - Draft Environmental Impact Statement, Department of the Interior, at http://parkplanning.nps.gov/document.cfm?parkId=442\&projectId=12515\&documentID=16763.

101 This term includes all units under the US National Parks Service, whether they are called "national park" or given another designation.

102 The authors are grateful for the information provided by Ms. Sezannah M. Seymour, the US’s ABS Focal Point, who provided this material on current developments and reports, including the NPS report.

103 Officially known as the "Lacey Act Amendments of 1981" (replacing the original Lacey Act), enacted as Pub. L. 97-79, Sec. 3, Nov. 16, 1981 (last amended 2003), codified in the US Code at 16 USC \$\$ 3371-3378.

${ }^{104}$ Included in the United States Code (federal law) as 18 U.S. Code $\$ \$ 2314$ and 2315 . The Stolen Property Act was originally enacted in 1949 and has been amended at least seven times since its original adoption.

105 Federal Technology Transfer Act of 1986, enacted 20 Oct. 1986 as Public Law No 99-502, codified in current US Code as 15 US Code 2781, 3701 and 3710 and elsewhere.

106 These documents were so identified in presentations and personal communications by Leonard Hirsch, (Smithsonian Institute), US delegate to the CBD, who stated that the US has determined that they are sufficient to satisfy Article 15.7. The authors have been unable to find any public US document confirming this conclusion. His communications also identified the "Trade Secrets Act," however, this law's ABS relevance was not clear upon review.

107 The National Institutes of Health program is described in numerous publications, including Rosenthal et al., 1999 ; Rosenthal, 1996.

108 Discussed in detail in Bhatti et al., 2007, the fourth book in this Series.

109 This information was provided by InBio, in October 2006, but relates to non-conventional uses of natural species only. Costa Rican agricultural researchers also engage in plant variety development using varieties from international collections. See, e.g., Moore and Tymowsky, 2005. A more in-depth analysis of the current state of Costa Rica's institutional and legal framework is available in Book 1 of this Series. Cabrera and López, 2007. 
benefit sharing, and to apply the "provider side" of this system - but has also formally adopted some user-side measures, which are applicable only to domestic (Costa Rican) users of Costa Rican resources. The government of Costa Rica has formally recognized that the ABS system is not yet functional, due to problems with applying ABS "beyond access."110 This book considers three primary Costa Rican instruments: its national biodiversity laws, its $\mathrm{ABS}$ regulations (Normas Generales para el Acceso a los Elementos y Recursos Genéticos y Bioquimicos de la Biodiversidad); ${ }^{111}$ and its national biodiversity strategy (Estrategia Nacional de Biodiversidad). ${ }^{112}$

\subsubsection{Brazil}

Brazil has also typically been considered a provider country, but is actively developing domestic industries and companies based on the utilization of domestic genetic and biological resources. Its ABS legislation is very comprehensive, addressing a broad range of activities, applicable to domestic users of Brazilian biological diversity. We have examined only Brazil's Provisional Act implementing the CBD. ${ }^{113}$

\subsubsection{Other countries with specific measures and processes of interest}

In addition to these countries that have been researched in depth, this study has sifted the general body of available ABS information, and identified several other instruments of provisions of interest, including the following:

- Japan: The Japanese Ministry of Economy, Trade and Industry, with the Japan Bioindustry Association, has developed Guidelines for Access to Genetic Resources for Users in Japan, ${ }^{114}$ which is of interest as one of the few formal efforts of any country to address the obligations of users under its jurisdiction, in addition, as discussed below, it contains one of the only existing examples of an incentive-oriented user measure;
- Australia: Australian law, including the Commonwealth (federal) law on ABS, ${ }^{115}$ the Queensland Biodiscovery Act. ${ }^{116}$ Both focus on the "provider side," and do not address the responsibilities of Australian users to share benefit when they use genetic resources from other countries, nor provide for the rights of source countries in Australian courts and agencies. These provider-side measures, however, give a clear indication of Australia's legal view regarding the duties and rights of domestic users of Australia's own genetic resources, and this perception may be carried over to address Australian users of foreign genetic resources. In that respect, these provisions are relevant to this study. ${ }^{117}$

${ }^{110}$ COSTA RICA: Estrategia..., at 2.4: "Knowledge in these subject areas is scarce, the ability to track ABS permits is limited. Practical ABS application under the legislation which has created the institutional framework is still in development.” Informal translation for purposes of this book only, by T. Young.

111 COSTA RICA: Decreto No. 31 514, 2003, issued pursuant to the Organic Law on the Environment ( $\mathrm{N}^{\circ} 7554$ of 4 Oct. 1995) \$\$ 46-47; and the Biodiversity Law (No 7788 of 30 April 1998), $\$ 62$.

112 COSTA RICA: Estrategia..., 1999. Accessed via the CHM's ABS Measures database.

113 BRAZIL: Provisional Act No 2, 186-16, implementing CBD Arts. 1, 8j, 10c, 15 and 16, Act. No 2,186-16, (Aug. 23, 2001). Several other instruments were available in the CBD database, but only in Portuguese, so the authors were uncomfortable using them for specific analysis.

114 JAPAN: METI/JBA, 2006, Guidelines for Access to Genetic Resources for Users in Japan, Ministry of Economy, Trade and Industry and Japan Bioindustry Association (adopted March 2005, published in English, 2006) available online in English at http://www.mabs.jp/information/oshirase/pdf/iden_tebiki_e.pdf.

115 AUSTRALIA: Environment Protection and Conservation Regulations, 2000, Statutory Rules 2000 No 181, as amended (taking into account amendments up to SLI 2006 No 131. ABS issues are addressed primarily in Parts 8A and 17, but also critically affected by Parts 9 and 10, which address protected areas and species and the manner in which resources within them can be used.

116 AUSTRALIA: Queensland Biodiscovery Act, Act No 19, 24 Aug 2004; and other documents available on the CBD's ABS measures database through March 2007.

117 A variety of non-legislative documents obtained through the CBD were also examined, but did not contain information on "user measures" as that term is used in this book. 
- The Netherlands: The Netherlands' policy document on genetic resources, entitled Sources of Existence: Conservation and the Sustainable Use of Genetic Diversity, ${ }^{118}$ also provided some useful insights into the perspective of a country which has jurisdiction over a large number of users of genetic resources (especially in the seed sector).

- Canada: Canada is currently engaging in the development of ABS provider measures. It has published (including through the CHM) a national policy description on ABS. ${ }^{119}$ While not addressing most "user-side" aspects, these provisions may give an understanding of how the user side is legally perceived.

- European Commission: For completeness, we also reviewed the primary EU documents relating to user measures, which implicitly assume that ABS is a matter of source-country law and contracts, requiring little from user countries. In addition

\subsubsection{Other studies and analysis}

This study is additionally supported by data obtained from countries which have complied with the $\mathrm{CBD}$ request for Parties and the Secretariat to "gather information ... and undertake further analysis relating to ... existing practices and trends with regard to commercial and other utilization of genetic resources and the to considering the provider-side issues within the EU (access to European genetic resources), it focuses on assisting developing countries to develop ABS frameworks. ${ }^{120}$ Its "user-side" discussion focuses primarily on disclosure of origin in patent applications. ${ }^{121}$ Although $\mathrm{ABS}$ is not mentioned, EU documents and strategies on Technology Transfer ${ }^{122}$ have been identified as potential mechanisms for benefit sharing. The EC has also suggested the possible applicability of a certification system in ABS. ${ }^{123}$

The authors examined all of the other ABS laws from around the world, which have been included in the CBD's online "database of ABS measures." Although many of these are detailed legislative efforts, none directly or indirectly addresses the Article 15.7 obligation of the users under the country's jurisdiction to share benefits with foreign source countries or providers. Accordingly, they are not discussed in detail in this chapter.

generation of benefits." ${ }^{124}$ From this process we identified four key studies which address that requirement an excellent study undertaken by the government of Germany, regarding the use of genetic resources by German companies, ${ }^{125}$ and subsequent studies undertaken in the United Kingdom ${ }^{126}$ and Belgium. ${ }^{127}$ Although based on relatively small samples and

\footnotetext{
118 NETHERLANDS: State Secretary of Agriculture, (undated), Nature Management and Fisheries, Sources of Existence: Conservation and the Sustainable Use of Genetic Diversity, available online at the website of the NL's ABS focal point at http://www.absfocalpoint.nl/documents/ note_on_biodiversity_Complete.pdf .

119 Guiding Principles and Features of ABS Policies in Canada (undated) obtained from the CHM.

120 See generally, EUROPEAN COMMISSION: EC, 2002, as well as the national ABS reports provided by other EU Member States: AUSTRIA, ESTONIA, and POLAND.

121 EUROPEAN COMMISSION: EU Directive on Patents in Biotechnology (EC/98/44); "Communication from the Commission to the European Parliament and the Council, the implementation by the EC of the "Bonn Guidelines" on access to genetic resources and benefit sharing under the Convention on Biological Diversity," COM(2003) 821 final, Brussels, 23.12.2003; and EC Regulation (EC) No 761/2001 allowing voluntary participation by organizations in a Community eco-management and audit scheme (EMAS).

122 These include the "Innovation and SME (small and medium enterprise) program," the "Partnership Agreement between Members of the African, Caribbean and Pacific (ACP) States and the European Community (Cotonou Agreement), and its Compendium on Cooperation Strategies," mentioned in EC, 2002. None of these documents specifically mentions ABS or is, in its current form, applicable to ABS.

123 Although no legislation has addressed these matters, they have been prominently discussed in the EC's primary report on ABS. EC, 2003, at 9 and 22.

124 CBD COP Decision VII-19.

125 Holm-Müller et al., 2005.

126 Latorre, 2005.

127 Dedeurwaerdare, 2006.
} 
responses, ${ }^{128}$ their results provide a kind of data greatly needed within the ABS discussions - user information. By definition, however, these studies are limited to those companies willing to respond, which restricts the potential to draw general conclusions from them.

Another important source of data is the CESAGEN study of the frequency and number of applications for patents utilizing certain categories of biological material. ${ }^{129}$ This study's methodology counted all patents that utilize key biochemical and genetic terms in their patent applications. As such it

\subsection{User-side legislative mandates}

In this part, we propose to consider the first category of Bonn Guidelines user-side measures described in part 3.1.2, above ab2 $^{132}$ the creation of laws within user countries to mandate that users comply with ABS requirements. In this context, the Guidelines call for three categories of action.

First, a law must specify the users' obligations and require users to comply with them. This provision is necessary under the Bonn Guidelines requirement that countries prevent the use of genetic resources without PIC and permission from the source country. This point is dealt with in 3.3.1, below. Second, it must develop standards for implementing that compliance. These measures (described in the Bonn Guidelines as "compliance with MAT") will be difficult to develop, since they seem to call for the user country to adopt and apply another country's laws and definitions. They are dis- could not come to definitive conclusions regarding the number and nature of patents based on "genetic resources" or subject to ABS requirements. Within its limits, however, it too is a groundbreaking study.

We have also considered the new "Draft Guidelines regarding Benefit-sharing for 'Natural Products,' " which is currently under preparation by UNCTAD's BioTrade Initiative. ${ }^{130}$ These guidelines are a work in progress that offers useful insights into problems encountered in the current climate of legal uncertainties. ${ }^{131}$ cussed in 3.3.2, below. Third, the law must create a system of enforcement and compliance which, as noted in the Bonn Guidelines, requires coordination between source and provider countries. This requirement is considered in 3.3.3.

These three obligations represent the most important unfulfilled mandate in the ABS regime, but their importance is often overlooked in favor of discussing other issues. It takes only a few minutes of legal analysis to understand their importance. When a person or company is utilizing resources from one country (the provider country), but operating in a different country (the user country), that person's activities are outside the reach of the ABS system, unless the user country law requires $\mathrm{ABS}$ compliance. The source country's laws only apply if the source country has jurisdiction - in other words, while the user and/or the genetic resources are inside the provider country. ${ }^{133}$

128 The German study's questionnaire was circulated to a list of 597 users, receiving 136 replies (23\%); the British study's was circulated to 600 users, receiving 127 replies (21\%); the Belgian study's was circulated to 400 organizations (heavily weighted in favor of the public sector), receiving only 57 replies (14\%). All three studies noted significant differences among the 10 sectors sampled, but were forced to base these conclusions on as few as four respondents in a given sector (possibly less in Belgium where graphs did not clarify numbers and other factors). Often all responses in a particular sector would have no response to a given question. Another limitation in the conclusions that can be drawn arises from the fact that all studies were anonymous, and that this might have enabled multiple replies from the same user.

129 Oldam, 2005.

130 See UNCTAD, Draft concept note: Practical Guidelines for Equitable Sharing of Benefits of Biological Resources in BioTrade Activities, 3 March 2007. Discussion in this book is based on the 31 January 2007 draft (not yet available for citation). It is discussed here with permission from the BioTrade initiative.

131 This draft is not available for citation, and is not quoted in this book.

132 Bonn Guidelines at 16(d)(iii), (vii), (iv), (vi) and (ii), in the order presented here.

133 This point is best illustrated by noting how desirable it would be for a government if it could impose taxes only on persons from other countries, thereby protecting its citizens and voters from increased tax costs. Obviously, such a situation would not be desirable to the persons taxed in this way. National sovereignty is a concept that ensures that only the sovereign government can legislate matters and persons within its borders and jurisdiction - it is, in essence, a protection to its citizens. 
Thereafter, ABS applies only through laws of a user country.

In the analysis of these three components of legislation, it is often necessary to separately consider two situations which are usually ${ }^{134}$ recognized to be very different legally:

- Compliant user: User has a direct relationship with the source country (has complied with PIC and obtained an ABS permit or other instrument specifying MAT);

- Non-compliant user: User has no direct relationship with the source country, having acquired the resources without contacting the source country, either

(i) by collecting resources "informally" without PIC, MAT or other permissions; or

(ii) by receiving the resources from a middleman (a collector bringing resources out of the country to give/sell them to users, a researcher who has identified a commercial application of the genetic resources, another user, etc.).

In this context, it is important to remember that noncompliant users often do not perceive themselves to be violating any law. They may be unaware of ABS requirements or may not believe that those requirements apply to them.

\subsubsection{Requiring compliance with source country ABS law}

As noted in 3.2, following the enactment of the CBD, several developed countries initially concluded that their existing legislation (contract law, criminal law, etc.) would be sufficient to implement $A B S$, so that no new law or interpretation was needed. On reflection, however, this initial analysis was erroneous in some respects, owing to certain oversights and to the unique characteristics of $\mathrm{ABS}$ issues.

\subsubsection{The requirement as applied to ABS-compliant users}

Up to now, most user-side discussions of ABS implementation have focused on the companies, institutions and individuals that have complied in whole or in part with source-country $\mathrm{ABS}$ requirements - i.e., users that have sought $A B S$ contracts or permits. On the basis of this focus, some commenters claim that ABS implementation will be addressed under contract law - through actions to enforce the "ABS contract." This view was stated in the CBD negotiations and thereafter in publications and discussions by environmental experts, ${ }^{135}$ it persists today in publications and discussions proposing standard contract formats as simplistic solutions to ABS difficulties. ${ }^{136}$

\section{[a] Application of contract law to ABS situations}

The main flaw in the contract law approach is its presumption that all users will obtain ABS agreements (contracts, permits or other arrangements) before obtaining or utilizing genetic resources. Even if this presumption were true, however, the availability of contract law to resolve $\mathrm{ABS}$ issues and problems would be dubious at best. Contract law is, by definition, a process that depends on definiteness - having an instrument or agreement, based on well understood concepts and definitions about which the Parties agree, and which a court can interpret and enforce. The functional application of contract law must also be based on a legally agreed, coherent, internally consistent, and logical system, which can be applied to the contract in question. Courts will usually refuse to enforce a contract where primary facts are ambiguous. ${ }^{137}$

Without clear means of understanding and interpreting $\mathrm{ABS}$ contracts and applying contract legal

\footnotetext{
134 The EC and many other comments on "user measures" do not acknowledge this distinction, and take the view that the entire implementation of ABS can be satisfied by provider country legislation, supplemented by user country adoption of patent disclosure requirements. EC, 2002 at 7.3); see also UNU-IAS, 2005 (directing nearly all attention to this issue.)

135 See, e.g., Glowka et al., 1998, at 4.

136 See, Scott, 2005.

137 The difficult issues surrounding the application of contractual law to ABS are examined in Part II of Bhatti et al., 2007, Book 4 in this Series.
} 
principles to them, it will be impossible for the courts to come to consistent, replicable decisions interpreting or enforcing those contracts. This is evidenced by the current situation, in which many users conclude that $A B S$ does not apply if resources were obtained from collectors, middlemen and others outside of the source country. This basic dispute about what actions "trigger" the $\mathrm{ABS}$ responsibility suggests that $\mathrm{ABS}$ contracts may not be enforceable, until these conceptual issues are resolved. Even if this issue is fully determined through the international negotiations, ${ }^{138}$ it will still be necessary to integrate them into national law through legislation. ${ }^{139}$ Until (i) these issues are resolved (legislatively and/or judicially) in each country and (ii) those solutions are recognized by the user country's courts, it may not be possible to obtain (or predict) the court's interpretation of those instruments, especially when the interpreting courts will be in a different country (the user country) rather than the one that issues the instrument.

Arguably, current ABS contracts in source countries (and the laws governing their negotiation) are highly detailed and rigorous precisely because the parties to an $A B S$ contract cannot depend on or predict judicial processes - the source country must find a way to function where there are no pre-existing well-explained legal concepts to address their particular needs. The resulting amount of detail in ABS contracts is one of the most common complaints of users. ${ }^{140}$ At present, however, there are no common principles between user and provider countries that the judiciary ${ }^{141}$ can rely on in interpreting and enforcing contracts. Source country laws can be seen as attempts to minimize the need for later "interpretation" or invalidation of the ABS contract or agreement. All countries can simplify relevant legal and contractual systems only by acting cooperatively to build confidence that each country's national law and court decisions will be consistent and generally predictable when applied in other countries.

To date, countries studied do not appear to have adopted or considered any measures to better enable the use of national contract law to address ABS issues. Such measures must consider the needs of foreign source countries in dealing with users, once the users have left the source country. Even the provider-side legislation in the user country does not create such a basis. For example, the current proposal being considered by the US government applies only to "research projects involving research specimens collected from units of the US NPS that subsequently resulted in useful discoveries or inventions with some valuable commercial application." ${ }^{142}$ Presumably the need to "finesse" the terminology and approach arises out of the current ambiguities regarding the nature and meaning of genetic resources and the function of the ABS system. But since this terminology is completely different from all other countries' attempts at ABS legislative terms, it cannot provide a solution to the transnational questions of ABS implementation and "genetic resources." International law provides no indications of how these issues could be resolved.

138 It is doubtful that all contractual interpretation issues will be fully addressed in the negotiations; however, it is hoped that enough clarity is provided to enable countries to adopt internally consistent systems, and to find ways of interlinking these systems to form the "international regime."

139

In many countries, the interpretation of contracts is aided by legislation that provides standards for contract analysis. For example, a section of the California Civil Code identifies many provisions which are assumed to be part of any contract, unless the contract specifically provides the opposite. UNITED STATES: CALIFORNIA: Civil Code Division III (Obligations) \$\$ 1427-1725. (General contract law only; approximately ten times that amount addresses more specific issues, such as credit transactions and consumer's rights). One such issue is order of payment and services (See, e.g., Restatement (2d) Law of Contracts, vol. II "performance and non-performance."). Unless the contract specifies differently, in a services contract the amounts due will be paid for only after the services are provided. Currently, there are no provisions in US law to define "genetic resources" or provide any guidance or indication as to how the unique elements of ABS agreements will be addressed by US courts.

140 See, Latorre, 2005; Holm-Müller et al., 2005.

141 Courts and other judicial and quasi-judicial processes and institutions.

142 US NPS, 2006, Draft EIS, presented as Alternative B. In this regulation, there is no need to distinguish between biological and genetic resources from national parks, because both are restricted. In the United States, it is specifically forbidden to take any material, living or non-living, from a National Park, without permission from the NPS. Outside of national parks, this approach would not help, since no US law has yet clarified the ownership of genetic resources. 


\section{[b] Measures to assist source countries in overseeing ABS contracts and users}

Contract law is not the only legal concept needed in order to enforce $\mathrm{ABS}$ contracts and agreements in user countries. There are many other factors that must be satisfied in order for the source country or other provider to have a realistic ability to call for compliance, or to seek and obtain legal redress if that call is ignored. One such factor is information (evidence). Given that the many of the user's actions occur outside of the source country, the provider will face many legal and practical obstacles that may prevent him from enforcing the contract (e.g., proving that there was a violation, or proof that payment is due). Even one who is not hampered by long distance, language and other obstacles would find it difficult to obtain many of these proofs. Usually, to gather information from a private entity, one must obtain a court order allowing inspection of that entity's operations and its records. Even when the order is granted, it will be necessary to hire experts to conduct the inspection and to carefully document the evidence gathered.

Given the equity concepts underlying $\mathrm{ABS}$, and its focus on developing countries, it is necessary to consider the practicalities arising from the need to oversee each ABS contract and user. All of these processes and experts are expensive and time-consuming. In addition, governmental fees can be sizeable, as can the costs of local officials who monitor the inspection (making sure that access is granted, and that the rights of entry are not abused). Typically the costs of legal processes are much higher in developed countries than in developing countries. Many developing countries would not have the money, time, or knowledge to enable them to use existing user country legal processes to oversee ABS contracts. Their only practical option is to rely on the user's progress reports (if any are submitted) to know how their contract is faring.
The equity orientation of $\mathrm{ABS}$ suggests the need for measures to assist source countries in overseeing and asserting their ABS-related rights.

\subsubsection{Users who have not complied with source- country $\mathrm{ABS}$ requirements}

Currently, in Europe (and presumably elsewhere), many commercial users of genetic resources assume that ABS does not apply to them. ${ }^{143}$ To some extent, the costs in time, money and risk involved in $A B S$ compliance constitute a perverse incentive, encouraging a company to avoid ABS, usually by finding a credible legal argument that ABS does not apply. ${ }^{144}$ Such arguments are easy to find in light of the current ABS legal ambiguities. Unless countries adopt legislation to require users under their jurisdiction to comply with the ABS laws of the source country, this will create an unfillable loophole in ABS. Users will essentially be permitted to decide for themselves whether to apply source-country laws.

Up to now, very little user-side legislation has been adopted or proposed to address the possibility that a user in the legislating country might be utilizing genetic resources of foreign origin without permission from the source country. Following adoption of the CBD, several countries, including both the United States and Norway, came to the initial conclusion that Article 15.7 could be adequately implemented in their countries without additional legislation. Since that time, however, Norway has recognized that Article 15.7 requires user measures that address the possibility that a user might fail to comply with the ABS requirements of the country that is the source of genetic material it is using. Norway's draft Nature Diversity Act, although not yet adopted, is the only current example of a national law that squarely takes on this question of the responsibility of its users of foreign genetic material. This Act states that

\footnotetext{
143 Holm-Müller et al., 2005, at 37; Latorre, 2005, at 28-30; Frison Dedeurwaerdare, 2006, at 34-38. To a large extent, the latter two surveys also assume that genetic resources from domestic providers need not comply with ABS (without consideration of species origin).

${ }^{144}$ Within the provider country, the applicant's interest and plans are often matters of public knowledge, particularly where the country has delegated its PIC responsibilities to local communities, merging them with general provisions relating to public participation. The result of this widespread awareness is often that the application is subjected to legal challenges from a variety of sources. Beyond the access phase, the user is frequently identified in the press and electronic media as a "biopirate," despite the fact that his genetic use and objectives became known because he acted in a non-piratical way - he applied for government approval. Young, 2006a.
} 
[i]mport for the purpose of utilizing genetic material from a country which requires prior informed consent for either the utilization or for the export can only happen in compliance with such prior informed consent. ${ }^{145}$

It does not specifically impose any obligation on the government to enforce this provision, or specify mechanisms for this enforcement; however, it is probable that such mechanisms would be developed after the primary law is adopted.

In Canada, although direct user measures have not yet been developed, ${ }^{146}$ national ABS policies include the principle that Canada should be

\section{[r]espectful of jurisdictional mandates and mindful of the desirability for inter-jurisdictional cooperation in the development of ABS policies. ${ }^{147}$}

Although this provision may refer only to sub-national jurisdictional issues (in the 12 Canadian provinces), it may still provide a basis on which to consider the rights of other countries and the obligation under Article 15.7 to implement the Convention in a way that results in benefit sharing.

In the Netherlands, while the national policy assumes that the interests of the source country or other provider can be implemented by contracts, it also recommends the development of codes of conduct (discussed in 3.9).${ }^{148}$ It specifically places this responsibility for compliance on the user and disavows any national obligation:

\section{The application of the policy... is mainly the respon- sibility of the business sector, institutions, researchers and individuals. ${ }^{149}$}

A similar provision is found in the US proposed legislation:

The burden of coming forward to initiate benefits-shar-
ing negotiations with the NPS would rest with individ-
ual researchers and would conform to the provisions of
research permit or MTA to which the researcher had
agreed when accepting the permit or MTA. ${ }^{150}$

The US has not adopted or proposed any userside ABS legislation. ${ }^{151}$ Reportedly, however, it has identified two existing laws as satisfying this need: ${ }^{152}$ The Lacey Act and The National Stolen Property Act (NSPA). Both are criminal statutes, enabling US officials to take actions against persons who have either (i) "transported, transmitted, or transferred goods;" or (ii) "imported, exported, transported, sold, received, acquired, or purchased fish or wildlife ${ }^{153}$ in

145 NORWAY: draft Nature Diversity Act, $\$ 60$, and similar language in provisions governing use of genetic material from these sources. All translations from Norwegian are informal translations for the purposes of this book only, by M. W. Tvedt.

${ }^{146}$ National processes are ongoing, but reportedly will focus on provider measures. Based on informal discussions, it appears that the legislation will be equally applicable to foreign and domestic users.

147 CANADA: Guiding Principles, supra., last bullet point. Another principle calls for policy to be “... building on and respecting Canada’s international commitments."

148 NETHERLANDS: "Sources of Existence" at 2.1-2.4.

149 NETHERLANDS: "Sources of Existence..." at 3.2.

150 UNITED STATES: National Park Service, September 2006, Servicewide Benefits-Sharing - Draft Environmental Impact Statement, Department of the Interior, U.S. at 2.4.1, page 41. A less complete cession of primary responsibility is found in the Norwegian draft which says, "The entity with the genetic material in hand is bound by the conditions imposed on the use of the material," NORWAY: draft Nature Diversity Act, at $\$$ 60. Similarly, BRAZIL, Provisional Act, Title IX, Art. 34, provides that "the person who uses or makes economic use of [genetic resources and TK] should make their activities compatible with the provisions of this Act."

${ }^{151}$ As noted above, the current regulatory proposal being aired by the US National Parks Service (NPS) focuses only on the provider side - i.e., NPS's ability to enter into benefit-sharing agreements for research specimen collection.

152 Presentation by Leonard Hirsch, see footnote 105, supra. He noted another law, a "Trade Secrets Act," but the authors research found only laws (with this name or on this topic) that are not relevant to ABS. Further inquiry did not produce other citations. Mr Hirsch also indicated that the US government subscribed to guidelines developed by the Public Interest Intellectual Property Advisors (PIIPA), a US NGO of IPR lawyers; however, those guidelines were not available online as of the date of finalization of this book.

153 The former requirement comes from the NSPA, the latter from the Lacey Act. That second provision probably does not apply to plants (other Lacey Act provisions make it illegal to take "fish, wildlife or plants," suggesting that plants are intentionally omitted from the international provisions). They do not mention microorganisms. 
violation of foreign law." These laws apply to the transport, possession, etc. of "property," "fish" or "animals."

These laws exemplify the problem all countries face in attempting to apply general law to ABS. For example, since no law in the US recognizes "genetic resources" as property, these two laws will be triggered only if the biological specimens were obtained illegally. In most countries which have adopted ABS legislation, however, genetic-resource rights are separate from the right to take or use "biological resources." This separation is necessary so that $A B S$ will not interfere with normal transactions involving biological products (food, clothing, wood, plants, etc.). The biological specimens may be collected legally, even if no right of access to or utilization of genetic resources has been granted. Although possession of the biological material may be completely legal, that does not necessarily mean that it is legal to utilize its genetic resources.

In addition, like other laws against theft and illegal trade, enforcement may depend on the market value of the items taken, rather than their use value. Under the NSPA, for example, the action can be taken only where the "stolen" material's market value is at least US\$ 5000. In the ABS context, however, many biological samples with low or non-existent market value have significant potential-use value. Reportedly, for example, users are collecting dung samples (of little or no cash value) in Africa, in order to research and utilize enzymes contained in it. ${ }^{154}$

Another problem encountered in applying criminal law is the manner in which these laws are enforced. Usually, enforcement decisions must be made by the government. The victim may report the crime, but may take no other action. It is the government's task to determine whether to devote its limited human resources (time and expertise) and expend other costs necessary to amass a case against the violator, and whether that case has a high enough probability of success to be worth the effort. This decision is usually made by prosecutorial officials who often do not give high priority to conservation-related crimes. ${ }^{155}$ This principle suggests a loophole in the draft Act in Norway, under which the applicant's failure to provide information on the origin or provider, and their PIC requirements (if any), is considered to be illegal and can be penalized.

Finally, reliance on the user country's governmental enforcement (criminal laws) ignores a major element of $A B S$ - the objective of equity that underlies the entire concept. ABS can only satisfy the equity objective when benefits are actually shared with the source country. Even if they are enforced with regard to $\mathrm{ABS}$ violations, criminal laws against theft, smuggling, receiving stolen goods or possession of stolen goods can only be enforced by the government in which the action is filed. The results of those enforcement actions are usually punitive - that is, the government may cite or arrest the person who steals, smuggles, transports or holds such goods. If the accused is convicted, then the user government may charge a penalty (fine), which is paid into the user government's accounts, or may imprison the violator. The government may confiscate the stolen goods, as evidence, and in some cases the confiscated goods may be returned to the victim after trial. In nearly every situation, a criminal case will not result in compensation or payment to the injured party (i.e., the source country). Hence, criminal penalties against a violator alone will not meet the CBD's ABS objective. ${ }^{156}$

\subsubsection{The roles of government, as user and advisor to users}

Another element of the direct application of the primary requirement relates to the situations in which the government is directly "utilizing" genetic resources, through government research agencies and institutions, as well as through government-sponsored programs and projects. In this context, national rules for compliance with source-country $\mathrm{ABS}$ requirements parallel the concept of "national procurement policies" which have been suggested as a primary

\footnotetext{
154 Personal communication, Robert Lettington, May, 2005.

155 See Anton et al., 2002.

156 Tvedt, 2007.
} 
means of promoting international environmental objectives. ${ }^{157}$ In research for this book, the authors noted one governmental program, the International Cooperative Biodiversity Groups (ICBG), under the US National Institutes of Health, which has reportedly adopted specific rules for benefit sharing in connection with its international projects for bioprospecting and the identification and analysis of genetic resources. ${ }^{158}$

Another instrument (with less binding force) is "Principles on Access to Genetic Resources and Benefit Sharing for Participating Institutions" 159 propounded by Kew Gardens as principles to be adhered to by individual botanic gardens, and endorsed by 21 other institutions. ${ }^{160}$ Relevant as user measures, the following excerpts from the principles although somewhat unspecific, indicate a basis for user guidance:

- Honour the letter and spirit of ... laws relating to access and benefit sharing.

- Share fairly and equitably with the country of origin and other Stakeholders, the benefits arising from the use of genetic resources and their derivatives including non-monetary, and, in the case of commercialisation, also monetary benefits.

o When acquiring genetic resources from ex-situ sources, whether from ex-situ collections, commercial sources or individuals, evaluate available documentation and, where necessary, take appropriate steps to ensure that the genetic resources were acquired in accordance with applicable law and best practice.

o Share benefits arising from the use of genetic resources acquired prior to the entry into force of the $C B D$, as far as possible, in the same manner as for those acquired thereafter.

- Use and supply genetic resources and their derivatives on terms and conditions consistent with those under which they were acquired.

- Prepare a transparent policy on the commercialisation (including plant sales) of genetic resources acquired before and since the CBD entered into force and their derivatives, whether by the Participating Institution or a recipient third party.

This document is not endorsed or adopted by any government. As such, its principles are expressed in nonmandatory language that would not be sufficient if adopted into the law of a CBD Party. For example, some of the principles "recommend" actions that are legally required in source-country $\mathrm{ABS}$ laws and/or that are binding commitments under the CBD. Although appropriate here, when these principles are included in a more formal legal instrument, it seems essential to "require" such compliance. Although not a substitute for more specific user-side laws, the Principles provide useful guidance, and serve as a strong indicator of the need to address the issues of ex-situ collections, transfers of genetic resources, and biological material that has been added to such collections prior to 1993 .

\subsubsection{Disclosures in patent applications}

One of the few specific tools that have been discussed for promoting the implementation of ABS contracts is the proposal to require or encourage disclosure of origin in patent applications - a concept that has been taken up in the Bonn Guidelines at paragraph 16.d(ii). Various versions of this mechanism have been adopted in Norway, Denmark and India, as well as Peru, Venezuela and the Andean Pact Community (APC).

\footnotetext{
157 See, Young, 2004 (unpublished).

158 Discussed in Rosenthal, Joshua, "Measure to Ensure Compliance with CBD and Access Legislation," Presentation at the International Expert Workshop on Access to Genetic Resources and Benefit-sharing, Cuernavaca, 24-27 October 2004. The policy is not available on the ICBG website and could not be obtained from the program manager so its specific contents cannot be discussed. See also Rosenthal, 1999, which describes the system in terms of a set of goals including conservation equities, but without specifically drawing out the ABS elements. (Experiences with ICBG projects are detailed in Chapter 9 of Bhatti et al., 2007).

159 The full text of the principles is found online at http://www.rbgkew.org.uk/conservation/principles.html.

160 http://www.rbgkew.org.uk/conservation/endorsements.html.
} 
In terms of impact, there are many variations among the patent disclosure measures in place at present. The EU Patent Directive, while allowing countries to adopt such measures, states that the measures shall not have any impact on the granting or validity of the patent. ${ }^{161}$ This provision did not prevent Norway and Denmark from imposing criminal penalties for nondisclosure or incorrect statements in disclosures, although the failure to make disclosure is not an appropriate legal basis for invalidating a patent. ${ }^{162}$ The Indian, APC, and Venezuelan laws are written in a way that allows rejection or revocation of the patent in the case of disclosure violations. These provisions, however, apply only to patents regarding the genetic resources of the country/region passing the law.

Unfortunately, there are so many limitations in this concept that it may not be a useful solution to promote benefit sharing in practice.

First, the problems of systemic ambiguity described above are also an obstacle to mandatory or voluntary disclosure. For example, Norway requires disclosure of origin of any "biological material" on which the innovation is based. Presumably this terminology was chosen, due to the uncertainty about which materials or information are "genetic resources." 163 A recent study has shown that an enormous volume of patent applications mention genetically described biological sources. ${ }^{164}$ An even larger number would describe the use of "biological material." Each country will theoretically have to consider thousands of patent applications each year, to find out if any of them involves the "utilization of genetic resources" or the "utilization of biological material" with origin in their country.
Second, the disclosure requirements currently do not obligate the government to verify the statements contained in the patent applicant's disclosure of origin. The government does not even commit to informing the source country named in the disclosure. Where voluntary disclosures are not made, there is no basis for determining the specific source country of the biological material used in the innovation. As a practical matter, these factors diminish the chance of full disclosure.

Third, the patent disclosure does not create any rights for the source country, but is only a mechanism that will give that country's officials some awareness that resources from their country are (or may be) being used. On the basis of this awareness, they will still have to make a demand on the user, who is located outside of their jurisdiction. ${ }^{165}$

Fourth, the patent disclosure does not confer any benefits-sharing obligation upon the user. Unless users offer benefits voluntarily or in response to non-binding "recommendations," such a requirement might not result in any actual sharing of benefits.

Finally, of course, the system presumes that users will agree that they are "utilizing genetic resources" of a foreign country, and will disclose the origin of those resources. This means that, at most, the same parties that have obtained ABS permits will also comply with the disclosure requirements. The value added by such a disclosure requirement, therefore, will probably be less than the cost of it, even if that cost is, as some have claimed, minimal. ${ }^{166}$

\footnotetext{
161 EUROPEAN UNION: EU Directive on the Protection of Biotechnological Inventions, EC/98/44.

162 See Note by the Executive Secretary, 2004, "Analysis of Measures to Ensure Compliance with Prior Informed Consent of the Contracting Party Providing Genetic Resources and Mutually Agreed Terms on which Access Was Granted, and of Other Approaches, Including an International Certificate Of Origin/Source/Legal Provenance," UNEP/CBD/WG-ABS/3/5, section II, D. Submissions of Denmark, Sweden and Norway.

163 See, NORWAY: draft Nature Diversity Act, at $\$ 60$.

164 Oldam, 2004, notes that nearly 500,000 of the patent applications filed between 1990 and 2003, that are listed in the Worldwide Database, include genetic-related keywords (protein, gene, DNA, amino acid, nucleic acid, enzyme, polypeptide, peptide, nucleotide, RNA, microorganism, human gene, genome, plant gene, animal gene, microbe, deoxyribonucleic, ribonucleic, proteome) in their abstracts of publication.

165 As discussed in Chapter 4, this is one of the primary fallacies in the patent disclosure idea - the fact that the IPR system functions through legal action initiated by the protected party.

166 Tobin, 2004.
} 


\subsubsection{Standards for determining performance}

In most legislative mandates, the standard is as important as the contents of the mandatory requirements themselves. In the ABS situation, the standard is the legislative measurement and objective factors that enable the user country or agency to confirm that the user has complied with the requirements described in 3.3.1. It is often assumed that the ABS standard for user compliance is "compliance with the law of the source country." As a practical matter, this can be a difficult standard to apply, for many reasons.

Legally, the most important characteristic of such a standard is "external verifiability" - the law should not depend on the ability of the agency or official to know what is in the minds of individuals nor the collective intentions of entities, in order for it to know if the standard has been met. In this connection, a problem may arise out of the need to apply the provider country's law - law which has not been adopted by the user country's legislature and may not conform to the requirements of user-country law. To fully apply the law of the source country, a court or agency in the user country must not only find the relevant law, but also learn about how it is applied. For example, to ask how the source country verifies compliance by the user, and how the source country's satisfaction can be determined. ${ }^{167}$

A country's user-side laws must govern users in that country who are using genetic resources of foreign origin. To do this, the most important single element is the requirement that each user comply with the ABS laws of the particular countries that are the source of his particular resources. Unless all countries adopt basically similar laws, this will mean that every user country must be able know and implement the laws of every other country. There is no direct experience with how such a requirement can function legally. One effort to address this gap is found in Norway's first draft Nature Diversity Act, which, as quoted above, provides that utilization or the import of genetic resources of foreign origin can only happen in compliance with any prior informed consent required by that foreign country.

PIC is, by definition, a "provider-side measure," since the requirements and authorities for PIC are entirely determined by the law of the source country. By tying compliance to PIC, the draft Act incorporates not only the PIC process, but also the source country laws and requirements under which the PIC was authorized and negotiated and the mutually agreed terms (MAT) that were produced. ${ }^{168}$

The Norwegian draft Act touches some of the most important questions relating to user-side legislation, without resolving these issues:

- How to find and determine the ABS laws and requirements of the source country;

- What to do when the user does not know or will not disclose the source country;

- How a user country's courts can determine and apply source-country law.

These three primary matters are discussed below, as well as other basic issues, such as equity, due process and the possible need to define clear end-points for the benefit-sharing relationship.

\subsubsection{Identifying and applying the source country law}

Determining applicable source-country law is difficult, primarily because many countries prefer to regulate using a different base point. As noted above,

167 Often this will require formal (diplomatic, in some cases) contact with another country. In many countries, direct contact between any governmental agency and its counterpart agency in another country is not simple, but requires that diplomatic officials be involved. See, e.g., Anton et al., 2002, at 82-92. Such contact may not always provide the needed information, which may, in some cases, be unobtainable.

168 CBD Arts. 15.4 and 15.7. In this connection, it is important to recognize that the CBD requires two separate MAT requirements - one for access (paralleling the PIC requirements), and another for benefit sharing. While the two may be negotiated together in some cases, this may not be possible in all situations, and it is possible that the duty to ensure that this second negotiation occurs is assigned to the user country. The inclusion of a second MAT process in Art 15.7 seems to indicate that user countries are expected to ensure that the user negotiates MAT with the provider country, regarding the benefits to be shared and the manner of that sharing. 
rather than the ambiguous term "genetic resources," they regulate on the basis of "biological material" or "research projects involving research specimens collected" from national parks, or other completely unrelated formulations. Even PIC and MAT requirements vary from country to country. In addition, many provider countries merge their PIC and MAT provisions with the concept of public participation. This causes these responsibilities to devolve onto the local communities involved, suggesting that many separate PIC requirements and MAT instruments may apply to a single bioprospecting project. ${ }^{169}$

Currently, none of the Contracting Parties have adopted any system for identifying and verifying exactly what source-country requirements must be met by a particular user under their jurisdiction. The Norwegian draft Act provides the only example of an attempt to regulate this.

That draft law would require compliance only where the genetic resources come from a source country that has adopted specific PIC requirements in legislation. This clause would suggest, for example, that a country with no specific PIC requirement in law does not "require PIC," and thus falls outside the rule of PIC compliance.

In fact, however, this assumption is not legitimate. One cannot say that countries that have not adopted specific ABS legislation have renounced their ABS rights. Many countries' legislators have been stymied by the uncertainties of the ABS concept, for example, and have not been able to find a way to adopt ABS laws that meet national legislative standards. Some may have simply decided not to allow their genetic resources to be used by any foreign user. In others, there may be general principles of that country's law which, although not mentioning ABS, are already sufficient to control situations in which a foreign entity seeks rights in the country's sovereign property, patrimony or even private property. Hence, one should not assume that the lack of a written ABS law enables unrestricted utilization of the country's genetic resources. This complicates the benefit-sharing picture.

\subsubsection{User measures where the source country is undisclosed}

The functionality of user measures may depend on eliminating some common perverse incentives currently created by the ABS system. Of course, the most significant perverse incentive is the one described at the beginning of part 3.3.1 - the user is beyond the jurisdiction of applicable ABS laws during most or all of his utilization of genetic resources. If he can take or obtain the resources outside of the source country without the costs and difficulties of ABS compliance, he will be "home free."

In adopting user measures, there is a strong need to find solutions that avoid creating additional perverse incentives of this type. For example, the Norwegian draft Act allows the user (only) to determine whether the source country requires PIC and to comply if it does. Moreover, if the source country is not known, then the user is not obligated to take any further action. All requirements for tracking the use of the genetic material are based on the user's identification of the source country and his determination of what obligations from source-country law apply.

There is a clear silent message from this provision - that it is better for the user if he "forgets" where he obtained the genetic resources. Similarly, this provision silently encourages the user to interpret source-country law as permissively as possible. In adopting user measures, countries might need to impose some alternative to PIC and MAT requirements, in order to avoid this problem. By linking user-side provisions so closely to PIC and MAT, the user country may tend to forget its overarching obligation to ensure fair and equitable benefit sharing in accordance with the goals and obligations of the CBD.

169 See Cabrera and López, 2007, at Chapter 2. In particular, for example, the Philippines requirement, calling for a separate PIC/MAT process for each area in which a collector is operating. This will mean that the same collector will be bound by many different sets of MAT, if his collection activities include more than one community. 


\subsubsection{Practical problems: Applying source- country law}

As noted in section 3.3.1 above, user-side measures must require or otherwise bring about compliance with the source country's law. The application of sourcecountry law by a user country may be very difficult, however, presenting several key challenges, particularly since the goal for a user country will normally be to clarify the ABS process for its users, agencies, and courts. Agencies are not, in most other situations, required to research foreign law, or to engage in legal or diplomatic processes in order to implement national law.

\section{[a]Description of the basic problems}

The challenges of using another country's law vary from straightforward administrative problems to underlying problems of sovereignty. For example, the source country's law may be in another language - a simple problem requiring only a technically qualified translator. But also each country's legal system and methodology is unique in some way - which raises a more complex problem that can be difficult to respond to, requiring in-depth legal research to determine how the source country interprets and applies its laws.

In general, there seem to be two options: The user country may directly interpret and apply the provider country's law; or it will ask the provider country to do so and give input into the user-country court's processes. Under first approach, the user country's courts may possibly come to a very different interpretation than the source country intended. The second approach will require the direct involvement of an official from the provider country, to determine directly whether the laws have been complied with. In practice, however, the result will probably be a combination of the two. Some key concerns that arise in this connection include:

- What happens if a source-country law or provision is "unenforceable" in the user country? This issue can arise, for example, where the user country has very strong constitutional protections for "private prop- erty," but the source-country law or contract gives the source country a right to interfere with private property rights in the national interest. The user country's courts and agencies may be constitutionally unable to apply the provider country's law, or apply the relevant contractual provision.

- What rules apply where there is no permit or ABS arrangement, especially where the user does not know or disclose the source country of the genetic resources? If it is not possible to apply a single "source-country" law, some other standard must be designated, to avoid the perverse incentive described above.

Perhaps ultimately the best solution to these questions will be through the international regime negotiations, if it can develop internationally agreed answers to them.

\section{[b] Current proposals for a partial solution - certificate of source, origin or legal provenance}

In nearly all user countries, it is likely that the user will bear some or all responsibility for identifying and documenting compliance with PIC and MAT. For credibility and effectiveness internationally, the user's analysis of the source country's requirements should be validated by the source country. This need has led some negotiators to suggest the creation of a "certificate of source, origin or legal provenance" (in this case, best described as a certificate of "legal provenance") in current international discussions, apparently viewing this as the primary "user measure" that the CBD calls for. ${ }^{170}$ Although a certificate-based system would address only one aspect of the issue, it could potentially be helpful in the creation of functional user-side measures. To accomplish this objective, the certificate must be designed to address this particular need. ${ }^{171}$ At present, the "certificate discussions" have attempted to develop a generic certificate without first coming to a clear understanding of its function as part of the ABS system or user-side

170 See, e.g., Barber et al., User Measures, 2003, which focuses on disclosure and tracking issues, including electronic and other data-sharing, border control, certificates and disclosure of origin, as three of the four topics (the other being "access to justice") that comprise "user measures."

${ }^{171}$ Normally, the certificate or documentation element of a legal system is created after the rest of the system is designed. In that way, the certificate's contents and the procedures for issuing the certificate will be appropriate to the need. The simplest example, in many countries, is the "birth certificate," which ensures that each person has access to an official document, in order to prove the country of his birth, his age, his parentage, etc. 
measures. ${ }^{172}$

The use of a certificate as a way of interlinking user and source countries already has some limited basis in existing national legislation. Costa Rica is the only country studied whose national law includes a "certificate of origin or legal provenance." ${ }^{173}$ It describes the certificate as follows: "[the certificate] certifies the legality of access to genetic or biochemical resources of biodiversity, and compliance with the terms by the permit-holder of interested party." The law offers the certificate as an option, which CONABIO (Costa Rica's designated competent agency) may issue, if requested by a user. This provision has never been utilized to date. ${ }^{174}$

User-side laws, apart from the Norwegian first draft Nature Diversity Act, do not require the user to provide information that could be contained in such a certificate, as a tool for user-country oversight. Many current proposals involving the certificate concept focus on giving information to the source country (discussed in 3.3.1, above), however, rather than on user oversight.

\subsubsection{4 "Equitable sharing"}

ABS calls for "equitable sharing" of the benefits arising from utilization of genetic resources. It is important to create a standard, to guide the courts in determining whether a share is "fair and equitable." This issue may arise especially where there is no ABS contract to aid the court in ordering payment of an "equitable share" and also in deciding how and to whom it will be given. In some countries, especially those based on the "commonlaw" tradition, a large body of decision-based law exists to help courts decide what is equitable. However, in other countries, the term "equity" is not well understood. ${ }^{175}$

In $\mathrm{ABS}$ contracts, the question of equity would apply where someone challenges whether the agreement was fairly negotiated. In some countries, these legal standards of fairness in contract law can supersede the provisions of the contract itself. Even where the contract is "fairly negotiated," a court can revise it, if it finds that the amount paid or given is unfair in absolute terms. ${ }^{176}$

\subsubsection{Due process of law}

Due process of law in this context is not a question of enforcement, but rather of a standard for determining whether the user knows and has complied with the provider-side law. In essence, due process of law addresses the rights of the provider and user when dealing with userside institutions. In the context of contractual relationships, due process comprises two elements - a procedural element and the protection of rights derived from compliance.

Any contractual relationship must, at some point, provide "user certainty." In ABS, the substance of that certainty is addressed primarily through rights granted under provider-side legislation. ${ }^{177}$ The protection of that certainty, however, depends to a large extent on the user country's basic laws - sometimes called "due process of law." Due process requires, inter alia, that the user has a right to know unambiguously what is legally required of him - exactly what provisions apply, and what he is required to do. For example, consider a law that "foreign-origin genetic resources may be utilized only if the user complies with source country ABS law." Due process only exists, if the users (and government agencies and courts, etc.) know when/whether "genetic resources" are being "utilized." They must also be able to determine whether a particular genetic resource comes from another country, and, if this is not known, what special requirements will apply. Currently, the ABS framework is not clear on any of these matters.

\footnotetext{
Although birth certificates vary from country to country, and sometimes may include other facts as well, these documents are relatively uniform in providing these three elements. It is not clear how successful the certificate discussions under the current negotiations will be given that they reverse this process, specifying the information that would be included in the certificate, before knowing what the certificate will be used for. 


\subsubsection{Enforcing the rights of foreign providers under user-country law}

The next practical element that must be considered under this heading is the manner in which source countries can obtain satisfaction of claims based on access or benefit-sharing issues in user countries. The problems of enforcement have generally been recognized:

Although a number of [source-country] legislative regimes have established mechanisms for monitoring, inspections, and verifications, experience has demonstrated limited resource capacity of governments to monitor all bio-prospecting activities within national jurisdiction... Difficulties also arise with respect to enforcement in cases of non-compliance with legislative requirements in provider countries or with contractual obligations.... Information provided by the Parties so far indicates limited experience in this regard with disputes relating to $A B S .{ }^{178}$

So far, however, these problems have not been addressed. The following sections consider three issues - access to information, disclosure requirements and enforcement.

\subsubsection{Source-country access to information about the utilization of genetic resources in the user country}

As a practical matter, ABS compliance will only be compelled if the source country can discover that its resources are being used and/or that benefits have arisen that should be shared. Even then, a system must be found to enable source countries to enforce their rights in user countries. If $A B S$ compliance cannot be compelled and no other incentive for compliance is found, then one would conclude that the CBD Contracting Parties have failed to meet a key responsibility under the Bonn Guidelines - to develop cooperation to address alleged infringements of access and benefit-sharing agreements. ${ }^{179}$

Access to justice under a user country's law and institutions begins from the understanding a country's justice system is open to those that are aggrieved under that country's laws, regardless of nationality. However, the bare right to bring an action in national courts or agencies cannot, by itself, provide certainty and functionality to a legal regime that operates through commercial (contractual) instruments.

Here also, the distinction between users with ABS contracts, and those without is significant. Where the user has obtained an ABS contract, legal questions will focus on the source country's powers of inspection and other matters described above in 3.3.1.1. Where no source country is known or named, however, the issue is even more difficult. How can a source country oversee the user and assert/protect its rights, if it does not know who the user is? This unawareness is another reason user-side $\mathrm{ABS}$ measures are needed. The user country is the only government with any chance of identifying who those users are and what resources they are utilizing.

\subsubsection{Disclosure as a step to enforcement}

A first step for source countries in seeking enforcement of $\mathrm{ABS}$ requirements is to have knowledge of the utilization of genetic resources. The concept of "disclosure of origin" provisions (see 6.5.2) generally serves as a means of shifting primary oversight responsibility from the user country back onto the source country. For example, under the Norwegian first draft Nature Diversity Act the information that is disclosed is not forwarded to the source country. The source country must come and find the information for itself. Disclosure places the burden of giving information on the one possessing the information - the user. In most discussions of the "certificate of source, origin or legal provenance," for example, the certificate's objective is primarily to give each source country a tool by which it can find out about the use of genetic resources that have origin in that source country. ${ }^{180}$ Many developed

\footnotetext{
178 Jalbert, 2005.

179 Bonn Guidelines, Art. 16(d)(iv). This obligation is also implicit in CBD Article 15.7's call for measures "with the aim of sharing ... benefits." See also Bonn Guidelines Arts. 55-57, calling for national monitoring and verification processes, and Articles 58-60, noting the need to consider various means of settling disputes, sanctions and remedies..

180 The extent to which this information will actually be conveyed depends on many factors, as discussed in paras 3.3.2.3, 3.3.3.1 and 6.5.2 of this book, particularly where disclosure is not mandatory and loopholes are not addressed.
} 
countries and other commenters said that the only user-side measure they intend to adopt is a disclosure-oforigin requirement. ${ }^{181}$ In this context, however, we must reiterate the two major limitations of the "disclosure" approach:

- Unless they are both mandatory and verified (currently none are) disclosure-of-origin requirements will probably be complied with only by users who have already complied with the source country's ABS law. The disclosure provision will provide little or no motivation for disclosure by non-compliant users; ${ }^{182}$

- Disclosure is not a remedy, but only a tool for showing the source country that it may have a claim - a basis for seeking a remedy. The source country will still, despite the disclosure, bear the burden of overseeing and enforcing compliance with $\mathrm{ABS}$ requirements, even after the user has left the jurisdiction of the source country and is in the user country.

As noted above, a few such laws have been adopted, but there has been virtually no experience with them.

\subsubsection{Remedies and penalties in user countries}

Once the source country (or source) is aware that a user is utilizing its genetic resources, that source country must mobilize processes for oversight or verification of compliance. If the user is not in compliance with the source country's law, then the country must be able to seek legal redress against noncompliant users who do not respond to less compelling processes. ${ }^{183}$

\section{[a] Legal rights and remedies}

With regard to the remedies available to the source country, the critical question is whether the user-country law enables remedies, or only imposes penalties. For this purpose, the difference between a "remedy" and a "penalty" is as follows:

- "Penalty" describes any action intended to punish the offender and/or to prevent future offences. ${ }^{184}$ Penalties include fines, imprisonment, confiscation of property, license revocation/suspension, and the restriction or curtailment of activities taken under the law or permit.

- "Remedies" are measures designed to compensate the injured party in a lawsuit. Remedies may include a variety of forms of compensation, ordered by a judge or agency, including -

$o$ payment of funds (either the funds due under a contract, or the liquidated value of the damage suffered by the injured party);

$o$ fulfillment of contractual requirements (including a judge's interpretation of the specific actions required);

o mandate or prohibition (orders to take action or to refrain from action); or

$o$ rescission or cancellation of a contract or other document.

The primary differences between these two are (i) who may bring the action, and (ii) who receives the money or other value paid if the defendant loses. In most countries, penalty laws are initiated by government, and all fines and other moneys collected are

\footnotetext{
181 See, e.g., EC, 2002, THE NETHERLANDS: "Sources of Existence..."

182 Many such users, as noted in footnote 284 and accompanying text, will conclude that they are not required to disclose. Some will refuse to disclose, or identify the source incorrectly, recognizing that a small penalty is the only actual risk of such a choice.

183 These issues are also addressed in detail in Book 5 of this Series, Young et al., 2007. As noted there, the best approach for the source country will be informal and non-public, in most instances, given that many users will be happy to avoid legal processes or bad publicity. The net result is to everyone's advantage, since it is obtained without the cost and difficulty of a legal case. However, once litigation or media allegations of biopiracy have begun to be public, this opportunity will be gone (bad publicity is nearly impossible to reverse).

184 Some kinds of penalties can be enhanced by the creation of a permanent public record of the offence. For example, the revocation of a government permit or license may be enhanced by the creation of a list of offenders. Being named on such a list may affect the chance that the violator will ever be able to obtain a similar permit in future. See e.g., BRAZIL: Provisional Act, Title VIII, Art. 30, par. 1.XIII, which allows administrative violations to be punished by inter alia, "prohibition of entering into contracts with the Public Administration for up to five years."
} 
retained by the government that brought the action. ${ }^{185}$ Confiscated property is held, destroyed or sold by government, or may be impounded as evidence, to be returned to the legal owner at the end of the trial. By contrast, actions for remedies are initiated by the injured party; and the amounts awarded are paid to the injured party. In most countries' organic law, the government is not allowed to bring private actions on behalf of individuals - it must focus on penalties rather than remedies. ${ }^{186}$ It is rare (almost unheard of) for any such law to mandate specific performance of a contract or another country's law. Thus an ABS action to claim a share of benefits must be brought by the source country (or other source) as a private claimant, or by some special entity acting on the source country's behalf.

A country's implementation of its user-side measures will normally be focused on penalty, rather than on ensuring or assisting the source country to obtain compliance with its ABS requirements. National courts will usually interpret their rights narrowly. If the user country's law does not specifically authorize its courts to issue an order requiring compliance, the chance of this result is very low.

Few of the national laws and other documents studied consider the provider's rights and remedies in the user country. The Norwegian first draft Nature Diversity Act notes only that the right of enforcement is limited to the Norwegian government, which "can, by court case, enforce the said conditions." 187

On questions of legal redress, however, it is also interesting to consider the measures and legislation adopted by countries which regulate domestic users of domestic genetic resources. In many of these laws, it may be argued that the same rights that the country provides for itself in dealing with users of its own resources may also apply where users in that country are utilizing another country's genetic resources. For example, Brazilian law presumes that private rights under the ABS contract are resolved in civil actions, but gives an additional, specific statutory right to the provider (country, community or individual) to receive compensation, if the user has caused any harm or damage in the course of his removal of specimens. ${ }^{188}$ It also empowers the government to impose administrative penalties ${ }^{189}$ (such as suspending permits and invalidating other administrative approvals), noting that these penalties will be "without prejudice to applicable civil or criminal sanctions." It is possible that Brazil might take the same administrative actions, where it gets notice from another country, about utilization of genetic resources in violation of Brazil's ABS laws. Brazilian law also specifically empowers and requires "competent federal bodies" to supervise, intercept and seize samples that have been "accessed in a manner contrary to this Act." It further provides that those powers and duties may be disseminated to other bodies. ${ }^{190}$

In Costa Rica, the particular kinds of remedial measures that apply for oversight of users of Costa Rican genetic resources have been very clearly specified. They include provisions for oversight of users, including the following:

- verification and control of holders of $A B S$ permission, ${ }^{191}$ including powers of inspection;

- investigation of possible violations of prior informed consent; ${ }^{192}$

\footnotetext{
${ }^{185}$ The disposition of fines differs from country to country. In some cases, administrative fines are retained by the administrative agency that assessed and collected them, in others they are deposited in the country's general fund.

186 Typically, the only civil actions a government may bring will be those alleging a violation of a contract with the government or a tort against the government. See, e.g., BRAZIL: Provisional Act, Title VII, Art. 28, par. VIII "When the Federal government is a party [to the contract], the ABS contract shall be ruled by public law."

${ }^{187}$ NORWAY: Draft Nature Act, $\$ 60$, and similar provisions throughout.

188 BRAZIL: Provisional Act, Title V, Art. 16, par. 10.

${ }^{189}$ BRAZIL: Provisional Act, Title VIII, Art. 30, par. 1.

190 BRAZIL: Provisional Act, Title IX, Art. 32.

191 COSTA RICA: Normas... at Art. 20.

192 Ibid.
} 
- suspension or cancellation of an ABS permit, due to changed conditions when (legal or illegal) ABS activities are or may be harmful to biodiversity or genetic resources; ${ }^{193}$

- sanctions, in accordance with Costa Rican law, where the user has obtained access to genetic resources without complying with the $A B S$ regulations. ${ }^{194}$

These must be addressed in "coordination with the interested parties and resource providers." Once the user is outside Costa Rica, there will also be a need to comply with the laws of the user country in taking these oversight actions. Here also, however, if Costa Rican officials were notified that a Costa Rican user was utilizing genetic resources of another country without $\mathrm{ABS}$ compliance, they might require that user to comply with the same provisions listed above, and might even apply the same sanctions.

\section{[b] Unadapted use of existing penal laws}

One approach that is frequently cited as a way of implementing $\mathrm{ABS}$ obligations on the user side is applying the user country's existing penal laws against a user who has violated the ABS laws of the source country. This approach has two flaws, when used as the primary (virtually the only) means of direct implementation of user-side ABS obligations:

- It does not provide a means by which the source country's right to an equitable share of benefits can be enforced; and

- ABS violations are different. Existing penal laws address the illegal taking or use of conventional property. They provide no basis for determining whether the utilization of foreign genetic material constitutes "stealing" or "illegal taking" of that material, when such "taking" has occurred, or how it is to be proven. It is almost impossible to answer these questions in a way that would allow these laws to serve as user-side measures for ABS implementation.

For example, as discussed in 3.3. and 3.4, the US has identified two criminal laws - the Lacey Act and the Stolen Property Act ${ }^{195}$ - as its primary user-side measures. Both are penal laws, which must be enforced by the US government through a criminal action against the violator. Another such provision is found in Australia, where the law provides that

\section{[a] person must not intentionally import a specimen if the person knows that: (a) the specimen was exported from a foreign country; and (b) at the time the specimen was exported, the export of the specimen was prohibited by a law of the foreign country that corresponds to this Part. ${ }^{196}$}

All of these laws suffer from the two above-listed problems. The only outcome of an action under either law would be penalty (fine or imprisonment). ${ }^{197}$ There is no way that these laws can enable a private remedy or action by the source country or other provider. More important, however, these laws only apply if the government can prove that the specimen or item was "stolen" or "illegally exported" from a foreign country. Given the vast grey area in distinguishing "biological resources" from "genetic resources," it is clear that a "specimen" (physical sample) can be exported completely legally in objective terms, so long as there is no overt statement by the exporter that the material will be used for genetic research.

As a practical matter, there is another problem agency discretion. None of these laws in any way requires the government to take punitive action. No private person may petition for its application. An

\footnotetext{
193 COSTA RICA: Normas... at Art. 27.

194 COSTA RICA: Normas... at Art. 2.

195 Described in 3.2.1.2.

196 AUSTRALIA: Environment Protection and Conservation Regulations, 2000, \$303GQ (1).

197 The Australian provision specifies a period of five years imprisonment for violation; however, it is possible that concepts of judicial discretion (found elsewhere in Australian law) would consider this to be an "indicator" of possible penalty range, or a maximum penalty, giving the judge the power to set a lower penalty, or suspend the penalty with no time served.
} 
action can be brought under these provisions only where the government has both clear evidence and confidence that its interpretation of the law is correct, and the willingness to spend limited personnel, time and money on bringing such an action.

\section{[c] Arbitration}

Another direct discussion of legal redress is found in the European Commission's communication on ABS and the Bonn Guidelines, which specifically notes "the possible role of arbitration for addressing infringements of ABS arrangements," in response to the difficulties connected to jurisdiction over the user and application of foreign law in the user country. ${ }^{198}$ This is not further discussed or elaborated in the Bonn Guidelines.

In practice, arbitration is a provider-side measure - the parties to any contract do not have a right to demand arbitration unless the contract specifically so states. This means that arbitration is only possible if either (i) there is an ABS contract (compliant user) that requires arbitration, or (ii) the parties later agreed to it. Thus the EC's comment implies that arbitration provisions will be more easily upheld by courts than other provisions of the ABS contract. ${ }^{199}$

\subsubsection{Additional complications - undisclosed source}

The more difficult question in enforcing user measures arises where there is no ABS contract or where the source country is not known or disclosed. As noted above, the law would create a perverse incentive, if it allows the use of foreign genetic resources without ABS compliance, in any case where the user does not know the source of the material. At the same time, the law needs to provide an appropriate avenue for users who legitimately do not know the specific provenance of the materials they are using.

Current scientific capability, coupled with the cost of genetic identification processes, indicate that science does not offer the user or the government a means of easy identification of the species that provided the genetic resource. Even if the species could be determined, however, the source country may still be unclear unless the species is endemic to a very narrow range, which is entirely within a single country. Narrow-range endemics constitute only a very small percentage of species. ${ }^{200}$ Thus, most species and sub-species have more than one country of origin. The "undisclosed source" problem is therefore a core difficulty for benefit-sharing negotiations.

\subsection{User-side administrative responsibilities}

The Bonn Guidelines also suggest administrative measures that are relevant to the user side of the ABS concept, of which the most frequently mentioned is the duty of each country to "designate one national focal point (NFP) for access and benefit sharing." 201 The primary duties of the NFP, as specified in the Bonn
Guidelines, are focused on the provider side. ${ }^{202}$ There are several significant user-side issues for NFPs to address. One of these is embodied in the task of developing "mechanisms to provide information to potential users on their obligations regarding access to genetic resources." The Guidelines also identify a role for

198 EUROPEAN COMMISSION: EU 2003, at 7.4.

${ }^{199}$ The authors have not reviewed this issue completely, but note that, in the US, arbitrators remain bound by the same contract law as the courts would apply, so that an ambiguous contract or one whose terms were subject to inconsistent interpretations would probably not be enforceable. Some aspects of arbitration are discussed in Book 5 of this Series - Young et al., 2007, in Chapter 5.

200 See generally IUCN SSC Red List of Threatened Species available online at http://www.iucnredlist.org. Joseph Vogel notes that the rarest species are often uninteresting to genetic research and development, owing to the uncertainty of a permanent source for research (or if the relevant biological material is not easily replicated). Personal communication, February 2004. In addition, Dietrich Jelden (Director of the German CITES Management Authority) notes that scientific analysis of the world's rarest species has been ongoing for a long time, so that these specimens are often the best known, rather than the least. Personal communication, March 2003.

201 Bonn Guidelines, Art. 13.

202 Specifically, to "inform applicants for access to genetic resources on procedures for acquiring prior informed consent and mutually agreed terms, including benefit-sharing, and on competent national authorities, relevant indigenous and local communities and relevant stakeholders, through the clearing-house mechanism." 
"competent national authorities" to "be responsible for monitoring and evaluation of access and benefit-sharing agreements;" and to "be responsible for implementation/ enforcement of access and benefit-sharing agreements." ${ }^{203}$

The task of naming a focal point is quite straightforward and 81 countries have done so, as shown in the CBD's ABS database. ${ }^{204}$ These authorities, even in countries with many users under their jurisdiction, are focused significantly on issues of access to that country's own genetic resources. In general, countries assign these tasks to agencies with scientific and conservation mandates, in recognition of the biological and taxonomic elements of provider-side ABS. On the user-side, however, these elements are not so essential, and other key issues (commercial and legal matters) may be more essential. ${ }^{205}$ It may therefore be necessary for countries to consider identifying two separate national focal points or competent authorities - one for user-side issues (monitoring users and enforcing ABS contracts), ${ }^{206}$ and the other for the providerside issues that are more commonly addressed by focal points at present. This need may become more obvious and common, once user measures are in place, and countries recognize the need for oversight of users under their jurisdiction and support for collections, researchers, and commercial and industrial entities.

It is important for all countries to address this task of providing information to users regarding access to genetic resources. ABS will be worth the effort only if users continue to want genetic resources and understand the administrative processes to obtain them. At least three developed countries have created or authorized programs to assist users by gathering information about the process of obtaining genetic resources access in various countries. Japan, through the Japan Bioindustry Association, is actively undertaking an in-depth program to pre-develop relationships with source countries to enable the development of $A B S$ arrangements between their users and a variety of provider countries in Asia and elsewhere. Similarly, the US and the Netherlands both report that they are developing information systems to compile information that will assist users seeking access to foreign genetic resources. This work is complicated, given that in many countries PIC and MAT responsibilities are decentralized and merged with public participation processes. In these countries, $\mathrm{ABS}$ requirements are individually negotiated, and may be different for each user. ${ }^{207}$

\subsection{Practical means of motivating compliance with user measures}

As a final element of this chapter's investigation of practical needs relating to user measures, we consider the value of other legislative approaches, of using, in addition to mandatory provisions, voluntary provisions and incentive/motivation measures. The CBD and the Bonn Guidelines call for all three of these types of measures, and various countries examined in this study have used or suggested all three.

\footnotetext{
203 Bonn Guidelines at 14(c) and (d).

204 http://www.biodiv.org/doc/lists/nfp-abs.pdf, as of 15 May 2007.

205 This side of the NFP's responsibility is often ignored. The British user study, for example, assumes that the ABS focal point will focus on ecosystem management collection practices, and possibly collection of returns on British genetic resources, rather than commercial and contractual matters: "In the UK, where there is a wealth of expertise in conservation and reserve management, the nature reserve authorities are well placed to negotiate any possible benefit-sharing returns (which are generally likely to be modest) and to control any collecting abuses (i.e. over-exploitation)." Latorre, 2005, at 5.3.1.

206 The authors have not done a census of national ABS competent national authorities (CNAs) to determine which, if any, have user-side responsibilities. We note that, in the Norwegian draft Nature Diversity Act, the agency responsible for provider-side measures is also tapped to oversee users. The US presumably expects user oversight to be undertaken by the criminal enforcement agencies. See footnote 105 .

207 One prominent example is the Philippines, where all aspects of PIC and MAT are devolved to the local community level. Consequently, every ABS arrangement is different in each locality, and they can be particularly complicated where numerous localities are being studied in the same project. Benvidez, 2003.
} 


\subsubsection{Mandatory}

The use of mandatory provisions in the user country offers the benefit of clarity for the provider country, and at least theoretically it would promote $100 \%$ compliance simply by requiring all users to comply. As noted, there are currently numerous obstacles to the creation of a completely mandatory ABS system. In particular, currently (since no user-side legislation exists) users who are not bound by source-country ABS law once they and the genetic resources have left the country are completely free of $\mathrm{ABS}$ requirements. A major legislative effort would be needed to create a complete network of user-side measures.

In terms of national legislative drafting, the mandatory approach is usually rather simple to create. The challenges of mandatory legislation are not in writing clear mandatory requirements, but in practical implementation. This is particularly true in the transboundary context. In a mandatory system, implementation must be based on oversight. It must be possible to confirm compliance with $\mathrm{ABS}$ requirements, and lack of compliance, based on externally confirmable criteria. This is not only a requirement for enforcement, but also for basic implementation. The system's implementation can be consistent and fair only if all users are applying the same standards in the same way. Mandatory provisions must be supported by specific oversight and enforcement mechanisms. A mandatory provision that lacks such enforcement mechanisms is no different in impact from a voluntary or non-mandatory one.

Typically, mandatory measures operate in two possible ways: either (i) the law is enforced through direct governmental oversight, or (ii) the government creates the laws (and controls certain aspects), but the person or sector benefited or protected by the law is responsible for overseeing its implementation. ABS is typically thought to prefer the second type of measure. Unfortunately, as discussed in Chapter 6, such measures are usually effective only where the benefited sector is financially able and motivated to incur significant costs and efforts in order to enforce the law. In many cases, the providers of genetic resources do not have the funds or ability to take on these tasks - so that basic implementation is a challenge and potential obstacle for ABS.

\subsubsection{Non-mandatory provisions (voluntary measures and recommendations)}

Another kind of measure that has been discussed in detail in the ABS context is the idea of "voluntary" measures, including documents like the "voluntary disclosure of origin in patent applications." Although castigated by some, voluntary measures can have a definite and useful role in any legislative system. The adoption of purely voluntary measures is very effective where the measures are desired by the regulated industry. This may happen where the industry recognizes a need to act in a more coherent way, but require government's help and guidance to do so. One factor that sometimes motivates an industrial sector to seek voluntary measures is their desire to avoid more restrictive legislation. Facing such a prospect, industrial groups will sometimes develop and accept voluntary standards. ${ }^{208}$
Many ABS measures, although mandatory in phrasing, will be voluntary in impact, because they do not enable oversight or any other means of government confirmation or other action to ensure or promote compliance or enforcement. Recently, several countries have suggested developing concrete information on industrial interest as a means of creating functional user measures. The Netherlands, as well as the EC and Switzerland, have all suggested creating voluntary measures, in the form of the "development and use of Codes of Conduct that contain the basic principles" ${ }^{\prime 209}$ to promote voluntary ABS compliance.

To date, the most active development of voluntary measures has been the procedures governing collection and transfer/tracking by ex-situ collections of biological specimens (which are primarily "middlemen," although

\footnotetext{
208 Several historical examples of this process are discussed in Young, 2006b, at 50. In some cases, the government formally adopts the voluntary standards, to ensure that the system is uniformly recognized.

209 NETHERLANDS: "Sources of Existence" at 2.4, 3.2.
} 
also engaging in taxonomic and other research). These procedures have been developed by botanic gardens ${ }^{210}$ and microorganism collections. ${ }^{211}$ Another ongoing effort is the work under the BioTrade Initiative (mentioned in 3.2.3) to develop a code of conduct for the use of biological extracts, focused on user activities and responsibilities. While the code's reach is much broader than ABS, the initiative has received strong indications that some users are interested in applying the guidelines to both genetic and biological materials, so long as their provisions are commercially reasonable.

Apart from these examples, most current proposals for voluntary ABS measures are not based on an analysis of their probable functionality or usefulness, but as responses to the discovery that mandatory measures are not possible or practicable. In general, this reasoning will result in voluntary measures that serve little purpose, unless they can be connected to some broadly recognized motivating factor or revised to become "incentive or motivation measures."

\subsubsection{Incentive and motivation}

Where mandatory (command and control) mechanisms are not practical - i.e., where they cannot function in a way that ensures consistent compliance - and there is insufficient desire in the regulated industries for voluntary measures to have the desired impact, the use of legal and/or economic incentive measures may still provide a solution. Conceptually, legal and economic incentives and other system-created motivation measures are very simple - rather than requiring a specific action (necessitating oversight and enforcement), the government adopts an opposite approach, offering some positive benefit to those who take the action. This approach places the onus of responsibility on the user, not by mandate, but by self-interest. The user will comply if it wants to receive the benefit. Incentive measures can cover most activities that would be normally be compelled through mandatory measures. Only the reason for compliance would be changed -
Recently, however, several initial studies of user practices and attitudes have been undertaken. ${ }^{212}$ These studies show that some industrial, commercial and research entities participating in the ABS processes and discussions clearly desire guidelines and assistance of this type. More clearly, however, they show that a much higher percentage of industrial, commercial and research entities do not yet hold this view.

A recent OECD assessment of voluntary mechanisms has noted that such mechanisms have limited impact, unless they are used selectively, as part of a "policy mix" that enables them to address issues where other mechanisms are either not needed (because there is a strong desire to cooperate) or not possible (because the basic system and relevant understandings are not yet developed). ${ }^{213}$ In ABS, there has been little analysis of the key question - industry's desire for such measures - except in Japan, whose user community includes many companies that have stated a strong desire to comply with $\mathrm{ABS}$ requirements.

instead of acting out of legal compulsion (taking the minimum action required by law), the user would act out of its own interests, possibly taking more intensive action, if a greater benefit is available.

The challenge in developing incentive/motivation measures is operational. It is imperative that the benefit provided by the measure to the user should be something desirable. Its subjective value to the user should be large enough to offset the costs and other impacts of compliance. In addition, that benefit should not be available to users who do not take the desired action. This means that there must be clear methods of proving or documenting that one qualifies for the incentive. Finally, in using incentives, one must not underestimate their costs. Incentive measures are not cost-free to the government, since it will be essential to have mechanisms for confirming compliance,

\footnotetext{
210 See the International Consortium of Botanic Gardens (ICBG) principles - "Principles on access to genetic resources and benefit sharing for participating institutions" (available at www.rbgkew.org.uk/conservation) and the International Plant Exchange Network (IPEN) Code of Conduct (www.biologi.uni-ulm.de).

211 Micro-organisms Sustainable Use and Access International Code of Conduct (MOSAICC), available at www.belspo.be/bccm/mosaicc.

212 Holm-Müller et al., 2005; Latorre, 2005; Frison Dedeurwaerdare, 2006.

213 Börkey et al., 1999, at 42 and 129.
} 
for preventing attempts to obtain the incentive without complying, and for keeping records. ${ }^{214}$

Up to now, relatively little attention has been given to the concept of incentive in ABS user measures, but with important exceptions.

In 2005, the Japanese Ministry of Economy, Trade and Industry (METI), in conjunction with the Japan Bioindustry Association, concluded a multi-year process through which they developed a set of guidelines for users of genetic resources (the "Japanese Guidelines"). ${ }^{215}$ Based on the Bonn Guidelines, the Japanese Guidelines provide a set of basic principles and suggestions for users seeking to comply with best practices for ABS compliance. There are two factors which cause the Japanese Guidelines to stand out when compared with other such guidelines. First, they are directly focused on clarifying the obligations of users as conceived under the Bonn Guidelines; and second, they include a direct incentive for users to comply with the guidelines. In Part IV, they discuss the ability of METI to provide assistance and advice, and other kinds of support, for businesses that "do business in a way that conforms to the [Japanese] Guidelines." In essence, this provision is an incentive measure - offering government assistance to any company that complies with the guidelines and still encounters difficulty in obtaining provider approval and other activities. The desire to avoid being labeled or misconstrued as "biopirates," coupled with this incentive may be a major factor in encouraging Japanese companies to comply with the Japanese Guidelines.

In addition, under their technical research ministries, several countries identify benefit sharing and/or ABS compliance as one factor in determining whether to authorize projects or issue grants. ${ }^{216}$ These programs are generally directed at the providers, organizations and agencies such as consulting firms and aid agencies, which are most likely to want to share benefits (or with a mandate to do so). It may also encourage applicants who are not so inclined to consider benefit sharing.

Legal recognition of the incentive approach exists, but has not been broadly applied. General biodiversity legislation in Costa Rica recognizes the usefulness of incentives as well, calling for the development of a variety of incentive systems, applicable to those users who are utilizing Costa Rican resources. Among these are tax credits and exemptions, administrative priority in some relevant applications and business licensing, and access to special businessdevelopment incentives. ${ }^{217}$

Other suggestions have been made for the global development of a "voluntary certification" system, as another type of incentive. ${ }^{218}$ Although it may sound

214 See, Smith and Young, 2006.

215 JAPAN: METI/KBA, 2006, Guidelines for Access to Genetic Resources for Users in Japan, Ministry of Economy, Trade and Industry (adopted March 2005, published in English, 2006).

216 According to the CBD Secretariat, "Denmark and Sweden provide examples of situations where access and benefit-sharing requirements are to be met as a prerequisite for funding. In Denmark, as set out in the submission, providers of funding for research and development projects should, by contract, include the application of the Bonn Guidelines as part of the conditions for funding. In Sweden, a policy adopted by the Swedish International Development Cooperation Agency requires the establishment of a material transfer agreement between the provider and receiver of genetic material in research cooperation activities financed by the Agency where those activities involve genetic material. From the Note by the Executive Secretary, "Analysis of Measures to Ensure Compliance with Prior Informed Consent of the Contracting Party Providing Genetic Resources and Mutually Agreed Terms on which Access Was Granted, and of Other Approaches, Including an International Certificate Of Origin/Source/Legal Provenance," $\mathrm{UNEP} / \mathrm{CBD} / \mathrm{WG}-\mathrm{ABS} / 3 / 5$, at para 29, "Incentive measures," citing "Communication from the Commission to the European Parliament and the Council," "The Implementation by the European Community of the 'Bonn Guidelines' on Access to Genetic Resources and Benefit-sharing under the Convention on Biological Diversity," Brussels, 23.12.2003, COM(2003) 821 final, p. 22." The US’s ICBG under the National Institutes of Health reportedly also uses benefit sharing as a factor in the grant approval process. Rosenthal, 1996; Rosenthal, 2006; and Rosenthal et al., 1999.

217 COSTA RICA: Ley de biodiversidad, No 7788, Art 100 (Incentivos). Similar attention to incentives, which may be applied to ABS, is found in El Salvador, Ley del Medio Ambiente, Decreto No 233, 1998, at Capitulo VI, Art. 32 (incentive objectives include incentives to promote sustainable use).

218 The primary proponent of this approach has been the Swiss government, which has undertaken some intensive work, originally focused on "ABS certification." Ultimately, that initial work has converted into the development of a guideline for negotiating ABS Agreements. See IISD, Stratos and Cabrera, 2005. The Swiss government continues to promote the idea of an ABS certification system. Following its lead, the EC and others have suggested further consideration of this concept. See, EC, 2003; and Holm-Müller et al., 2005, at para 2.4.1. The Costa Rican law cited in the previous footnote also suggests the creation of an "ecological label" as a possible incentive measure. 
simple, the idea of creating an ABS certification system will be quite complex and costly, both in creation, and in upkeep. ${ }^{219}$ For voluntary certification to provide an incentive to comply with ABS, for example, it must provide a benefit to compliant users, and that benefit must not be available for users who do not comply with $\mathrm{ABS}$ requirements. Most important, that benefit must be of sufficient value to counterbalance the costs of compliance. Another critical point about certification is that it does not aim for $100 \%$ participation, but assumes that some percentage of the sector will choose not to seek certification. The certification idea remains a tantalizing one to some participants' negotiations. By itself, however, it is clearly not a sufficient incentive/motivation tool for ensuring benefit sharing compliance. ${ }^{220}$

The critical question underlying both voluntary measures and incentives, however, is the atti- tude and knowledge of the industry. In the German and British national user studies, it was quickly clear that even those users that were motivated enough to respond to written questionnaires on the topic were largely unaware of the $\mathrm{CBD}$ and the $\mathrm{ABS}$ concept and responsibilities. ${ }^{221}$ The EU has suggested the possibility of including ABS issues (compliance with the Bonn Guidelines) in its EcoManagement and Audit Scheme (EMAS), indicating that it may develop standards on ABS compliance to be added to the existing standards by which EMAS-certified companies can "evaluate and improve their environmental performance." At present, the EU views the EMAS as a voluntary measure, rather than an incentive, noting that such a scheme would "serve the purpose of helping users to improve their overall environmental performance, including in relation to access and benefit sharing but would not alter their legal obligations." 222

\subsection{Summary - national adoption of user-side measures under the Bonn Guidelines}

The current status of national compliance with the user-country elements of the Bonn Guidelines is relatively grim. Once a user is operating outside the source country - has gone "beyond access" - the user is also basically beyond the reach of the source country's laws and legal processes. This leaves all provider or source legislation vulnerable, owing to the nearly complete lack of enforcement.

At a minimum, it appears that the objectives of ABS functionality, if addressed through mandatory mechanisms, must be met by the following user-side measures:

219 See Young, 2004. In Holm-Müller et al., 2005, at para 5.2.4, this result is seen in ABS, where the MOSAICC system was cited as a useful voluntary system that "can be disseminated in the entire concerned sector at low transaction costs." The authors noted that MOSAICC is now facing temporary difficulties arising out of the fact that, although heretofore realized only through government financing, MOSAICC's funding is now dwindling and a more permanent funding basis is needed.

220 The fact that ABS issues are relatively unknown and complex make it unlikely that consumers or others will be interested and knowledgeable enough to choose products or convey other benefits based on whether they have the "ABS label." This suggests that it will probably be more effective for ABS proponents to approach existing social and environmental certification bodies and ask them to add ABS points into their certification standards. For certification to have a positive impact on the environmental or social issue it is addressing, it is necessary that it must certify some behavior that is actively beneficial and that can be objectively verified. These elements may not be easy to find in the ABS context. A general discussion of the use of certification to achieve environmental objectives is found in Young, 2004. An initial essay on the idea of certification in ABS, but not touching any of the above issues, can be found in Glowka, 2001, "Towards a Certification System for Bioprospecting Activities" (Swiss State Secretariat for Economic Affairs).

${ }^{221}$ Holm-Müller et al., 2005; Latorre, 2005. In the German study, for example, out of more than 150 respondents, only 30 indicated that they had sufficient knowledge of the CBD and ABS to answer questions regarding their compliance with ABS responsibilities, and far fewer than that actually knew what ABS was. The British study (at 3.1.1) indicated that more than $80 \%$ of respondents were aware of the CBD, but that this "general awareness of the CBD does not necessarily imply the understanding of its provisions" and finding that "a large proportion of [respondents] have only a basic grasp of the relevance and implications of the CBD to their work." Similar results appear to have been found in the Belgian study (Frison Dedeurwaerdare, 2006), though these did not follow the template of the two earlier studies and are thus not directly comparable and did not provide the same level of specificity in reporting results.

222 "Analysis of Measures to Ensure Compliance with Prior Informed Consent of the Contracting Party Providing Genetic Resources and Mutually Agreed Terms on which Access Was Granted, and of Other Approaches, Including an International Certificate Of Origin/Source/Legal Provenance," UNEP/CBD/WG-ABS/3/5. 
- Requiring users of foreign genetic resources to comply with the source country's ABS measures;

- Setting standards for the enforcement of these requirements; and

- Providing bases for enforcement against users who do not have ABS permission to avoid a perverse incentive favoring non-compliance or non-disclosure (and to promote equity).

Many difficulties and challenges of this task have been identified, which suggest that mandatory measures may not be the most effective option, and indicate a need to shift the global paradigm in a way that focuses on incentive/motivation, alone or in combination with mandatory and permissive measures. To date, however, the overwhelming view still focuses on a mandate-based ABS system. Consequently, this book's primary approach is to focus on such measures.

One significant reason behind the failure to adopt user-side measures is the lack of a rigorous analytical basis underlying ABS, which could provide legislators and draftsmen with a basis on which to build their systems. The following chapters examine and elucidate that basis as the authors' understanding after lengthy research and analysis. Thereafter we offer suggestions of user measures which recognize the realities and objectives of promoting research, development, and industrial and commercial activities, while still achieving the goals of the third objective of the CBD. 


\section{Analyzing the "Building Blocks" of the ABS Concept on the User Side}

The world is not uniformly divided into "user countries" and "source countries," since each country's role in ABS depends on the particular transaction involved. Any country may be a source of genetic resources. If the user is operating in another country (as explained in chapter 3 ), the country where the use occurs - whether highly developed or not - it is the "user country" of that transaction. In this respect, all source countries face the same problem - that user-country law does not require users to comply with $\mathrm{ABS}$ requirements as to the use of foreign genetic resources. Ultimately, then, all countries must adopt user-side measures under CBD Article 15.7, and all countries will benefit if such legislation is adopted and implemented.

As noted in Chapter 3, the lack of measures governing users of genetic resources after they have left the source country is seriously inhibiting the functionality of ABS. It is certainly not the only roadblock to a functional $A B S$ regime. Even if all other obstacles were cleared, however, this lack of reciprocal measures would still prevent the system from operating.

From the perspective of the countries with the greatest number and variety of users, ${ }^{223}$ the lack of user-side measures is easily explained. The ABS concept is "disordered" - that is, it is legally ambiguous and uncertain. Most of the countries with high numbers of users possess legal systems that are functionally dependent on rigorous interpretation - laws must be based on a logical and internally consistent framework. If a law does not meet these standards, national constitutions, organic laws, judicial practices and mandates will deem it to be "unenforceable." In that case, it will not be legally possible to take actions or enforce them under that law.

In drafting the CBD, it was expected that each country's national implementing legislation would resolve the Convention's ambiguities at the national level and that, over time, these national decisions would combine and grow into a systematic "international regime." 224 Several factors, however, have prevented this organic development process. ${ }^{25}$ At present, no consistent and rigorous analysis has been generally agreed that provides sufficient basis for adoption of user-side measures in these and other countries.

Although current negotiations are ongoing relating to the international regime, it is not clear whether it will result in a series of concrete conclusions (a kind of international instrument sometimes called "agreed interpretations") or only in additional policy statements and stronger statements of national obligation regarding ABS. Either way, however, it will be necessary for each country to develop a clear analytical foundation for national user measures that will provide a regime-wide basis for a functional $A B S$ regime. As noted in 2.7.4 and 3.5, above, there may be many ways of doing this, however, the current discussions focus on a system that is based on legal mandate (requirements) rather than incentives. This chapter analyses various necessary elements, beginning from the current paradigm and its ambiguities, and providing a credible legislative analysis that could be used to develop national legislation and other practices to satisfy countries' responsibilities as to users under their jurisdiction.

This chapter focuses on the primary application of Article 15.7:

Each Contracting Party shall take legislative, administrative or policy measures, as appropriate, and in accordance with Articles 16 and 19 and, where necessary, through the financial mechanism established by Articles 20 and 21 with the aim of

\footnotetext{
223 Generally reckoned to be the US, Japan, the countries of Western Europe, India and Australia.

224 See, Hendrickx et al., 1993; and Glowka, 1998 assumes this without stating it.

225 Discussed in Young, 2006b, at 17.
} 
sharing in a fair and equitable way the results of research and development and the benefits arising from the commercial and other utilization of genetic resources with the Contracting Party providing such resources. Such sharing shall be upon mutually agreed terms.

The ambiguities and inconsistent interpretations of this language cover a broad range. They grow out of three central undifferentiated concepts -

- "genetic resources," which defines the overall scope of ABS,

- "utilization of genetic resources" which describes the trigger of $\mathrm{ABS}$ relevance, and

- "benefits arising" from that utilization, which triggers the benefit-sharing obligation of Article 15.7 .

Although the words "genetic resources" existed prior to the CBD, they had not been used to describe a legally recognizable interest or property that can be the basis for granting exclusive or non-exclusive rights. Hence, it is central to any legislative development in ABS to clarify these three concepts in terms that both provide a legal basis for their application, and take into account the practical needs to ensure that the ABS concept is legally implementable. On the basis of that analysis, the chapter then conceptualizes legally the functional system of benefit sharing. That is, how that system is triggered, and how it might operate.

Interpretation and implementation of Article 15.7 (from both user-side and provider-side) turns on three primary questions: What are "genetic resources"? What activities constitute the "utilization of genetic resources" for the purposes of ABS? and When do "benefits aris[e]" from the utilization of genetic resources?

Unanswered up to now, either in law/policy or in expert literature, the answers to these questions must yield a basic framework that can be consistently applied in all relevant legal situations leading to replicable or predictable results. ${ }^{226}$ The ABS regime cannot function if neither user companies, source countries, researchers nor other providers have sufficient "legal certainty" regarding the nature and value of $\mathrm{ABS}$ rights or contracts. The following sections answer those three questions through the application of the principles of legal analysis and interpretation. ${ }^{227}$

226 For another discussion of the concepts "genetic resources" and "utilization of genetic resources", see Tvedt, 2006.

227 Even in carefully negotiated international legal instruments, it is frequently necessary to engage in the process of legislative interpretation - to study the language, content and intention of the instrument to obtain a legally specific understanding of the meaning and intent of particular provisions. In addressing this issue, the authors have undertaken a legal analysis in accordance with the rules promulgated by the Vienna Convention on the Law of Treaties, 1969, regarding the manner in which international binding instruments should be interpreted, where there are issues of unclarity or insufficient understanding, or where the treaty is to be applied to a situation or question not directly answered in the language of the treaty.

To ensure that the document is readable and accessible to the target audience, however, we have summarized our longer legalistic analysis, which will appear at some point in a legal journal. In the meantime, this footnote sets forth the Vienna Convention's eight components of interpretation process, in order of their legal effect:

(i) Direct application of the language of the Convention itself (Vienna Convention, Art. 31, paras 1 and 2).

(ii) Direct application of the language of other documents that are part of the same treaty, such as, in the current analysis, the Cartagena Protocol and relevant annexes to the CBD (see Vienna Convention, Art. 31, paras 2 and 3).

(iii) Direct application of the language of separate instruments between the same parties "which establishes the agreement of the parties regarding its interpretation." (Vienna Convention, Art. 31.3(b)) Such "agreed interpretations" have not yet been used in the CBD, where COP decisions are not executed by national plenipotentiaries.

(iv) Subsequent practices which help to establish the agreement of the parties (Vienna Convention, Art. 31.3 (b)). In the context of the CBD, this category describes "COP decisions."

(v) International customary law (included by generic reference in Vienna Convention at Art. 31, para 3, and defined by Statutes of the International Court of Justice, Art. 38.1(b)).

(vi) Information gleaned from study of "the preparatory work of the treaty and the circumstances of its conclusion" (Vienna Convention, Art. 32).

(vii) Broader analysis of the objectives or intention of the instrument (authorized under Vienna Convention, Art. 32).

(viii) Determination of the meaning from contemporaneous information regarding the intention of the parties (Vienna Convention, Art. 32.)

The order of precedence is clearly set by Vienna Convention at Art. 32. If the first method (linguistic analysis) yields a clear interpretation which answers all relevant legal questions, then the remaining steps are not needed, however, as noted below, they may still be used to confirm the meaning that has been determined by the interpretation. 


\subsection{Policy bases for benefits arising out of the utilization of genetic resources}

\subsubsection{The nature of "genetic resources"}

The ABS framework as envisioned in the CBD is clearly bounded by one critical concept - the notion of "genetic resources" as a kind of material or interest that can be owned (whether exclusively or non-exclusively), controlled, transferred, or subject to other rights and controls.

Core questions in this regard concern the legal meaning of the term genetic resources and how, practically, genetic resources are treated among users and others. The use of this term has been spreading since its inclusion in the CBD, and it has appeared in numerous international discussions and documents, ${ }^{228}$ and in many national laws. Even so, however it still lacks the definitional clarity or regulatory development necessary for enforceable legislation. Posing the question "what is a genetic resource?" to any group will yield a variety of answers. None of these various usages have yet been able to clarify the meaning of the term, which is often used inconsistently.

An important first observation regarding "genetic resources" is its relationship to the continuing evolution in scientific knowledge. Genetic material is originally physically bound to and arises from a physical, identifiable source - a biological specimen of plant, animal, microbial or other origin. This is a primary difference from other intellectual properties, which are protectable because they arise from an intellectual source (human innovation). As technology advances, it is increasingly unnecessary to maintain any connection to the physical source, during the process of utilization of the genetic resource. Already innovations based on genetic and biochemical research have been created by persons who never had access to the physical material - only to information about its genetic and/or biochemical characteristics, for example through digitalization. Nanotechnology, as applied in the context of genetic use, will expand the number of ways that genetic resources can be utilized, and further reduce reliance on physical samples.

In general, analysis of a legal term begins from its stated definition, ${ }^{229}$ turning to other methods of interpretation only where (and to the extent that) the definition is unclear. ${ }^{230}$ To understand the term "genetic resources," then, it is necessary to start with a set of three interconnected definitions from the CBD:

- "Biological resources" includes genetic resources, organisms or parts thereof, populations, or any other biotic component of ecosystems with actual or potential use or value for humanity.

- "Genetic resources" means genetic material of actual or potential value.

- “Genetic material" means any material of plant, animal, microbial or other origin containing functional units of heredity. ${ }^{231}$

Read together, as many commenters have noted, these definitions do not provide a clear basis for determining which resources are "genetic resources." Yet it is

${ }^{228}$ See, e.g., the Intergovernmental Commission on Genetic Resources, Traditional Knowledge and Folklore (IGC), the discussions in the WIPO Standing Committee on Law of the Patents (SCP), in FAO and the International Treaty on Plant Genetic Resources for Food and Agriculture (ITPGRFA) and in the TRIPS Council of the WTO. These four processes have generally attempted to utilize (i.e., to wait for clarification of) the CBD definitions and concepts. A fifth international process, focused on marine genetic resources, is the deliberations of the UN Intergovernmental Consultative Process on Oceans and the Law of the Sea (UNICPOLOS). In this process, however, the meaning and application of CBD terminology has not been used, so that much of the "marine genetic resources" discussion has focused on applying limits on the taking of samples - a "sustainable use" matter - rather than on actual issues of ABS and the CBD's third objective. See report of the 8th Meeting, at http://www.iisd.ca/vol25/enb2543e.html.

229 A treaty shall be interpreted in good faith in accordance with the ordinary meaning to be given to the terms of the treaty in their context and in the light of its object and purpose. Vienna Convention on the Law of Treaties, 1969, Art. 31.1. Where a word is not defined in a treaty, it is given its "standard definition" - a process that can be problematic where there are many "original versions" of the treaty, in different languages.

${ }^{230}$ Vienna Convention on the Law of Treaties, 1969, Article 31.4, reads: "4. A special meaning shall be given to a term if it is established that the parties so intended."

231 CBD Article 2 (definitions are unnumbered, but appear in alphabetical order in each version. They are therefore in a different order in each of the official texts). 
clear, both from a contextual reading of the CBD and from a historical analysis of the CBD negotiations, that Article 15 was clearly intended to apply only to "genetic resources" and that the Parties perceived genetic resources to be distinguishable from other biological resources which are acquired and used in bulk. Thus, a clear understanding of the meaning of this term should include an understanding of its positive and negative limits on the scope of Article 15.

Linguistic analysis of these three definitions suggests that the difference between "genetic resources" and the broader category of "biological resources" may depend on two distinguishing characteristics: the material must "contain functional units of heredity" and it must be of "actual or potential value." These two basic concepts form the theoretical underpinning for determining the meaning and scope of the term "genetic resources."

Both terms are difficult. Many non-legal analyses note that nearly all material of biological origin contains "functional units of heredity" and that, based on the objectives of the CBD, all biological material is of “actual or potential value." From a legal perspective, however, the interpretation of these concepts is critical, because they provide strong indications of the negotiators' intentions regarding the role of genetic resources within the CBD. From this basis, it will be possible to determine how the limits of "genetic resources" can determine the scope of ABS, and how this concept integrates with the concepts of "utilization" and "benefits arising" to form the analytical and legislative basis for implementation of an ABS system.

\subsubsection{1 "Containing functional units of heredity"}

The first qualifying element - material that contains functional units of heredity - although problematic, provides an important legislative indicator of the nature of "genetic resources." It is the integral link between the concept of genetic resources and the special properties to which Article 15 is directed.

The term "functional units of heredity" is not defined anywhere in the CBD. Its use mirrors the primary problem in any legislative document that uses technical terminology - determining how that term is understood, and by whom. Where the document's target audience is technical (technical experts and regulators) then the term will be understood and applied technically. Regulations will be developed citing particular scientific texts or statistics that will give a precise definition of the element and a standard for its measurement. ${ }^{232}$ Where the target audience is not highly technical, however, use of a technical term can be problematic, since it may mean different things to different audiences.

In the CBD, the use of the term "functional units of heredity" was selected by policy makers, rather than genetic scientists. Consequently, it was not clarified scientifically at the time and appears to have been variously understood by the different negotiators. Interpretation of this term can come from three kinds of sources: technical definition, political definition, and interpretation by subsequent legal and legislative action.

Technical experts note a general view that "functional units of heredity" is not a standard scientific concept. When they attempt to apply it, they generally assume that it refers to DNA and RNA. $^{233}$ Under this definition, many biological products (such as extracted oils), which do not contain either DNA or RNA, are not "genetic material."

232 The problem of developing agreed scientific and technical standards to be applied by all countries is not uncommon in international technical negotiations. Wherever the international community seeks to create a single scientific definition or concept that can be applied in all areas or in transboundary relationships, it is necessary to address both the needs of the scientific community that will apply the standard, the governments that will adopt it, and the regulated communities (industry and the private sector) that will be governed by it. An example of this level of detail and specificity is found in the Cartagena Protocol on Biosafety, where negotiations of technical issues were long and difficult, and implementation of the resulting standard has posed additional challenges.

233 A standard work on this subject is Watson, J., 1987, Molecular Biology of the Gene, The Benjamin/Cummings Publishing Company (4 ${ }^{\text {th }}$ ed.). Seizo Sumida, for example, notes that it remains the commonly held scientific perception: "I am sure, as a biochemist, that the functional units of heredity are DNA and RNA, not protein, if molecular biology has not changed the definition since my time as a researcher." (Personal communication, 9 Mar 2007.) 
Recently, a much publicized project was completed, which mapped the entire human genome. That project, however, yielded unexpected results, which have led some scientific commentators to suggest that DNA and RNA are not so much "building blocks" of heredity as a bio-molecular database wherein the biological information about the entity is stored. ${ }^{234}$ These scientists posit that reproductive proteins fill much of the role conventionally thought to be assigned to DNA and RNA. Finding a scientific definition of "functional units of heredity" is made more difficult by the fact that the Convention does not use the term gene or DNA-molecule or any other more definite term, possibly in an effort to maximize the flexibility of Article 15 and enable it to cover the evolving state-of-the-art in the utilization of genetic material.

Unfortunately, however, it is not likely that a scientific definition alone would resolve this question, even if one could be agreed. ABS is not a technical or micro-engineering system, but a commercial and a legal one. ABS law and policy define the government's right and duty to control utilization of genetic resources and share benefits. Consequently, varying interpretations of the term are legion, based on very different conceptual pictures. Often, these conceptualizations focus on the layman's perspective that "functional units of heredity" refer to whatever biological component gives a particular species, sub-species or variety its unique physical/biochemical characteristics. ${ }^{235}$ As a result, many participants in ABS discussions include DNA, RNA, proteins, chemical properties and other factors as "genetic resources." Noting that the genetic material or resource must "contain" functional units of heredity and that heredity is what defines the differences between various species/varieties, they assume that $\mathrm{ABS}$ applies to any unique characteristics of any species or variety. Discussions under this theory frequently speak in terms of "genetic and biochemical characteristics" and even more broadly. ${ }^{236}$

\subsubsection{2 "Of actual or potential value"}

The concept of actual or potential value is equally important in determining the intended scope of "genetic resources." This term establishes a commercial or developmental element as the second and defining step in the ABS scoping process. The logic behind targeting Article 15 at a narrow category - genetic resources - rather than all biological resources, is clarified by this concept. It suggests that ABS applies only when the resource involved is perceived to be valuable as a consequence of its genetic characteristics i.e., not when biological material is used for bulk purposes, such as food, construction materials, etc.

This conclusion is based on an extrapolation of the intent of the drafters. The definition of genetic resources emphasizes "value" - either actual or potential - that is inherent in the genetic material. This value must tie to the inherited characteristics and genetic components of the species. These terms were added into the Convention for the purpose of recognizing this value, as new technologies continue to make that value real rather than theoretical. Similarly, the ABS concept's overall focus on grasping a part of the revenues from these technologies for equitable (distributive) and conservation purposes is clearly value oriented. Thus, the definition of genetic resources appears to target a new value - the value that arises when material of biological origin is used in a way that takes advantage of the functional units of heredity.

\footnotetext{
234 The genetic mapping resulted in far fewer possible combinations than expected, leading to the conclusion that DNA may not be the "building blocks of life," but rather in the nature of a record or library of the specimen's cellular information. Commoner, 2002.

235 Or in the most extreme case, a particular specimen of extraordinary characteristics, such as a winning race-horse or other desirable breeding animal.

236 Note, for example, the African Model Act, which would apply benefit-sharing requirements to all uses of biological resources.
} 


\subsubsection{3 "Genetic resources" in international and national instruments}

Before concluding by accepting this approach to the meaning of "genetic resources," it is necessary to briefly consider the questions of prior and subsequent official uses of the term. ${ }^{237}$ After an in-depth and detailed survey of this question, ${ }^{238}$ however, it is clear that only a small number of instruments are directly relevant to this question, and that they do not alter our analysis. The following overview is offered for clarity and to answer the most frequently raised points.

Global instruments: Although they cannot be considered primary juridical bases for the CBD (because they do not have the same Parties), the International Undertaking on Plant Genetic Resources for Food and Agriculture ${ }^{239}$ (in existence before the CBD), and the International Treaty on Plant Genetic Resources for Food and Agriculture, ${ }^{240}$ which replaced it (several years after the CBD's adoption) are generally thought to be important in addressing issues under Article 15. In particular, both of these documents use the words "plant genetic resources" very prominently, however, they use this term in a generic way which is nearly identical to the manner in which the term "bio- logical diversity" is used in the CBD. ${ }^{241}$ The primary change made by the International Treaty when it replaced the Undertaking, apart from conversion into a binding instrument, is its creation of a multilateral system (MS) governing access to and use of certain "plant genetic resources for food and agriculture" which are held in international or national collections or otherwise brought within the scope of the Treaty. The use of "plant genetic resource" (PGR) as a term largely refers to accessions of plant seeds which are exchanged for plant breeding purposes. The FAO has recently commenced additional work on the issue assessing whether there is a need for specialized measures for Farm Animal Genetic Resources (FAnGR). ${ }^{242}$

When the term "genetic resources" is used in WIPO forums, those discussions only refer to the CBD usage - there is no specific WIPO-approved or accepted definition. International patent law in general does not use the term "genetic resources" at all. When genes, cells or biochemicals are subject to patent protection, other language is used.

National and regional instruments: One of the unfulfilled expectations of the CBD's negotiators was the expectation that critical issues, including clarification

237 In Article 31.3, the Vienna Convention on the Law of Treaties specifies as a principle for the interpretation that:

3. There shall be taken into account, together with the context:

(a) any subsequent agreement between the parties regarding the interpretation of the treaty or the application of its provisions;

(b) any subsequent practice in the application of the treaty which establishes the agreement of the parties regarding its interpretation;

(c) any relevant rules of international law applicable in the relations between the parties.

238 In addition to the instruments mentioned in this section, we have reviewed all national laws and regional instruments contained in the CHM's ABS database as of 1 September 2006, as well as the outputs and deliberations of the post-CBD processes considering questions of genetic resource issues before the World Intellectual Property Organization (particularly through its Intergovernmental Committee on Genetic Resources, Traditional Knowledge and Folklore) and the World Trade Organization.

239 International Undertaking on Plant Genetic Resources for Food and Agriculture (1983), adopted as FAO Conference Resolution 8/83. As a non-binding instrument, the Undertaking did not have Parties, but Countries (called "Adherents") submitted documents indicating that they would adhere to the undertaking.

${ }^{240}$ International Treaty on Plant Genetic Resources for Food and Agriculture (Rome, 2001). The Treaty was approved under Article XIV of the FAO Constitution.

241 The term "genetic resources" was not used anywhere in the Undertaking in a way that could be applied to a specific item or category of items that could be devisable or excludable in any way. Instead, it was a basis for the primary "requirements" of the Undertaking, to wit: identification of plant genetic resources, and especially those that are "in danger of extinction" (Undertaking, at Article 3, directly foreshadowing CBD Article 7), in-situ and ex-situ conservation (Undertaking, at Article 4, foreshadowing CBD Articles 8 and 9), capacity building (Undertaking Article 6 , covering capacity building, technology transfer, international technical assistance and financial support, foreshadowing CBD Articles 12, 13, 17 and 18); and networking and data-sharing (Undertaking, at Article 7, foreshadowing CBD Article 17, and the CHM). The Undertaking's provisions for access do not apply to "genetic resources," but only to samples of particular varieties, and in fact call for them to be provided "free of charge, on the basis of mutual exchange or on mutually agreed terms." (Undertaking at Article 5.) These obligations continue to be the base obligations under the International Treaty, supplemented by the MS provisions. The overwhelming similarity between the concept of "plant genetic resources" in the IT and that of "biodiversity" within the CBD is discussed in Young, 2006b.

${ }^{242}$ Hiemstra et al., 2006 and Tvedt et al., 2007. 
of basic concepts of ABS, would be resolved by the development of a body of national implementing legislation, ${ }^{243}$ which would slowly grow into an interconnected or interoperable set of instruments. This is a common way of developing international law. If all Contracting Parties had adopted ABS implementing legislation that clarified genetic-resource concepts within their own country, the combined information could eventually be used to create a conformed international understanding - a basis for the entire system. The collective analysis of all such practices would thus be a practical route to clarifying CBD provisions that are vague or ambiguous as written. ${ }^{244}$

As examined in detail by other authors, ${ }^{245}$ however, national legislative efforts have not generally specified or clarified the use of this term. In general, national definitions have taken one of two approaches - either omitting the entire "genetic resource" concept and developing legislative measures around other concepts $^{246}$ or retaining the same language as the CBD definitions, without adding any language or interpretation to resolve practical implementation issues. $^{247} \mathrm{~A}$ few countries have combined these approaches, using a different term, but giving them essentially the CBD definitions. ${ }^{248}$ Two particularly notable examples are the Costa Rican Biodiversity Law and regulations, which specifically regulates both "genetic and biochemical resources" 249 and Brazil's Provisional Act No2, which uses the term "genetic heritage" - and defines it in terms of "information of genetic origin, contained in samples." ${ }^{250}$ Although both of interest, neither clarifies the concept with sufficient precision to enable interpretation and enforcement. Consequently, state practice does not appear to add markedly to the analytical determination of the functional role of genetic resources in ABS.

\subsubsection{Summary - biological versus genetic resources}

The basic definitional conclusion about "genetic resource" must be viewed in the broader context of the CBD, where the term genetic resources appears only in a few key provisions, specifically listed in the third objective. ${ }^{251}$ The rest of the Convention addresses a wide range of issues under the all-encompassing term "biological resources." Based upon its usage in text, the term "genetic resources" appears to have been

243 See Glowka et al.; Hendrickx et al., 1993. State practice is one important element in customary law. Statutes of the International Court of Justice, Article $38.1 \mathrm{~b}$.

${ }^{244}$ Vienna Convention on the Law of Treaties, 1969, Article 31.3 (b).

245 See, for example, Cabrera Medaglia and López Silva, 2007, Book 1 in this Series.

246 For example, the proposed US measures on benefit sharing with regard to National Parks would apply to "research projects involving research specimens collected from units of the NPS that subsequently resulted in useful discoveries or inventions with some valuable commercial application." US NPS, 2006, Draft EIS, presented as Alternative B. Malawi's law applies only to "plant germplasm" - a very limited category that appears to be completely "physical" (not informational) in nature. (MALAWI: Environmental Management Act, Art. 36). The African Model Act, by contrast, would apply benefit-sharing concepts to all biological resources. African Union Model Legislation for the Protection of the Right of Local Communities, Farmers and Breeders, and for the Regulation of Access to Biological Resources (formally endorsed by all African Union States, but at this writing, not adopted in whole or in part by any). A more controlled version of this approach is found in the BioTrade discussions and first draft guidelines, which focus very broadly on the involvement of "natural ingredients" or "biological resources."

247 This approach is taken in a large majority of the legislative measures that are contained in the ABS database.

${ }^{248}$ For example, the African Union Model Legislation for the Protection of the Right of Local Communities, Farmers and Breeders, and for the Regulation of Access to Biological Resources, would apply ABS to all "biological resources." Bhutan takes the approach of defining genetic resources indirectly - by defining which biological resources are not genetic resources: "This Act shall not apply... [w] here the biological material is used as a commodity for the purpose of direct use or consumption as determined by the Competent Authority, based on the processes and end use of genetic resources, in accordance with the provisions of the Act." Biodiversity Act of Bhutan, art 4.a. Norway's draft Act avoids the term "genetic resources" by focusing only on the issue of "genetic material."

249 COSTA RICA: Normas Generales para el Acceso, Art. 1, et passim.

250 The entire definition reads: "information of genetic origin, contained in samples of all or part of a plant, fungal, microbial or animal species, in the form of molecules and substances originating in the metabolism of these living beings, and in extracts obtained from in-situ conditions, including domesticated, or kept in ex-situ collections, if collected from in-situ conditions, within the Brazilian territory, on the continental shelf or in the exclusive economic zone." BRAZIL: Provisional Act N² (186-16, 23 August 2001) at Art. 7 (translation provided by Brazil to the CBD). The rest of the law, however, discusses "genetic resources" as physical material.

251 Article 15, 16 and 19.2, as well as an integrating reference in Article 9(b). There is a possible inferred reference to genetic resources in Article 17.2 's provisions regarding repatriation of information. The only other appearances of the term are in the third objective (Article 1), and in the definitions of genetic resources and in-situ conditions. 
coined and defined for the sole purpose of enabling clarity and functionality with regard to the benefitsharing provisions in the ABS system. Seen in this way, the function of the term "genetic resources" in the CBD is solely as a determinant of the scope of the ABS obligations.

For this purpose, the definition of genetic resources can be clearly explained. The focus on the "functional units of heredity" as the defining characteristic of genetic material suggests that legal interpretation must recognize some specific link to the hereditable interest in the material, beyond the biological properties of the organisms where it once was found. It also underscores the difference between genetic and biological resources - "biological resources" consist of many specimens, each of which may be owned or used individually, whereas "genetic resources" refers to a kind of material that is present in the entire species, but which the system will treat as a single disposable

\subsubsection{The nature of activities that constitute "}

The second formative concept underlying the benefitsharing obligation is the "utilization of genetic resources." Within the Convention, "utilization" serves as the link between the scoping concept of "genetic resources" and the outcome concept of "benefit sharing." ${ }^{52}$ In all its formulations on benefit sharing, the Convention focuses on utilization (rather than access to or export off) the material, as the action to be addressed. Thus, the second critical element underlying the benefit-sharing framework is the concept of "utilization of genetic resources." Although primarily a tool of functional application (discussed in 4.3 ), it is necessary to briefly analyze it conceptually.

\subsubsection{The hidden issue}

Upon a closer legal analysis of the text of Article 15.7, it appears that the "utilization of genetic resources," not the genetic resources themselves should be seen as the central element. This is appropriate, because utilization is, of course, the "value creation" element within commodity under the sovereign control of each country where it has origin. The second interpretive step concludes that genetic resources are linked to a particular kind of actions and intentions - those that use or create "actual or potential value" out of the "functional units of heredity."

Operationally, however, other key concepts (discussed in 4.2.2 and 4.2.3 below) are used more concretely in Article 15 - to create the clear distinction between situations which require ABS actions, and those which do not. The role of "genetic resources" is to identify the overall scope of the system - to determine what actions and situations should be included within the ABS framework. It will not be necessary (or possible) in applying ABS principles to make some firm determination that one item is a "genetic resource" and another is "biological."

\section{utilization of genetic resources"}

Article's 1 and 15. (Before value can be shared, it must be created.) Existing legislation and the international ABS discussions have seldom focused on the point of value creation, but have centered instead on the various confusions and obstacles involved in trying to define "genetic resources." However, a functional definition of "utilization of genetic resources" is potentially much easier to create, and produces a practically applicable concept based on externally confirmable criteria. In brief, it is easier to define a basis for recognizing that an activity is "utilization of genetic resources" than to guess whether a resource is "biological" or "genetic."

\subsubsection{Defining "utilization of genetic resources"}

The CBD does not define or explain the meaning of utilization of genetic resources except to note in Article 15.7 that utilization includes both "commercial and other" activities. ${ }^{253}$ Presumably, the drafters assumed that the standard usage of the word "utilization" is clear without specialized definition. However,

252 See CBD Art. 1 ("benefits arising out of the utilization of genetic resources"); CBD Art. 15.7 ("the results of research and development and the benefits arising from the commercial and other utilization of genetic resources"); and see CBD Art. 16.3 ("which makes use of those resources") and 19.2 ("arising from biotechnologies based upon genetic resources").

253 Efforts to distinguish non-commercial research from "utilization of genetic resources" (see, e.g., Fernandez-Ugalde, 2005) would have to take into account this clause which suggests that research was originally believed to be within the scope of "utilization" for this purpose. 
"utilization of genetic resources" is specialized. Only the manner in which a resource is used can provide the external means for determining whether that resource is a "genetic resource" or other biological material. ${ }^{254}$ If the special meaning of "utilization of genetic resources" is made clear, it can provide a practical basis for "grounding" the concept of genetic resources genetic resources are not simply the biologically encoded information in species (nor the specific cellular material containing that information), but they are tied to utilization - realization of the value of the functional units of heredity of that material.

It may be easiest to develop this understanding by considering practical factors. For example, one difficulty with the concept of "genetic resources" is the need to distinguish some category of resources that are not covered by ABS - i.e., instead of asking "Which resources are genetic resources?" we are tempted to ask "When is a biological resource not a genetic resource?" Alas, the answers to this second question have also proven illusive.

By focusing on utilization, however, it should be possible to answer the more relevant question - defining "utilization of genetic resources" by identifying the activities that are and are not "utilization of genetic resources." Many activities seem clearly to be excluded. For example, the harvesting, milling and sale of timber products, although utilizing the tree as a biological resource, are probably not utilizing its genetic resources.

The other list is also possible - kinds of activities that are unequivocally included within the concept. For example, making a new living modified organism using insertion of recombinant DNA ( $\mathrm{rDNA}$ ) from a donor organism into a recipient organism seems clearly to be the utilization of genetic resources. Synthesis of DNA from wild biological sources seems also be an activity that utilizes the intangible information in that biological source.

Although it leaves a large "middle ground" activities which must be evaluated in more detail this approach may be an effective tool for practical determination of when ABS applies. Unlike the distinction between genetic resource and biological resource, it is more feasible to differentiate utilization at the practical, observable level, using a rational objective standard rather than relying on one's ability to discern the intentions of a collector or holder of biological material before that material has been used or consumed.

\subsubsection{Value of the concept}

Few commentators have, as yet, considered the role of utilization of genetic resources as a linking concept between "genetic resources" and "benefits arising." They have been focusing primarily on "genetic resources" and "benefits" and ignoring the active elements - "utilization" and "arising." If the ABS regime recognizes "utilization of genetic resources" as a basis for its operation, it may be able to move away from irrelevant questions relating to the movement of specimens across borders, and eliminate the desire to force regulating officials to find (and to discern the intended use of) each biological sample or part. It will also enable the system to address the problem of users who are utilizing genetic resources obtained without going through any legal process or scrutiny. ${ }^{255}$ "Utilization of genetic resource" could be determined without a speculative determination of the future of the specimen or other matter (i.e., whether the material is a "genetic resource"), looking only at whether the user took an action that is considered to be the "utilization of the genetic resources" - a question that can be answered objectively and documented by evidence.

${ }^{254}$ If utilization of a genetic resource refers to any activity which uses a specimen which contains or was derived from biological material that contains DNA - it might include blowing one's nose on a cotton handkerchief. Clearly, the utilization of genetic resources means something else.

255 The basic problems with the "intention" element of the "genetic resource" concept, as it is currently used, are discussed in many different sources, including Cabrera Medaglia et al., 2007; Young, 2006b. Intention is an element of every existing definition of "genetic resources," and of every use of an alternative term ("research samples," "genetic heritage," etc.) except for those systems which ignore the entire issue and apply ABS to all biological resources (creating a broader problem, as set forth in 4.3.1, below). When controlled at the access level, ABS faces the problem that the difference between genetic resources and other resources is determined by the intention of the holder - something that is not knowable at the time of collection. Even in the laboratory, there may be a distinction between "biological research" and "genetic research," yet arguably only the latter is subject to ABS provisions. 
This suggests the critical need to define and apply the concept of "utilization of genetic resources" as a core focus (perhaps "the core focus") of the system, rather than to attempt to develop a tracking system for individual specimens and grapple with the need to determine when untracked specimens are transformed from normal biological specimens into "genetic resources" to be tracked. ${ }^{256}$ The simpler solution - focusing on utilization of genetic resources - is only possible where there are well functioning userside measures under the ABS system.

\subsubsection{The nature of "benefits arising" from the utilization of genetic resources}

The benefit-sharing obligation is focused on the "benefits arising from the commercial and other utilization of genetic resources." ${ }^{257}$ It is these benefits which must be shared equitably. Thus "benefits arising" is the third building block of the benefit-sharing system. Conceptually, the nature of "benefit" is not sufficient alone - the ABS system focuses specifically around "benefits arising from utilization." This concept has a dual role in user-side legislation - both as a trigger of the user-side obligations (sharing benefits, results and other requirements) and as one part of the determination of the value and nature of what must be shared. To define this concept, it is necessary to ask three questions: "What constitutes a 'benefit' for these purposes?" "Benefits to whom?" and "Which benefits 'arise from the utilization of genetic resources?"

\subsubsection{What are "benefits" for Article 15.7 purposes?}

The CBD gives only three words of guidance regarding "benefits arising," but they are very important to the formation of the ABS system, specifically stating that the concept includes "commercial and other benefits." ${ }^{258}$ Supplemented by references to results of research and development, Article 15.7 indicates a very comprehensive scope of benefits that might arise from utilization. ${ }^{259}$ The Bonn Guidelines underscore this broad scope by including a long list of examples of benefits in Annex II. This point is very important to the system - it specifically includes non-commercial benefits among those that must be equitably shared.

In considering the inclusiveness of "benefits," several facts must be remembered. First, many outcomes of the utilization process may be speculative, incomplete or intangible.

Second, it is not possible to evaluate the "benefits arising" question solely on commercial terms. Many benefits are not commercially oriented or valued, but are of ideal or factual or informational character. Under the CBD, it appears that information and research results are considered to be benefits arising for this purpose. In most cases, however, it will not be possible for the user to "liquidate" this type of benefits - that is, to determine its financial value, and pay the source country a monetary sum, as one would for financial benefits.

Third, in commercial utilization of genetic resources, the actual benefit-sharing obligations will often be triggered by the terms in the ABS contract (i.e., the mutually agreed terms that are negotiated through the prior informed consent process). The monetary and other forms of payment to satisfy the benefit-sharing obligation might happen at many

256 At this writing, the CBD has authorized, but not yet received the report on a further examination of the concept of "certification of source, origin or legal provenance of genetic resources" by a "group of experts." CBD-COP Decision VIII-4 (UNEP/CBD/COP/8/4) at Part C, para 1. The Group was not asked to come to a conclusion regarding such certification, but to consider the options and impacts. While there remains a possibility that the COP will simply adopt a form certificate without directly linking it to any specific performance or other aspect of the new regime, there is still hope that the certificate will develop as an organic part of the regime, addressing the specific points at which the regime (as ultimately developed) will require documentation.

257 CBD Article 15.7, calls for equitable sharing of "the results of research and development and the benefits arising from the commercial and other utilization of genetic resources." See also the more general statement in Article 1 (the third objective of the CBD) also based on the "benefits arising out of the utilization of genetic resources."

258 CBD Article 15.2, emphasis added.

259 It appears unnecessary to try to distinguish between "research results" and "non-commercial benefits" since the two are treated the same under Article 15.7. 
stages - even before the benefits have actually arisen, since many users and most source countries will agree to a system of milestone payments, during the course of the research period, rather than a long-term share in the product, process or other innovation that is developed. A complication here, however, is that the amount, type and value of benefits that will arise from a particular utilization is unknowable at the time of the PIC and MAT processes. Contractually, this issue can be addressed in a variety of ways, one of which might be the inclusion of a dynamic process for determining the final amount of benefit-sharing obligations. $^{260}$

The wording of Article 15.7 suggests that "benefits" should be broadly conceived - that the term should include all data, innovations, proceeds, rights and property which has been created or developed through any process which involves the genetic resource.

\subsubsection{Whose benefits are considered?}

The obligation to share benefits is general in scope. Fair and equitable sharing applies to all benefits that "arise" from the utilization of a particular genetic resource. There is no indication that this obligation is limited to persons who have signed ABS contracts - it appears to apply to all who have benefited from the utilization of genetic resources. This suggests a need for reasonable limits. As with utilization of genetic resources, there seem to be benefits that are clearly not included in the sharing requirement and those which seem clearly to be included. For example, the individual employees of a user company, research institute, or collection are not required to share the benefits of their individual employment (salary, etc.), even if directly tied to working on the particular resource. At the other end of the spectrum, consider a company that has developed a new pharmaceutical incorporating genetic material from a particular species in the product or in the process of its creation. The profits from this activity are clearly benefits arising from the utilization of the genetic resources, as is the information developed by the company about the species and its genetic and biochemical characteristics, and triggers the obligation under Article 15.7.

The immediate reaction to this example is to suggest that benefit-sharing requirements should be limited to direct benefits that are received by some defined class of "users" or to persons who acquired the genetic resources in specific ways. Before adopting such a definition, however, it is useful to consider experience in other commercial sectors. In some commercial situations, detailed laws are needed to prevent companies from bypassing legislative requirements that apply only to "direct users," "direct owners" or "direct beneficiaries" of a particular type of contract or other legal arrangement. ${ }^{261}$ Such companies might transfer properties, data or rights to controlled entities or individuals, or take other actions that convert "direct" benefits (subject to benefit sharing) into "indirect" (not-shared) benefits.

\subsubsection{Which benefits "arise out of" utilization of genetic resources?}

The most difficult practical question relates to determining the linkage between benefits and genetic resources. This linkage is still a source of controversy internationally, and there is no clear majority view about it. Some questions that have arisen in discussions of this issue focus on the nature of the utilization process, for example:

- Consider the case in which data about the genetic or biochemical properties of species $\mathrm{X}$ was received from another researcher (no physical contact with any samples or material). Does the synthesis of a new compound on the basis of this data constitute a benefit arising from the use of the genetic resources of species $\mathrm{X}$ ?262

\footnotetext{
260 This issue is discussed in greater detail in Bhatti et al., 2007.

${ }^{261}$ For example, most countries' laws state that a government official may not participate in official decisions that affect any company in which he holds a financial interest. Complex requirements may be imposed to ensure that he is not merely masking his interest (deeding it to his children or to a family-owned corporation) in order to take governmental decisions that promote his own private interest.

262 See, Mgbeoji, 2006. This question is based on an actual case.
} 
- On the other hand, consider the collection of a species for taxonomic analysis and conservation. Does this constitute a benefit? If so, who has benefited:

o the source country (whose species are more "marketable" to users of genetic resources)?

o the user country (who may be saved the costs of broadly "prospecting" for new species)?

o the collection or analytical body (which might receive a fee for these services)?

These same questions have been posed regarding middlemen who perform initial screening of compounds and then sell them to other users. Answers may differ, depending on the technical level of the activities undertaken and/or information generated.

Even when linked to clear determinations of the meaning of "utilization of genetic resources," the question may arise whether all information, products, processes, or other outcomes of those processes should be considered to be "benefits arising" from the utilization of genetic resources. A natural biochemical substance ("genetic resource") being studied may be difficult to maintain in laboratory conditions, prompting the researcher to develop a new kind of container or container coating. Is this new innovation a "benefit arising" from the utilization of the genetic resource?

For clarity, it is necessary to note that the systemdefining question - "which benefits arise out of utilization of genetic resources?" is quite different from the operational question - "what forms of payment may be made under benefit-sharing arrangements?" This latter question has been described in some detail in the Bonn Guidelines. ${ }^{263}$ It is important to look closely at the Guidelines and to understand their role in the national legislative process. Specifically, in developing these voluntary guidelines, the Parties were not discussing or interpreting the conceptual bases of ABS. Rather they were only considering and evaluating current practices used by countries and users seeking to apply existing understandings of ABS in transactions. Thus the Bonn Guidelines did not focus on what "benefits arise" from utilization, but approached the issue from a very different perspective - the administrative question of what forms of payment (money, joint venture participation, services, technology, etc.) may be useful in the drafting of $A B S$ contracts. Although not answering the questions posed in this chapter, the work in the Bonn Guidelines constitutes one point of departure that can be used in developing the functional triggers of benefit sharing.

\subsection{The functional relationships - the three triggers of benefit sharing}

Building on the conceptual base described above, the functional process of benefit sharing can be expressed in legislatively relevant ways by considering how the three concepts described above interrelate with one another. Functional user-side measures can be built by considering the actions involved such as the collection, research, use, development and production based on genetic resources, and considering where and how the benefit-sharing obligations are triggered in regard to these actions. It appears from the analysis above, as well as the national legislation in existence, and national and global experience with $\mathrm{ABS}$-related systems, that there will be two or three effective triggers of the users' benefit-sharing obligations. The following discussion addresses how that system is triggered, and how it operates legislatively within the userside framework. It focuses on three primary questions:

(i) how the various benefit-sharing and ABS compliance obligations are triggered (this section);

(ii) how benefits are determined and shared (section 4.3); and

(iii) whether, when and how these obligations end or are exhausted (section 4.4).

${ }^{263}$ Bonn Guidelines, adopted by CBD-COP Decision VII-24.A, Appendix II. 


\subsubsection{The first trigger - "genetic resources" as a functional element}

Policy clarity about the meaning of "genetic resources" is only the first milestone. A separate question - how this concept will be used in legislation - is more difficult. In this context, "genetic resources" fills the role of a meta-criterion - it is a factor that is used in developing the functional criteria of "utilization of genetic resources" and "benefits arising from genetic resources," but is not a specific criterion to be applied to each individual user or claim. However, as a principle guiding regulatory development, the term can fulfill its CBD role of defining the outer limits of the benefit-sharing obligation.

Based on the international and national discussions to date, it seems likely that any new ABS-oriented system on either the user-side or the provider-side will have to include this specific "triggering" question for each transaction: Are genetic resources involved?

As the first "trigger" in determining whether an ABS obligation applies, the concept of "genetic resources" will have to be expressed in a concrete way that clarifies the functional distinction between "genetic resources" (to which ABS applies) and "biological resources" (to which ABS does not apply). This must be done in a way that does not encourage law- and policy-makers to presume that ABS legislation is simply the development of a series of rules applicable to "genetic resources."

As noted above, however, most biological material contains functional units of heredity, making it hard to use this fact as a criterion for differentiating genetic resources, which are covered by ABS, from biological resources, which are not. Hence, two specimens of the exact same subspecies might be treated differently, based on two users' different intentions - a factor that is not externally verifiable. Moreover, at the time of in-country collection of specimens, collectors may intend only to sell the biological resource, and may not care whether the buyer intends to use it as a "biological resource" or as a "genetic resource." Intentions related to a specimen may change over time. After the first sale, the specimen may come into the hands of one who intends to utilize its genetic properties. Thus, a system based on the movement of genetic resources would have to track all biological materials and information over its life and that of its progeny, in order to determine when or whether it eventually becomes a "genetic resource."

The following discussion considers four different possible legislative views of genetic resources:

(i) "Genetic resource" is the same as "biological resource;"

(ii) "Genetic resource" is a specific kind of material (e.g., prepared sample or extract);

(iii) "Genetic resource" refers to intangible value, e.g. genetic information, when transferred in intangible form, e.g. as a formula or in digital form;

(iv) "Genetic resource" is a combination of the tangible biological material ("micro-tangibles") and the intangible asset (the genetic information).

As demonstrated by the following summaries, it will be possible for legislative draftsmen to develop a functional ABS framework and take steps to maximize "legal certainty," regardless of which view is chosen. This fact underscores the primary problem currently preventing $\mathrm{ABS}$ functionality - the issue is not that the Parties have chosen the wrong interpretation, but rather that they have not agreed on, adopted or applied any interpretation.

\subsubsection{Option 1: "Genetic resources" as synony- mous with "biological resources"}

Assuming that the term "genetic resources" is coextensive with "biological resources" will partially solve some problems, while creating others. It has been suggested as a simple solution that will eliminate the difficult question of identifying which resources the ABS obligation addresses, by basically requiring $\mathrm{ABS}$ for all material of biological origin. ${ }^{264}$ But obviously, it

\footnotetext{
${ }^{264}$ As noted in footnote 247, supra, the African Union Model Legislation for the Protection of the Right of Local Communities, Farmers and Breeders, and for the Regulation of Access to Biological Resources (formally endorsed by all African Union States) avoids the genetic resource
} 
would create a substantial problem, in that it would apply $\mathrm{ABS}$ to an extraordinarily large number of resources and activities. This could result in both intentional and unintentional restrictions and impediments to trade and exchange of biological material. ${ }^{265}$ Moreover, it might be conceptually necessary for developing countries to "share benefits" with developed countries which may be the original source of staple commercial goods that are internationally grown and traded.

For legislative regime developers, however, this approach merely moves the complex, detailed aspects to another part of the legislative framework. Instead of winnowing out "non-ABS-transactions" by determining that they are not transactions in genetic resources, the legislative developer would have to develop a more complex system that identifies many different kinds of compliance and applies different benefit-sharing systems, depending on other criteria (type of utilization, nature of benefit, etc.).

\subsubsection{Option 2: "Genetic resources" as tangible "genetic material"}

Another option would involve identifying specific tangible materials (genes, extracts, etc.) as "genetic resources," addressed by the ABS regime only when they are transported in this physical form. This approach again attempts to eliminate the need to consider intangible factors, such as the intent of the holder or transporter of the material, but raises other concerns. The key question underlying this approach is whether (i) it applies only where the material is transported separately (as prepared samples), or (ii) it includes material that is mixed with or a part of some other item or product (including perhaps an entire animal or plant) which could later be raised or propagated, or whose genetic material could later be extracted and multiplied.

If the term "genetic material" applied only to the former, then implementation would be simple. There are certain methods of sample preparation that are clearly undertaken for purposes of scientific research into genetic or biochemical analysis, and it may be suggested that $A B S$ should recognize only these samples as "genetic resources." 266 This approach could drastically limit the scope of the ABS obligation, if applied only to materials prepared in this way at the time of transport.

It is, however, perfectly possible to utilize live specimens, and even other parts of dead or preserved specimens to generate genetic material for study and utilization. Legislatively, the question would arise: At what point in time is the definition applied (before or after collection, exportation/transport, or even planting, breeding or multiplication)? This approach would focus on the point at which the resource user begins to take actions involving the value of the functional units of heredity of the resource.

\subsubsection{Option 3: "Genetic resources" refers to intangible "genetic information"}

Increasingly, the use of genetic resources is seen to occur with minimal contact with the specimen in nature, and in some cases, with no contact with any physical specimens or extracts. ${ }^{267}$ This prompts the suggestion that "genetic resources" should be understood as genetic information or information about the gene's function in the organism - in other words, as information that can be transferred in a non-physical form (e.g. in digital form, or through other means of transferring research results and technical information) as DNA sequences (mapping DNA scientifically) or as chemical formulas (biochemical properties) derived from the variety/subspecies.

definition problem by applying its benefit-sharing provisions to all "biological resources." Art. 3, et seq. According to some sources, if this approach were applied to the international ABS regime, it would enable northern countries to bring actions against southern developing countries that allow their citizens to engage in commercial trade in roses, for example. Personal communication, Leonard Hirsch.

${ }^{265}$ Nearly all food and a large amount of furniture, clothing, ornamental items, and industrial commodities are based on components of biological origin. Consequently, in addition to the delays and impediments of an added set of bureaucratic requirements, this definition might also create delays through the enormous number of such requirements to be processed.

${ }^{266}$ A standard for recognizing specific kinds of prepared samples could be developed, as under CITES, for example, which provides certain exclusions in the case of "preserved, dried or embedded museum specimens, and live plant material which carry a label issued or approved by" the appropriate government authority. CITES, Article VII. 6.

267 See, e.g., Mgbeoji, 2006, "Analysis of Four Claims..." 
In one sense, this approach provides the clearest distinction between genetic and biological resources one is physical, and the other intangible. It will also create a more durable basis for flexible application of ABS to new situations, as the technological state of the art continues to evolve. This definition could be robust enough to cover genetic resources even when they have not been directly collected from the source country. Detaching the definition of "genetic resources" completely from the tangible aspects would, however, create a serious problem of oversight and identification of users, as well as potentially narrowing the scope of the obligation. As such, it might increase attention to incentives and other mechanisms designed to increase user-transparency regarding the links between their various uses and innovations and their biological/genetic sources.

\subsubsection{Option 4: "Genetic resources" combines physical and informational elements}

The CBD's use of physical terms such as "material" in the definition may suggest that "genetic resources" encompasses both (micro)physical and intangible/informational elements - the information and its biological source. This option suggests that "genetic resources" should include any of the following:

(i) the micro/physical component (extracting, multiplying and studying genetic or biochemical material);

(ii) the information (synthesis or other development, or processes to do so); and (iii) the intangible and tangible being used together (i.e., where a molecule or sequence cannot be synthesized or multiplied, but must be continuously collected from wild sources).

This approach appears to integrate all of the positive elements of the first three options, keeping the range of the term relatively broad (option 1), but allowing it to focus on the points at which the resources move from being primarily potential (many options for how they will be used) to being clearly focused on value arising from functional units of heredity (option 2) the point at which the user's intention begins to be reflected in action. This approach retains the robust nature of the concept that may continue to apply when technology changes, and the potential value in the genetic material can be realized or communicated in new ways (option 3).

\subsubsection{Summing up - the genetic resource trigger} Nature becomes a "resource" when it is mixed with human innovation and activity. Thus, it has always been recognized that "genetic resources" exist only where human activity is involved. A definition of "genetic resources" that recognizes both its physical and its intangible aspects, also recognizes the broad variety of human actions that might convert a natural specimen into a "genetic resource." This dynamic understanding of "genetic resources" is closely linked to the next element in the trigger mechanism for benefit sharing: utilization of genetic resources.

\subsubsection{The second trigger: "Utilization of genetic resources"}

As shown in 4.1 and 4.2.1 above, it is nearly impossible to identify specific material as a "genetic resource" or to require controls on transboundary movement of materials on the basis of their identification as "genetic resources" regardless which alternative presented in section 4.2.1 has been chosen. Specimens crossing national borders as biological resources may be indistinguishable from those destined to be genetic resources. Specimens frequently change hands, and can be multiplied and shared with many different users, for different purposes and obtaining different types of results. After years of thought, the authors have concluded that one cannot directly regulate all "genetic resources" per se, no matter how they are defined, unless we are willing to impose some level of control on all movement of any biological material.

These facts strongly suggest that an ABS system cannot be based on a species-by-species or specimen-by-specimen oversight. For a regime to be functional, it must be based on something that may be empirically or at least externally determined - a process that may differ across the range of species, 
activities and objectives for which the material is obtained. ${ }^{268}$ Functionality requires that the concepts be defined in a robust manner which would be sufficiently clear and definite to enable clear determinations about when the ABS system applies. For this, the triggering concept must be practical and externally verifiable. "Utilization of genetic resources" meets both these needs and can thus be enforced by the contracts, agencies and courts.

The utilization-based approach seems to offer a much higher level of concreteness and a greater ability to serve as the engine that moves the ABS regime. In essence, this utilization can be a concrete grounding of the genetic resources definition, so long as it is based firmly on an agreed overarching perception of "genetic resources" and their difference from other biological material. More important, however, utilization of genetic resources is an objective standard. A number of activities can potentially be categorized and verified as utilization of genetic resources.

There are two decided advantages for legislators, in creating and applying legislation focused on the "utilization of genetic resources." First, as noted above, utilization is an action, and as such may be externally verifiable most of the time. Second, and equally positive, the phrase has not been defined in the CBD. Thus, the Parties have the ability to craft the concept to fit experiences, practices and problems encountered in ABS-related activities up to now.

The functional challenge, therefore, is to determine what activities should be covered by the term "utilization of genetic resources" and draft legislative standards and criteria to encompass those activities. In technical legislation, this is accomplished using at least one of the following:

- Descriptive criteria (the qualities that an activity will display when that activity constitutes "utilization of genetic resources");

- Examples and categories (a list of the particular activities or categories of activity that constitute "utilization of genetic resources").

It is common to include both kinds of approaches in legislation, by providing that -

(a) the following is a list of activities that constitute "utilization of genetic resources" for purposes of this law: [here insert one list];

(b) In addition to the items listed in (a), any activity that meets the following criteria shall be considered to be "utilization of genetic resources" for purposes of this law: [and here another].

This approach would maximize legislative guidance to courts, agencies and users seeking to apply the law, and would provide concrete examples that might help clarify and solidify the concept administratively.

\subsubsection{Lists or categories of utilization of genetic resources}

The listing/category approach offers great potential for ABS, especially because it can provide a comfortable basis for compromise with regard to issues of current uncertainty. Thus, for example, there are many controversies about the inclusiveness of the concept of genetic resources (e.g., Do all activities that breed or reproduce a species constitute "utilization of genetic resources"?).

Categories might not only help in determining whether ABS applies, but can also provide a basis for differentiating ABS requirements. The ABS requirements of a particular use activity can be designated specifically and governed by activity-specific benefitsharing provisions. Where there is a dispute about whether ABS applies to an activity, compromise provisions can be agreed between the affected industry or sector on one hand and source countries and providers on the other. Some categories might qualify for streamlined processes, simplified documentation or special incentives, and could be tied to specific types and levels of benefit sharing. Some of the activities that would benefit by this treatment include:

- utilization activities considered by some to be

268 Pythoud (2005) raises a question if "... there [is] a specific type of use of genetic resources that might require additional international instruments to support implementation of CBD Art. 15?” 
"normal trade" in agricultural products and natural ingredients; and

- conventional (historical) processes for agricultural variety development, such as selection, seed saving, cross breeding, hybridization, etc., which could be regulated in connection with the International Treaty on Plant Genetic Resources for Food and Agriculture and plant breeders' rights (including the concepts developed in UPOV).

These categories could cross reference other relevant instruments, as discussed below, providing an added incentive for compliance with those instruments. This will enable the overall system to operate consistently with regard to these activities, while focusing its primary attention on categories that are subject to a different level of scrutiny and performance.

In this analysis, we have identified four possible ways to categorize utilization of genetic resources:

\section{By sector:}

Agriculture, aquaculture, pharmaceutical, neutraceutical (agro-pharmaceuticals), cosmetics, ex-situ collections, basic scientific research, etc.;

\section{By objective:}

Food and food security; health and medicine; commerce; conservation; sustainable use; etc.

By specific genetic-related activity:

Breeding, cultivation/variety development, extraction and identification of characteristics or properties, taxonomic characterization, genetic manipulation, synthesis of sequence or formula, nanotechnological activities, etc.

\section{By developmental stage andlor type:}

It may also be possible to set a dividing line between genetic resource utilization and other activities based upon the position of that activity in the spectrum from collec- tion to product development. Some activities that are typically undertaken in the source country may be "utilization" as well as those in the user country:

Activities that are most often done in source country:

biodiversity inventory, ${ }^{269}$ specimen collection; initial taxonomic or biochemical analysis.

Activities that are sometimes done in source country, but often taken "Beyond access":

exportation or transport of specimens; taxonomic or biochemical analysis; laboratory extraction; research; finalization/publication of research results; transfer of specimens or results to other potential users; application for intellectual property right protections; development of commercial and scientific applications (of the discovered characteristic, gene or formula); production; sale.

Another factor that may have to be taken into account is the species' conservation status. Protected species or collections often have special status in law, and this status may affect the rights and obligations relating to their utilization. A category approach may integrate any or all of these factors; it can establish a high number of detailed acts, or it can include a small number of broadly defined activities.

\subsubsection{Plant genetic resources as a particular category} Some efforts directed at categorization have already received significant approval. One hundred twelve of the CBD's 190 Parties (plus one country that is not a CBD Party) have ratified the ITPGRFA, a document whose purposes include the development of a mechanism for access and benefit sharing with regard to

\footnotetext{
269 The "inventory" is a primary requirement of the CBD (Article 7). Although this requirement has been incompletely addressed in many countries, it could ultimately form a potential basis of utilization-based benefit-sharing methodologies under the international regime, as well as risk assessments for introduction of LMOs (under the Cartagena Protocol) and controls on the introduction of alien species that might threaten ecosystems (Article 8h).
} 
plant genetic resources. It creates effective categories as follows:

"Sector" (category): $\quad \begin{aligned} & \text { Agricultural plants } \\ & \text { (for food and agriculture) }\end{aligned}$

$\begin{array}{ll}\text { “Objective" (subcategory): } & \text { Utilization/conservation } \\ & \text { for food and agriculture }\end{array}$

1st tier Status: $\quad$ Species/varieties listed in

Annex I of the Treaty

2nd tier Status (3 options): PGR in national/international collections; Varieties in the public domain held by Members; Varieties held by others offered through the MS.

Each of these categories is both inclusive and exclusive. To apply the Treaty's special standards, the utilization must be within the general category of agricultural plants and not apply to other taxonomic kingdoms or to plants which are not "agricultural." It must also be within the food and agriculture objective, and must not involve uses that are only or primarily in the "chemical, pharmaceutical and/or other non-food/feed industrial" realm. ${ }^{271}$ In addition, the status of the specimens involved must satisfy the first-tier classification (a species or variety included in the MS) and one of the second-tier classifications regarding the ownership of the resource.

For those using this system, the ITPGRFA provides a streamlined process and a standard format contract governing both access and benefit sharing. Any activities that fall outside of the treaty's categories will be addressed under the overall ABS system. This approach - carving out segments of the overall body of genetic resources, whether by sector, by type of user or on some other basis - is continuing to develop, and has been recognized to some extent by the CBD COP, in its statement of support to the ITPGRFA. ${ }^{272}$

\subsubsection{Further international development}

The ITPGRFA's effort to create a separate ABS system for defined categories of resource and specific uses has been watched with interest by other sectors. For example, the FAO has recently commissioned studies on the relevance of Farm Animal Genetic Resources (FAnGR) to the ABS system. ${ }^{273}$ This issue, like agricultural crops and variety development, spans a broad range from the breeding and husbandry at the level of individual animals, which offers very little justification for inclusion in the ABS process. ${ }^{274}$ FAO's initial inquiries clearly posit the ultimate possibility of separate treatment for Farm Animal Genetic Resources - potentially through a specially adapted instrument. ${ }^{275}$ Similarly, the application of $A B S$ to wild animal genetic resources has also been raised in international meetings as another potentially severable ABS issue. ${ }^{276}$

In the broadest approach, these separate treatments would create a categorization system that eventually includes all biological resources of all types. That system would specify a legislative taxonomy, dividing all resources into two groups: those which

\footnotetext{
270 ITPGRFA Article 3 Scope; and see Article 10.2 Objective of the MS.

271 The ITPGRFA, at Article 12.3(a) provides that "Access shall be provided solely for the purpose of utilization and conservation for research, breeding and training for food and agriculture, provided that such purpose does not include chemical, pharmaceutical and/or other nonfood/feed industrial uses."

272 See CBD-COP Decision VI/6.

273 See Hiemstra et al., 2006; and Tvedt et al., 2007.

274 The right to determine the breeding use of individual animals that one owns is a basic right of the owner of the animal in all or nearly all countries. The commercial system for animal breeding at this level has been documented for over 1000 years. (See, e.g., Bennet, D., 2004, "The Origin and Relationships of the Mustang, Barb, and Arabian Horse" in The Spanish Mustang, introduction; and Lewis, B. "Egyptian Arabians, The Mystique Unfolded" in Arabian Horses of the Pyramids (http://www.pyramidarabians.com/news/articles/arabianmystique.html), both of which document evidence of controlled animal pedigrees dating back more than 2 millennia, and formal written records as early as 1300 AD.

275 The Hiemstra et al. study discloses a number of differences between use of plant genetic resources and use of farm animal genetic resources suggesting that the ITPGRFA approach would not be productive in the animal sector.

276 The $11^{\text {th }}, 12^{\text {th }}$, and $13^{\text {th }}$ CITES COPs all noted concerns that veterinary specimens (blood samples) would be used for commercial development. For this reason the CITES COP has so far refused to adopt special expedited or non-document-required transport of these specimens.
} 
are covered by the ABS framework and those which are not. It would also potentially apply different levels of performance or different types of systemic requirements based on various factors. In the end, many other options and list-based approaches (both inclusive and exclusive) might integrate with one another through this system.

One challenge, common to all statutory lists, is that the list will become outdated as technology develops new methods of utilization of genetic resources. This is problematic if the list is internationally agreed in a treaty format. It is particularly difficult and timeconsuming to change an international plenipotentiary instrument, unless that instrument contains special provisions for updating it. ${ }^{277}$ The loss of flexibility caused by a rigorous listing system could be an obstacle for ABS effectiveness, unless the categories are expressed in a flexible way, or a mechanism for management of the lists and categories is also developed. One such mechanism is the inclusion of a "criteria" basis for identifying other actions that constitute the utilization of genetic resources.

\subsubsection{Descriptive criteria for identifying utilization of genetic resources}

As an alternative or supplemental approach, ABS legislation could develop and apply a set of descriptive criteria to determine whether a particular activity constitutes the utilization of genetic resources. Such criteria can be applied by regulatory decisionmakers, and used in developing or providing further guidance regarding the lists and categories described in 4.2.2.1. Obviously, the challenge of this approach will be to find a set of criteria which are sufficiently broad and descriptive to address new kinds of uses that arise after the legislation is developed, but also sufficiently focused to be legislatively certain. An overly flexible criteria-set would eliminate the value of legislative efforts to define the boundary between ABS-regulated activities, and those that are not covered by ABS. It is essential that these criteria enable users, governments, judges, and providers all to know with relative certainty whether a new kind of activity or technology constitutes a "utilization of genetic resources" or not.

The next question to be considered now is "What are the characteristics of 'utilization of genetic resources?" Obviously, the main characteristic is that it utilizes "genetic resources" (leading back to the question of what that term means). Apart from this, however, the Parties will be able to develop answers to this question based on their overall conception of how the ABS regime should work. As noted above, national delegates currently express a range of opinions from including all uses of all biological resources, to including only genetics laboratory work leading to the development of commercial or industrial products. As noted above, it is important to make some concrete and specific decisions about this question. If the term remains general and undefined, then laws regulating it cannot be implemented.

In the end, this is a matter for political agreement, whether at the national or international level. However, where user-side measures are being developed, there seems to be a strong recognition of the need for mechanisms for inter-functionality of national laws i.e., for an international agreement.

\subsubsection{The third trigger: "Benefits arising out of the utilization of genetic resources"}

Where a user's activities have passed the first trigger ("genetic resource"), and the second trigger ("utilization of genetic resources"), indicating that he is subject to $\mathrm{ABS}$ responsibilities, the third trigger ("benefits arising") comes into play. This trigger is important because it provides both the basis and the timing for the primary user obligation - benefit sharing.

\subsubsection{Timing of "benefits arising"}

In developing the benefits-arising trigger, the critical

\footnotetext{
277 One example of this in the environmental area is CITES, where a one page amendment, adopted in 1983, is still not in force (having as of this writing 46 of the 54 ratifications necessary). If it ever does enter into force, the amendment would only be binding on those countries that have ratified it, and any countries that become Parties after the amendment enters into force. This fact will create a bifurcated Convention until all Parties have ratified.
} 
question is "When and how do ABS benefits arise?" This question can be difficult, both theoretically and practically. Theoretically speaking, the creation of a benefit happens in many incremental steps, from the creation of data through the marketing of a product. An analysis of the biochemical or genetic properties of a species, for example, is determined through a number of different texts and processes. While these activities are ongoing, users (whether academic researchers or commercial entities) have an interest in protecting their data, so that it can be analyzed and presented or used as an integrated whole. At the same time, source countries have a strong interest in having a share in this information.

Many kinds of benefits (data, processes, formulas, etc.) are protected by institutional secrecy - supported by laws affording privacy, freedom from unwarranted search, and the right to protect "trade secrets" even in documents which they are required by law to file. In some cases, the existence of a benefit simply cannot be externally discovered. In addition, it may not be possible for a source country or other external entity to discern the linkage between a known benefit (a new product) and the ingredients and processes by which it was created or is manufactured.

In general, the most effective approach to this question is to focus on determining when geneticresource utilization activities result in capture of the "actual or potential value." This will occur in commercial development when a commercially valuable commodity is created (whether a product on the market or an IPR or other marketable right). In non-commercial development, this could be defined as the point at which the research, analysis, cataloguing or other activity is completed and ready for publication. ${ }^{278}$ At this point, where a benefit exists, it will be possible to rationally determine the amount or nature of the benefit-sharing obligation.

\subsubsection{Operation of the benefit trigger}

Functionally, it is important to remember the role of the "benefits-arising" trigger. It triggers the statutory/CBD obligation to share benefits, but it does not control the sharing of benefits. This distinction is important for purposes of "user-side" legislation - the law must be able to answer the question "Have benefits arisen from the utilization?" as part of the determination of the user's responsibilities, especially in cases where there is no existing $\mathrm{ABS}$ contract. Even in provider-side measures, the sharing of benefits will often happen at some time other than the dates on which the benefits arise. In the best cases, both the date and the nature of such sharing will be specifically addressed not only in provider-side legislation but also in the mutually agreed terms that document the ABS relationship. Very often if there is an ABS contract, benefits will be liquidated (that is, the parties agree on a specific sum that will constitute the benefit share) and paid in advance, before the benefits arise, in the form of "milestone payments" or other contractual forms. ${ }^{279}$

The role of "benefits arising" is tied to the rights of the government, source country or other provider. When all three triggers are "triggered" then it is legally possible to ask the user the key question - Have benefits been shared? There are usually three possible answers:

(i) Yes, pursuant to MAT;

(ii) Yes, without MAT; or

(iii) No.

Where he gives answer (i), there may be no further legal question. Answer (ii) may give rise to questions about whether the sharing was "equitable" (discussed in Chapter 5) and answer (iii) may trigger other mechanisms for enforcing the user-side legislation and for enabling the source country to obtain compliance with its legislation. In all three cases the user legislation must be sufficiently clear to allow courts and others to review these answers.

278 As noted in the case of the Tricolor Frog, however, publication of such data, even where the publication is not compensated and completely unconnected to any commercial objective, can have the impact of eliminating the value of the data, from the perspective of the source country. See, Mgbeoji, 2006.

279 Described in Cabrera and López 2007. See also, Rosenthal et al., at 7. "Drug discovery is a high-risk science. That is a very small proportion of research endeavors result in a major drug that will yield financial benefits to the research organizations and their partners.... By integrating research and development toward [the] objectives [of (i) pharmaceutical and agricultural discovery, (ii) scientific and economic development and (iii) conservation] from the outset, the ICBG aims to make substantial and incremental contributions ... without pinning all hopes for success on the relatively low probability of producing a major pharmaceutical or agricultural product." 


\subsection{Applying the triggers - the CBD obligations to share benefits and research results}

Functionally, the three triggers (or other provisions of an ABS Contract binding the user) all lead to a key event - the user's sharing, "in a fair and equitable way, the results of research and development and the benefits arising from the commercial and other utilization of genetic resources." ${ }^{280}$ It is hoped that these responsibilities will be addressed directly in mutually agreed terms developed by the user and source country or other source. The fact is, however, that this will not always happen. Consequently, user-side measures must also consider two other purposes:

\subsubsection{Source-country agreement to benefit-sharing terms}

In $A B S$ discussions, one key fact is frequently overlooked: Article 15 provides for two separate MAT requirements - one for access (paralleling the PIC requirements), and another for benefit sharing. ${ }^{281}$ The inclusion of a second MAT process seems to indicate that simply sending some "benefit" to a source country is not enough - the benefit must be shared in accordance with provisions that are agreed by both sides. An official mechanism is needed for determining the reasonable expectations of the source country, and setting a basic standard of "equity," where the user has not obtained PIC/MAT or where the ABS contract is deemed inequitable.

It is useful to recall that, in the actual benefitsharing process, different types of benefits occur at different stages of resource utilization. For example, during specimen collection and identification, basic benefits (the collection and labeling of samples for study) already arise. Benefit sharing at this level is usually reflected by a contractual requirement that the bioprospector provide the source country "reference sam-
- determining compliance with MAT, where these issues are raised in the user-country's agencies, courts or other forums; and

- imposing responsibilities on users who have not obtained MAT or disclosed the source of the genetic resources.

In this section, we briefly consider the obligations to share the benefits arising from utilization subject to mutually agreed terms governing that benefit sharing; and some implications of the obligation to share research results.

ples" - duplicates of all specimens collected. At this point in the ABS process, the contribution of the genetic resources to the benefit obtained is very high. Hence, source countries usually expect an equal share - a duplicate or reference sample. At later stages of $\mathrm{ABS}$, however, even though the source country's contribution to the result is less, the kinds of intangible and informational benefits that arise cannot be divided one either obtains the information or not. Thus the source country's "share" in this kind of benefit is probably the entire benefit. This in turn raises questions of whether his use of that benefit may be restricted, and what those restrictions may be, and other potential legal controversies (as described in the next section).

In addition, the second MAT, specifically focused on benefit sharing, emphasizes that mutual agreement on benefit sharing may be required in the cases where there was no initial ABS contract at the time of "access," tying into the problems of applying source country law to persons in the user country.

\footnotetext{
280 CBD Art. 15.7.

${ }^{281}$ CBD Arts. 15.4 and 15.7. While the two MAT processes may be negotiated together in some cases, this may not be possible in all situations, and given that many benefits arise "beyond access" it is possible that the user country might be responsible to ensure that this second negotiation has occurred.
} 


\subsubsection{Sharing research results}

The obligation to share research results has not yet been discussed in sufficient legal detail, although it has potentially far-reaching consequences for both the user and the source country or community. Both Article 15.7 and the Bonn Guidelines recognize that research results are a benefit to be shared. One problem with this type of sharing, however (further discussed in chapter 5), relates to the user's interest in exclusivity of the information he obtains. Exclusivity or complete confidentiality is often a primary value of the resource at this stage of $\mathrm{R} \& \mathrm{D}$. A researcher forced to share preliminary results loses the trade-secret protection of those results, and may lose the ability to generate commercial benefits. Conversely, a researcher who publishes results (genetic sequences, biochemical formulas and other analytical results) non-commercially without the permission of the source country may have essentially eliminated the source country's ability to obtain any commercial benefit from those genetic resources, since users can use the published information, without coming to the source country.

A right to share in "the results of research and development," if unequivocal, could mean that the source country has a right to all data (preliminary and analyzed), whether public or not. This is not a small matter. Such a right could enable a much greater ability of developing countries to participate in technical industries and even in global commerce involving the use of genetic resources. In some ways, right to such information is significantly more valuable than the right to a share of the user's financial benefits from a development perspective. Where a new discovery of a particular chemical component is kept secret, it has value as a discovery which can be sold or transferred to another entity. Once the compound and its properties are known, however, the would-be buyer will have no reason to continue to deal with the discoverer.
Research and development results are thus most valuable when they are "closely held" (known only to a few). Even a non-commercial publication of these results could seriously diminish their value as a potential source of commercial or exclusive benefits. On one hand, it is inequitable to require the researcher to completely devalue his results (and his ability to obtain appropriate return on his efforts) by sharing them in an unrestricted way with the source country. On the other, it may be inequitable to allow him to dispense information (research results) of potential commercial value in a way that prevents the source country from obtaining any share in future benefits derived. ${ }^{282}$ The sharing of benefits must strike a balance or find a compromise between these various needs.

These dilemmas emphasize the importance of including a clear benefit-sharing obligation in userside measures, as a "background" law that can prevent inappropriate uses of this type by users who are not acting on the basis of MAT. A user-side mechanism to ensure benefit sharing can enable such balancing while closing the potential loopholes. ${ }^{283}$

Particular mechanisms could cover a broad range, and may in some cases be complex. One approach would define the researcher's benefit-sharing obligation in terms of a reasonable return on the value of the information. This definition would still allow information results to be used by other companies. A different mechanism would require other users of the data to share benefits with the source country, even though they did not actually contact the source country or obtain physical material in their research and development processes. A third the use of diplomatic communication between the governments - may be too difficult and time-con-

282 See, e.g., the Tricolor frog case, described in Mgbeoji, 2006. The researcher who published research results about the frog's unique poisons did not seek or receive any compensation or commercial benefit from that research. On the basis of the published data, however, multinational corporations filed 17 different patents for new synthetic compounds based on the researcher's results. One has since developed and patented a product or pre-product. That company had no contact with the source country or any part of any Tricolor frog.

283 Discussions of the possibility of a "research exception" normally are inconclusive, owing to the possibility that research will result in commercially usable results. However, a few countries have adopted generic "research exceptions." See, e.g., BULGARIA: Biological Diversity Act: Art. 66.4 "Gratuitous provision of genetic resources may be agreed where the said resources are intended for non-commercial purposes: scientific research, education, conservation of biological diversity, or public health benefits." 
suming to be considered as a national measure, but may be applied via an informal international mechanism (between National Focal Points or Competent Authorities from the two countries). ${ }^{284}$ As further discussed in Chapter 6, none of these options would be easy, but some mechanism or approach to these issues seems essential.

\subsection{Identifying an end point for the benefit-sharing obligation}

One critical issue that has come up only obliquely is the question of when the benefit-sharing obligation ends. This is a difficult issue, both politically and technically. To the genetic-resource user, the value of the resources will diminish greatly if it is linked to an eternal obligation to make payments to the source country, or if there are permanent restrictions on his use of

\subsubsection{Fulfillment of the ABS contract}

Like any other kind of contract, a well drafted ABS contract will provide clear indications of when and how the user will complete or fulfill his benefit-sharing responsibilities. To date, there has not been significant experience with benefit-sharing agreements; and it is not clear how they will terminate, or what contractual practices will be most appropriate.

One fact is clear, however - these contracts may be very long-lived. Invention and development in the field of genetic resources require a long lead time. This may imply the need for a similarly long duration of the contractual obligation. Since 1992, few ABS contracts have actually produced any the products and discoveries that arise from that use.

The terminus of the benefit-sharing obligation has been indirectly addressed in three types of discussions: ABS contractual responsibilities, transfers of genetic resources and research results, and the application of ABS to "derivatives" of genetic resources.

payments based on "benefits arising." This suggests that source countries may prefer "liquidated benefits" clauses - that is, developing a specific benefitsharing amount based on a pre-estimate of (i) the chance of benefits arising, (ii) the possible value of such benefits, and (iii) the "time value" of getting a smaller payment sooner, rather than waiting for a possibly larger payment later. This approach is based on averages. As to resources that do not eventually produce a benefit, the source country may receive a larger payment per resource. For those that eventually do produce valuable results, the user may pay less per resource. The important lesson is that the ABS contract should ideally clarify when and how the benefit-sharing obligation will be concluded.

\subsubsection{Transfers of genetic resources to third parties}

An important issue at the heart of many current ABS concerns is the user's subsequent transfer of the genetic resources themselves and/or of the research results (information) obtained. From the source country's perspective, a transfer of genetic resources may effectively end the benefit-sharing relationship, where the original collector is the only party known to the source country, unless some control or oversight measure exists. On one hand, users, researchers, collections, taxonomists and even middlemen feel that they have a right to transfer materials which are under their control, and to make a profit or other benefit out of the sale or other transfer. Users who obtain materials from such persons and entities often assume that, since they did not directly collect the resources in the source country, no benefit-sharing responsibilities apply. ${ }^{285}$ A similar view applies to foreign-origin biological materials that have been growing in the user country for many generations. The user's failure to get permission from the source country for the use of these materials may

\footnotetext{
${ }^{284}$ National law often requires that contact be made through highest level officials rather than directly between ABS focal points.

${ }^{285}$ Henkel, Thomas, "A Perspective from Pharmaceutical Industry," Presentation to High-level Experts Meeting - Addressing the Access and Benefit-Sharing (ABS) Challenges in the Context of the Convention on Biological Diversity (Tokyo, 8-9 February 2007) and other remarks in that meeting.
} 
seem to the user to be a minor omission at most.

Legally, however, it would create an enormous loophole in the ABS system to decide that a user has no benefit-sharing obligations unless he collected the genetic resources directly in the source country. Any non-user collector could acquire samples and transport them out of the source country or cultivate a subsequent generation before selling them or passing them on to a user, to escape benefit-sharing obligations. The fear that users are commercializing products through such perceived loopholes is one of the reasons that source countries have sometimes imposed strict limitations on bioprospecting and other research activities. The wording of article 15.7 does not enable these loopholes since it talks about sharing "benefits arising" and does not limit that obligation to a specific group of contractual relationships.

The "utilization focus" may offer one solution to this issue. It would base the sharing obligation on whether the activity of the transferee (third party) is a "utilization of genetic resources" (as discussed in 4.2.2). If so, his activity triggers benefit-sharing responsibilities, even if he has not been in the source country or touched the original biological material. This approach, however, presupposes clear legislation in the user country. It also cannot be reasonably applied, unless the law determines a reasonable and well-defined end point for the benefit-sharing obligation.

\subsubsection{Application of ABS obligations to "derivatives" of genetic resources}

The term "derivative" is not used or defined anywhere in the CBD. Nevertheless, the question of how ABS should apply to derivatives ${ }^{286}$ has become one of the most contentious issues relating to the further development of the international regime. In ABS discussions, "derivatives" is perceived in several different ways:

- One usage considers "derivatives" to refer to "material that is later bred, cultivated, or otherwise generated through some multiplication process in the user country";

- Others use the term to mean meta-extracts, fractions or essences obtained from a plant, animal or other sample;

- A third meaning refers to a product or commodity created utilizing the genetic resource - which may be used in the development of further products, innovations or benefits.
This conceptual confusion means that people with different understandings are using this term in negotiations, as if it were clear and defined. Consequently, discussions are at "cross purposes" (non-communicative and unlikely to result in a shared understanding and agreement).

At the substantive level, the whole discussion of derivatives stems from a static understanding of the term genetic resources. The use of a non-static approach (see options iii and iv, in 4.2.1) would essentially eliminate the need for a derivatives discussion, since each use, whether direct or through another interim product, would be separately evaluated as a possible "utilization of genetic resources." If the Parties ultimately decide to utilize a more static definition, then the derivatives question must be fully resolved, beginning with a clear and shared definition of "derivative."

286 See for example Fowler et al., 2004; and Chambers, 2003, 318-320. 


\section{Applying Concepts of Valuation and Equity to Genetic Resources}

Issues of valuation and economics are expressed indirectly in the $\mathrm{CBD}$, through the requirement that the level of benefit sharing should be "fair and equitable." In general, the details concerning valuation and equity in $\mathrm{ABS}$ are determined individually at the contractual level, in cases where a contract has been obtained. Systemically, however, the obligation of fair and equitable sharing goes beyond that - it is one of the three primary objectives of the CBD. "Equity" is a sweeping concept, but is clearly derived from and connected to the concept of "value" (not only monetary value but other value as well). From the user side, questions regarding the "equitable share of benefits" involve four issues:

- Valuing the "benefits arising from the utilization of genetic resources" and the contribution that the genetic resources have made to the creation of that benefit, including a variety of approaches to valuation (discussed at 5.1-5.3);

- The fairness issues - balancing the equities of the transaction (discussed at 5.4);

- Broader equity and public interest issues (discussed at 5.5); and

- The interconnection between valuation, equity and the public interest (discussed at 5.6).

\subsection{Valuing "benefits arising"}

The primary determinant of the benefit-sharing obligation is the creation of a benefit through genetic resource utilization. Even after one solves the immediate problems (What is a benefit? and when does it arise?), the notion of "equitable benefit sharing" suggests that the system must have a dependable system for valuing the benefit arising from genetic-resource utilization. After this issue is addressed, the second step is determining an appropriate and equitable share of those benefits attributable to the genetic resources.

As a practical matter, value of the benefits
Each of these issues must be considered in determining what constitutes an "equitable share" for the provider of the genetic resources. Non-transparency regarding value as applied in ABS, coupled with the long delay between most ABS transactions and any direct benefit sharing, has led to a situation in which negotiations are fairly random in setting the specific amounts to be paid as "benefit sharing" under ABS contracts. From the user side, another challenge is determination of an "equitable benefit share" where no ABS contract has been obtained. In addition, of course, a contract can be challenged for lack of fairness, as well as for procedural and substantive deficiencies.

This chapter considers the need to understand value factors as another layer of complexity in the process of creating and administering benefit-sharing legislation. In addition to the Chapter 4 tasks of (i) determining what "genetic resources" and "benefits arising" are, and (ii) integrating that concept into a system for triggering the benefit-sharing obligation, it still remains necessary to have some idea about the value they represent and to integrate that understanding into the difficult process of equitably sharing the benefits arising from utilization of genetic resources. This issue of valuation and equity forms a critical link to the other objectives of the CBD conservation and sustainable use - without which there is no justification for an ABS system.

addressed in ABS contracts and legislation occurs in one of two steps - either by pre-estimating (leading to an agreed amount for benefit sharing, which can be paid early in the ABS relationship), or by waiting and valuing each benefit, as it is received. In general, the pre-estimation and pre-payment process can happen only where there is an ABS contract or other agreement - currently, there is no basis in the CBD or elsewhere for unilaterally choosing and imposing a set value on either Party. Consent to a specified payment as full or partial satisfaction of the benefit-sharing obligations must be reflected in MAT. 
Usually, one or both parties to an ABS contract will prefer to use such pre-agreed estimates as a method of concretizing the benefit-sharing element of the ABS contract. Even where the parties agree to wait for results before determining how benefits shall be shared, the means of computing that share will be decided in advance, through either negotiation or the source country's law.

On the user side, where there is a contract and it was fairly negotiated, the contractual result will usually be controlling. Legislation will be needed address economic valuation of the benefit received, only (or primarily) in situations in which the user did not obtain an ABS contract. These tools will also be used where it appears that either the user or the source did not participate fairly in the negotiation process.

Given the variety of different kinds of results, outcomes and outputs that may be "benefits arising" from genetic-resource utilization, the valuation question can be difficult. The particular source of that benefit may be a specific genetic resource, which has value to a particular country or community based entirely on its potential to produce ABS benefit sharing. In those cases, an altruistic researcher who blithely publishes and shares his results will have effectively converted the value of that genetic resource from ownership (or potential value) held by the source country to global ownership benefiting the entire planet at the expense of that source country. ${ }^{287}$ If he has done this without the approval of the source country, he may earn their wrath, in the form of a claim based on the value of the lost benefit-sharing opportunity. Thus, the determination of the source country's fair and equitable benefit share may, in many cases, be closely linked to perceived value of the genetic resource.

\subsection{Excludability and the value of genetic resources}

The valuation process in ABS is very complex. To understand it, we must begin from the premise that "genetic resources" are something more than simply the raw materials of biotechnology. ${ }^{288}$ Within the $\mathrm{CBD}$, the specialised legal right to utilize genetic resources was created as a mechanism for integrating a variety of linked objectives and rights (ABS), through a legislative and contractual system.

Analysis of this valuation question must begin very basically, by considering how genetic-resource value differs from the traditional kinds of value accorded to "biological resources" throughout history. Variations in "genetic value" of such resources was traditionally thought to depend primarily on the physical "quality" of the particular material being transferred - the value of one kilo of grapes is much higher when the grapes are of the type, quality and condition that enable them to be used to produce champagne - much lower when they can only be sold for consumption as "table grapes." Economic advantage in regard to grapes was sought by improving relevant qualities (breeding new varieties, choosing vineyard sites, developing soil treatments to improve the quality and amount of the harvest, etc.). Value to the vineyard owner or other dealer was based on a combination of factors - primarily, the amount of material produced and sold, and the price obtained.

By contrast, the use of a grape variety's "genetic resources" may depend on none of these qualities. Particular genetic or biochemical data or material may be valuable as "genetic resources" where it is linked to properties that can be used or replicated in other ways. Their value may depend on either or both of the elements described in 4.1 - the micro-physical genetic material and the genetic information it contains. Whether these components are utilized individually or together, the "utilization of genetic material" is recognized to confer a different or additional value beyond the "bulk value" of the particular biological resources, and does not depend on the ripeness or other physical condition of the vineyard's entire production.

\footnotetext{
287 See, Mgbeoji, 2006, discussed in more detail in 4.2 and 4.3, above, especially footnotes 261, 266, 277 and 281.

${ }^{288}$ McAfee, 1999, p. 146, with further references.
} 
The value of "genetic resources" must be discussed in the perspective of both drawing benefits from using the units of heredity (micro-physical material) and utilization of the genetic information that they contain. Valuation must target the new resource value, separating the bulk value of the bio- logical resource from the value of its tangible and intangible genetic resources. This would include, for example, DNA sequences and biochemical formulas, whether contained in whole specimens, prepared samples, extracts, or written scientific notation or descriptions.

\subsubsection{Genetic resources - as excludable or non-excludable goods?}

In order to understand value of "genetic resources" it might be useful to look to economics and pose the question of what type of "goods" a genetic resource is. Economic theory establishes a distinction between excludable and non-excludable goods. ${ }^{289}$ An excludable good cannot be used by more than one person at a time. ${ }^{290}$ Most physical goods are excludable, for example, no one else can eat the apple you have just eaten, and in normal circumstances only one person can effectively use a laptop at any given time. A non-excludable good can normally be used or consumed by several people at the same point of time. This is often illustrated by the following quote from Thomas Jefferson: "[h]e who receives an idea from me, receives instruction himself without lessening mine; as he who lights his taper at mine, receives light without darkening me". ${ }^{291}$ Other people's access to an idea or innovation does not reduce the original holder's use of it. For instance, one person's reading a novel does not limit the ability of others to read and fully enjoy the same story. However, each physical copy of the book is distinctly excludable as only one person at a time can read that copy.

Whether a genetic resource is excludable or nonexcludable depends in part on how easy it is to utilize it and/or exercise a legal right to it. This is an important construct to help understand how national legal systems can be designed to enable source countries to capture an equitable share of their value. Systems for capturing the value of specific physical goods are generally simpler and more easily regulated than those which govern non-excludable goods, such as ideas and non-patented innovations. It will be easier to transform the value of non-excludable goods into a commercial return if there is a legal institution making them valuable.

Physical goods, for example, are excludable, in the sense that they have a finite level of usability. As a practical matter, they can be considered either owned or un-owned. An owned resource's excludability is linked to a particular person or entity - its owner. If the resource is movable, its excludability is protected by the owner physically - locking it or storing it in a location under his control or supervision. Non-moveable resources (real estate) are protected by registration or other systems to secure the property right. Legal ownership does not prevent others from using the resource, but it does provide a legal right to do so. An owner may use legal process to recover moveable property that has been taken from him, even if that property is in the control of another person; he may also use the law to remove one who is occupying physical property that he owns. Un-owned physical goods are excludable by either (i) being converted to individual ownership, or (ii) being used. Thus, the air we breathe is generally un-owned; however, only one person may breathe a specific volume of air at a time. Companies which fill and rent air tanks for SCUBA divers temporarily convert some air into an owned resource, by taking it to fill pressurized tanks.

National law may have the deciding impact on whether a particular good is owned or un-owned. The clearest example of this is fresh water. In some countries, freshwater resources are un-owned. Where surfaceand ground-waters are plentiful, for example, they are usually un-owned - any person may take and use

\footnotetext{
289 See for instance, Waldron, 1993, printed in Chisum, 1998, 48-49, where the terminology "crowdable" and "non-crowdable" is used.

290 Ibidem.

291 Thomas Jefferson, quoted in Chisum, 1998, 6. It is notable that "ideas" are not "goods" for these purposes, unless/until they become innovations or otherwise capable of being transferred and/or made excludable.
} 
them. Water companies may convert unowned water to an owned good, by distributing it through drinking water systems, or selling it in bottles as mineral, filtered or purified water. Where water resources are less abundant, however, rights to use water may be subject to restrictions - they may be, in effect, owned (controlled) by government until private entities obtain a right to own some of it, by complying with relevant controls. This enables government control of water use to ensure that critical water needs (irrigation, energy production, etc.) have priority over new residential developments or other land/water uses. ${ }^{292}$

As noted in the Jefferson quotation above, ideas are a classic example of a non-excludable resource, but only after they are shared. Shared ideas and knowledge can be applied by many persons simultaneously without reducing the use by others. Consequently, the primary way that ideas can be protected (and others excluded from them) is by keeping them secret. However, to encourage the development of ideas, it has been necessary to provide a means by which they may be made excludable even after they are shared with the public. Through this type of exclusion, research and development can be an economically desirable choice, giving the holder an (excludable) right to reap the initial value from his intellectual products. The intellectual property regime, particularly the patent system, was originally designed to establish exclusive rights to certain non-tangible products of intellectual work, as a means of encouraging intellectual development and enabling it to be shared and developed while still providing valuable rights to the creator of the idea.

Functionally, this system works as follows: The inventor describes his invention in a formal written application and by the grant of a patent that invention receives a time-limited property-right protection with regard to the invention, as described. During the term of the patent, the inventor has a specific legal right to exclude other uses of his innovation and/or to control such uses in a way that earns him a return on his work.

All of this raises the primary question for this book - Are genetic resources excludable or non-excludable? This question may have different answers depending on which of the two aspects of the geneticresource concept (micro-physical or intangible/informational) are primary in each situation.

\subsubsection{Excludability of the micro-physical element}

When considering the micro-physical genetic material, the excludability discussion should be considered at different levels. In order of specificity those levels are:

- Individual gene;

- Gene sequence;

- Expressed characteristic (enzyme, protein, etc.);

- Genome (variety or subspecies);

- Shared characteristics (within a higher taxon).

At the level of an individual gene, excludability would seem to depend on how the gene is linked to the characteristics of the biological specimen from which it was isolated. Each gene is linked to a variety of different characteristics. In some cases, the particular gene will be interesting because it comes from an extraordinary specimen of the species/variety. For example, genes may be taken from a particular sheep which has a natural immunity or susceptibility to malaria. The value of an isolated gene linked to that immunity/susceptibility will be based on the quality of the specific animal. At the beginning of the research, this gene will probably be a completely excludable good, since the owner of the animal will have absolute control over its utilization. Over time, however, the researcher may multiply the genetic material or reproduce it in another animal, raising questions about the continuing excludability of the good.

292 FAO, 1995, "Forest Management Legislative Development in Tonga" (FAO) (control needed to prevent negative environmental impacts to the island hydrological system, caused by unrestrained water use). Similarly, current discussions of "payments for environmental services" focus on the use of incentive measures to minimize up-gradient water use in countries whose laws consider water to be an un-owned resource. See PerrotMaître, and Davis, 2001, "Case Studies of Markets and Innovative Financial Mechanisms for Water Services from Forests" (Forest Trends). 
Genetic research, however, focuses on genes based on the species/subspecies/variety of the source specimens. A gene present in the entire taxon would seem non-excludable unless a single owner, government, or other entity has control over all members of that taxon.

This is not a "bright line test" however - there is no clear distinction between shared genes and completely individual genes. Typically, there will be a gradual transition between the genes that exist in many organisms and are completely non-excludable, for instance the gene that codes the color green in spruce trees, to the genes that are excludable because they are more limited, such as genes in a species that is threatened by extinction, or those linked to a particular characteristic (i.e., particular birch trees that despite wind and weather have remained standing and over time have genetically adapted themselves to the climatic conditions of even the most windswept fishing villages in Norway). In other cases, specific mutations might exist in only a smaller number of organisms, increasing the chance that the gene itself will be an excludable good.

A significant amount of the work that is considered to be the "utilization of genetic resources" involves direct utilization of extracts of materials such as enzymes and proteins that are expressed by a particular species. Analysis of the biophysical properties of the poison in a tropical frog is essentially study of a higher level of microphysical material linked to the hereditary characteristics of the species.

At the level of least specificity, many geneticresource uses are posited on the qualities shared by the entire genome, or the inheritable qualities of an entire organism (the particular plant, animal, fungus, etc.). This type of research, again, may be excludable or non-excludable, based on whether the particular objective is to utilize an individual specimen's uniqueness (breeding one's mare to a famous racehorse, for example, in hope of replicating the stallion's special characteristics) or to harness the qualities of the entire variety. The genetic resources of the stallion are essentially an excludable good, controlled by its owner(s). The use of the genome is more commonly considered under ABS principles, however, with regard to variety development and the use of traditionally developed or locally isolated varieties. In these cases, the excludability will depend on how widely the rights to particular kinds of use of those gene resources are held. If all in the community have the right to breed or authorize the use of the variety, then it may not be excludable unless the community has agreed to control such uses by others. The more broadly these rights are disseminated, the less chance that sufficient control will be possible to render the genome to be an excludable genetic resource.

\subsubsection{Accessibility of intangible or informational element}

Another aspect of the excludability of genetic resources relates to the intangible element - the information contained within the species. This information must be generated or decoded through human action. Given that several persons can possess the same knowledge without excluding others from it, knowledge about genetic information is typically a non-excludable good. In general, if non-excludability does not discourage people from working on the species, the chance for a more rapid development may be higher for nonexcludable goods than for excludable goods. The information element of genetic resources may possess "effective" excludability in certain instances, depending on the accessibility of the information or the ability to un-code or identify that information.

Generally, genetic information is manifested in many ways. One aspect is the genome and species data, when rendered in informational form (as gene sequence, biochemical formula or other document or image). Much of this type of information is only excludable to the extent that (i) the biological source material is difficult to obtain, (ii) the scientific process is prohibitively costly, or (iii) the analysis can only be done in a special laboratory, to which access is limited. In any species, each gene or combination is 
linked to many different characteristics of the specimen, ${ }^{293}$ or coded to particular enzymes or proteins. Identifying the particular gene linked to particular characteristics is a more specialized study. Increasingly, the capacity to identify and decode genetic information is common, found in laboratories around the world. This suggests that most kinds of genetic data can be obtained by anyone ready to do the work and expend the necessary resources. Hence, isolation of a gene or its linked characteristics may not be a basis for excludability.

Intangible genetic resources are more excludable when they require more than standard analysis. For example, analysis may focus on questions about how genes work together to bring out various abilities in an organism. When seen as biophysical commodities, genes might be more excludable, both in fact and in law.

Another kind of knowledge that is often very important in bioprospecting is information about the physical properties of the organism. For example, it is common to screen plants, insects and other organisms for pharmacological properties. Other kinds of analysis may focus on the particular way in which those properties function or are manifested in the species. The excludability of these analyses again depends on the accessibility of specimens, on access to necessary processes and facilities and on the fact that there are many such potential inquiries. It is not common for two researchers working independently to focus on the same questions about the same species, using the same analytic processes.

\subsubsection{Patents as measures to convert non-excludable resources into excludable ones}

The objective of extending patentability to living matter, including genes and entire varieties, can be understood in light of these excludability questions, to provide a system by which users can capture the value of their discoveries and innovations, rather than depending on possession (or similar physical control) and secrecy. Through patents, users seek to establish exclusive rights. In many cases, this exclusivity itself is the primary benefit arising from the user's activities. For the ABS system, however, it is also notable that the patent system's ability to provide exclusivity may increase the attractiveness of genetic research and development, offering the user time to recoup his costs before others begin using his innovation.

The ABS mechanism under the CBD is meant to create a value for genetic resources, by sharing benefits arising from the utilization of this mostly non-excludable resource. The task of the ABS system is to create a manner in which to give value to the genetic resource and share it appropriately so that source countries do not feel a need to block access or limit the exchange of genetic resources in an attempt to make them excludable and thus valuable.

\subsection{Approaches to valuing the contribution of genetic resources}

The uncertainty of valuation in the ABS process has generally caused CBD Parties to avoid the valuation discussion, possibly to protect their position in future negotiations of individual ABS arrangements. At the same time, however, the lack of transparency regarding valuation of genetic resources, in general and in specific contracts, has been a major factor contributing to the complexity and difficulty of ABS negotiations and documentation in developing countries. Clear standards for valuation and sharing would serve two primary purposes:

- to alleviate misunderstandings and unrealistic expectations of both providers and users; and

- to provide a concrete basis for the implementation of user-side measures, including especially in determining the obligations of a user who has not

293 One of the most important results of the Human Genome Project was the discovery that there are not sufficient number of genes or gene combinations to reflect all of the characteristics of Homo sapiens. One of the ineluctable conclusions drawn was that each gene is linked to multiple factors, and that other factors (besides) genes may also be involved. Commoner, 2002. 
obtained an ABS contract with the source country.

This section considers two approaches to assessing the value of genetic resources: "similar contracts" and "alternative value." It also considers the challenge of valuation timing, another issue in genetic-resourcebased relationships.

\subsubsection{Using prior contract data for valuation of genetic resources and negotiation of benefit share}

At present, most processes for valuation of genetic material occur in the context of contractual negotiations between the user and the source country (or the agency, community or individual given the authority to engage in these negotiations). Although some commenters have strongly stated that private contracts are the only solution needed to address and solve all ABS issues and problems, without any need for national legislation, ${ }^{294}$ practical evidence and analysis have indicated that this is not the case. Even apart from the obvious commercial legislation needed to clarify and enforce each ABS contract, both in user and provider countries, ABS must also provide tools for contractual valuation. The need for accepted methods of appraising the value of genetic resources for contractual purposes becomes obvious when one remembers that, in most countries, genetic resources are considered to be public goods, managed under the oversight of the national government. Consequently, some mechanism is necessary to assure the negotiating government official that he is getting fair value for a public resource which he is sworn to preserve and use in the best interests of the country and its citizens.

One traditional method of value appraisal applies directly in contractual negotiations. This method is derived from comparison of the values of similar property in similar transactions. Professional appraisal standards ${ }^{295}$ governing this type of valuation system use special characteristics of these "similar transactions" to provide a market-comparison estimate (range) to help guide negotiations and expectations regarding the contractual price for this resource. ${ }^{296}$
To create and apply an appraisal system in ABS, it will be necessary first, to develop or adjust appraisal standards so that they can be applied to this specialized category of goods. Most important, however, the use of this mechanism for valuation would require, as an essential element, a high level of market transparency. A large percentage of $A B S$ contracts negotiated to date are confidential despite the fact that the genetic resources that are the subject of the agreement are a public resource, administered by a government official. Sometimes, although other contents of the contract may be disclosed, the Parties are not permitted to disclose the financial elements. The resulting market opacity has several obvious results:

- Source countries and their negotiators often have unrealistic expectations of the value that they can realize through the $\mathrm{ABS}$ transactions;

- Parties with limited experience of other ABS transactions may be encouraged to accept inappropriate (too high or too low) payment as the user's benefit-sharing obligation. ${ }^{297}$

The current lack of market transparency may appear to some users as an opportunity, but will also continue to foster unrealistic expectations and ultimately contribute to the high level of legislative and negotiation complexity for those seeking ABS contracts.

Transparency about prices and financial terms will enable the development of professional appraisal standards, which can ease contractual negotiations.

\footnotetext{
294 See, e.g., Scott, 2005.

295 There are many levels of professional standards addressing financial appraisal of various kinds of properties in various contexts. One example that is currently widely available is Parnham and Rispin, 2000, Residential Property Appraisal (Spon Press).

296 Tosh and Rayburn, 2006.

297 One example of this was an offer to Namibia - the user offered to pay the country US\$ 5,000 for the right to inventory and take samples of all wildlife in the country. Wynberg, 2002.
} 
This will not be an easy task, of course, given the many different types of genetic resources, categories of uses, objectives of users, and situations of source countries. According to economic theories, price setting in a free market is based on identification of a specific set of common assumptions that are not easily found in the context of genetic diversity. Few generalizations can be made about the "consumers" (users) and "providers" (sources). Principles of supply and demand suggest that users may find it easier to walk away from the negotiation, given the non-exclusivity of the resource - a situation which may create price competition (coined a "race to the bottom"298) among sources. It has been noted that the "[c]urrent form of contractual approach is leading to low value of individual transactions and not to full valuation of environmental services provided by biodiversity." 299

Perhaps most important, where public goods (genetic resources) are disposed of through private contracts, equity and $\mathrm{CBD}$ objectives will not be supported by commercial practices. Private negotiations rarely, if ever, reflect the interests, needs and values of the society or community.

\subsubsection{Valuation using the "alternative value" method}

Another approach to understanding the value of the genetic resource, which may be particularly useful, is the question of alternative value - that is, building valuation on the basis of the value of the currently-used resources and processes, which the genetic resources will replace. In essence, this process builds the evaluation of one component of the final product by starting at the end - with the ultimate market price of that product. From this price, the user subtracts the value of other inputs (ingredients, research, processes and development, etc.), as well as a reasonable return on the investment, leaving the value of the input. This value is then used to determine the source country's "equitable share" of the total profit.

This approach can be rephrased in the form of a question asked at the point at which a final product or result is obtained: What would the value of the product have been, without the genetic resources? This question emphasizes the need to link valuation to the results derived from the utilization of genetic resources rather than to access.

This approach determines the value of the genetic resource at a much later point in the utilization process. As a result, it alters the composition of the value formula. Where value is determined at the point of bioprospecting, a very large percentage of that value is speculative - potential value. ${ }^{300}$ After screening, the balance between "potential" and "apparent value" shifts, with those specimens which do not display the sought-after characteristic dropping in potential value, without increasing apparent value. For genetic resources that pass the screening, however, the apparent value increases, becoming a higher proportion of the resource's total value. At the time the product is developed, the value of its genetic resources will have almost completely shifted to the "apparent value" side. Taken as a whole, however, it is not clear whether this shift (from many specimens with an estimated potential value to the final value of the one genetic resource which has been sifted out) will increase or decrease the "value of the genetic resources" in a particular ABS transaction.

One difficulty with any recognition of the alternative value approach, however, is the tacit acceptance of current approaches to the "relative value" of biodiversity as compared with technology. Unlike genetic resources, the contributions of technology and industrial development have been well recognized, and the recognition is

\footnotetext{
298 Vogel, 2007.

299 Fernández Ugalde, 2005.

300 In bioprospecting the chance of a hit in random screening may be low. Estimates of the "hit-rate" vary. The probability for finding the useful gene undertaking random screening for pharmaceutical use has been estimated to be between 1/6000 and 1/30000. Lesser, 1998, page 71, with further references. All sources generally agree, however, that industry needs to screen, test and research a large number of samples in order to get one hit. This low probability is often used as a main argument for concluding that genetic material is valueless or of very low value. Lesser (1998) has suggested that the value of genetic resources could correspond to the probability of finding a useful gene.
} 
reflected in the financial value and monetary return. Methods exist for estimating value of technology, whereas no means of valuing biodiversity has been generally accepted. In today's society, technology is highly appreciated and has been given a high valuation estimate. A low estimated or perceived value of genetic material removes the punch from the arguments in favor of ABS, suggesting that there will be few (or no) potential benefits to be shared. Overall, there are repeated claims that the value of genetic resources is insignificant. ${ }^{301}$ These low estimates become the ammunition for the biotech industry's arguments against regulation of rights to genetic material and benefit sharing. ${ }^{302}$ Conversely, some of the same commentators present figures illustrating that value created from biotechnology is high, to justify their claim that developed countries should refrain from imposing benefit-sharing obligations. ${ }^{303}$

Legal and practical institutions and mechanisms must recognize that value-creation in sectors using genetic resources is substantial and increasing. ${ }^{304} \mathrm{On}$ the other hand, the "alternative value" method generally fails to adequately reflect social, environmental and equitable elements of the value of the genetic resource factors that are critical to the determination of the source country's "equitable share" of benefits.

Beyond these rather theoretical discussions, there is need from a practical point of view to develop more specific methods for calculating a fair and equitable benefit share.

\subsection{The fairness requirements - fair sharing and equity}

The primary user-side obligations in Article 15 are directed at a specific result - "the aim of sharing in a fair and equitable way the results of research and development, and the benefits arising from the commercial and other utilization of genetic resources..." 305 This mandate highlights the two equitable aspects of the benefit-sharing concept - fair sharing and equity. While all the issues discussed in the first five chapters of this book are essential for the functioning of the ABS framework, that framework can achieve its true objective only through this "fairness and equity" element.

ABS was not created with the objective of establishing a well-functioning international market for the negotiation and sale of resources based on commercial contracts. If that had been the negotiators' intention, it would have been created under the global trade regime, perhaps as part of the WTO family of instruments and processes. Moreover, if that had been the intention, the problems, costs and obstacles that have prevented
ABS from full and effective operation through the past 15 years would probably have caused the abandonment of the concept, rather than a redoubling of efforts to make the system become functional.

Rather, the goal of ABS is the creation of a system by which countries which have conserved and provided access to their genetic resources and the ecosystems that foster them can receive a share in the value that is derived from those resources, and a lingering incentive for continuing to conserve their resources and use them sustainably. By utilizing a commercial tool (contracts between source countries and users) the Parties sought to make this sharing direct. However, in this choice, the Parties also created a need for legal provisions and standards to enable all users (and providers/sources) to know what is required - and especially to know when the arrangements they make will meet the required standard of "fair and equitable" sharing. The CBD assigns the responsibility for oversight of this standard to the country

\footnotetext{
${ }^{301}$ Hirsch (2005), for example, argues that: "We need to get past the green gold expectation." One of his points is that "Perhaps there will be a few blockbuster drugs created that will make fortunes for the lucky country of origin of the original substance, but most new products are not the results of a single gene expression."

302 Hirsch, 2005.

303 See Wolfe and Zycher, 2005; and Finston, 2005 (with further references).

${ }^{304}$ Hodges (2005) refers to sales of only marine biotech products, estimated at some US\$ 100 million in 2000 (with further references). Wolfe and Zycher (2005) also presents figures that value created in biotechnology is high.

305 CBD Article 15.7, italics added.
} 
with jurisdiction over a user - to ensure that such a user behaves in a fair and equitable way, and to seek to promote an equitable and balanced approach by other (source) countries in dealing with users.

The following sections consider the practical and legal questions relevant to developing user measures that embody and promote -

\subsubsection{Practical issues - legislation to ensure}

As described in earlier sections of this chapter, the task of valuing the benefits arising and the contribution of genetic resources to those benefits is not a simple matter of applying a formula. Even after these values are understood, it is necessary to develop and apply two additional steps - the process of determining the "fair share" that should be paid to the source country, and the process of determining how (in what form) that share should be paid.

\subsubsection{Determining a fair share}

The "fair share" concept has not been well examined in commercial, scientific, contractual or legal terms. In most cases, in addition to the genetic resources, the activities that utilize genetic resources involve a great many other kinds of inputs, including the other ingredients and properties that are combined with the resources, the processes that are applied, the investments of capital and time, and especially the technical development and innovative work. In addition, many products of genetic-resource utilization actually involve more than one genetic resource. As a matter of law and administrative practice, it would be difficult to develop a mechanism that weights all of these different types of contributions and determines what share of the profits or other results is attributable to any one input.

Legislation can provide some standards and other bases for evaluating the concept of fair sharing. Given the multitude of possible inputs, however, any such standard will probably be a simplification to provide a guide for courts and agencies dealing with users who do not meet their basic $\mathrm{ABS}$ requirements through an agreement with the source country. In practice, fair-share provisions will usually depend on the concrete situation between the parties, often expressed in a contractual agreement. It is important to remember
- fair sharing - determination or evaluation of the fair share that should be paid to source countries under ABS legislation;

- equity - reflection of the contribution and needs of source countries; and

- practical application of these concepts - balancing of equities, objectives, benefits and responsibilities.

\section{"fair sharing"}

one other aspect of the equity principles - their usefulness as guidance for courts, arbitrators, officials and others seeking to determine a "fair share" where there is no agreement among the parties, or where that agreement was not fairly entered into.

\subsubsection{2 "Sharing" intangible benefits}

One issue of concern with regard to the establishment and application of standards governing the sharing of "benefits arising from...the utilization of genetic resources" derives from the fact that some of those benefits - the results of research and analysis - may be non-commercial and intangible. Like the genetic resources themselves, once they have been shared outside of the research institute in which they are developed, research results and analytical conclusions are non-excludable. Thus, there may be no way to partially share these results - unless the parties (directly or through the development and application of legislative/equitable standards) can either (1) define a way of valuing sub-components of research or of determining what level of information is a sufficient "share" to compensate the source country or (2) set limits on what the party receiving a share in the research results may do with those results.

One way of looking at this concept would be to approach it in stages, determining the source country's share at each stage, according to two factors:

- the relative contribution of the genetic resource as compared with other inputs at this stage of the process or activity; and

- the difficulty or risk involved in sharing results or conclusions. 
This approach is built on the view that the source country's right to information can be restricted as necessary to ensure that both user and source receive a fair balance of value, in accordance with their contribution. It recognizes that, at the collection and initial analytical stages, the source country's inputs constitute a much higher percentage of the total of all inputs, than at later stages in the $\mathrm{R} \& \mathrm{D}$ process. Under this thinking, the user can restrict the sharing of later-stage research results, either by placing restrictions on the use of shared information, or by communicating only particular portions of those results.

This approach breaks down in some cases, due to two other factors - the importance of the genetic resource, and the interests of the source country. In some applications, the genetic resource and the research results it generates constitute only one part of a product development process. It may contribute one means of solving a particular $\mathrm{R} \& \mathrm{D}$ problem. In those situations, the "relative contribution" approach would provide a clear basis for determining the user's rights. In other situations, however, the entire process only exists because of the genetic resource. For example, research examining the peculiar characteristics of the poison in the skin of the Tricolor frog would not have been undertaken, but for that particular genetic resource. Although the user contributed significant effort to the development of the information, one cannot at any stage consider the contribution of the genetic resources to be minor, given their importance to the entire work, even at the point at which the research focused on synthesis of a new chemical that possessed the special properties identified by the research. Looking at the contractual situation, if the frog had not been available, there would not be any prince (product) from it.

Beyond this, when fair-sharing principles are applied to informational components of the research, those principles sometimes make "standard assump- tions" regarding the interests of the user and the source country, because the nature of the user and his objectives may differ widely across cases. A commercial user engaged in $R \& D$ may have a strong interest in maintaining confidentiality of the research results, analysis and other information, in order to ensure that competitors are "excluded" from use of this data. In this case, the interests of the source country and the user are very similar. If the source country has a right to receive a "benefit share" in the profits from the new innovation, it will want to ensure and maximize those profits, including by excluding others from using the information. In these cases, the justification for delaying the sharing of data is practical - the fewer individuals who have access to the data, the less likely that one individual will "leak" the data to another user (valuing his own interests ahead of the organization's or the company's).

Where research is undertaken or used with no commercial purpose, however, the researcher's altruistic motives may be at odds with the country's perceived "best interests." The user who publishes data for no commercial gain ${ }^{306}$ has decided to give the information about the particular genetic resources to the world. In effect, his action eliminates any possibility that the source country may receive a benefit-share, other than its microscopic share in the benefit given to the world. While a particular country may agree to this choice, many may feel that the best interests of the country will be better served by finding a commercial user who can convert the source-country's interest into a larger share of more concrete benefits. ${ }^{307}$

\subsubsection{Forms of payment}

The other element that affects the fair-share question is the form of payment. In practice, up to the date of this writing, relatively few benefit-sharing contracts call for payment a specific share in the user's profits, patents and other benefits. This type of payment (called a "royalty" in publishing and other industries)

\footnotetext{
306 In many cases, the particular researcher will gain notoriety, points toward academic tenure, or other non-sharable benefits from the publication.

307 The Tricolor frog case (Mgbeoji, 2006) particularly illustrates this principle, since the information that was published with no commercial return was later used by a number of pharmaceutical companies in patented synthetics. This also illustrates the value and impact that the patent system might bring to source countries. In essence, the user's patent constitutes a way of preserving value for the purpose of maximizing the source country's share, however, it must be noted that the system only operates this way when it does not prevent the country from utilizing, or having a say in the utilization of, its own resources.
} 
can be relatively difficult for users, who will be required to undertake very strict accounting processes, in order to provide accurate and auditable records of all of the factors that must be considered in determining the share to be paid. Such limits may restrict the ability of the user to engage in other contracts.

Similarly, larger user companies and institutions are often willing to postpone results - where for example the research results create a usable/patentable discovery or innovation, but the company feels that other technical innovations in future will improve the profitability or effectiveness of its practical application. In those cases, although a patent may be filed, little or nothing may be done to utilize the patented concept for many years (if ever).

As a consequence, it is common for $A B S$ contracts to "liquidate" the benefit share, by identifying other forms of payment which, when made, will constitute a current substitute for the direct sharing of benefits which would otherwise come over a long and unpredictable term, might not be sharable at all, or might be delayed by the company's strategic decisionmaking. The Bonn Guidelines identify a long list of possible forms that such payment may take, ${ }^{308}$ including

\section{- monetary payments}

Payments of money often occur in the form of up-front payments, milestone payments, royalties (as described above), license fees, ${ }^{309}$ "special fees to be paid to trust funds supporting conservation and sustainable use of biodiversity" (a limited form of monetary payment), research funding;

- other forms of concrete, documented payment based on commercial value $e^{310}$
A number of specific rights may have specifically determinable commercial value - for example, the right of participation in joint ventures; ;11 "joint ownership of relevant intellectual property rights," transfers of knowledge and technology and other such legally binding relationships may be given instead of direct share of money or property;

\section{- "non-monetary benefits"}

A number of benefits are entirely outside of the monetary commercial analysis. For example, a contract might simply require direct sharing of research and development results; other access to scientific information; "collaboration, cooperation and contribution in scientific research and development programs;" a general right to "participate in product development, education and training, access to genetic-resource facilities and databases;" capacity building of various types; ${ }^{312}$

\section{- less direct or tangible benefits ${ }^{313}$}

A number of conditions (general improvement of the source country's situation) may be counted among the means of paying for access or liquidating genetic resources, including

a. contributions to the local economy;

b. research directed towards priority needs, such as health and food security, taking into account domestic uses of genetic resources in provider countries;

c. institutional and professional relationships that can arise from an access and benefit-sharing agreement and subsequent collaborative activities;

\footnotetext{
308 Bonn Guidelines, adopted by CBD-COP Decision VII-24.A, at Appendix II.

309 This item ("license fees in case of commercialization") is not clearly stated or explained within the Bonn Guidelines. Presumably either it means that the source country will receive a share of license fees paid to the user for use of the genetic resource or innovation based on the genetic resource (a subcategory of "royalties"), or else it means that the source country will have the right to license the innovation directly or to receive a rebate of license fees for it.

310 These are included under the heading of monetary payment, but are different legislatively, contractually and practically.

311 This item is simply listed as "joint ventures" but is assumed to refer to a participatory interest for the source country.

312 The CBD objectives underlying these activities are discussed in detail in the CODA to this book.

313 These benefits are separated as it is not generally possible to apply them as benefits in this form. Particular concrete benefits may be developed under any of these categories by, for example, (i) specifying a particular activity or payment to contribute to the local economy, (ii) committing to undertake a specific research project; (iii) committing to specific labeling or other actions to provide public recognition of the source's contribution, etc.
} 
d. food and livelihood security benefits; and

e. social recognition.

The acceptability of these types of payments in satisfaction of the benefit-sharing obligation is usually determined by contractual agreement (MAT). Under normal contract law, such agreement is presumed to be a fair share, so long as the contractual negotiations were fair, and all parties have complied with their responsibilities. These concepts are integrated into Article 15 through two requirements - that source countries must give their "prior informed consent" to access, ${ }^{314}$ and that the parties to the ABS arrangement must mutually agree to the terms on which access will be granted and benefits shared. Together, these provisions incorporate the full range of legal principles for fair contract practices, since a country's consent or acceptance of a contract will not be binding if the user concealed information or misinformed the source country representatives in the course of the negotiations.

\subsubsection{Principles and objectives of equity}

In some ways, the concept of equity may provide the most useful guidance on the sharing and benefit aspects of ABS. "Equity" is a concept with many meanings, and with a very specific meaning in law. In some countries based on Common Law principles, special legal rules called "equitable principles" or "equity" exist to ensure that laws are fair, as well as rigorous. It has been argued that by including the reference to equity (a well-known concept in legal circles) in the text of the $\mathrm{CBD}$, the negotiators intended to apply these principles. However, it is also clear that the CBD's general reference would not be sufficient to incorporate the principles from a single legal system or category of legal systems. Rather, the term must be viewed as an indicator of international principles. Hence, in some legal
So long as the negotiations were fair, reliance on the parties' agreement to determine the specific payments and manner of payment is considered to be the best approach to satisfy the benefit-sharing obligation, because it eliminates the need to determine the particular needs, interests, plans and other factors that comprise the source country's perspective on the value of the various kinds of payment.

In legislation and other user-side measures, valuation questions arise primarily where there was no ABS contract or where it was unfairly obtained or where one of the parties has not complied with that agreement. In these situations, the law will have to develop standards, not only for determining the value of the source country's share, but the manner in which it should (or can) be paid. ${ }^{315}$ Such standards also form one critical basis for evaluating the fairness and substance of the ABS contracts themselves in some legal systems.

systems, the term "equity" refers to a well defined form of governmental action, in others, it refers to a concept of social fairness, and in some, it is seen as a branch of morality or even divine justice. In an international legal instrument, its application is less specific but "connotes an aspect of law and legal reasoning." 116

Equity provides an adaptive legal basis for addressing novel concepts, especially those that are more complex, less specific or less concrete than the comparable legal principles. This is possible because equity focuses on fairness rather than specific valuation formulas. In applying equity, it is necessary to move beyond "providing fair value in return for goods provided." One must also consider the factors

\footnotetext{
314 The adjective phrase "prior informed" connotes the main principle of contract law - that the source country should have access to all relevant information before making its decisions. These issues are detailed in Bhatti et al., 2007, Book 4 in this Series, at Part I.

315 Negotiations often focus on finding combinations of benefits which increase the value to the source country, while decreasing the cost to the user. For example, a user might agree to pay $\$ 100$. In the course of negotiations, the user suggests that it could instead give $\$ 50$ in cash, plus equipment valued at $\$ 65$. This raises the value of the payment received by the source country. At the same time, the user may be able to obtain the equipment for $\$ 35$. This would mean that, effectively, the user pays $\$ 85$ and the source country receives $\$ 115$ - everybody is better off. Obviously, the commercial effectiveness of this kind of substitution depends on the actual value of the substitute goods to the parties.

316 Todd and Watte, 2005, Equity and Trusts, at p. 1. (The entire quote reads "The term 'equity' can be used to describe a form of social fairness or branch of morality or even an aspect of divine justice but in the context of modern legal studies the term 'equity' simply connotes an aspect of law and legal reasoning.")
} 
involved in calculating and compensating formal and informal contributions, disgorging unfair profits, equalizing access to the benefits of collectively owned (or developed or provided) resources, ensuring fairness in common-resource distribution, and other aspects of "real justice."

In the opening sections of this chapter, we have seen that it is nearly impossible to value "genetic resources" as specific exclusively-owned property. Consequently, it would be very difficult to speak of a "fair return" on genetic resources. However, the CBD does not call for a "fair return" on genetic resources, but a fair and equitable share of benefits arising from them. This suggests different ways of evaluating benefit sharing, beyond the vain attempt to assign a specific value to a specific genetic resource. Equitable principles might address the sharing question in other ways:

- In some cases, equity might call for a fair return on the historical contribution of a country or community which has, through many decades and centuries, followed practices which, although financially rewarding, resulted in a higher level of conservation and the preservation of traditional varieties.

- Similarly, equity might look at the extent to which a particular product or innovation would have been developed without the genetic resource. If the existence and properties of the genetic resource are the reason that the innovation or product was developed, then its contribution to the final product may deserve a higher share.

- Finally, equity may look at the wider biological contribution that enabled the particular genetic resources to exist - at the need to protect the entire ecosystem over a long time, against many threats, in order for the genetic resources to be available today. This is one of the apparent theoretical underpinnings of the entire CBD framework, and a major justification for its inclusion of ABS.

\subsubsection{References to equity in the $\mathrm{CBD}$ and Bonn Guidelines}

Within the CBD, the use of the term "equitable" cannot be guided solely by one country's legal tradition or even one category of legal systems. Rather, it must be guided by a broader standard, beginning with the Convention's terms, the Bonn Guidelines, and principles of international law. ${ }^{317}$ In the Convention itself, however, the requirement of equity is encompassed primarily through the use of the word "equitable" in describing the overall objective of the Convention, and in specific description of the benefit-sharing and technology-transfer requirements. ${ }^{318}$

The equity concept also appears in the Bonn Guidelines, but only in the context of a source-country question - how benefits should be distributed. Although this is a matter solely within the source country's discretion, the Guidelines recognize the larger equitable objective of the Convention, where they note that -

benefits should be shared fairly and equitably with
all those who have been identified as having
contributed to the resource management, scientific
andlor commercial process, including governmental,
non-governmental or academic institutions and
indigenous and local communities. Benefits should
be directed so as to promote conservation and sus-
tainable use of biological diversity. ${ }^{319}$

For purposes of national and multinational implementation, these two references give little guidance on how the term "equitable" affects the ABS system.

\footnotetext{
317 The Vienna Convention on the Law of the Treaties notes this progression, beginning with article 31.1: "A treaty shall be interpreted in good faith in accordance with the ordinary meaning to be given to the terms of the treaty in their context and in the light of its object and purpose." Articles 31.3 and 32 clarify that subsequent practices and international law are also applied, where the text is not clear on a particular point.

318 CBD, Articles 1 and 15.7. Article 19.2 calls on Parties to "promote and advance priority access on a fair and equitable basis." The term "equitable sharing" also appears concerning traditional knowledge (see $12^{\text {th }}$ Preambular paragraph; Article 8.j), although expressed in hortatory rather than mandatory terms.

319 Bonn Guidelines, Art 48.
} 
However, equitable principles that have already been accepted as principles of international law can provide a partial guide. The following sections briefly summarize those principles and consider the specific ways that "equity" should be applied in user-side implementation of Article 15.

\subsubsection{Internationally recognized equitable principles}

The linkage between the term "equitable" in Article 15.7 and the recognized "principles of equity" familiar to English-speakers ${ }^{320}$ is much less clear in translation to languages other than English, as countries operating under Roman or Code Napoléon systems do not use this term in the same way (or collect the same mix of principles under a single conceptual grouping). ${ }^{321}$ In international law, many principles of equity have been formally recognized, through an ongoing process that considers the relevance of legal concepts across the range of countries, and identifies "general principles of international law." 322

It is clear that international practice includes the application of equity, ${ }^{323}$ particularly where it is specifically incorporated into the text of an international instrument. The capacity of equity to recognize conditions and situations that are not already protected by established legal rights, as recognized by international law, is uniquely relevant to $\mathrm{ABS}$ and to the $\mathrm{CBD}$ as a whole. Although not protected by legal rights, some countries have arguably contributed more than others to the preservation of biological diversity - which is now recognized to be a valuable commodity. Equity would recognize this contribution in the form of a right to share, when the commodity is sold or when someone obtains financial benefit from it.

For purposes of applying the "equity" component of ABS, it is useful to consider the following examples of equitable principles applicable to individual actions that have been recognized in international law, ${ }^{324}$ in terms of their application to ABS: 325

\section{[a] Historic contribution}

One aspect of equity is the recognition of historic contribution: Legal and contractual practices should recognize and recompense one who has engaged in a long pattern of actions that have contributed to the value of a property, right or other good. In the ABS context, this principle suggests that States that have historically succeeded in preserving their biodiversity are recognized as having achieved something concrete. Many states that are highly biodiverse or that are sources

${ }^{320}$ Like nearly all global negotiations, the CBD negotiations were conducted primarily in the English language. While plenary discussions and those in formal subcommittees ("working groups") were simultaneously interpreted, English was the primary language (without interpretation) for the work in many "Contact Groups", "Friends of the Chair" groups and other smaller negotiating bodies in which much of the terminology was developed. In addition, in many instances, interim drafts of various documents and proposals were circulated in English only.

${ }^{321}$ Generally, the same basic principles exist in civil and Roman law countries and other kinds of legal systems, but they are expressed differently and not unified as a separate body of legal thought.

322 The Statutes of the International Court of Justice refer to "the general principles of law recognized by civilized nations" as one of the most relevant sources of law. Article 38 (1) c.

323 Although the application of equitable principles in international law is not as well interpreted as in national and domestic law, they are clearly so applied, without the need for adoption. See, e.g., North Sea Continental Shelf Cases, ICJ Reports (1969) 3 at $48-50$ (developing equitable principles to address issues of maritime delimitation, having ruled that no existing rule of treaty or customary law would apply fairly).

324 The following discussion focuses on equitable principles of private action, which have been addressed in international cases. There are, in addition, a number of other kinds of international principles (those governing the relationship between countries under international agreements so called "public international law" - which are also decidedly focused on equitable objectives. For example, international law generally recognizes a principle of ex injuria non oritur jus - that no benefit can be received from an illegal act - as well as a principle called ex aequo et bono that decisions should be made "according to the right and good." ICJ, Article 38(2) sets this as the primary right and mandate of the court in making its decisions. Finally, it is common in international jurisprudence to discuss or support decisions de lege ferenda - that is, relating to the law as it should be if the rules were changed to accord with good policy. All of these are in essence, equitable principles, as the term "equity" is used in domestic law in most Anglophone countries.

325 Other concepts of common law equity that may be relevant to ABS, and might be applied in future, include the recognition of a commercial responsibility of one party to a transaction. A person may be deemed "de facto (or quasi) fiduciary" if he undertakes certain activities based on another's trust in him. In those cases, he will be held responsible to protect the rights and interests of that other party, particularly where the other party is legally or practically incapable of protecting his interests himself. 
of large numbers of endemic species ${ }^{326}$ find that their industrial and commercial structures and other tools of financial development are less developed than those of the country of the user. Arguably, these two conditions are linked - a country with well developed industrial structures may have created them at significant cost to the country's biological richness. A country that could not (or has chosen not to) develop in this way, has not received a benefit that could have enhanced incomes and livelihoods. Its biological diversity was attained at a historic cost that can now be recognized and compensated under equitable principles.

Therefore, when conserved biological and genetic resources are converted to individual commercial benefit, $\mathrm{ABS}$ concepts and equity may suggest a basis for recompense of that historical contribution. ${ }^{327}$ Most important, this contribution was not focused on the preservation of an individual species, but rather on the preservation of the entire ecosystem and the physical factors that allowed it to thrive. This suggests that equitable principles must consider the conservation of the entire ecosystem, in evaluating the equity side of benefit sharing. This may necessitate a broader scope of valuation of the source country's contribution (as a basis for evaluating the level of "sharing" that would be equitable in circumstances).

\section{[b] Unjust enrichment - quantum meruit}

This principle says that one person should not be able to unfairly take advantage of another's situation to earn a benefit that should belong, at least in part, to that other person. As an example, consider a farmer

\subsubsection{Practical implications of equity in $A B S$}

The only legal standard expressed in the ABS context is the obligation that benefit sharing must be "fair and equitable," yet interpretation of even this standard remains in doubt. One approach to this standard is to who, mistaking the location of the boundary between his farm and the next, plants, tends and harvests a crop in a field that actually belongs to his neighbor. On the basis of a law which says that the owner of the farm owns the crops that are harvested from it, the neighbor takes the harvested crop and sells it. Although the law is not broken, the result is unfair the farmer incurred all of the costs and should not pay such a bitter price for his mistake. Equity would either split the profits from the crop, or give all the profits to the farmer and require him to pay a reasonable sum as rental for the field.

Increasingly in the area of genetic resources, arguments of fairness are based on the idea that companies should not be allowed to profit from products based on resources derived from developing countries and local communities without paying or providing other recognition of this contribution.

\section{[c] "Clean hands"}

The "clean hands" doctrine states that a person who has failed to "do equity" cannot use equity as a basis for a claim against another. ${ }^{328}$ In the ABS context, this concept raises an interesting possibility - that the access country's compliance with the "access" side of ABS might be conditioned, either legally or equitably, on other conditions necessary to support access, in addition to specific commitments of the specific user. For example, the ABS contract might include a condition that the user must use the resources only in a country that has fully complied with its ABS obligations - i.e., a country that has adopted user-side measures.

conclude that it has no present meaning, and call for the adoption of new and specific legal principles and mechanisms. ${ }^{329}$ A second option is to recognize the existing body of laws and principles applying and

\footnotetext{
326 Countries that notably do not possess large numbers of species (those that consist primarily of desert and tundra ecosystems) may have an extraordinary share of the rarest of them. See, Windberg, 2004.

327 This view was reflected by the CBD's Expert Group on ABS, which noted that "benefits should be shared fairly and equitably with all those who have been identified as having contributed to resource management, scientific and/or commercial process." Report of the Second Meeting of the Expert Panel, Document UNEP/CBD/WG-ABS/1/2 (2001), para 110. This language was specifically intended to reflect that both current and historical contributions are relevant.

328 See Diversion of water from the River Meuse (1937) PCIJ, Ser. A/B, no. 70 p. 77.

329 See, e.g., Dross and Wolff, 2005, quoted in 5.6.2. or a recent statement in a workshop entitled "Promoting social justice and equity in conservation
} 
explaining these standards, which has been developing over many centuries, and has been integrated into international law, through specific legal decisions and international agreements.

Simply stated, the "fairness" standard has existed in law for more than 3000 years. ${ }^{330}$ National courts, arbitrators and other legal processes were founded on the basic principle of fairness as an objective and over the years have developed a body of laws and principles to clarify and implement that standard. These legislative developments enable those who might be judged under fairness standards to predict with reasonable certainty how those judgments will be decided, and to forestall any action or claim of unfairness (or piracy) by acting in a way that will be recognized as fair. The concept of "equity" constitutes a further set of such principles, which provide a conceptual framework through which the court can determine what amounts are owed to a successful claimant. These principles are designed to meet the goal of "remedying" the injured party - providing value that makes him "whole." For example, if a user has utilized genetic resources without entering into an $\mathrm{ABS}$ contract, principles of equity may assist the courts in creating this relationship post facto.

In most countries, the general principles of fairness and equity exist as a background to all legal action. In addition, however, most countries' laws include specific provisions describing how the basic principles of fairness and equity can be applied to certain situations - particularly to new and/or unique situations. One important result of the "codification" of basic legal principles is legal certainty. Where a person or entity seeks to develop a commercial relationship (whether contractual, legislative or otherwise) on which he can rely, he needs to be able to depend on that relationship and will take steps to ensure its validity. In general, he does this by complying with the rules of law and with principles that assure enforceability.

On the question of legal certainty, ABS presents a number of challenges that can be addressed primarily through accepting some shared understanding of the concepts of fairness and equity. Unless national law clearly delineates some principles and norms on which all $A B S$ parties can rely, the chance that the agreement will be overturned as "unfair" or "inequitable" will be a disincentive to users until reliable standards are adopted. Although ABS discussions of legal certainty have focused on negotiations and regulatory measures of developing countries, standards are also necessary on the user side. Norwegian law, for example, specifically provides that any contract can be invalidated if a court finds it to be unfair, even if the contract meets all standards of an enforceable contract (fair and mutual consent, full disclosure, no fraud, neither party under a disability, etc.). Unless countries agree to certain internationally accepted principles of fairness in the ABS context, both source countries and users will suffer from a lack of legal certainty, should they seek remedies or other legal rights in the user country.

More perplexing challenges arise where the specific source is unknown or does not consent to utilization. ${ }^{331}$ Agreed principles of fairness and equity in ABS must provide a basis for determining how benefits shall be collected and used or distributed. They must also consider the rights of the source who does not consent to the particular use.

within the framework of the CBD" (World Conservation Forum, 18 Nov. 2004) that "we have no idea what 'equitable' means. It is a meaningless concept until the international regime negotiations provide clarification."

330 In fact, the provision of standards of fair transactions, to apply when one party uses or causes the loss of the property of another party, is the basis of most of the earliest codes. See, e.g., the Code of Hammurabi, the full text of which in translation to English can be viewed online at http://www.wsu.edu/ -dee/MESO/CODE.HTM.

331 The CBD specifically provides that the source country's obligation to provide access extends only to access that is obtained for "environmentally sound uses." It is not clear whether or how this provision will apply to utilization and benefit-sharing requirements, however, the nature of the utilization is presumably one element that may be a part of MAT. See, Bonn Guidelines at 44.b. 


\subsection{Broader equities - achievement of the Third Objective}

The valuation/equity analysis also raises a broader concern - the interests of the local, national or world communities. These broader equities are sometimes referred to as "the public interest." They constitute two of the most important building blocks on which the CBD is based - Article 1's listing of the three objectives of the CBD; and Article 3's express recognition of each State's "sovereign right to exploit their own resources [including genetic resources] pursuant to their own environmental policies." 332 Together, these provisions underscore the public's interest in the long-term existence of biological diversity for all purposes $^{333}$ as part of each State's responsibility to conserve and sustainably use biological diversity. ABS would not exist if it were not for these objectives; consequently, any consideration of the operation of the ABS regime must take into account the broader public interests and how they are potentially impacted by the access to, use of and sharing of benefits from genetic resources. In recognizing the value of genetic resources and providing a mechanism for countries to obtain a share of that value, the CBD seeks to create or enhance incentives to conserve biodiversity - as a means of keeping that value intact. ${ }^{334}$ The precise incentive mechanism by which this is accomplished needs to be developed and made functional in a practical way.
No contract or negotiator, even a government agency charged with working in the public interest, can balance the global interest in issues like biodiversity, food security and health - for the simple reason that no one country can support these objectives alone. Few countries (and virtually no communities or individuals) will be willing to give up a right to a commercial or other valuable share in the benefits of utilization of genetic resources, when all other countries (communities, individuals) are receiving shares. As long as ABS processes are commercial/financial negotiations, they will be generally unable to recognize the broader public interests solely by depending on contracts, or on other action at local and national levels. Even at the global level, it is difficult to recognize and balance all types of interests.

This implies a need to rethink the value added to society by the utilization of genetic resources. When uses are guided by broader needs, biotechnology contributes added value to society. ${ }^{335}$ The potential social value created by agricultural, pharmaceutical and other activities that may be considered to "utilize genetic resources" is substantial, and can be of inestimable importance to developing countries, and to the CBD's objectives, if it can be mobilized to enable conservation of biological diversity.

\subsubsection{Preserving diversity - recognizing the relationship between a genetic resource's uniqueness, its ecosystem and its value}

The CBD intended the Third Objective of Article 1 to be a support and incentive to the other two objectives ("conservation of biological diversity and the sustainable use of its components"). The nature of that support and incentive is not yet clearly understood and expressed. At a minimum, it seems clear that ABS cannot achieve this objective through an economic or commercial approach alone, nor through established

332 Article 3 provides in full that "States have, in accordance with the Charter of the United Nations and the principles of international law, the sovereign right to exploit their own resources pursuant to their own environmental policies, and the responsibility to ensure that activities within their jurisdiction or control do not cause damage to the environment of other States or of areas beyond the limits of national jurisdiction." It is supplemented in Article 15.1: "Recognizing the sovereign rights of States over their natural resources, the authority to determine access to genetic resources rests with the national governments and is subject to national legislation."

333 The CBD specifically recognizes the long-term nature of these interests in the 22nd preambular paragraph which notes that the Parties are "[d]etermined to conserve and sustainably use biological diversity for the benefit of present and future generations."

334 This connection is particularly recognized by the US Government through the National Institutes of Health's International Cooperative Biodiversity Groups: "The popular conception of modern bioprospecting efforts is based on the notion that success toward conservation is dependent on major commercial success in drug discovery. In that model, discovery of an important and profit-making drug will generate economic benefits that will in turn make conservation a viable economic action." Rosenthal et al., at 7.

335 Hodges, 2005; Osman, 2005. 
mechanisms of individual equity.

Much of the value of any given genetic resource rests in its unique qualities, rather than the amount of biological material sold. In many types of utilization, only a very small amount of biological material may be required to explore and exploit a species' genetic resources. ${ }^{336}$ Clearly, the value of the genetic resource is not reflected in the commodity cost of buying or acquiring the biological material from which it is extracted or identified. ${ }^{337}$ Thus, the value element that is often ignored is uniqueness. Samples are obtained not for purposes of individual ownership, but to take advantage of the unique characteristics of the species. In essence, the genetic resource user utilizes not only the purchased flower, but the entire species or variety - the functional units of heredity shared by all.

The ultimate issue and basis for the genetic resource's true value is much greater than this. Preservation of a wide diversity of species at the local, national and global levels is a primary objective of the CBD. This must also be a major objective of the users of genetic resources, whose efforts depend on the continued existence of the greatest possible selection of individually unique resources.

In a very important sense, then, the value of the genetic resource is calculated by the value of the diversity of biological resources - the continued taxonomic diversity of species on the planet. The resource utilized in a particular biotechnological process or research activity is not a single specimen, nor even the single species, but the diversity of species, genes and alleles from which it was selected, whether available through direct collection from the wild or by accessing ex-situ collections. The loss of an ecosystem may cause or contribute to the extinction of the one useful specimen or genetic sequence that might someday be the source of a vitally important discovery. The expectation in the negotiations of the CBD was that this value could be maintained by a contribution from the beneficiaries of the utilization of genetic resources, through the mechanism of benefit sharing. The valuation of genetic resources should reflect not only the preservation of the ecosystem from which it was obtained, but the integration of the costs of ecosystem conservation more generally.

Considering the cost and efforts involved in creating the ABS system, it is clear that the value of that system is more than its ability to enable a new kind of financial transaction. The challenge is finding a way to integrate the recognition of the value of biological diversity into the valuation system of benefit sharing. In essence, to answer a key question: How can the value of diversity be assessed?

\subsubsection{The CBD - an obligation to make genetic resources valuable}

In the original CBD negotiations, the ABS element assumed that users in developed countries had the technologies, infrastructure and capacity needed to benefit from the biodiverse genetic resources of lessdeveloped countries. These benefits were taken without providing any return to the source countries whose conservation practices or less-developed status prevented them from obtaining these same advantages. ABS was linked to social welfare and to the fact that less developed countries include some of the most biodiverse (per capita or per hectare) on the planet, countries that thus bear a very high percentage of the direct responsibility for conservation and sustainable use of resources.

\footnotetext{
336 Although sometimes stated universally, this claim is not always true. Some genetic resources have up to now proven difficult or impossible to breed, cultivate or otherwise multiply. Such resources may only be used by bulk collection of biological samples. Meliane, I., "Process Analysis, prospecting for and using marine GR for pharmaceutical purposes" (2003, unpublished).

337 A classic example is given where a buyer purchases a sack of beans in a commodity market in a developing country, but later utilizes their genetic material without obtaining any other permission or paying any benefit share. (This scenario describes an actual case in which the purchaser planted the beans and then patented the progeny of the original beans as a new variety. See, Young, 2006a. Clearly, under ABS concepts, the purchase or other acquisition of samples of the physical commodity does not automatically confer the right to utilize its genetic resources. If the potential right to utilize genetic resources were included in the value of every transaction involving bulk biological material, the resulting high cost and the difficulty in assessing it would put a burden of transaction costs on trade in commodities that these markets could hardly be prepared for.
} 
For practical and equitable reasons, $\mathrm{ABS}$ must be seen not only as a commitment to create ABS, but also as an obligation to make it profitable for developing countries. Hence, if the experiential data on ABS to date indicates that it has not been financially beneficial to developing countries, the Contracting Parties have an obligation to make it beneficial, rather than to drop it as an unpromising concept.

This view is recognized, at the inter-governmental level, by at least some developed countries. For example, the EC has noted the following, as one of the reasons for adopting legislation to implement the
Bonn Guidelines:

The above mentioned CBD objective reflects the need felt by the negotiators of the Convention to ensure that companies and research institutes, located in industrialized countries, are obliged to share the gains derived from the use of genetic resources... this is an issue of equity: the EC should take action because it is fair to do so. ${ }^{338}$

One challenge to the international community is how this can be done from a practical point of view.

\subsection{How economic, equitable and public interest principles inter-relate in ABS legislation}

The ABS concept finds its justification and basis in three often-opposing concepts: equity, valuation and the public interest. In order to build the foundation for the ABS system, it is essential to examine the nexus of these three principles. Together they pose a legislative challenge - to design a commercial or contractual legal system that can function while still serving the public interest. Stated alternatively, countries need to create public interest legislation that is implemented through commercial concepts based on valuation, while reflecting equitable principles.

Although our discussion of the issues of valuation, equity and public interest are somewhat theoretical or academic, these concepts have a very concrete and functional relevance. Significant costs and efforts are being expended to enable ABS to function as a commercial system. Yet neither the market nor national law have yet provided any reason for that system to exist.

If the ABS system does not meet expectations, it will have to be either reconsidered and reformed (in fulfillment of the mandate of Article 15.7) or elimi- nated, with the consequent failure to contribute to a very important objective. Hence, ABS cannot be left on its own, to develop organically through normal commercial means. Normal mechanisms of commercial contracting cannot reflect or create equitable and public interest benefits. Laws, policies and other governmental actions, required by Article 15.7, are necessary, as well. On the user side, these laws are conceptually difficult in one respect - they function indirectly. The system for implementing separate private contracts does not (cannot) create the terms of a contract between another sovereign nation and a private user. The user-side legislation must find a way to "sculpt" this legal relationship, without directly dictating it.

How can national legislation apply the understandings provided above regarding the valuation of genetic resources, the application of equitable principles, and need to ensure that $A B S$ serves the public interest? The national legislative draftsmen seeking to implement the obligations of Article 15.7, as well as the user governed by those provisions and the source country entering into a contract, all have an interest in this question.

338 EC, 2003, under the heading "Why Should the EC Implement the Bonn Guidelines?" 


\subsubsection{Reconciling value, equity and public interest in commercial ABS}

The creation of user-side measures is not a simple task (as discussed in Chapter 3). As the system is currently envisioned, national user-side legislation would not impose specific requirements or percentages on users. Rather, it would enable and encourage each user to engage in contractual negotiations and it would require compliance with the resulting instrument (MAT). The user and provider enter into specific negotiations and produce a specific agreement.

Although not selecting the subjects and contents of contractual negotiations, national contract law provides a framework. It normally focuses on placing limits to ensure that both sides deal fairly with one another, and creates a legal requirement that parties bound to a contract must comply with it, and ensure that where a contract is required one will be obtained. So long as the private contract meets these basic standards of fairness, the law provides a platform for interpretation, application and enforcement.

In that regard, user-side $\mathrm{ABS}$ measures must serve a variety of objectives. At the commercial/economic level, they must require and enforce compliance with the ABS contract; but also create mechanisms, motivations and incentives to encourage users who have not obtained such an agreement. In terms of equity, the measures must create a framework that ensures that $\mathrm{ABS}$ is applied on the basis of equitable principles. They must also enable or ensure that the system compensates source countries and providers not only for the specific value of the genetic resource, but for its role in the ecosystem and for their historic and current contributions and rights. In the international public interest, the measures must attempt to ensure the link between the ABS system and the objectives of promoting conservation and sustainable use, as well as integrating with national and international efforts to achieve Millennium Development Goals. None of these objectives can be considered without integrating the others.

When a country is adopting provider-side legislation, its commercial ABS provisions can be concrete - enabling, guiding and facilitating the development and negotiation of ABS contracts. ${ }^{339}$ In empowering a government agency to grant rights in natural resources or other national interests, a country may specify all of the terms of the contract if it chooses. User-side measures, however, cannot do this, since user-side country is not usually a party to that ABS contract. Consequently, the legislation must have a very different role - providing a basis of rationality, legality and equity on which to define and limit the application of foreign law and to control domestic users.

On the user side, valuation, equity and public interest issues can be promoted by ABS legislation in five practical ways:

- First, these same process provisions can provide the legal basis of enforceability, by which the courts and agencies can determine whether and how to apply source-country law or to interpret an ABS contract.

- Second, the user government can provide a basis of rational and transparent valuation in $A B S$ contracts, indirectly, through its regulation of users who have not obtained ABS contracts from the source country. In essence, by stating how ABS requirements will be calculated and applied to this group of users, the law can provide a "baseline" that can serve as guidance to users in negotiating benefit-sharing contracts.

- Third, these provisions can clarify the key difference between users who have obtained ABS contracts and those that have not. For the latter group, the government will decide what benefitsharing measures are required. This may be a very important incentive for users to comply with $\mathrm{ABS}$ requirements and negotiate $\mathrm{ABS}$ contracts at an early stage in their activities.

- Fourth, overall user-side measures demonstrate how the laws from source countries and contracts negotiated under those laws will be applied in

339 This concept is outside of the mandate of this legislation, but many aspects of it can be inferred from the prior discussions. 
user countries.

- Fifth, over time, the cumulative force of all national user-side measures could help define the common international bases that can be used in ABS processes (PIC and MAT) and their application worldwide. Where the users are governmental (government-sponsored research institutes, projects and other activities), they can adopt these principles directly in procurement and other policies required of all persons negotiating with a source country on behalf of the user government.

At any time during the years since the Convention was adopted, user measures could have played all of these roles. If these steps had been taken more immediately, a rational and functional $\mathrm{ABS}$ system might already exist, eliminating the need for the current negotiations.

\subsubsection{How value, equity and public interest principles can be translated into practice}

User-side national legislation is challenged to provide the maximum level of guidance to users, source countries, agencies, institutions and courts, to increase their ability to come to conclusions that are generally similar sufficiently uniform that users and source countries can have some certainty about what rules and guidance will be applied and how. The three key issues discussed in this chapter - economics, equity and the public interest - are the tools of this guidance, but their use poses the following challenges:

Valuation and economic application: Genetic resources (except where patented by a user able to defend the patent) are almost entirely non-exclusive resources, apart from the fact that source countries claim sovereign rights to control their "access" and/or to obtain a share of benefits arising from utilization. This non-excludability in the practical sense means that national legislation and international negotiations are focused on finding ways to make them excludable legislatively. The work on ABS presents many parallels to IPRs, where a legal system has been developed to give innovators the ability to convert their ideas and innovations (not practically excludable) into IPRs over which they have the powers of exclusion of other users. As to their genetic resources, each country theoretically possesses that sovereign right with regard to any species that originated (was found in in-situ conditions) in their country. All countries then have an interest in reaching some legally consistent view regarding the excludability of their own genetic resources - an interest that can only be met by user-side measures.
A key practical challenge in this respect is timing. A genetic resource can only be truly understood and valued at the end of the resource utilization and $R \& D$ processes - something that may happen over a very long period of time. The negotiation of the ABS transaction, however, happens at a very early stage, and in general all parties have an interest in moving the benefit-sharing payments to the "front-end" of that process - as close as possible to the time and conditions of the negotiations. The result of these motivations, frequently, is a trade-off between basing the agreement on the speculative potential value of a large number of genetic resources at the collection stage, or tying it to a percentage of actual benefits obtained at some point in the relatively distant future.

Equity and the public interest: Another valuation challenge relates to the need in some cases to determine the source country's "fair share" of benefits arising from the utilization of genetic resources. This computation will involve determining a single standard for weighing the potential contributions of many very different types of inputs into the product or other result. Additional issues arise when developing the comparison of value between the source country's "fair and equitable share" of benefits, and the actual form of payment made, e.g., receiving laboratory equipment as payment of a benefit share.

Finally, equity poses an even murkier challenge. Although directly arising from the wording of Articles 1 and 15, the nature and application of equitable prin- 
ciples in determining the source country's benefit share has received little attention. For example, in a recent publication on the subject "benefit sharing," it is dealt with as follows:

\section{The adjectives "fair" and "equitable" remain} unclear. This is probably due to the fact that the adequacy of the benefits depends on the circumstances of the individual case. Generally, conditions shall be fair and practical for both the provider and the user. ${ }^{340}$

Obviously, significant work is needed at the international political and analytical levels to raise expert awareness of the nature of primary legal concepts. The other main justification for current efforts to make ABS work is contractual fairness. ABS was created as a quid pro quo forming the basis for developing country participation in the CBD. It is a firm and binding commitment made by all countries. Consequently, it is incumbent upon all countries to either bring it into functional existence or renegotiate the CBD entirely.

In the application of these principles, one must recognize the role of benefit sharing as a goal in conjunction with the other objectives of the CBD: the conservation and sustainable use of biological diversity. It is also closely tied to international types of equity, including intergenerational equity, poverty alleviation, food security and health. In the context of these objectives, a strict contractual approach to the ABS process and the valuation and sharing principles it applies does not necessarily lead to a fair and equitable result.

${ }^{340}$ Dross and Wolff, 2005, pp. 56-59 (with further references). 



\section{(2) Measures that Can Be Taken to Meet the User-side Commitment of the CBD Parties}

At this point, it is appropriate to attempt to synthesize and apply the information from chapters $2-5$ into a single discussion of measures that can be taken and how such measures can be analyzed and developed. This chapter begins (section 6.1) with a legislative evaluation of the nature of the obligation of all CBD Parties regarding users under their jurisdiction. Section 6.2 discusses the fact that simple legal mandates and permissive instruments will not achieve the user's objective, unless the motivational structure of the user country's laws is designed to promote achievement of these goals. In section 6.3, the inter- national systemic needs and their relationship to the success or failure of user-side measures are discussed. Section 6.4 presents the authors' primary suggestions regarding the manner in which $\mathrm{ABS}$ legislation can be conceived and adopted from the user side - always assuming the various challenges described in parts 6.1-6.3 can be resolved. The final section looks at a variety of proposals that are currently being discussed internationally, and considers their potential applicability, and the factors that must be determined before any of these provisions could be finally adopted and utilized.

\subsection{User-side obligation: Achieving the benefit-sharing result, not simply adopting measures}

Although it is often overlooked, the phrasing of obligations in Article 15.7 is very important. Those obligations are expressed in terms of results rather than specific actions. Where other parts of Article 15 call for specific action, Article 15.7 requires a specific result equitable sharing of the results and benefits of genetic resource utilization with the country from which the

\subsubsection{Benefit sharing as the objective}

There are a variety of kinds of measures, legal obligations, policies and other incentives that a country may choose from to meet its Article 15 commitments. In selecting among them, the country should attempt to ensure not only that it will alter behavior, but that this alteration should result in actual sharing of benefits. In particular, the Bonn Guidelines, although only non-binding suggestions, offer a brief but specific range of actions that may be utilized to comply with Article 15.7..$^{341}$

Essentially, the measure of successful compliance with ABS will be the extent of benefit sharing. On this measure, the future of ABS is dubious. There are virtually no user-side measures, and a large number of resources were taken from in-situ conditions. The CBD specifically chooses not to list specific actions that will be considered to satisfy the Article 15.7 obligation, but leaves the selection of specific measures open. Article 15.7 is still obligatory. Thus, the Parties' obligation is to arrive at the result, no matter which legislative, administrative and/or policy paths are taken.

users have concluded that they are not obligated to comply with ABS. If the lack of user-side measures continues, the current situation will probably continue - that is, benefit sharing will continue to be nearly non-existent. In some cases, it is strongly asserted that mandatory or "binding" measures are needed. However, if other kinds of user measures are developed which lead to a significant level of benefit sharing, then it will not matter what type of measures are used.

This suggests that countries have fairly wide latitude to craft user-side measures that will achieve international (CBD) objectives, in conjunction with national interests and objectives of the user country. If

341 Bonn Guidelines, Article 16(d), discussed in 3.1 and considered in developing the recommendations in section 6.3.2, below. Although nonbinding, these recommendations were intensively negotiated. 
these measures are tried and proven insufficient to achieve the results required, however, the Party or Parties must find new options and recommendations and possibly amend the Bonn Guidelines to reflect such new experiences. A measure that is adopted with great fanfare, but does not add value to the ABS process by resulting (directly or indirectly) in additional benefit sharing is not a meaningful step towards meeting the Article 15.7 objective and obligation.

\subsubsection{Binding/non-binding and voluntary/mandatory concepts}

\section{Countries have been discussing whether or not ABS} measures or the ABS regime should be "legally binding" since the World Summit on Sustainable Development. In this context, a perception that ABS compliance can be achieved through "voluntary" user-side measures has also been a subject of significant discussion. These discussions have been complicated by an incomplete understanding of these legal concepts, especially the terms "binding" and "voluntary." An accurate understanding of "binding and non-binding" and "voluntary and mandatory" provides a very important basis for discussing userside measures.

\subsubsection{The term "legally binding"}

It is important to recollect that the term "legally binding" refers to particular obligations or commitments, rather than to entire concepts. This means that the term "legally binding regime" is not meaningful - a regime is simply a combination of measures. Measures within the regime may be "legally binding," but the regime is simply "in existence" or "functional." Under international law, provisions in international agreements are generally binding on governments - even those that may not be mandatory. These provisions are not directly applicable to individuals or private entities, however, before they are implemented in domestic legislation. ${ }^{342}$ Countries must adopt legislation that implements the international requirements, applying them to individuals and entities under their national jurisdiction.
In the ABS context, Article 15.7 is a binding and mandatory obligation of every country that is a Party to the $C B D$ to adopt user-side measures. In order to meet their CBD obligation, all countries must adopt measures that result in benefit sharing. Many in the ABS negotiations presume that this requires national implementing legislation to impose a binding legal obligation on all users of foreign genetic resources. To date, however, no country (developed or developing) has adopted any legislation that does this.

Other parts of the ABS system do impose binding obligations on private parties through contracts. A contract is binding wherever its parties agree that it will be so. In the ABS context, private parties seeking genetic resources must enter into an agreement (mutually agreed terms) through which they agree to be bound.

It is not difficult to create legal obligations in legislation or contract that are binding in theory. One simply has to write binding language - e.g., "the user shall...". The difficulty is to design the legal system so that the relevant obligations are binding in fact - i.e., that the users will either want to comply, be compelled to comply and/or be subject to penalty or other negative consequences if they do not comply.

\subsubsection{2 "Voluntary" or non-binding measures}

Discussions of "voluntary approaches" often misunderstand the nature of the legal concepts underlying voluntary measures. At base, a "mandatory" user-side

\footnotetext{
342 Some countries' national legislation says that all international agreements automatically become law within that country. Although this sounds like a simple answer, it presents a problem. International laws describe what countries must do, but usually say nothing about regulated persons or entities. An international law may call on countries to "adopt legislative measures," for example. This requirement cannot be imposed on an individual. And until the country does adopt those measures, the individual cannot guess what those measures will say. Hence, until the national implementing law is adopted, the international instrument is not binding within the country. A small number of international instruments are "self-executing" - that is, they include all of the relevant provisions of national law in the international instrument itself. The countries that become parties to such an instrument may instantly apply it, from the day that the country formally ratifies it. (See, for example, the international contract law treaties of UNCITRAL and UNIDROIT). Very few countries actually ratify most of these treaties, however. (Some of the UNIDROIT and UNCITRAL instruments have only a few parties.) Typically national legislatures prefer to make their own choices about these matters.
} 
measure is any legal provision (requirement or prohibition) that is directly applicable to every user of foreign genetic resources. All mandatory measures share this quality. There are two very different kinds of "voluntary" measures:

- Motivational measures provide that "if the user does XX, then he will receive or qualify for YY;"

- Permissive measures are simply statements that "the user may do XX." In some cases, permissive measures are stated as recommendations.

The key to both types of measures is that the user has a choice: he may choose not to take the voluntary action, and that choice will usually be perfectly legal. In impact, however, the two kinds of voluntary measures are very different.

Permissive measures do not provide the user with any personal reason why he would want to act. This means that they are most useful where the target populations already want to take the action, but need guidance or want the government to adopt a unified approach. ${ }^{343}$ To date, as noted in 3.5, nearly all proposals of "voluntary" ABS measures are permissive in nature - that is, they are recommendations, not tied to any substantial motivation or incentive. For example, discussions of "voluntary disclosure in patent application" do not include any reason why a patent applicant would want to make that disclosure. Discussions of the possible creation of a "certificate of source, origin or legal provenance" 344 are entirely permissive - stating that a certificate may be issued, but not indicating any particular role for the certificate, or the reason why the user would need or want one. There is, at present, no ABS situation that requires or will be made easier or more effective by a certificate. ${ }^{345}$ Unless the regulated community wants them, permissive measures do not provide a reason for altering behavior.

By contrast, motivational measures (including financial and other incentives) can provide some benefit or other desired outcome that can convince users to take an action that they would not otherwise consider. This will happen when the result of action $\mathrm{YY}$ is more valuable to the user than the costs of the other option (action XX). Motivational measures can function without using financial incentives, where they provide other benefits, such as protection from liability, increased legal certainty, tax deductions, access to special governmental services, priority treatment, etc. The primary question is whether the particular motivation is sufficiently desirable to give the users a reason to comply.

It is important to remember two things about the use of either type of voluntary measures. First, even motivational measures have varying levels of effectiveness. Some kinds of motivation are virtually $100 \%$ effective - by giving a protection or benefit that is considered by all users to be essential. Many registration systems and some tax benefits are examples of this type of motivation measure. ${ }^{346}$ Other motivational measures, however, (such as social and environmental certification systems) are considered highly successful if $10 \%$ of the target population complies.

Second, many measures which are phrased in law as "mandatory" are effectively voluntary in impact, owing to lack of enforcement. If it is impossible to enforce a mandatory provision against a user, then the measure will be effectively voluntary. Consider for example, the user who has left the regulating country and is now be operating in a country which does not require him to comply with the source country measures. It may be impossible for the source country or any other person or entity to obtain knowledge or proof of

\footnotetext{
343 Börkey et al., 1999.

344 See, e.g., CBD COP Decision,VIII-4, paragraph A.2.a et passim. In the most recent discussions a fourth possibility - "certificate of compliance" has been suggested, however, it has not been formally adopted by the AHWG-ABS, and does not markedly change the current analysis. CBD, Report of the Meeting of the Group of Technical Experts on an Internationally Recognized Certificate of Origin/Source/Legal Provenance, UNEP/CBD/WG-ABS/5/2, 20 February 2007.

345 This permissive approach already exists in national legislation in Costa Rica - the country with the highest profile ABS legal system - however, no user has ever sought a certificate. Cabrera Medaglia, Jorge, Personal communication, 26 March 2007.

346 Discussed in detail in Ruiz and Lapeña, 2007 (Book 3 in this Series) at chapter 4.
} 
violation, if the user's activities are protected by confidentiality or trade-secret principles. If the user is intent on full compliance with source-country law or his ABS contract, then the law and contract will operate as motivational measures. To other users, however, the effect of these instruments may be only permissive. Consequently, in drafting mandatory measures, it will be important to consider the user's motivation to comply.
As discussed in more detail in 3.5, voluntary mechanisms will have the strongest impact where the target population desires them, or where it provides a sufficient motivation. A system which consists solely of voluntary measures will rarely be effective, but when used selectively as part of a "policy mix," it can provide a useful tool.

\subsection{Using incentive and other motivation factors}

A specific user-side system must be adopted in order to comply with the Article 15.7. Such a system will be very unwieldy, however, and possibly unworkable, if it depends entirely on oversight and enforcement (by the source countries, user countries, NGOs or private claimants).

This situation is not hopeless, however. It is true of nearly all non-criminal legal regimes. ${ }^{347}$ To address it, the legislative body must focus on "system design." Simply stated, it must adopt a law that (i) requires compliance and (ii) is structured in a way that causes most persons to prefer to comply. For example, many laws require the registration of certain kinds of businesses or experts. On one hand, these laws encourage compliance through the knowledge that one who is found to be non-compliant will face penalties or other punishments. At the same time they provide a motivation as well - by complying with the registration law, an expert may be included in a public registry of experts, or a business may be entitled to claim special deductions from its taxes. Both mandatory and motivation elements are important. Without incentive, the expert or business might be less likely to comply, unless the government undertook regular

\subsubsection{Elimination of perverse incentives}

The first step in creating a positive ABS motivational structure is the elimination of perverse incentives. Presently, the legal, practical and financial situation of users who are unaware of or intentionally violate $A B S$ inspections or audits of the entire sector.

The most important element of system design is the elimination of "perverse motivations." It is here that the current $\mathrm{ABS}$ legislative frameworks find problems. As a result, users often express a strong motivation to avoid any compliance with ABS. This desire may also appear indirectly, in the form of corporate statements that ABS does not apply. Companies making these statements may not have researched the issue, but simply concluded that if they acquire their specimens in the user country - from an ex-situ collection, another user, a researcher or some other person - then, by definition, they are utilizing domestic genetic resources, regardless of the actual origin of the genetic resources acquired.

Currently, no law or other incentive in the userside or provider-side national legislative frameworks creates any motivation for companies, researchers and others to confirm that this assumption is correct. ${ }^{348}$ The following sections briefly discuss the motivational structure of user-side measures, and consider how incentive/motivation provisions can be used, either as alternatives or complements to mandatory provisions.

administrative and other requirements can be significantly better than those who comply. By violating or ignoring $A B S$, the user saves time and money which the compliant user spends in meeting

\footnotetext{
347 A more detailed examination of how the success of a legal regime depends on the motivations of the persons/entities regulated is found in Ruiz and Lapeña, 2007, at Chapter 4.

348 Henkel, Thomas, "A Perspective from Pharmaceutical Industry," Presentation to High-level Experts Meeting-Addressing the Access and Benefit-Sharing (ABS) Challenges in the Context of the Convention on Biological Diversity (Tokyo, 8-9 February 2007) and other remarks in that meeting. See also Latorre, 2005.
} 
the administrative and regulatory requirements of source-country ABS law, including PIC and MAT. Users who avoid ABS compliance may also be saved the direct financial cost of paying the source country an "equitable share" of benefits received. In essence, the costs and time spent in compliance with bureaucratic requirements constitute a competitive disadvantage for the compliant user, as compared with the non-compliant user.

At present, the only existing user-side measures are voluntary disclosure of origin in patent applications and the draft Norwegian Nature Diversity Act. Both of these measures would increase this disparity, rather than remedying it. The only users that would be affected are "ABS-compliant users" - that is, those users who have already incurred additional costs and lost time, in order to comply with source-country ABS requirements and who are willing to comply with the additional user-side requirements to disclose the source of genetic resources used. Even under the Norwegian draft, compliance is effectively voluntary. To avoid the requirement, the user must either (1) make the determination that the source-country law does not apply, or (2) decide that he cannot be sure which is the source country. No evidence or proof of either conclusion is needed. The user would not be obliged to comply with the draft Act.

As noted above, it is essential that ABS-compliant users should be at least on equal terms under the law, with those who are not compliant. The mandatory provisions described in 6.3.2 are designed to accomplish this, essentially ensuring that all users, whether they have an ABS contract with the source country or not, shall be under an obligation to comply with source-country requirements, including their benefitsharing obligations.

\subsubsection{Creating a disincentive for non-compliance}

A second aspect of the motivational structure of a legislative framework is its ability to discourage users who choose non-compliance. While penalties and punishments are one potential type of disincentive, they are not the primary tool, since they generally apply only to a small group of intentional or reckless violators. Other kinds of disincentives, however, can also be effective.

For example, consider a user without an $A B S$ contract. The law could impose strict legal requirements on every user that has passed the legislative triggers of utilization of genetic resources, and "benefits arising." At this point, a user who has not obtained an ABS contract could be required to meet some

\subsubsection{Removing disincentives for compliance}

As detailed in other works, ${ }^{349}$ there are numerous disincentives which discourage $\mathrm{ABS}$ compliance. In addition to the significant time and money that they must spend on administrative processes, many users find that $\mathrm{ABS}$ compliance results in a potentially harmful lack of "legal certainty" regarding rights obtained. Users who participate publicly in ABS nego- particular requirement. The law might require that benefit sharing compliance should be set by either (i) post-facto negotiation with the source country, or (ii) benefit-sharing obligations that are defined by the responsible agency or court, in accordance with statutory standards. Any of these options would theoretically yield a final result that is less favorable to the user than his own negotiation of an ABS contract at the beginning of the transaction.

This could create a positive incentive to obtain and comply with PIC and MAT at an early stage in the utilization process, because the user will have more control over the ultimate requirements in that way.

tiations are often the only available targets for claims of "biopiracy" in the press as well as the courts.

Without belaboring a point which has been made throughout this book, the adoption of user-side measures may actually decrease the amount and detail of provider-side measures that are currently in place in

349 See, Young, 2006a, and Young, 2005. 
countries with ABS legislation. Many of those intensive requirements exist as part of the source country's desire to strictly impose controls and oversight on users. Because the users are not governed by any ABS legal requirements after they or the resources are outside the source country, responsible agencies in source countries attempt to develop very detailed requirements within the ABS contract, in the hope that those provisions can be enforceable under contract law.
If user-side measures in the user's home country are in place and sufficient, then the source country will be able to dispense with much of the most onerous of its requirements, and focus on collaborating with user countries to ensure that all users are integrated into the ABS system. The net result will level the playing field between compliant and non-compliant users (elimination of the competitive disadvantage), leading to relaxation of the intensive demands of source-country ABS legislation.

\subsubsection{Positive incentives and motivators of compliance}

The most important question in ABS relates to the development of positive incentives and motivators. No matter how completely ABS laws eventually cover the globe (both user-side and provider-side measures in all countries), one key difficulty will remain - activities in laboratories are difficult or impossible for governmental inspectors to confirm with certainty. It would be very costly and ineffective to rely on periodic inspections or other methods of finding out whether particular users are utilizing genetic resources with origin in another country. In addition, testing or other scientific mechanisms to identify genetic material are not only costly, but may not be able to identify specific varieties, local populations or other genetic differences that would help pinpoint their source country.

This means that, although full coverage of userand provider-side measures in all countries would create a legally functional system, it would hardly be sufficient to ensure universal or near-universal compliance by users. To achieve this goal, and to eliminate the need for costly governmental oversight, it would be advisable to link ABS compliance to positive incentive and motivation measures - that is, to provide some (financial or non-financial) benefits for users who comply with $\mathrm{ABS}$ requirements. There are many areas in which incentives would be possible and would inspire companies and other users to participate. In order for incentive/motivation measures to function in this way, however, they must meet two basic criteria:
- The incentive or motivational advantage must be sufficiently valuable to the user (in financial or nonfinancial terms) that it offsets, in whole or in large measure, the additional costs of compliance; and

- The system must ensure that this incentive or motivational benefit is only available to those who comply with $\mathrm{ABS}$ requirements and cannot be obtained by others who do not meet the requirements.

If either of these criteria is not satisfied - that is, if the advantage is not particularly valuable or if it can be obtained without compliance - then the incentive/ system will fail. ${ }^{350}$

There are a number of incentives which can be provided through the user-side legislation that may be sufficiently valuable to provide a real motivation for user compliance. For example, the Japanese Guidelines ${ }^{351}$ include an incentive measure under which the government of Japan will help the user if some difficulty arises in negotiations or discussions with source countries, so long as the user has complied with the Guidelines. This type of motivation could be extended to include a broader range of protection from liability (both liability to source countries and other formal claims) for users that have complied with user-side measures. This kind of liability protection would not be "immunity," but would require the user to fully comply with clear and concrete laws and legal requirements of the source country, as specified in the user-country's law. It would have to be carefully drafted to avoid sanctioning

350 See, e.g., Young, 2004

351 JAPAN: METI/KBA, 2006, Guidelines for Access to Genetic Resources for Users in Japan, Ministry of Economy, Trade and Industry (adopted March 2005, published in English, 2006) available online in English at http://www.mabs.jp/information/oshirase/pdf/iden_tebiki_e.pdf. 
illegality. ${ }^{352}$ If it is carefully drafted, however, such a provision would have a double impact, providing an incentive for user compliance, and also providing an incentive for more $\mathrm{R} \& \mathrm{D}$ involving genetic resources from source countries.

Another type of positive incentive would arise from user-side measures that help to increase the user's legal certainty regarding his rights to use genetic resources. As challenges and claims relating to the use of genetic and biological resources increase in frequency and stridency, user measures which clarify the specific user rights that will be protected and supported through $\mathrm{ABS}$ compliance can provide an important incentive for users to comply with ABS, as a means of avoiding or nullifying such claims. (As noted, in some cases it has appeared that ABS compliance may actually increase the chance that the user will be targeted.)

Other simpler, but highly effective, forms of incentive might also be offered with limited impact on the budget of the responsible agency, including the following examples:

- the creation of special tax credits for ABS compliance and special higher levels of tax deductions for the costs involved;

- access to special governmental services, including priority for certain kinds of permits and other legally controlled benefits;

- qualification for participation in government projects programs; ${ }^{353}$

- preferential status in the government procurement policies; and

- participation in national programs for assistance and support to technological development.

It may also be valuable to consider the incentives which might be provided by other countries, especially countries in which the products of genetic-resource utilization are marketed. Such incentives might include administrative priority in certain applications or recognition of otherwise-disputed patents.

The most important aspect of these incentives, however, is the fact that they are not entirely cost-free. In a few cases, these incentives cause some level of reapportionment of costs (for example, countries giving tax credits do not lower their total income from taxes, the credit merely reapportions some part of the taxpayers' obligation from the credited sector to other sectors). In all cases, however, it is essential to develop means of confirmation of the critical elements of the incentive. If there is no confirmation, then the necessary criterion - that the incentive is only available to those who comply - would be lost, and the measure would not promote the objectives of ABS.

\subsection{Creating an international system for ABS}

Particularly since 2002, when the World Summit on Sustainable Development and CBD COP-7 raised the prospect of new international negotiations on $\mathrm{ABS}$, new attention has been given to the systemic aspect of the ABS framework and the need for an internationally negotiated perspective on the ABS regime. To do this, countries must recognize several existing elements of the ABS system, including the international laws that mandate national implementation, national laws that govern both user and provider side of the transaction, and all relevant types of contracts.

\footnotetext{
352 For example, the law would have to address the impact of a claim on the user's ability to continue to use the resource or to market products based on it, during the pendancy of a legal claim.

353 The United States National Institutes of Health (NIH) provides an example of this approach through its recent Program on International Cooperative Biodiversity Groups (ICBG), where access to ICBG funding opportunities and other coordinated government projects was conditioned on compliance with provisions relating to equity and the obligation to share the (research) benefits with the country in which the project was operating. Rosenthal, 2004.
} 


\subsubsection{Why national measures are not sufficient alone}

The CBD was designed to be implemented by national law. It created no international mechanisms, apart from designation of the GEF to serve as its financial mechanism. The only international institutions it created were the COP and Secretariat, both of which have coordination and review functions, but no direct implementation responsibilities. This general view is clear in the Convention, under which both access and benefit-sharing obligations are to be met by national measures. During the negotiations, many concerns about the nature of genetic resources and how they could be regulated were dismissed as matters that would be settled under national law. ${ }^{354}$ Both during and after the negotiations, many user countries took the view that the user side of ABS could be addressed by national law without any specific legislative support or additional measures.

As noted in 3.3.1, however, the national legislation expectation has resulted in two serious problems. The first is an area of operational confusion. Fewer than $15 \%$ of CBD Parties have attempted to adopt any type of separately designated "ABS legislation." This creates a dilemma for user-side implementation. Where the source country has no ABS legislation, $\mathrm{ABS}$ issues must be addressed through general principles of its national law. ${ }^{355}$ This heightens legal uncertainty for users, for user-side ABS focal points, and for the creation of user-side legislation that mandates compliance with source-country requirements.
The second problem - an unfilled gap in the current $\mathrm{ABS}$ regime - is much more serious. As discussed in Chapter 3, no country has adopted user-side $\mathrm{ABS}$ legislation - that is, a law that directly requires users of foreign-origin genetic resources to comply with source-country ABS requirements (and/or to share benefits). Lacking such a provision, users are not directly bound by the ABS regime, except when they are in direct contact with the source country. This omission creates a large loophole in ABS, essentially freeing all other users from any legal obligation of $\mathrm{ABS}$ compliance. It also constitutes a significant and perverse incentive, counteracting any "recommendations" by user governments calling on their users to comply with sourcecountry ABS law. For the functionality of the international regime, this system presents a contradiction. Unless all countries have met their obligation to adopt user-measures, those that have imposed access restrictions on their own genetic resources are in effect placing their domestic users at a disadvantage. They can compel their domestic users to comply with $\mathrm{ABS}$ requirements, but have no ability to compel compliance by other users who have left the source country.

Until user-side measures are adopted, requiring or enabling benefit sharing, other elements of the international regime cannot ultimately be effective. Many of the ABS concerns that led to the current negotiations could have been resolved without further attention if a consistent system of user-side measures had ever been adopted.

\subsubsection{Steps possible in unifying the "international regime"}

Beneath the basic failure of any Party to adopt user development is needed. measures, however, is the underlying fact that the ABS concept was not well enunciated in the CBD. The original expectation that it would be clarified through the cumulative impact of 190 countries' legislation and experience was ultimately not met. It is strongly argued that further international

\subsubsection{Identifying the need for further international agreement}

A brief examination of existing national legislation provides clear evidence of the reasons that $\mathrm{ABS}$ cannot function solely through uncoordinated national legislation.

\footnotetext{
354 See, Glowka, 1998 at 4. To this day no country's property law has ever found an effective way to address this issue or to consistently integrate it into national property frameworks. Given that the ABS regime addresses only transboundary transactions, it could function effectively only if all countries either addressed it in a harmonizable way in national law, or came to concrete agreement on this concept.

355 CBD, Article 15.5, provides that PIC and MAT are required in a source country, "unless otherwise determined by that [country]."
} 
The basic disconnection is obvious from the outset of any ABS transaction. The source country's legislative requirements may be built on one framework of definitions, scope and triggers, while the user country will impose measures on the basis of a slightly different framework. This may lead to a controversy over whether the source country's requirements have been met, or need to be met, by the user. For example, the US's provider-side legislative proposal would regulate "research projects involving research specimens collected from specified lands." ${ }^{356}$ Consider the outcome if a foreign user obtains specimens in the US and then uses them in a country, whose user-side measures apply only to "genetic material." In that case, the US might have no recourse under the other country's law, if the user country's law does not apply to research samples taken in this way. Until all countries share an understanding of "utilization of genetic resources" and how ABS functions, the dramatic differences between countries' "providerside" measures will make it very difficult or impossible for user-side measures to function.

At the time of this writing, negotiations are ongoing in the CBD for the elaboration of the "international regime on ABS." There is some hope that these negotiations will ultimately result in one or more documents that clarify the overall framework, and enable all countries to meet both sides of their legislative/institutional obligations under Article 15. It is equally possible, however, that these efforts will not resolve key questions, leaving the Parties in essentially the same state that they have been in to date, but having spent a good deal more money and time in negotiations. ${ }^{357}$ In either case, the legislative problem will still have to be addressed by every country - converting the $\mathrm{ABS}$ commitment into provider-side responsibilities and implementable national user-side measures.

\subsubsection{Questions to be addressed in the interna- tional regime negotiations \\ Ultimately, the regime negotiations may address}

many political matters, but may also create an "agreed interpretation" of the primary unanswered questions that currently obstruct national implementation. For the purposes of this book, the latter is of greatest interest.

The primary discussion throughout this book has consisted of an examination of the obstacles to ABS implementation and options for addressing them through national legislation. Lack of international consensus on these topics places heavy burdens on each legislating country. Thus, international negotiations may support national implementation and coordinated operation of the ABS system, if they provide clear answers to as many of the following issues as possible:

(i) The exact nature and precise role of "genetic resources," "utilization of genetic resources" and "benefits arising from the...utilization of genetic resources." (Section 4.1 analyzes one option for development of these concepts in an integrated way);

(ii) The manner in which these three concepts interlink to form the ABS functional system. (Section 4.2 presents one option for functional interlinkage);

(iii) Whether there are particular activities or subject areas that can/should be separately dealt with, as the ITPGRFA seeks to deal with the ABS aspects of agricultural use of specific crops, and how they can be identified, developed and integrated. (In section 4.2.2.2 and elsewhere this book considers the possibility of defining and regulating categories of utilization of genetic resources); 358

(iv) Either an approach for determining the "source country" of a particular genetic resource where the user does not know or disclose that fact ${ }^{359}$ or

\footnotetext{
356 This example is based on the proposed regulations currently being discussed by the US National Parks Service, as discussed in Chapter 3.

357 At present, after four meetings of the AHWG-ABS, three technical expert meetings, and lengthy multi-day discussions in at least three COPs, the Parties have not yet been able to agree on the practical objective of their work (adoption of a protocol, adoption of some other instrument, etc.).

358 Pythoud (2005) raises a question: "[Is] there a specific type of use of genetic resources that might require additional international instruments to support implementation of CBD Art. 15?” See also Tvedt, 2006. The ITPGRFA will provide a testing ground for this approach, as it comes to be adopted and fully implemented by the countries that are Parties to the CBD.

359 See, Ruiz and Lapeña, 2007, at Chapter 5.
} 
some mechanism for benefit sharing that automatically applies in such instances. (Some of these issues are described in more detail in 3.3 and 3.4);

(v) The manner in which the country of the user will enforce or determine compliance with the law of the source country. (Some of these concerns are described in more detail in 3.3.3);

(vi) A mechanism for communication between the user country and source country to address these issues. (Some of these issues are discussed in 3.3.2.3); $; 60$

(vii) The manner in which these issues and the ABS framework can be responsive to changes in the fast-growing field of biotechnology that may affect it; ${ }^{361}$ and (viii) The possibility of adopting a system for evaluation or transparent negotiations and setting standards for determining what is fair and equitable benefit sharing. (This issue is generally dealt with in Chapter 5.)

The choice among the various possible specific answers to these questions is not as important as getting some answer for each one, so long as the answers are internally consistent. In Chapters 4 and 5 , we have emphasized an approach which we think provides a logical consistency on which a functional $\mathrm{ABS}$ regime can be based. We offer this set of solutions not only for its own merits, however, but as evidence of how the final agreed approach (whatever it is) can be conceived, analyzed and regularized before it is adopted.

\subsection{Practical implementation of ABS "Beyond Access" - adopting user-side measures}

\subsubsection{Legislative justification}

No country may legislatively control any person's actions under the jurisdiction of another country. Even where one country seeks to punish a person who has fled to a second country after being convicted of a serious crime, the second country must adopt and apply law that enables it to take action (to extradite the person, or to make some other arrangement) upon the request of the first country. Consequently, the entire ABS objective is made nearly impossible by the lack of user-side measures. As a result of this omission, the entire $A B S$ system is effectively voluntary-permissive (i.e., not required and not supported by motivation factors).
On the road to a functional international system for genetic-resource regulation, a legal framework in the user country is necessary in order to enable the source country to assert its sovereign rights over genetic resources in the place in which those rights are infringed. A collector may, while in the source country, obtain biological samples in accordance with the source country's sustainable-use laws ${ }^{362}$ and the laws governing the ownership of biological material. If he later begins to utilize its genetic resources in another country or transfers it to some other person who does so, the laws of the source country no longer have any direct impact on either the collector or user.

360 One aspect of this process might be the use of a "certificate of source/origin/legal provenance" or of "compliance" which might (depending on its contents) provide an initial one-way method of communication between the source country and the user country. However, processes of verification of the contents of the certificate, and of ongoing compliance with relevant laws and with the terms of the ABS arrangement, will seem to require other communication systems as well. See, Ruiz and Lapeña, 2007, at chapter 4.

361 The slow process of recognition of the implementation problems of ABS, and of getting to the point of knowing whether international action will be taken to solve some of these problems indicates that a flexible mechanism is needed. Otherwise, any ABS system that is concrete enough to be functional will probably be too slow in adjusting to changes. In this connection, a lesson can be learned from patent law where all the main criteria (e.g. invention, novelty and inventiveness) are dynamic and evolutionary by nature, making the patent system robust enough to adapt to changes in technological research and development. Flexibility is provided through the practice of altering and reconsidering the interpretation and practice of the terms rather than amending the wording of the acts.

${ }^{362}$ Laws often govern sustainable collection practices. See, e.g., the "FAO The International Code of Conduct for Plant Germplasm Collecting and Transfer," found online at http://www.fao.org/AG/AGp/AGPS/PGR/icc/icce.htm. 
To achieve the desired results, however, user-side measures must be integrated into a coherent, internally consistent framework of legal requirements, administrative agencies and regulatory systems, motivational provisions, and enforcement standards. This is not a pessimistic view and does not assume that users are non-compliant and/or that the ABS system will only function if users are forced and penalized. A great many users who have made intensive efforts to comply with $\mathrm{ABS}$ requirements have been labeled as

\subsubsection{Legislative objectives}

With no current replicable standards and comprehensible framework for determining what they must do, users have very little basis for analyzing and predicting the costs and risks connected with ABS. ${ }^{364}$ The objective of "legal certainty" in ABS will be met when, at a minimum, the users (i) know what specific actions are required of them; (ii) can be confident that compliance with these provisions will protect them against such claims; and (iii) can pre-estimate the costs of compliance with a fair degree of certainty.

Ambiguities in the ABS framework appear to be preventing the adoption of user-side ABS legislation. ${ }^{365}$ It is also true that the primary user countries have not made serious attempts to do this, despite having access to some of the foremost legal scholars and institutions in the world. As leaders in legal development, these countries might have been able to head off the current round of costly and time-consuming international negotiations (and the risk that they will come to undesirable conclusions) had they developed and implemented effective and balanced user-side "biopirates" in the press and subject to other kinds of ABS claims. ${ }^{363}$ On the other hand, many entities that are using genetic resources with origin from other countries have specifically and flatly denied that their actions give rise to $\mathrm{ABS}$ obligations. Clearly, the rights and duties of users must be clarified, to protect them, as well as to make the system function.

measures following the Convention's adoption.

Although international regime negotiations are in process, many regulatory questions will remain to be decided at the national level, even after the conclusion of those negotiations. ${ }^{366}$ Many of the primary questions identified in this book may not be formally resolved by the international discussions. Hence, national legislative measures, and the leadership of key developed countries in their adoption, can still have a major influence in forming the international regime. The following discussion focuses on the drafting of legislation and its role in defining and enabling implementation of the benefit-sharing obligation, with particular attention to the legislative problems of interacting with source-country law, and integrating motivational and incentive elements. These issues address two primary applications of benefit-sharing responsibility, (i) the responsibility of users who have obtained an ABS contract from the source country, and (ii) the responsibility of users who have not done so. ${ }^{367}$

\footnotetext{
363 Young, 2006a.

364 See, the Japanese Guidelines, footnote 113. A significant part of those guidelines is directed at the numerous "grey areas" on the user-side of ABS that are not answered by the Bonn Guidelines or any other consensus.

365 Most such countries have not formally stated this. A few have indicated (directly or by implication) that no formal ABS legislation is needed on the user side.

366 See, for example, the Cartagena Protocol, which calls for many specific results and requirements, but enables many different approaches to their implementation.

367 This second category might include some users who are intentionally violating the source country's law (biopirates), but also many users who do not know about $\mathrm{ABS}$ requirements, or who believe that those requirements do not apply to the particular situation.
} 


\subsubsection{The user-side legislative challenge: Relating to source-country law}

In adopting user-side measures, legislators must consider more than the words of the CBD - they must think about how the user-side measures will function legally. Although very difficult, this issue is also very basic - how can one country impose a blanket requirement to comply with the $\mathrm{ABS}$ laws of other countries? Although it may sound simple to those who are not legislative experts, this question is very challenging.

The challenge arises from the basic concept of national sovereignty - from the fact that national law of one country cannot generally control the rights and actions of another country. Most discussions of userside measures assume that the user country will require its users to comply with the $\mathrm{ABS}$ laws and contract terms as defined by the source country, through PIC and MAT. In essence, this provision amounts to allowing another country's legislators to govern the user-country's citizens and companies. This raises a number of problems, owing to the complexity of implementation. A "simple" statement that users of foreign genetic resources must comply with the source country's ABS law will require the user to engage in a complex legal analysis, including:

(i) identifying the source country;

(ii) identifying the relevant provisions of the source country's law and determining how they are applied by the source country;

(iii) determining whether the user has complied; and

(iv) if not, determining how to compel compliance.

This requires a significant level of effort by the user country, which must confirm each of these elements, even if the user has done so and submitted a primary analysis. Worse, since no two countries are alike, the user country must undertake a new analysis for each
ABS situation. ${ }^{368}$

\subsubsection{1 ... where there is an ABS contract}

Once the source country is identified, especially if there is an ABS contract in place, steps ii and iii of the above analysis might be answered directly by the source country. In most countries, however, government agencies and courts are not usually willing to take direction from another country on primary matters of governance such as the decisions of national courts. Consequently, the law will usually require the user country's own agencies to make this determination. Although they may seek input from the source country, to avoid any erosion of their country's sovereign authority, they must retain all other rights and duties of governance, including the right to refuse to take actions that violate public policy.

The alternative would be to simply require users of foreign genetic resources to share benefits based on standards and laws of the user country. In effect, this approach creates two levels of requirements. To meet the user country requirements, the user must prove that he has shared benefits with a source country. He must simply document (in a manner acceptable to the user country) that he has taken the minimum actions necessary under the user country's law to satisfy the benefit-sharing requirement that is imposed on all their users, by the user-side government. This will in essence create a double-permit system, since the user must meet the source country requirements, as well. As noted in Article 15.7, the user can only get credit for sharing benefits with a source country, if he has that country's knowledge and approval.

\subsubsection{2 $\ldots$ in the absence of an ABS contract}

Where the user does not know (or will not tell) which is the source country, or where the source country has not given $\mathrm{ABS}$ permission, a more difficult question arises - how to provide for benefit sharing, where the source country is not participating. The basic problem can be stated simply: It is not appropriate for any

368 Presently, as noted in Chapter 3 (and see Cabrera and López, 2007), the breadth of the concept "genetic resources" differs greatly from country to country, and most countries use a different term when speaking of genetic resources, to make it clear that they have carefully and separately determined which precise resources and activities will be covered by their ABS law. 
other country to determine how a source country's genetic resources shall be governed. A user country which legislatively adopted provisions mandating specific benefit-sharing in the event that the user did not get an ABS contract is essentially authorizing its users to obtain and utilize source-country genetic resources without source-country approval. In effect, it would be usurping the source country's sovereign rights to dispose of or control its genetic resources.

In practice, however, it is essential to apply benefit-sharing requirements to situations in which the source country is not known or has not been contacted, for at least five reasons:

- System integrity: If the user can avoid the $\mathrm{ABS}$ system by stating that he does not know the origin of the specimen (or by refusing to state the origin), a loophole is created that could easily swallow the entire system.

- Commercial motivation: Any system which imposes extra costs on the compliant is at risk. Companies that incur additional costs (financial, human and regulatory) to comply with benefit sharing are placed at a competitive disadvantage as compared with other companies that avoid those costs. In practice, companies that operate at competitive disadvantage face a higher chance of commercial failure than those that avoid unnecessary expenditures. The ABS system without a "default payment" provision would thus promote the survival of non-compliant companies.

- Perverse incentive: As noted above, a perverse incentive is created, if $A B S$ requirements only apply when the source country is known and disclosed. Similarly, if a country imposes only provider-side measures, and imposes them on both domestic and foreign users, it creates a preference for foreign users, and an incentive for its own users to obtain resources in foreign countries, given the difficulty or impossi- bility of enforcement of ABS outside of the source country.

- Reciprocity: The equitable principle of "clean hands" says that "one who calls for equity must do equity." If a country does not apply $\mathrm{ABS}$ requirements to all users, then it may not be able to call for similar protections from other countries. ${ }^{369}$

- International objectives: If the countries continue to adhere to the objectives of the CBD, then they have both moral and political reasons to promote its equitable, conservation and sustainability objectives.

Solutions are generally difficult. The national positions of developed countries studied for this book have ignored this issue. In some cases, it has been suggested that use of genetic resources without $\mathrm{ABS}$ compliance could be overseen by national penalty legislation (a process that might allow the user country to fine or imprison the violators, but would not result in any payment to or other sharing with a source country). It is relatively rare to find any current example of a law under which a government is required to obtain redress on behalf of any private person or for any foreign person, entity or country.

Where the source country is undisclosed, or has no ABS legislation, the issue may be significantly more complicated. The user country would need to identify the source country, if possible, and find some replacement for the PIC process of another country. The only "legally comfortable" solutions would be either:

- to create "default" processes and requirements applicable wherever the source country does not have legislation in place; and/or

- to create an international fund or other mechanism for collecting "orphan shares" - where the source country is not known, not disclosed, or not participating.

${ }^{369}$ Note that the US documents on genetic-resource issues specifically mention the genetic resources used to create the TAQ Polymerase - extremophiles collected in Yellowstone National Park. See, UNITED STATES: National Park Service, September 2006, Servicewide Benefits-Sharing - Draft Environmental Impact Statement, http://parkplanning.nps.gov/document.cfm?parkId=442\&projectId=12515\&documentID=16763. U.S. Department of the Interior. Although this happened long before the CBD was adopted, it demonstrates the relevance of user measures as protections for both developed and developing countries. 
Both approaches would appear to require international agreement, and would still require the user country to oversee use of genetic resources, and to adopt procedures for determining the source of resources utilized in their country.

\subsubsection{Operative framework: user-side law relating to the benefit-sharing requirement}

Although many other user-side measures are relevant and necessary, they all revolve around a clear benefitsharing obligation on the user side - the requirement that users must comply with source-country law and/or share benefits, when using genetic resources with origin in another country. Without such a provision, user-side law can never be more than permissive voluntary provisions, and the $\mathrm{ABS}$ regime cannot be functional as a system to achieve the Third Objective. At most, users who are outside of the source country may engage in benefit sharing with the source country. If he does not think the source country's law applies to him, a user will have no incentive to confirm this conclusion, and if he prefers not to comply with ABS he will not (cannot) be compelled. ${ }^{370}$

Accepting the need for these measures, the country must adopt several elements:
a. Scoping provisions;
b. Direct benefit-sharing obligations;
c. Implementation and oversight structure;
d. Enforcement; and/or
e. Incentive measures.

All of these seem essential to the overall functioning of the ABS regime, although for many countries, only the first two will be needed immediately, accompanied by a commitment to future legislative development for its implementation, and many countries may choose to delay the adoption of incentive measures while experience with the basic system develops.

\subsubsection{Scoping and coverage - terms and triggers} If a country is going to require all users of genetic resources to engage in a benefit-sharing process, it will be necessary to have a clear legislatively applicable framework which clarifies (i) which persons are users of genetic resources (and when); and (ii) which benefits must be shared (and how). Thus, one must know at the outset, what activities constitute "utilization of genetic resources" (since a person or entity is a "user of genetic resources" when he engages in these activities). It must also be legislatively clear what results constitute "benefits arising" from such utilization (since the benefit-sharing obligation is triggered when benefits arise) and how one determines a "fair and equitable share" of such benefits. Consequently, the conceptual clarification of terminology is vital.

\section{[a] Definitions and scope for the triggers of the benefit-sharing obligation}

At a minimum, this seems to require clear definitions or scoping provisions to clarify which activities/resources are covered ("genetic resources" and/or "activities utilizing genetic resources"), and when benefits arise that trigger the sharing obligation. The most important fact of these definitions is their interrelationship. Chapter 4 discusses a basic approach to this, creating a carefully nuanced understanding of this suite of concepts based on pre-existing international commitments and the assurance that they are specifically applicable - that one can know objectively which activities (or resources) are governed by this law, and which benefits shall be the basis for the benefit-sharing obligation. In these processes, it may be useful to indicate how (if) the outputs of the international regime negotiations will impact the scope and coverage of these measures at the national level.

\section{[b] Stricter or different coverage}

The scope of national legislative measures on ABS can have a significant impact not only on the rights and activities in the legislating country, but also on the

370 This is essentially the current status quo. Consequently, the fact that many companies and researchers engage in intensive efforts to comply with ABS requirements, including by sharing benefits, says a great deal that is positive about the existence of a core of social responsibility in these institutions, and perhaps about the power of civil society and other groups to use pressure to push some institutions in the direction of social responsibility. 
manner in which national law integrates into the international ABS system. Often, in discussing national legislative measures, an international regime or convention will state that the Parties may adopt stricter or different measures than those set out in the convention. ${ }^{371}$ "Stricter measures" are often a way of ensuring that certain minimum requirements can be adopted in all countries, even those which do not have the ability to make complex determinations. For example, a simpler regulatory scheme will often be stricter in coverage, to ensure that it covers all species and actors that must be addressed under the international commitment. In other instances, however, the international agreement intends to create an interfunctional commercial process. In such systems (such as the WTO, IPPC and other instruments), it is not permitted to impose stricter measures, although it may be permissible to choose to adopt less strict measures. ${ }^{372}$ In these cases, countries do not actually commit to regulate. Instead, they promise that their regulations in a particular area will not exceed a certain level of strictness or control.

The CBD does not make either statement, probably because it was originally expected that the Convention would be implemented by national legislation, and because nearly all of its provisions relate to matters solely within a single country's jurisdiction. ${ }^{373}$ With regard to Article 15, it is difficult to guess whether stricter measures are allowed or prohibited. On one hand, many countries have adopted very limited definitions of "genetic resources," or applied ABS to narrower substitute terms. ${ }^{374}$ On the other hand, however, some countries have maintained a very general definition of "genetic resources" or even broader terms, to ensure that their ABS law accommodates the maximum coverage possible. ${ }^{375}$

Based on the obligatory language of Article 15.7, it would appear that user-side measures must be designed to cover all genetic resources regulated by any source country. This means that, where a source country's ABS provisions extend to other resources (beyond "genetic resources"), the user country will have a CBD duty to ensure benefit sharing of at least the "genetic resources," and the option to extend these protections to other resources. ${ }^{376}$

The functionality of ABS, which depends on each country's ability to achieve the results required under Article 15.7, may be possible only if there is a clear international standard of coverage. Left up to individual countries, a serious problem would exist for a country with a very limited definition and scope in its provider-side measures, when applying the law of a source country that uses a broader scope or definitional structure. This disconnection will be an obstacle for ABS functionality, even if all countries separately adopt both provider-side and user-side measures.

It is hoped that this critical gap can be filled by

${ }^{371}$ For example, the Cartagena Protocol or CITES must be at least as strict as the basic international requirements in those instruments. See, e.g., Cartagena Protocol, Art.2.4.

372 See e.g., International Plant Protection Convention, Art. 1. This provision notes that the Convention does not require any controls on species imports. In operation, Parties agree on a maximum level of national controls on plant products in trade, stating that no stricter standards may be used.

373 Even matters of cross-border liability (Arts. 4.b and 14) are only within one county's jurisdiction, in the sense that an action against a cross-border source of pollution must be brought in the country of the polluter, unless some special agreement with that country is applied.

374 As noted in Chapter 3, national systems currently utilize very different definitions of "genetic resources," sometimes creating and using different terms including "genetic heritage." (BRAZIL: Provisional Act No2,186-16.) Another approach is found in the Norwegian draft Nature Diversity Act, which also avoids the term "genetic resources," focusing on "genetic material from other countries" and on those who import it "for the purpose of utilizing genetic material." (NORWAY: draft Nature Diversity Act at \$60). The US National Parks Service regulations on benefit sharing are focused exclusively on research samples: "research projects involving research specimens collected from units of the NPS that subsequently resulted in useful discoveries or inventions with some valuable commercial application." (US NPS, 2006, Draft EIS, presented as Alternative B).

375 The African Model Act (African Union Model Legislation for the Protection of the Right of Local Communities, Farmers and Breeders, and for the Regulation of Access to Biological Resources, formally endorsed by all African Union States, 2003) specifically applies its ABS processes to all biological resources.

376 As noted above, virtually all transactions involving biological material are already governed by contract laws, and laws relating to illegal taking of the physical materials. It is only in the context of "utilization of genetic resources" that legal rights are not tied to the legal possession/acquisition of the physical sample. Hence, if one has violated national laws regarding biological resources, the source country will have normal recourse through existing laws and practices. 
the international regime negotiations. As shown in our analysis in Chapter 4, however, it will still be possible to resolve the issue through dispersed national legislation, if key countries with large numbers of high-profile users under their jurisdiction (and others) would adopt user-side measures based on a shared understanding of the three interlinked concepts "genetic resources," "utilization of genetic resources" and "benefits arising from the...utilization of genetic resources" - as described in Chapter 4.

\subsubsection{Provision imposing a direct benefit-sharing obligation}

The most direct element of user-side legislation is relatively simple to draft. The user country's law could simply state, in appropriate legislative terminology, that users of genetic resources with foreign origin must comply with all relevant laws of the source country including the responsibility to equitably share the commercial and other benefits arising from the utilization of those resources.

For countries that do not have significant number of users under their jurisdictions, this provision may be nearly all that is currently needed to satisfy their Article 15.7 obligation. For example, in many countries, the only users are developing agricultural varieties using conventional methods. If these countries are Parties to the International Treaty, and have developed the legislation necessary to implement it in their country, they may need only a simple statement about benefit sharing as to resources not on the ITPGRFA's Annex (and a call for the responsible agency to develop further regulations when/if other users and utilizations occur).

For all countries (including those with many users), this basic provision can support actions by source countries, communities, NGOs and others in user-country courts and agencies. It is not a complete solution; however, if even one user has been subject of an effective $A B S$ lawsuit, knowledge of that action may motivate other users to comply with $\mathrm{ABS}$ measures.

Finally, where a country's law imposes a clear duty on its own users, that provision may be a tool for motivating other countries to adopt user measures. Although no country has done so, source-country law could require that no user shall be given $\mathrm{ABS}$ permission unless the resources will be used in a country that provides basic user measures ${ }^{377}$ - i.e., a country that requires users of foreign genetic resources to (i) comply with the laws of the source country; (ii) comply with the terms and conditions of any relevant permit or contract; and (iii) notify the source country when the resources have been accessed. ${ }^{378}$ In essence, this approach reflects a basic fact of international trade law - WTO member countries cannot unreasonably control the entry of goods into their territory, but they clearly have a sovereign right to decide whether or not to sell, license or grant other rights to their own resources. A country would be legally within its rights to refuse genetic-resource access rights, unless the resources will be used in a country that will support and protect those rights.

\subsubsection{Oversight measures in user countries}

Once a user-side requirement is in place, it must be implemented. The law and/or the responsible governmental units must develop mechanisms and regulations clarifying how the requirement will be applied in practice, and how those practices will be overseen and confirmed. This step is essential to the functionality and fairness of the regime. It enables users to know exactly what they must do or document in order (i) to comply with the user-side measures, and (ii) to be able to prove that they have compiled. It provides a standard that the government or other users can apply when they need confirmation that the user has complied. Necessary regulatory provisions might include the following:

377 In the Seychelles, a proposed draft law was prepared by a team of foreign consultants, under a consultancy financed and undertaken by IPGRI. It is contained in Lettington and Dogley, 2006. In Article 20, that draft law provides that "The Competent Authority, in consultation with the Coordinating Agency and lead agencies, shall have the discretion to refuse access to the genetic resources of Seychelles where it is reasonably believed that the applicant is from, or otherwise based or operating in, jurisdictions that do not provide adequate guarantees for the respect and enforcement of this Act.

378 Ibid. The user measures described in the text are Articles 32-34 of that draft law. 
- Objective, externally determinable indicators by which a user can know that he is "utilizing genetic resources," including the manner in which the government or a court or litigant can objectively determine or confirm this issue;

- Indicators that define the various points at which a "benefit has arisen";

- Regulations that clearly spell out the benefitsharing process, in three possible situations:

o Where no benefit sharing is required by the source country - to confirm/document that conclusion;

o Where the relevant source-country law is identified - to comply with relevant benefit-sharing provisions and confirm or document that compliance; or

o Where neither option is reasonably possible for the user - to comply with user-side provisions by which the user country's government takes on the responsibility of benefit sharing.

- Mechanisms for documentation of these components, which will enable the user to prove their compliance.

No matter what the laws of the source country say, the measures in countries with jurisdiction over the user's activities will have the most direct impact on most users. Thus user-side measures will ultimately determine the functionality of the ABS regime.

\section{[a] Clarification/specification of coverage questions} For purposes of legislative and regulatory clarity, mandatory measures applying the $\mathrm{ABS}$ requirements (and incentives) must be based, to the greatest extent possible, on concrete factors - specifically, the three concepts and triggers described in Chapter 4 - genetic resources, utilization of genetic resources, and benefits arising from that utilization. For example, the adoption of a list of practical steps for case-by-case analysis to determine which resources are "genetic resources" does not appear to be possible. It might enable a few commodities to be completely excluded, ${ }^{379}$ but would not provide much help in determining whether the benefit-sharing obligation applies.

In general, for purposes of giving effect to user-side measures, it will be critical to develop objective methods of determining

- whether a person's or entity's actions constitute the "utilization of genetic resources," and

- which results and interim outcomes of that utilization constitute "benefits arising" from that utilization, triggering the user-side obligation to share benefits.

As discussed in 4.1.2 and 4.1.3, one of the most effective ways of "concretizing" these two concepts is through the use of listing provisions and other descriptive legislation. For example, to determine which activities constitute the "utilization of genetic resources," the law would usually create two specific components:

(i) a description of the attributes of "utilization of genetic resources" - describing observable characteristics or indicators which, if present, trigger the "utilization of genetic resources" element of the law; and

(ii) either a list or a process for developing a list of specific activities or categories of activities that constitute "utilization of genetic resources."

A user who is engaging in a listed activity should have the right to prove that his specific activities are not "utilization of genetic resources," based on the descriptive criteria. The government or other person seeking to require benefit sharing may seek to apply

\footnotetext{
${ }^{379}$ For instance, purified vegetable oil contains no DNA or RNA. (Personal communication, Seizo Sumida.) If the ABS regime were to determine that "genetic resources" means "DNA or RNA or any specimen or part containing DNA or RNA," then that definition would exclude processed vegetable oil, and possibly some other products.
} 
the law to an unlisted activity, based on those same criteria. A similar approach may be used to identify "benefits arising" from such utilization, and to specify when a benefit has "arisen."

\section{[b] How the "triggers" function in practice}

It is important at this point to compare the difference between the legislative triggers and the practices of access and benefit sharing. Currently, it is still expected that benefit sharing will normally happen through the ABS contract between the user and the source country, either directly or derivatively through some other provider. To date, although many ABS contracts are not available for review, a number have become public, in whole or in part. These agreements generally share a number of common factors, including the fact that some or all payments are made before any actual benefits have arisen. ${ }^{380}$ In some cases, these initial payments are specifically dubbed "access" payments (fees charged for collecting the specimens, etc.), but in others they have been designated as "milestone payments" or "progress payments." The Bonn Guidelines recognize this practice, noting that the timing of payments is a matter that may be agreed among the Parties, ${ }^{381}$ and that

[n]ear-term, medium-term and long-term benefits should be considered, including up-front payments, milestone payments and royalties. The time-frame of benefit-sharing should be definitely stipulated. Furthermore, the balance among near-term, medium-term and long-term benefit should be considered on a case-by-case basis. ${ }^{382}$

With regard to benefits, the Guidelines focus on the type of asset that may be transferred to the country under benefit-sharing obligation, rather than on the particular "benefits arising" from the utilization of genetic resources.

Thus, the legislative "triggers" do not tell all users what they must give in benefit sharing or when they must give it. A user with an $\mathrm{ABS}$ contract must simply comply with that agreement. Rather, the triggers are designed to create a specific point at which the duty of users is legally clear and applicable. When a user has met both triggers - utilizing genetic resources and receiving one or more benefits arising from that utilization - then the user country will be able and obligated to determine if that user has complied with ABS. Prior to triggering both, a user's obligation is still inchoate - that is, there is still no non-contract basis for claiming that he has violated his $\mathrm{ABS}$ responsibilities.

In addition to identifying the specific triggers, user-side legislation will have to provide specific steps that must be taken. For instance, some countries may wish to generate a list of "users of genetic resources," by requiring any user to file a notice at the time of the first trigger - i.e., whenever that user commences an "activity utilizing genetic resources." This approach may be useful, as it may cause users to realize at an earlier stage in their activities that they must comply with $A B S$ responsibilities. It also enables a broader range of oversight, since the government will have a basis for confirming that a person or entity is complying with these requirements at an earlier stage.

Other countries, however, may prefer to minimize record-keeping - requiring proof of compliance only after both triggers have occurred. To apply the triggers in this way, the government could require that

within XX days after the user receives any benefit arising from the utilization of genetic resources, he must provide (or be able to provide) appropriate documentation showing that he has complied with national benefit-sharing obligations of the source country.

This provision does not release the user from the duty to make earlier payments, if required under the ABS contract, but only provides a clear point at which the user country can confirm compliance generally. At that point, a user in compliance with an $\mathrm{ABS}$ contract

\footnotetext{
380 See Cabrera and López, 2007, and Rosenthal, et al, as quoted in footnote 279.

381 Bonn Guidelines, at $\$ 45$.

${ }^{382} I d$. , at $\$ 47$.
} 
must only provide documentation of that compliance; however, a user without such agreement will have to comply with user-side measures governing his benefitsharing obligation.

\section{[c] What is required? A category approach}

One of the most difficult aspects of the benefit-sharing requirement is the determination of what specific payments, forms of payment, shares, etc., are applicable to particular activities and users. Where the user has negotiated an ABS contract that specifically addresses benefit sharing, these matters are usually resolved. The only open questions might arise where the user is accused of not giving full disclosure or otherwise engaging in unfair commercial or contractual practices. If both sides of the $\mathrm{ABS}$ contract mutually agreed to fair and un-coerced terms of benefit sharing, then compliance with these terms should satisfy the user country's measures as well.

Where no agreement exists, however, a different question arises - what benefit-sharing requirements should be imposed by the user country, and how should those benefits be distributed? One way of resolving this question involves the application of the "list" or "category" approach to "utilization of genetic resources," described in [b]. There may be activities in which the activity itself appears to share benefits without further need to impose obligations on the user. This might happen where the benefit is universally available without any cost, for example. Other activities that involve more conventional uses of genetic resources (development of plant varieties, apart from LMOs, for example) may involve a lower level of benefit sharing (possibly under the ITPGRFA). It may be possible to develop a rather comprehensive "scaled" approach to benefit sharing, under which some activities are subject to lesser requirements and others to greater requirements, depending on the extent to which the contribution of the genetic resources is compensated in other ways and the nature of the activity involved.

The scale of benefit sharing as developed might ultimately serve as a basis for increasing the transparency of benefit-sharing negotiations, addressing one of the problems most frequently cited by both source countries and users - the fact that parties lack a shared understanding of the cash amounts involved in reasonable benefit sharing. A category system can be a focal process which finds a way to value various elements described in Chapter 5:

- the value of the genetic resources;

- the value of the benefits to users arising from the use of genetic resources;

- the "contribution" which the genetic resources make to the product or other benefit-arising;

- the value of benefits to be shared;

- the share of benefits that the source country should receive; and

- the value or comparability of the kinds of benefits paid to the source country with the source country's share of benefits arising.

\section{[d] Non-commercial benefits}

One particular area of concern relates to the sharing of non-commercial benefits - particularly research results and preliminary findings. A problem that has been confronted by some innovative analyses in recent years is the question of determining whether, when and how non-commercial benefits should be shared. ${ }^{383}$ There are very strong and compelling arguments suggesting that these benefits cannot be "shared" under conventional economic approaches, given that the sharing of preliminary data is an "all or nothing" proposition. One either receives the information or not. It is not usually possible to apportion data, since (i) random excerpts from the data will not have any value, and (ii) in order to agree that a "fair and equitable share" of the data is provided, someone will have to review all the data. In addition, it is hard to know when research results cease being preliminary, and become a "benefit arising" from the utilization of genetic resources.

383 Fernández Ugalde, 2005. 
In highly competitive commercial $\mathrm{R} \& \mathrm{D}$ sectors, there is often a strong interest in protecting all types of information. Some researchers and bioprospectors legitimately fear that others may preempt their findings, if those others are able to find simple non-scientific facts, including which species are being studied, where bioprospecting is being undertaken, etc.

In this atmosphere of rivalry and accompanying secrecy, requirements to share preliminary data, including the taxonomic identification of the species or varieties collected or the provision of reference samples (sometimes required by law in the source country ${ }^{384}$ ), may raise concerns about confidentiality for the user. This is particularly true in some developing countries, where controls on government-held information may sometimes be less dependable. Even where the country's laws require government to keep certain information confidential, the environmental or wildlife ministries who are charged with ABS oversight may not be trained or equipped in a way that ensures compliance with those requirements. Even giving duplicate samples to the agency might have this effect, if the agency later sells them to another user, for example.

It is possible that user-side measures can address some of these issues. One option might be based on national cooperation. If the user country has effective and protective laws governing trade secrets, ${ }^{385}$ it can serve as the holder of confidential information. A researcher whose activities utilize genetic resources can declare relevant information about the species, specific origin, particular research, etc., in a notification to the user country at the time of the first trigger (see [b], above). The source country could derive certainty regarding its rights in these benefits from knowing that the user is under government oversight, while the user could have a greater level of confidence in the protection of his trade secrets, if they are held in a country whose governmental trade-secret protection he trusts.

A more recent concern, however, has arisen with regard to researchers whose only goal is publication of their research results and data. As noted earlier, if those results enable other users to develop commercial products on the basis of genetic information, then the decision to publish and timing of publication may be of interest to source countries. ${ }^{386}$ In this case, a user country that keeps a list of users of foreign-origin genetic resources may be able to intercede between the researcher and the source country, to ensure that similar situations do not occur, further increasing source countries' desires to control, limit or otherwise stifle biological research.

\section{[e] Transparency}

A serious impediment to the numerous calls for streamlining and regularizing the $\mathrm{ABS}$ process is the fact that most $A B S$ contracts and negotiations are not transparent. This fact arises out of the very different perspectives of the parties to such an agreement. To the user, the ABS negotiation is a commercial negotiation - something which is confidential between the parties to the agreement in most similar situations. To many source countries, however, it is an agreement to transfer a national asset. Most countries require government officials to be very transparent in such negotiations, both to protect the official from later claims of improper or self-interested conduct, and to enable the civil society to serve as a watchdog.

The problem of "unrealistic expectations" cannot be addressed when the parties cannot obtain key information about the costs and value of similar properties. It is easy to see the value of public records

384 See, BHUTAN: Biodiversity Act, Art 9.b "Competent Authority, through the Authorized Agency, may grant access if ... [inter alia $]$.... The applicant agrees to deposit with the Authorized Agency duplicates of each sample collected and the associated information on collection sites of collected materials gathered from farmers' field or government forest."

385 "Trade secrets" laws generally provide that, where one is required to disclose confidential information to the government, that information can be tagged as a "trade secret" and the government must ensure that the information so provided is not made available to anyone, whether directly or indirectly. These provisions are common in IPR law, but also appear in nearly every law under which a commercial or industrial operation is required to file detailed technical information (reporting laws, permit applications, etc.).

386 Mgbeoji, 2006. 
of real-estate transactions, daily stock-market quotations and other transparency systems, in ensuring that negotiations are based on reasonable knowledge and expectations. It may be possible for the user country to provide an intermediate option in this regard. They could agree to maintain "blind" statistics (verified by the parties, but otherwise reported anonymously) regarding $\mathrm{ABS}$ contracts involving users in their country.

\section{[f] Benefit-sharing without an ABS contract}

It is critical for user-side legislation to avoid creating a "loophole" with regard to users who do not have ABS contracts or disclose the source of the resources they use. There appear to be a variety of options, some or all of which may be combined in legislation.

\section{Requiring post-facto negotiation of $A B S$ contracts:}

In this case, where the source country is known, but the user has failed to obtain an ABS contract, it may be appropriate simply to give the user a specified time to comply with the source country's laws - that is, to undertake PIC and MAT procedures, and comply with whatever benefit-sharing provisions are required. After a "hit," source-country expectations may be inflated by inputs from a variety of information sources. This might provide an incentive for users to obtain agreements at an early stage.

\section{Intergovernmental negotiation of ABS contracts:}

Another option, which could be used alone or in conjunction with the first option (applied where the first option is not possible or if the user does not comply within a specified time), would require the user country to inform the source country directly, after which the two countries could jointly determine the benefit-sharing responsibilities that should be imposed on the user.
Depending on how this option is worded, the government's involvement might lead to a more appropriate solution than the user could obtain alone. If so, it might be useful to impose conditions on the user which, if satisfied, could entitle the user to seek government assistance with the negotiations. ${ }^{387}$

\section{Where source country is not known or disclosed:}

For user-side legislation, the greatest difficulty arises where the source country is not known to or disclosed by the user. In those situations, it would be difficult for the user country to impose a benefit-sharing obligation. It may not be possible to determine the source country of a particular sample through scientific analysis, even where the relevant equipment and technicians are available within the country. ${ }^{388}$ Legislatively, it would seem essential to provide a mechanism for benefit sharing in these cases. Any practical approach to addressing this situation would appear to require two elements:

- a mechanism for less direct benefit sharing, such as the creation of a trust fund used to assist developing countries, or a mandatory process under which the user gives such assistance directly to one or more developing countries; and

- a legislative formula or formulas for determining the appropriate amount and form of benefitsharing payments.

While the creation of a trust fund will be a relatively manageable task, ${ }^{389}$ the valuation element, as discussed in Chapter 5, is a very difficult legislative measure. To date, little effort has been made to address the economic valuation issues most relevant to legislative development. ${ }^{390}$

387 A version of this approach is found in JAPAN: Guidelines for Access to Genetic Resources for Users in Japan, under which users may call upon the government for help in ABS negotiations and processes in source countries, so long as the users have complied with the Guidelines.

388 Personal communication, Leif Christoffersen, Diversa Corporation, 7 May 2005. A further discussion of the legal capability of modern technology to identify the species that is the source of particular genetic resources is found in Ruiz and Lapeña, 2007, at Chapter 5. In all cases, identification will not discern the source country unless the species is already known to be a narrow-range endemic found only in a particular country. In addition, each use of this kind of analytical process may be very expensive. It may be difficult to use these processes as a primary enforcement/oversight tool i.e., for general determination that the species involved does not have its origin in the user country, but it may be possible to require the user to undertake such analysis, where the source country is unknown or undisclosed. 


\section{[g] Confirmation of the data provided by the user} The final legislative challenge to be considered in this section is data confirmation. In order for a legislative framework to be effective, it is essential to provide some mechanism for ensuring that notifications, documentation and reports are complete and correct. Recent experience with CITES implementation has demonstrated how easy it is to manipulate reports, statements, notifications and documentation with regard to species origin and other factors. ${ }^{391}$ Although these violators constitute only a small percentage of the number of persons importing and exporting CITES species, they involve a very large volume of illegal traffic in controlled specimens and parts.

In ABS implementation, the opportunities for such abuses and the difficulty (near impossibility) of confirming the validity of statements made constitute major problems for legislative drafting of both provider-side and user-side measures. While most users may honestly com- ply with reporting obligations, the failure to provide confirmation mechanisms is one way in which national legislation might create a perverse incentive, encouraging the unscrupulous to find ways of manipulating the system, particularly given the potential value of genetic resources. ${ }^{392}$

In some cases, policy-makers and international negotiators are quick to suggest that $\mathrm{ABS}$ oversight can be added to the responsibilities of other agencies (customs and patent offices are two that are most commonly mentioned). Owing to the specialized and technical nature of many ABS claims, documents, notifications and reports, however, it is probably not within the qualifications of officers in other agencies operating with different mandates to take a major evaluative role in ensuring $A B S$ compliance.

\subsection{Proposals for internationally accepted ABS measures and tools}

In recent years, the problems of ABS implementation have been considered by a number of experts, as well as by national and regional institutions, and the international discussions under the CBD. Concerns about the various gaps in the ABS system have led to a variety of proposals for individual measures or tools designed to address such gaps. While none of these tools would substitute for userside measures, they might be of use, once most countries have formally addressed their basic national responsibilities.

The following discussion considers five types of measures that have been formally or informally proposed or suggested. The first measures it considers are focused on the problem of international communication between the user country and the source country. This is a critical element of the ABS system, but also a matter which is often very difficult to address in practice. $^{393}$

In the current discussion, the problem of transboundary information flow is addressed in different ways, depending on which direction information is flowing:

problem for this particular type of fund); and (ii) ensuring that the funds involved are protected from being redesignated for other purposes (not normally a difficulty in developed countries).

390 A Norwegian study by Romstad and Stokstad, 2005, discusses valuation of genetic resources but focuses only on the genetic resources as an input to biotechnology rather than looking at the social and biological contribution made by genetic resources in situ. Their literature review concludes that due to the lack of alternative scenarios, "...the value estimates of most applied studies to date are questionable" at page 24.

391 These matters were discussed in detail in the Expert Workshop for EU-CITES Authorities on EC Legislation on Wildlife Trade - Experiences, Challenges and Future Perspectives (14-17 November 2006, Vilm, Germany). Smugglers and other violators have been found to be manipulating CITES export and import permits, listing the wrong species, duplicating the permit for "species parts" and using it to justify re-exports and sales of a number of specimens far in excess of the original amount imported, etc.

392 In recent years, many criminal enterprises which formerly focused on drugs and other criminal sectors have turned their attention to crimes such as illegal wildlife trade, since the penalties and level of enforcement and prosecution are significantly less in these sectors. Anton et al., 2002.

393 Most countries, for example, do not authorize government officials below the highest levels to interact directly with government officials of other countries, unless there are clear limits and controls on that interaction. 
- "Certificates of source, origin or legal provenance" - proposals designed to provide information from the source country to the user country; and

- "Disclosure of origin" e.g., in patent applications - to provide information from the user country to the source country.

The other three proposals discussed here relate to substantive problems of identifying source countries and determining how benefit sharing should be undertaken. These proposals include

- The "internationalization" of benefit sharing through the use of central funds and other tools;

- The development of "standard" or "minimum" provisions applicable to countries which have not adopted formal "ABS law;" and

- The creation of a "standard contract" to regularize ABS negotiations.

\subsubsection{Source-country validation: Certificate proposals}

The idea of creating an "internationally agreed certificate of source, origin or legal provenance" (to which some add "compliance") is now being discussed. ${ }^{394}$ It may be obvious, even from the title, that this discussion is a bit premature, since the primary negotiators do not know what element (source, origin, legal provenance or compliance) must be certified. The various certificate proposals embody quite different concepts. As to each bit of information included in the certificate, one must ask "Which agency or other person is able to certify this fact?"

For example, as noted in 2.4 , the terms "source," "origin" and "provider" are still not clearly defined in CBD discussions. It is entirely possible that, for a particular genetic resource, the source country, country of origin and provider country might be three different countries. A specimen may be native to (found in in-situ conditions in) several different countries, it may have been originally collected in the wild by a researcher, ex-situ collection or other person who took the resources out of one of these to his home country. From that researcher's country, it may have been sold or transferred to a user (directly or through other intermediary transactions). It is questionable whether a single person, community or agency that granted the ABS could certify the "legal provenance" of the resources in this example.

Neither can that person validate the "legal prove- nance" of the specimens, nor the user's or collector's "compliance" with the ABS laws of the source, origin or provider country). Similarly, "compliance" is an ongoing process in ABS, since the user must not only obtain PIC and MAT, but must continue to comply with them throughout a long period of access and utilization of the resources.

Thus, the context, purpose and use of the certificate must be known first, before a certificate can be created. If the "certificate of source" is needed (where a law requires the user to verify the source of the material), then it will be necessary to adopt standards for determining the source country - including for documenting the path by which a particular resource got into the hands of the user. In some cases, it may also be necessary to determine the source very narrowly, where, for example, there is a claim that the material was collected on indigenous lands, which are subject to special treatment under national law.

If a "certificate of origin" is called for, standards and mechanisms for making this broader taxonomic/geographic determination (possibly through integrated searching of all national biodiversity inventories) will be needed. Because there can be many countries of origin for most species, it may be necessary to include some cut-off mechanism so that the search process is reasonable.

394 See the original mandate for work on this issue, at UNEP/CBD/COP/7/21 VII/19 E, (request) 7, page 304: "Requests the Ad Hoc ... " UNEP/CBD/COP/7/21 VII/19 D. 
Certification of "legal provenance," "compliance" are also problematic from a practical perspective. Here the main problem is the need for such a certificate to be "binding" in some way. The certificate will be used by some purchaser or agency as proof, but the question is "proof of what?" "Legal provenance" is often taken to be proof that the user complied with the initial requirements relating to PIC and MAT prior to access or utilization of the resources. Normally, to avoid legal abuses, the agency that issued the ABS contract or permit would not be authorized to certify legal provenance. Hence a certificate of "legal provenance" would normally be issued or validated through a different agency or office or through the Attorney General, to ensure that governmental processes are undertaken in a legal and non-biased way.

Similarly in a certificate of "compliance" one may be essentially certifying that the genetic resource is being utilized with permission, or that the user has complied with relevant obligations, etc. However, if this is the objective, the source-country government can usually issue such a certificate only for a single point in time. In essence, the certificate says "As of the date shown below, the official signing this certificate can attest that, to the best of his knowledge, that XX." A year (or a month or a week) later, the statements made in the certificate may no longer be true, or the official may have discovered some condition or violation that invalidates the certificate. The only solutions

\subsubsection{Communication of user-side information to source countries - disclosure of origin}

One conceptual problem with the ABS framework as it currently is discussed, is that it will require source countries and providers to undertake the lion's share of ABS enforcement. This burden may eliminate most possibility of enforcement. If they are to enforce their rights, however, source countries must have detailed information concerning the utilization of genetic resources by users operating in other countries. As noted in 6.4.4.3[e], the source country's complete lack of access to any such information (apart from the to this problem appear to be either -

(i) to create a certificate that is fully binding on the country (so that the official's lack of knowledge, or subsequent changes or discoveries cannot override the statements in the certificate); or

(ii) to tie the certificate to a specific point in time only, and create a system that transfers responsibilities to the source country along with the transfer of the resources.

Other kinds of certificate requirements have been suggested, including most prominently certificates regarding the transportation of genetic resources across national boundaries. All these must face the questions of verification and other implementation problems, once they have been designed and agreed (see 6.4.4.3[e]-[g]). Before that can happen, however, it is necessary to determine what specific function the certificate is intended to fulfill in the ABS system, and to ensure that legal consequences follow any person who fails to obtain a certificate. ${ }^{395}$

The development of certificates and other mechanisms for improving transboundary information flow with regard to $\mathrm{ABS}$ compliance may be extremely useful in many ABS contexts. Until the contextual needs are developed sufficiently, however, it is probably unprofitable to engage in more detailed discussion of the mechanisms that need to be created to address them.

unverified reports by users who have ABS contracts) provides a major obstacle to the functionality of $A B S$ as it is currently conceived. Over time, it has been recognized that some other mechanism is necessary to provide information about users who are generating benefits through the utilization of genetic resources. Up to now, the only laws or proposals which address this concern relate to "disclosure of origin." Disclosure measures of this type have been adopted as laws in three European countries. ${ }^{396}$ Proposals for mandatory

\footnotetext{
395 Tvedt, 2006.

396 Note by the Executive Secretary, 2004, "Analysis of Measures to Ensure Compliance with Prior Informed Consent of the Contracting Party Providing Genetic Resources and Mutually Agreed Terms on which Access Was Granted, and of Other Approaches, Including an International Certificate Of Origin/Source/Legal Provenance," UNEP/CBD/WG-ABS/3/5, section II, D. The submissions of Denmark, Norway and Sweden address this issue.
} 
disclosure have been aired in both $\mathrm{CBD}$ and IPR forums. ${ }^{397}$

Under the mandatory disclosure proposal, patent applicants whose innovation was created utilizing genetic resources would be required to disclose information about the source, provider and/or legal provenance of those genetic resources in their patent application. Without commenting on the political processes or various technical arguments against such a requirement, ${ }^{398}$ we note that little attention has been given to date regarding the questions of primary relevance to this book - how the disclosures will operate, and what impact they could have on the achievement of the objective of fair and equitable benefit sharing.

The potential effectiveness of disclosure proposals for fair and equitable benefit sharing is questionable at best. ${ }^{399}$ Many experts have noted that the work of officials processing patent applications is already both difficult and time-consuming. Some have cautioned about the additional costs to the patent system, which is entirely separate from environmental and conservation ministries and finds its funding in the private sector, and as such will have a very weak institutional incentive (at most) to implement this requirement. ${ }^{400}$ It has also been noted that the object of the $\mathrm{ABS}$ disclosure is not related to improving the patent. The few mandatory disclosure proposals that exist generally state that false disclosure or other violation of this requirement will not result in rejection or revocation of the patent. ${ }^{401}$ The failure to meet the ABS disclosure requirement in Norway is regarded as a crime, punishable by fines and imprisonment... but the patent will still be valid. And the possibility of imposition of those fines is relatively limited. It is far from easy to convict a person guilty of not providing such information. ${ }^{402}$

Moreover, unless these disclosures are verified in some way, they would seem unlikely to provide any value not already provided by national $A B S$ legislation in source countries. Those who feel that they need not comply with source-country ABS - because, for example, they assume that resources are not subject to ABS requirements - will probably also feel that they are not required to comply with the patent disclosure requirement either.

\subsection{3 "Internationalized" mechanisms for benefit sharing}

Suggestions have been proposed for addressing the forgotten or undisclosed. The following sections problem of identifying the source country or country of origin, in cases where the actual source is unknown, discuss proposals for "internationalization" as a means of simplifying the issue.

The full submissions are found in "Submission to the CBD, in preparation for the third meeting of the CBD Ad hoc Working Group on ABS," reproduced as UNEP/CBD-WG/ABS/INF/3/1.

397 Proposals have been aired before the TRIPS Council of the WTO (see the proposal from the EU WTO document IP/C/W/383); the WIPO meetings on the Patent Co-Operation Treaty (see the Swiss proposal, WIPO document PCT/R/WG/4/13); and the WIPO Intergovernmental Committee on Genetic Resources, Traditional Knowledge and Folklore (IGC). So far, however, it has not been suggested in the Standing Committee on Law of the Patents for the draft Substantive Patent Law Treaty (draft SPLT). Such a solution to the benefit-sharing challenge was suggested by Hendrickx, Koester and Prip in 1993.

398 An excellent and detailed analysis of the "mandatory disclosure" proposals, in terms of their impact on patent law, is found in the WIPO response to the CBD, currently in interim form as Annex to WIPO document WO/GA/32/8. These matters have also been one important part of the discussions in the Intergovernmental Committee on Genetic Resources, TK and Folklore.

399 Tvedt, 2007.

400 While additional costs will undoubtedly arise, the question of the cost of the system should be a balance between cost and benefit - what additional value to the ABS framework will be derived from the additional institutional costs? It will also be necessary to determine how these costs will be allocated among governmental sectors, and borne by the most appropriate agencies and individuals. All of these matters are clearly important. Unfortunately, much of the discussion of this issue is steeped in invective, and some of the most widely publicized comments about the costs of a disclosure system have been highly controversial, but easily discounted because they appeared to have been based on insufficient data and understanding of both ABS and IPR law. Wolfe and Zycher, 2005. This document was circulated very widely in many languages prior to CBD SBSTTA-11.

401 See e.g., EU Directive on Biotechnological Patents EC/98/44 (preamble).

402 Tvedt, 2007. 


\subsubsection{International fund and "standard payment" or tax system}

One option, which was first suggested in the CBD negotiations, ${ }^{403}$ is the creation of an international system under which benefits, in the form of a standard payment, would be collected from users without reference to specific uses or specific resources. In this system, "users" would be defined by category of operation (e.g., pharmaceutical companies, seed companies, etc.) and all persons and entities within those categories would be charged. Such benefits would be paid into an international fund and used for particular activities designed to promote conservation, sustainable use, and the livelihoods of rural communities and indigenous peoples.

A variant on this approach would create a system wherein benefits from the use of a particular species would be shared among all countries that constitute "countries of origin" for that species, under the CBD definition. ${ }^{404}$ Although the technical and technological aspects of this approach are somewhat prohibitive at present, it underscores the problem posed by having multiple countries of "origin" for each species.

The "fund" option, although generally preferred by the legal experts and those charged with implementing ABS, did not find general favor in the negotiations. It was eventually dropped, in preference for the model in which each country separately controls all genetic resources found within its jurisdictional boundaries through a combination of national legislation and private contracts. In the ensuing 15 years, however, the failure of $A B S$ to develop into a thriving market tool paying benefits to individual countries has been recognized as a system-design problem. As noted in 6.4.4.3[f], above, some kind of "fund" or other more general benefit mechanism may be needed in order to apply ABS to users who do not know or will not disclose the source of the genetic material that they use. It may be possible to develop this mechanism internationally and/or to link such a mechanism to other elements of the ABS process. There are some who feel that such a fund could create positive incentives for companies to enter into regular ABS contracts.

\subsubsection{The Fund under the International Treaty on Plant Genetic Resources}

A modified, narrower form of this approach has been adopted in the form of the ITPGRFA's Multilateral System (MS) and Fund. Its basic premise is that agricultural varieties (in the international collections and elsewhere) should be exempt from standard ABS processes, because the benefits arising from utilization of these resources are already shared by the world both through unrestricted access to the collections and through the development of varieties and processes that enhance food security, directly benefiting all countries. The MS serves in the first instance as a vehicle for maximizing access to listed plant genetic resources. In addition, however, the access provided through the MS is itself considered the primary benefit of the system.

The International Treaty has recently adopted a "standard material transfer agreement" (SMTA) to be the form contract that will be used in all MS transactions between collections and users. ${ }^{405}$ MS users must pay a specific benefit (currently set at $1.1 \%$ of the profits from the product, except for sales of the product as a commodity) into the Treaty's financial mechanism (expected to be a Trust Fund), which

should flow primarily, directly and indirectly, to farmers in all countries, especially in developing countries, and countries with economies in transition, who conserve and sustainably utilize plant genetic resources for food and agriculture. ${ }^{406}$

This obligation will not apply, however, when "such a

\footnotetext{
403 Glowka et al., 1994, introduction.

404 See, Vogel, 2007. This approach would be based on the "species inventory" - a primary requirement of the CBD (Article 7) which has been incompletely addressed in many countries.

405 Standard Material Transfer Agreement, adopted at the first meeting of the Governing Body of the ITPGRFA, accessible online at http://www.fao.org/AG/cgrfa/itpgr.htm.

406 ITPGRFA, Art. 13.3 .
} 
product is available without restriction to others for further research and breeding." ${ }^{407}$

The most important element of the ITPGRFA system is the International Agricultural Research Centres (IARCs), many of which include large collections of plant germplasm. ${ }^{408}$ These collections offer many functional supports to the Treaty's operation, including the fact that they were generally using a standard MTA system and international oversight mechanism before the Treaty went into force. If the ITPGRFA system functions effectively, it will provide several additional incentives for countries to provide material to these collections.

As of this writing there is relatively little information about how the Treaty, MS, SMTA and Fund are operating, since the system has been completed very recently. If it is found sufficiently useful, the ITPGRFA might provide a useful approach which could be applied to other resources. Already, FAO is considering whether there is a need to develop a separate mecha- nism for "Animal Genetic Resources for Food and Agriculture," but has recognized that existing animal breeding practices have very different legal needs from those of plants.

\subsubsection{Special collections for access and use of genetic resources}

Another international approach has been suggested for various types of research institutes. The most basic form of this approach is found in the "MicroOrganisms Sustainable use and Access regulation International Code of Conduct" (MOSAICC), ${ }^{409}$ created by a consortium of culture collections, their users, and governmental, industrial and environmental authorities, directed at providing good practices and traceability with regard to this important aspect of biological diversity. Although implementation of MOSAICC is voluntary, the target group is generally very interested in implementing this system, given their particular concerns with preserving both research and sources of specimens.

\subsubsection{Advantages and disadvantages of standard contracts}

In some discussions, it has been suggested that the Parties should consider the development of a "standard contract" for ABS, following the lead of the ITPGRFA and its recently adopted SMTA. Given that such an approach may become an option at some point, it is useful to consider how it would be adopted and used, before setting it as a current goal.

Initially, one must consider the major systemic obstacle to this approach - in the current ABS system, standard contracts could apply only to "access" situations where users collect resources directly from the source country. Hence the adoption of a standard contract would not eliminate the need for user-side measures and would not solve the problem of lack of implementation in the user country.
One aspect of the creation of a model agreement is the need to get all parties to agree in advance to use it. In effect, this constitutes a pre-negotiation of at least part of all future ABS contracts. However, if adopted in international negotiation, the agreement would bind only the source countries - who constitute less than half of the future parties to ABS contracts. Most users are not governments but private companies and researchers. In addition, in some countries, the provider-side of $\mathrm{ABS}$ negotiations is also devolved to private landowners, who negotiate on their own behalf, and who receive benefit sharing directly. ${ }^{410}$

Many countries consider genetic resources to be part of their national patrimony or state property, protected by the government's fiduciary duty to its citi-

\footnotetext{
407 ITPGRFA, Art. 13.2(d)(ii).

408 The IARCs are generally unified under the overarching Consultative Group on International Agricultural Research (CGIAR), see http://www.cgiar.org/who/index.html.

409 Online at http://bccm.belspo.be/projects/mosaicc/.

410 One example that was studied in the context of researching this book is found in Australian law.
} 
zens. By agreeing to the model, all countries would in essence be limiting their ability to control, negotiate and vary the terms and conditions by which they are selling/transferring this property.

The negotiation of standard or model agreements usually focuses on two questions: (i) Which provisions will be standardized in the model and which are left blank to be filled in individually? and (ii) Which model provisions may be changed or cut in the course of the negotiations, and how? The model only streamlines negotiations where it minimizes the ability of the parties to alter model provisions. This approach was relatively straightforward in the ITPGRFA process, given that the SMTA's primary use will relate to accessions from the IARCs. Those collections are all part of a single system (the CGIAR) that had already been increasingly under unified governance and contracting structure prior to the adoption of the Treaty. Even so, the negotiations of the SMTA were difficult and controversial.

In the case of $A B S$, there is currently little standardization as all countries are operating under their individual governance systems. They have been encouraged to adopt individualized "benefit-sharing plans," 411 further entrenching the uniqueness of each ABS negotiation. If the CBD Parties generally agree to adopt a standard contract which includes sufficient flexibility to address all the variability of the ABS concept and the legal and political differences among source countries, it is quite likely that the document may not resolve negotiation problems. Users of model documents often create inadvertent problems, by writing in new provisions that conflict with model

\subsubsection{Standard or "default" legislation}

Another option that has been informally suggested is the development of "standard legislation" - measures that will apply to transactions in any country that has not yet adopted its own provider-side legislation provisions, and then failing to exclude or cancel the model provision. These cases often lead to litigation to determine whether the contract is binding, and which provisions apply. If the standard provisions are problematic, the Parties will ultimately convert them into guidelines or recommendations, allowing the negotiators of any ABS contract to choose other options. Premature model development may result in the (costly) creation of a model that is never used. ${ }^{412}$

In general, model contract provisions are best created when there is significant experience with the operation of the contractual system or sector involved. As any contract lawyer knows, experience rather than legal analysis is the best source of knowledge regarding issues, operations, surprises and controversies that arise under contracts.

This general rule is also applicable in international negotiations. The ITPGRFA's SMTA could be negotiated early in the Treaty's life, because the Parties already had many years' experience with the IARCs and their model contracts. There is another risk in international negotiations that does not trouble the drafters of model contracts for private negotiations - international documents must often be adopted by plenipotentiary negotiation processes, which means that it is much more difficult to revise or amend them when experience shows that some provisions are not functioning well. Accordingly, it may be better to wait until there is broader experience with ABS contracts, and their content and functionality are more generally known.

(including PIC and MAT). Here also, the rights and uniqueness of each country would suggest that it would be difficult to develop a single document that would function as default legislation for countries

411 ten Kate, K., A. Wells, M. Baudoin and B. Zapata, "The role of strategic planning in the design of national policy on access to genetic resources and benefit-sharing: The genetic resources component of Bolivia's National Biodiversity Strategy and Action Plan," Royal Botanic Gardens, Kew (UK) and Directorate General for Biodiversity (Bolivia).

412 One possible example of this is the provisions of the UN Convention on Law of the Sea (UNCLOS. Montego Bay, 1988), with regard to "marine scientific research." UNCLOS, Arts. 143, and 238-265. The wide latitude of countries to use other means of authorizing researchers in waters under their jurisdiction or dominion has meant that the MSR provisions are rarely used and have not developed into a useful part of marine governance. 
that do not have a specific ABS law. As noted above, for example, the fact that a country has not adopted a specific, separate written law exercising its sovereign rights under Article 15 does not eliminate those sovereign rights. Most countries already have some law (written or not) defining the government's role with regard to its own resources, patrimony, state property, and other matters over which it has sovereign rights. Often, this law will be sufficient to enable the government to address at least some key aspects of the access side of ABS without adopting any separate law.

The problem with standard legislation might be more obvious, if one considers the same option for user-side measures. Most countries with many users under their jurisdiction would be unwilling to accept externally derived user measures that they have not adopted legislatively.

Thus, default legal provisions directly contravene the most basic sovereign rights of each country - the right to govern themselves and all matters within their jurisdiction. Default legislation can only be effective where the country has specifically signed and ratified it and then adopted it as national legislation, which somewhat defeats the purpose of creating default measures. 



\section{Conclusions: User-side Measures - A Necessary Element of the International Regime on ABS}

In conclusion, we return to the basic purposes that led to the writing of this book. The CBD objectives are essential international priorities, linked to the longterm well-being of the planet and the more urgent needs to alleviate poverty and promote sustainable improvement in the areas of health, food security and international equity. Biotechnology and modern development are critical elements of achieving those priorities. When fed with access and the rights to utilize micro-physical material and genetic information, these commercial motivations can create a broad range of benefits that can be used to further fulfill both environmental and developmental objectives. Mechanisms such as technology transfer, repatriation of information and capacity development can also be fuelled by a burgeoning market in biotechnology, if that market is also inexorably linked back to the goals of conservation and sustainable use. The CBD is somewhat unclear about the mechanisms by which this linkage and support will function, but it clearly envisions that $\mathrm{ABS}$ shall provide both benefit and incentive elements.

In the past 15 years, however, the specifics of how ABS will function, and how it will serve those primary objectives have been subjects of long debate. This book has provided a basic analytical pathway to help enable countries both to recognize the reasons why it is in their best interests (individually and collectively) to implement Article 15.7, and also to provide a legal basis on which they can take initial actions toward the goals of

(i) satisfying the requirements of due process of law (eliminating ambiguity and inconsistency that would make a law unenforceable) within their own country; and

(ii) enabling rational interaction of user-country laws with source-country ABS laws in each transaction.
The lack of national examples and experience in the area of user-side measures has prevented us from making a full set of final conclusions on these points. However, based on the application of primary legal and legislative standards, as well as the existing body of commentary, data, analysis and opinion on ABS, some of our conclusions are very clear.

First, we note that all countries are required to adopt user-side measures under CBD Article 15.7. Unlike the CBD's requirements on the provider-side (access), Article 15.7 does not specify particular actions that must be taken, but specifies the results that must be achieved - "sharing in a fair and equitable way the results of research... and the benefits arising from the...utilization of genetic resources." Although the Bonn Guidelines provide a list of userside measures that might be useful in satisfying Article 15.7, these are not the only options. If they are not successful in achieving the required results, then other measures will be needed.

Second, we conclude that no country has successfully adopted the primary user-side measures that are necessary - that is, a basic provision requiring users under their jurisdiction to fairly and equitably share benefits arising from their utilization of genetic resources with origin in another country. Virtually none of the user-side legislative requirements set out in the Bonn Guidelines have been adopted in any country.

Third, we note a primary need which can be thought to underlie the complete failure of countries to adopt user-side ABS legislation - the lack of a unified, internally consistent framework to clarify the key definitions and triggers of $\mathrm{ABS}$ obligations. While recognizing the difficulty of developing such a framework, we suggest that it is possible to extract the first elements of a functional framework out of the language of the CBD, and have offered a set of elements around which functional national implementation could be constructed: 
"genetic resources" - a meta-concept which incorporates certain characteristics of each species, whether obtained and utilized directly (by obtaining samples and specimens) or indirectly (by utilizing information, such as gene sequences, biochemical formulas and other unique properties of the species). They represent a right which is not obtained with the specimens but must be agreed to by the source country. Genetic resources are not externally or objectively determinable by looking at the resource, because the potential to use genetic resources is present, to some extent, in nearly every biological specimen.

"utilization of genetic resources" - an objective concept that can be verified by inspection, reports, results and other externally determinable factors. One who engages in the utilization of genetic resources triggers the application of ABS user-side measures with regard to those activities.

\section{"benefits arising" from the utilization of genetic resources - another objectively verifiable concept that constitutes the "second trigger" of user measures. When benefits arise from utilization, the user becomes fully obliged to share a fair and equitable percentage of those benefits.}

While none of these three is simple to adopt or to apply, they can be interlinked together to form an internally consistent framework for user-side measures that will arguably address the full range of situations to which Article 15 is intended to apply. They will also provide a basis for implementation of other genetic-resource-related commitments of the CBD, including the genetic-resource components of technology transfer, capacity building, biotechnology opportunities and biosafety implementation.

Fifth, the issues of valuation and equity in $\mathrm{ABS}$ are still rather dark and murky waters, legislatively. While significant inquiry into these issues has been conducted and is ongoing, their role in legislative implementation has largely not been discussed. Their most significant application is in the area of user-side measures - oversight of compliance with ABS contracts and with the broader obligation to share benefits.

Sixth, one of the most important gaps that prevents further progress toward $A B S$ functionality is the loophole by which users who do not know or disclose the source country of the resources they are using are not required to engage in any benefit sharing or substitute activity. Even more than the practical unenforceability of ABS contracts, the failure to adopt user measures to close this gap has rendered ABS a very ineffective system, and closed many options for increasing its effectiveness.

The near total lack of existing national user measures (that is, a country's legal, administrative and other measures to address the responsibilities, rights and needs of the users of foreign genetic resources who are under the country's jurisdiction) has prevented the preparation of a "best practice" analysis, but given rise instead to a discussion of the primary elements that would be necessary to meet the requirements of Article 15.7 and the Bonn Guidelines. At a minimum, those requirements seem to call for either

(i) provisions that impose a benefit-sharing obligation on all users of foreign-origin genetic resources, including those who have not obtained an ABS contract, or who have obtained the genetic resources from some third person, outside of the country of origin; or

(ii) incentive/motivation measures that are sufficient to engender a high level of benefit sharing by users seeking to obtain the incentive or advantage.

If the latter measures are sufficiently strong, they may eliminate the need for mandatory measures entirely. Even in that case, however, the user-side legislative process will not be cost-free, as there will still be a need to oversee the incentive measures to ensure that they are only available to users who comply with $\mathrm{ABS}$ requirements.

Mechanisms for the user-side implementation of ABS have been proposed and may be useful in future, but will not create an effective regime, unless and 
until countries adopt a basic framework of user-side measures. In the meantime, it is inappropriate for developing countries to repose confidence in disclosure requirements or in certificate systems that are not linked to implementation or enforceable benefit-sharing commitments. WIPO and the CBD discussions seem to give too much attention to these tools, given the stage of the current negotiations. Pending agreement on the objectives of the negotiations or on the manner in which the ABS framework should be conceptualized, disclosures and certificates will constitute, at most, permissive and unverified voluntary statements.

There is hope that the current ongoing CBD's negotiations of an "international ABS regime" may result in concrete and usable outputs. One strongly desired result could be the Parties' adoption of agreed interpretations of key terms. The negotiations might also develop structures for collaboration between each user country and source country in a variety of areas, including

- oversight of users;

- data collection and control;

- application of trade-secret protection pursuant to which users could confidently provide critical information that enables the ABS system to function as a transparent market, in which all parties have reasonable expectations;

- development of bilateral agreements and relationships to aid users seeking access to genetic resources;

and other matters. These results might in turn produce enough regime-wide specificity to enable the creation of formal mechanisms, such as certificates designed to address particular information needs of the regime.

Another possibility, however, is that the negotiations might simply adopt a process for longer-term regime development, and authorize the creation of certificates and other tools when the need for them arises. It is also possible, however, that the negotiations will result in even less concrete outputs, thereby returning the responsibility to the states to develop national legislation and engage in the slow process of adjustment by which all countries' various approaches will eventually become inter-operable.

There is one final question that must be addressed: Why would any country would adopt user measures? Essentially, as viewed independently in each country, user measures appear to require the country's industrial and research communities to pay money to other countries. This may be politically difficult to "sell" to legislators within any country, and may constitute a major disincentive preventing legislators from adopting real user measures. Accordingly, it is essential to enunciate the rationale for CBD benefit-sharing legislation, from the perspective of the user country and commercial and market interests.

Ultimately, there are multiple rationales which are all equally valid. Countries which may not be able to exploit these resources themselves bear all significant costs and missed opportunities in protecting their biodiversity. These sacrifices would be compensated by those who exploit those resources in new ways and who would not otherwise recompense any of the environmental and conservation costs. The most practical expression of the reason for taking this step, however, was enunciated by the European Commission:

The issue of $A B S$ is potentially a win-win situation for trade and environment since benefits arising from the commercial use of genetic resources can be used to foster the protection of biodiversity and since the expectation of such benefits is an incentive to conservation. ${ }^{413}$

In the same way, the adoption of user-side measures by all CBD Parties and non-parties would be a winwin situation for users of genetic resources. User-side measures can provide a balance in ABS which is currently heavily weighted (and sometimes myopic) in

413 EC, 2003. 
addressing only the interests of the source countries and providers. User measures can increase the confidence of source countries, enabling them to streamline and regularize their $\mathrm{ABS}$ processes, decreasing the regulatory burdens that currently oppress researchers and the small percentage of genetic resource users who obtain those resources by bioprospecting in source countries. 


\section{CODA: Beyond Beyond Access - Other User-side ABS Obligations in the CBD}

One important aspect of user-side measures and obligations is embodied in the commitments that countries made under other primary obligations of the CBD, which (apart from general financial obligations of Parties under Articles 19 and 20) relate to ensuring or promoting

- source-country participation in scientific research/development based on that country's genetic resources;
- technology transfer; and

- information exchange.

These responsibilities may not be easily passed through to users. Consequently, any country with jurisdiction over users of foreign-origin genetic resources may need to provide a higher level of direct government action and involvement to meet these commitments.

\section{CODA 1 Promoting "full source-country participation" in scientific research}

Article 15.6 identifies one further ABS obligation connected with the use of genetic resources (beyond the obligation to bring about benefit-sharing):

\begin{abstract}
Each Contracting Party shall endeavor to develop and carry out scientific research based on genetic resources provided by other Contracting Parties with the full participation of, and where possible in, such Contracting Parties.
\end{abstract}

\section{CODA 1.1 Duty to carry out research}

At a minimum, Article 15.6 suggests that user governments must either engage in or promote research. At present, however, few governments may be directly involved in the level and volume of scientific study that will enable the development of scientific research programs and activities based on genetic resources, and their implementation in the source country. This
Although Article 15.6 has not been well promoted or developed, its requirements may ultimately be among the most important in Article 15. In essence, these provisions are an affirmative commitment to scientific development, and they apply only to genetic resources. ${ }^{414}$ On its shoulders, this commitment carries a further obligation - this research shall be developed and carried out with the source country's "full participation" and, where possible, in that country.

suggests a need to allocate funds and incentives for the development of partnerships between user governments and their companies, universities, and (private, parastatal and governmental) research institutions, which are collectively the primary vehicles through which developed countries engage in "scientific research based on genetic resources."

\section{CODA 1.2 Establishment of facilities and research activities in the source country}

The other requirements of Article 15.6 seemingly cannot be passed through to industry. In most countries, it is not accepted for the government to compel private companies to establish operations in a particular country, to engage in partnerships or to take other actions, although they may provide incentives and inducements to take this type of action. Moreover,
Article 15.6 does not call on governments merely to regulate, but to take action. It seems clear that, in order to bring about this shift in the location (and thus the capacity development) in the genetic research field, it will be necessary for governments to take action that provides incentives or encouragements to companies that would otherwise be unlikely to under-

414 The other commitment to technological development is CBD Article 18.5, which calls on Parties to "promote the establishment of joint research programs and joint ventures for the development of technologies relevant to the objectives of this Convention." 
take the additional expense and regulatory demands of developing foreign research projects and facilities.

To date, there has been little information provided through $\mathrm{CBD}$ reporting and similar processes, regarding any country's concerted effort to implement

\section{CODA 1.3 Creation of opportunities}

Article 15.6 envisions a very important kind of benefit sharing and technology transfer, the creation of research and development opportunities. In terms of CBD objectives of promoting conservation and sustainable use, this "research opportunity" provision appears to be more important even than benefit sharing, for several reasons. First, a directed program which creates research facilities and assists in their development and successful operation will, of necessity, provide a broader understanding throughout the country of the importance of preservation of the country's biological diversity. Even if only communicated informally, the enlargement of recognition of this value by an educated and employed sector within the country will by definition add to the extent of acceptance by the electorate - the seat of primary decision-making in democratic systems around the world.

Second, as demonstrated by the current genetic research facilities located in and operated by developing countries, local development of facilities and capacity in this field fills a critical gap that is virtually unmet by existing research facilities in developed countries - the development of genetic-resource-based solutions to locally specific environmental, food security, and other problems. While developed-country facilities and companies offer their solutions to the world, their analysis of the problems to be addressed by genetic research is strongly tinged by the suite of issues most relevant to North America and Europe. For example, while multinational GMO development has focused
Article 15.6. To some extent, this reticence may be caused by the same internal political factors which are mentioned in the opening of this chapter - after all, there is an argument that an increase in the research capacity of developing countries may increase competition with user-country companies. ${ }^{415}$

on assisting farmers to combat specific problems (tolerance to certain pesticides and resistance to certain lepidopteron pests), the most pressing problems for farmers in Guatemala and South Africa, for example, have been adapting to more localized problems and conditions. ${ }^{416}$ Genetic research facilities and projects in these two countries have largely not needed (or attempted) to develop products that might compete with multinationals, but have tailored their work to addressing a more locally relevant suite of concerns.

Similarly, significant academic developments relating to potentially interesting properties such as the anti-parasitic properties of crocodilian blood (being studied and documented in the academic world) ${ }^{417}$ currently have little financial appeal for developed country pharmaceutical companies. However, intensive efforts to determine how these properties might be used pharmaceutically may be of critical importance to researchers in Africa, where the number of deaths from amoebic parasites (and connected diarrheic infections) are significant. ${ }^{418}$ Pharmaceutical development of these properties into saleable medicines may never yield the profits available for products directed at northern markets, but, if developed through sponsored or supported programs may have greater positive impact than the entire US\$ $21,500,000$ expended annually by the US on all of its international development, economic and technical assistance programs. ${ }^{419}$

415 See for example, UNITED STATES: Technology Transfer Act, 15 USC Sec. 3701, which includes a variety of incentives, including access to federal technology, as inducements for research and development, as well as international technology transfer and technical assistance by US enterprises.

416 Briefly discussed in Hårstad, 2005, reviewing more detailed information developed through the UNEP-GEF biosafety projects, and posted online at http://www.unep.ch/biosafety/. This website provides a wealth of information regarding the level of utilization of genetic resources through modern laboratory genetic modification by over 100 developing countries and countries in economic transition.

417 See, Merchant et al., 2006.

418 See, WHO information system, at http://www.who.int/topics/en/.

419 From US Agency for International Development, 2008 Budget Request, available online (in summary form) at http://www.usaid.gov/policy/budget/cbj2008/fy2008cbj_highlights.pdf. 


\section{CODA 2 Technology-transfer obligations in support of the third objective}

As noted above, the CBD appears to recognize that it may not be possible to make progress on the entire scope of the third objective through Article 15 alone. Although the negotiators clearly preferred Article 15 and its approach of passing on $\mathrm{ABS}$ requirements to user companies, the Convention also recognizes the broader equity needs of the benefit-sharing objective. In this connection, it notes a number of specific, separate national obligations of the Parties, in addition to Article 15. All of these requirements are specifically linked to $\mathrm{ABS}$, however, in that they utilize the basic mechanism - identification of the "country providing the genetic resources" as the recipient of particular kinds of benefits and support to national development.

In general, these provisions can be considered in two groups - (i) provisions that call on user countries to adopt further legislation (or extend the reach of benefitsharing legislation beyond the immediate "user" of particular genetic resources), and (ii) provisions linked to matters of direct national responsibility (such as Articles 20 and 21 (financial resources) of the CBD), which clearly cannot be "laid off" by imposing the obligation on user companies.

\section{CODA 2.1 Technology transfer and the sharing of less direct benefits}

In the first group, the Convention identifies a number of areas in which countries may attempt to promote the achievement of the third objective through legislation and policy. Thus Parties have specifically committed to take measures to provide the source country with "access to and transfer of technology," "220 "effective participation in biotechnological research activities" 421 and "advance priority access to the results and benefits arising from biotechnologies," 422 where the technologies, activities and results being provided utilize genetic resources from that country.

Each of these provisions is interesting individually, however, the collective importance of technology transfer (Articles 16, 18 and 19) to the achievement of all of the CBD objectives is more relevant to the current analysis, and has not been adequately studied. At this point, the analysis simply notes these three sub-clauses, and considers only two primary points - (i) the integration of technology transfer responsibilities with the $A B S$ provisions of Article 15 and (ii) the relatively subtle distinctions among these three specific provisions.

\section{CODA 2.2 Technology transfer as an element of benefit-sharing}

The scope of Articles 16 and 18, "technology transfer" and "technical cooperation (capacity building)" are not a part of the benefit-sharing system of Article 15 and contain hardly any reference to "genetic resources." These articles impose a broader requirement - to support all three objectives and the implementation of all the operative articles. Their relevance to ABS can be discerned by comparing their general provisions with those addressed to countries' with users under their jurisdiction. Similarly, the determination of what constitutes "utilization of genetic resources" under Article 15 , and when the ABS system ceases to apply (discussed in 3.3.2.6) may also be relevant in determining the point at which the Article 15 responsibilities of users are converted into the Article 16 and 18 responsibilities of user countries.

420 CBD Article 16.3, which provides in full that "Each Contracting Party shall take legislative, administrative or policy measures, as appropriate, with the aim that Contracting Parties, in particular those that are developing countries, which provide genetic resources are provided access to and transfer of technology which makes use of those resources, on mutually agreed terms, including technology protected by patents and other intellectual property rights, where necessary, through the provisions of Articles 20 and 21 and in accordance with international law andconsistent with paragraphs 4 and 5 below."

421 CBD Article 19.1, which provides in full that "Each Contracting Party shall take legislative, administrative or policy measures, as appropriate, to provide for the effective participation in biotechnological research activities by those Contracting Parties, especially developing countries, which provide the genetic resources for such research, and where feasible in such Contracting Parties."

422 CBD Article 19.2, which provides in full that "Each Contracting Party shall take all practicable measures to promote and advance priority access on a fair and equitable basis by Contracting Parties, especially developing countries, to the results and benefits arising from biotechnologies based upon genetic resources provided by those Contracting Parties. Such access shall be on mutually agreed terms." 


\section{CODA 2.3 Comparing the "technology transfer" obligations}

Four separate provisions of the CBD focus directly on transfer of technology to source countries (Articles 15.7, 16.3, 19.1 and 19.2) and a fifth does so indirectly (Article 15.6's provisions relating to "full participation" of the source country in scientific research). It seems appropriate to briefly consider the differences between them. In this discussion, it is useful to remember a basic rule of statutory interpretation - the assumption that every provision in a statute has a purpose. In other words, no provision should be assumed to be meaningless or a duplication. This raises a question: Do developed-country obligations of technology transfer extend further with regard to source countries that have provided genetic resources?

One of the clearest differences between Article 15.7 and the other provisions regarding technology transfer and sharing is their description of the countries with whom technology or results should be shared. While Article 15 applies to any country "which provided the genetic resources" without distinction, Articles 16.3, 19.1 and 19.2 apply "especially" to "developing countries." This is an important difference.

The existence of these three additional specific technology transfer provisions relating to genetic resources underscores the fact that Article 15 was intended to create a neutral mechanism for equitable recognition and compensation of the contribution of genetic resources to products and research. It also underscores the fact that the Convention's overall goal of equity cannot be met solely by such a neutral mechanism, but must be supplemented by special provisions for developing countries that are sources of relevant genetic resources. The specific reference "equity" in Article 15.7 is not repeated in the technology transfer provisions of Articles 15.6, 16.3 and 19.1.
The Convention appears to recognize that it will be necessary to transfer technology, and to promote technology transfer and national "participation" by developing countries in technological and product development, even beyond the particular equities of the individual transaction.

Another obvious distinction among the provisions is the nature of the information, technology and results being transferred. While Articles 15 and 16 focus on any research or information arising out of the utilization of genetic resources, Article 19 is focused specifically on "biotechnology." The difference between biotechnology and other utilization of genetic resources is not entirely clear in the CBD; however, it is clear that Article 19's provisions are generally stronger and more demanding than Articles 15 and 16 , suggesting that national governments have a much greater role with regard to "biotechnology" (whatever that is).

There is a further distinction among these four provisions regarding the type of action each country is expected to take. Articles 15.7, 16.3 and 19.1 all call for "legislative, administrative or policy measures, as appropriate," while Article 19.2 calls for "all practicable measures." Again this stronger and broader language appears to indicate that the Parties feel that there are at least two categories of utilization of genetic resources - "biotechnology" and "other utilization" and that the former is subject to a higher level of national obligation. In the opposite direction, Article 15.6 simply requires Parties to "endeavor" to carry out research measures in the source country and with source-country participation. This too suggests a lower level of obligation, where the development involved is not "biotechnology."

\section{CODA 3 Other genetic-resource-related responsibilities of user countries}

Finally, it is noted that several other CBD requirements are directly focused on the benefit-sharing objective and should be integrated with other user-country measures under ABS. Of these, one of the most important is Article 17, which requires countries to "facilitate the exchange of information, from all publicly available sources..., taking into account the special needs of developing countries." It also notes specifically that "such exchange of information shall where feasible, include repatriation of information." This provision could be very important to the ABS regime, if user countries make an affirmative effort to implement it. A frequent comment made during the CBD negotiations related to the fact that information 
taken from or based on the source country is rarely shared or repatriated. Regarding the claim that this information it is "publicly available," it is noted that source countries often do not have any practical means of finding or accessing it. Repatriation might also constitute the basis of a "registry" through which user countries keep track of information and genetic resources that have been accessed, utilized or otherwise "acquired... in accordance with the Convention."

Perhaps more important, however, are the ABS-related provisions of Articles 20 and 21, regarding the provision of financial assistance, both for implementation of the ABS system, and for actual contributions and benefit sharing. In several places, the CBD specifically notes that Articles 20 and 21 should be called upon, "where necessary," to enable the creation and operation of national ABS systems, and to support and create incentives through which benefit sharing can become a reality. ${ }^{423}$ Accordingly, it is necessary to note under Article 20.1, that countries have the obligation, through the financial mechanism and otherwise, to "provide, [each] in accordance with its capabilities, financial support and incentives in respect of those national activities which are intended to achieve the objectives of this Convention." More specifically, developed country Parties are expected to "provide, and developing country Parties avail themselves of, financial resources related to the implementation of this Convention through bilateral, regional and other multilateral channels." (Art. 20.3)

Perhaps most important to the overall creation of a functional $\mathrm{ABS}$ regime at international and national levels, the Convention calls on Parties to "consider strengthening existing financial institutions to provide financial resources for the conservation and sustainable use of biological diversity" (Art. 21.4).

423 See, Articles 1 (including the phrase "and by appropriate funding" in its description of the equitable benefit-sharing objective); 15.7 (noting that legislative, regulatory and other measures should be supplemented, "where necessary, through the financial mechanism established by Articles 20 and 21"), 16.3 (calling for technology transfer to be made available "where necessary, through the provisions of Articles 20 and 21 and in accordance with international law"); and the 15th and 16th preambular paragraphs (calling for "new and additional financial resources and appropriate access to relevant technologies.") 



\section{References}

Anton, M., N. Dragffy, S. Pendry and T.R.Young (eds). 2002. Proceedings of the International Expert Workshop on the Enforcement of Wildlife Trade Controls in the EU. IUCN-ELC and TRAFFIC International.

Bryant P.J. and D.S. Simpson. 1984. Intrinsic and extrinsic control of growth in developing organs. Quarterly Review of Biology 59:387415.

Barber, C.V. 2005. "Defining the Purpose, Scope and Modalities of an International Regime on Genetic Resources Access and Benefit Sharing: Some Issues for Discussion." Paper presented at the International Expert Workshop on Access to Genetic Resources and Benefit Sharing, Cape Town, 20-23 September 2005.

Beattie, A. 2005. "New Products and Industries from Biodiversity", Chapter 10 in Ecosystems and Human Well-being: Current State and Trends. Millennium Ecosystem Assessment.

Benavidez, P. 2004. "Philippines: Evolving Access and Benefit-sharing Regulations." Carrizosa, S., S. Brush, B. Wright and P. McGuire (eds), Accessing Biodiversity and Sharing the Benefits: Lessons from Implementing the Convention on Biological Diversity, pp 153-175. IUCN Environmental Policy and Law Paper No. 54. IUCNELC, in collaboration with BMZ, Germany and GRCP, University of California, Davis.

Bhatti, S., S. Carrizosa, P. McGuire and T. Young. 2007. Contracting for ABS: The Legal and Scientific Implications of Bioprospecting Contracts. IUCN Environmental Policy and Law Paper No. 67/4, The ABS Series.

Bostyn, S.J.R. 2002. "A European Perspective on the Ideal Scope of Protection and the Disclosure Requirement for Biotechnological Inventions in a Harmonised Patent System - The Quest for the Holy Grail?" The Journal of World Intellectual Property 5(6): 10131046.

Börkey, P, M. Glachant and F. Lévêsque. 1999. Voluntary Approaches for Environmental Policy: An Assessment. OECD.
Brown, M.G. 1994. "Is your Measurement System Well Balanced?" Journal for Quality and Participation 17(6): 611.

Cabrera Medaglia, J. and C. López Silva. 2007. Addressing the Problems of Access: Protecting Sources, While Giving Users Certainty. IUCN Environmental Policy and Law Paper No. 67/1, The ABS Series.

Casas-Castañeda, F. 2005. "User and provider country measures in the context of the international regime on access and benefit sharing." Paper presented at the International Expert Workshop on Access to Genetic Resources and Benefit Sharing, Cape Town, 20-23 September 2005.

Chambers, W.B. 2003. "Emerging International Rules on the Commercialization of Genetic Resources - The FAO International Plant Genetic Treaty and CBD Bonn Guidelines." The Journal of World Intellectual Property 6(2): 311328.

Chaytor, B., R. Gerster and T. Herzog. 2002. "The Convention on Biological Diversity - Exploring the Creation of a Mediation Mechanism." The Journal of World Intellectual Property 5(2): 157180.

Commoner, Barry. 2002. "Unraveling the DNA Myth: The spurious foundation of genetic engineering." Harper's Magazine, February, p. 39.

Coughanowr, C., M. Ngoile and O. Lindén. 1995. "Coastal Zone Management in Eastern Africa Including Island States." Ambio 24(78).

Correa, C. 2004. "The WIPO Draft Substantive Patent Law Treaty: A Review of Selected Provisions," Working Papers 17, South Centre.

Dahr, B. and R.V. Anuradha. 2004. "Access, Benefit Sharing and Intellectual Property Rights." The Journal of World Intellectual Property 7(5): 597639. 
Dross, M. and F. Wolff. 2005. New Elements of the International Regime on Access and Benefit Sharing of Genetic Resources - the Role of Certificates of Origin. German Federal Agency for Nature Conservation.

Dutfield, G. 2002. "Sharing the Benefits of Biodiversity - Is there a Role for the Patent System?" The Journal of World Intellectual Property 5(6): 899932.

Farnsworth, E.A., 2006. "Comparative Contract Law." Reimann, M. and R. Zimmermann, The Oxford Handbook of Comparative Law, pp. 899937. Oxford University Press.

Fernández Ugalde, J.C. 2005. "User and provider country measures in the context of the international regime." Presented in International Expert Workshop on Access to Genetic Resources and Benefit Sharing, Cape Town, 2023 September 2005.

Fowler, C., G. Hawtin, R. Ortiz, M. Iwanaga and J. Engels. 2004. "The Question of Derivatives Promoting Use and Ensuring Availability of Non-proprietary Plant Genetic Resources." The Journal of World Intellectual Property 7(5): 641663.

Fowler, C., M. Smale and S. Gaiji. 2001. "Unequal Exchange? Recent Transfers of Agricultural Resources and their Implications for Developing Countries." Development Policy Review 19(2): 181204.

Dedeurwaerdare and Frison. 2006. Infrastructures publiques et régulations sur l'Accès aux ressources génétiques et le Partage des Avantages qui découlent de leur utilisation pour l'innovation dans la recherche des sciences de la vie: Accès conservation et utilisation de la diversité biologique dans l'intérêt général. Service Public Fédéral Santé Publique, Sécurité de la Chaîne Alimentaire et Environnement, Belgium Environmental Directorate.

Gervais, D. 2003. "TRIPS, Doha and Traditional Knowledge." The Journal of World Intellectual Property 6(3): 403419.

Girsberger, M.A. 2004. “Transparency Measures under Patent Law regarding Genetic Resources and Traditional Knowledge - Disclosure of Source and Evidence of Prior Informed Consent and Benefit Sharing." The Journal of World Intellectual Property 7(4): 451490.
Glowka, L., F. Burhenne-Guilmin, H. Synge, J.A. McNeely and L. Gündling. 1994. A Guide to the Convention on Biological Diversity. IUCN Environmental Policy and Law Paper No. 30.

Glowka, L. 1998. A Guide to Developing National Legislative Frameworks to Determine Access to Genetic Resources. IUCN Environmental Policy and Law Paper No. 34.

Hårstad, J. et al. 2005. Evaluation of GEF Support for Biosafety. GEF.

Hendrickx, F., V. Koester and C. Prip. 1993. "Convention on Biological Diversity Access to Genetic Resources: A Legal Analysis." Environmental Policy and Law 23(6): 254-255.

Hiemstra, S.J., Drucker, A.G., Tvedt, M.W., Louwaars, N., Oldenbroek, J.K., Awgichew, K., Abegaz Kebede, S., Bhat, P.N. \& da Silva Mariante A. (2006). Exchange, Use and Conservation of Animal Genetic Resources: Identification of policy and regulatory options, CGN Report 2006/06. Wageningen (NL) Centre for Genetic Resources.

Hirsch, L. 2005. "Provider and User Country Measures - Do Two Wrongs Ever Make a Right?” Paper presented at the International Expert Workshop on Access to Genetic Resources and Benefit Sharing, Cape Town, 20-23 September 2005.

Hodges, T.J. and A. Daniel. 2005. "Deep Sea Genetic Resources and the International ABS Regime: Reflections on the Challenges Ahead." Paper presented at the International Expert Workshop on Access to Genetic Resources and Benefit Sharing, Cape Town, 20-23 September 2005.

Holm-Müller, K., C. Richerzhagen and S. Täuber. 2005. Users of Genetic Resources in Germany. BFNSkripten 126. German Federal Agency for Nature Conservation.

Hubert, P. and S. Hernandez. 2005. "Evaluation économique de l'utilisation des ressources génétiques en France." Interim report. 
IISD, Stratos and J. Cabrera. 2005. A Guide to Using the Working Draft ABS Management Tool. Swiss State Secretariat For Economic Affairs.

Jalbert, O. 2005. "Access to Genetic Resources and Benefit-Sharing under the Convention on Biological Diversity, the Bonn Guidelines and the Negotiation of the International Regime on Access and Benefitsharing." Feit, U., M. den Driesch and W. Lobin (eds.), Access and Benefit-sharing of Genetic Resources: Ways and Means for Facilitating Biodiversity Research and Conservation While Safeguarding ABS Provisions, pp. 9-18. BfN Skripten 163. German Federal Agency for Nature Conservation.

Krasner, S. 1982. "Structural causes and regime consequences: regimes as intervening variables." International Organization 36(2): 185205.

Latorre, F. 2005. Review of the Experience of Implementation by UK Stakeholders of Access and Benefitsharing Arrangements under the Convention on Biological Diversity. DEFRA, Royal Botanic Gardens Kew.

Lesser W. 1998. Sustainable use of Genetic Resources under the Convention on Biological Diversity, Exploring Access and Benefit Sharing Issues. CAB International.

Lettington, R. and D. Dogley. 2006. Commentary on the Development of the Republic of Seychelles Access to Genetic Resources and Benefit-sharing Bill. IPGRI.

McAfee, K. 1999. Selling Nature to Save it? Biodiversity and Green Developmentalism. Environment \& Planning D: Society and Space. Pion.

Merchant, M.E., K. Mills, N. Leger, E. Jerkins, K. Vliet and N. McDaniel. 2006. "Comparisons of Innate Immune Activity of all Known Living Crocodilian Species." In Proceedings of the 18th Working Meeting of the Crocodile Specialist Group, pp. 343-359. Montélimar: IUCN CSG. [Also see poster presentation at that meeting: M. Merchant et al., "Effects of Bacterial Lipopolysaccharide on Peripheral Leukocytes in the American Alligator," p. 364].
Mgbeoji, I. 2006. "Analysis of Four Claims of Unauthorised Access and Misappropriation of Genetic Resources and Associated Traditional Knowledge." Reprinted in: Young et al., 2007, Covering ABS: Addressing the Need for Sectoral, Geographical, Legal and International Integration in the ABS Regime. IUCN Environmental Policy and Law Paper No. 67, The ABS Series, Book 5.

Moore, G. and W. Tymowsky. 2005. Explanatory Guide to the International Treaty on Plant Genetic Resources. IUCN Environmental Policy and Law Paper No. 57.

Nuffield Council on Bioethics. 2001. The Ethics of Patenting DNA. The Nuffield Foundation of Bioethics.

Pythoud, F. 2005. “The International Treaty on Plant Genetic Resources for Food and Agriculture, a key component of the International Regime on Access and Benefit Sharing." Paper presented at the International Expert Workshop on Access to Genetic Resources and Benefit Sharing, Cape Town, 20-23 September 2005.

Oldam, P. 2004. "Global Status and Trends in Intellectual Property Claims." Genomics, Proteonomics and Biotechnology. CESAGEN.

bin Osman, M. 2005. "Issues of bioprospecting and implementation of ABS legislation at national and regional levels." Paper presented at the International Expert Workshop on Access to Genetic Resources and Benefit Sharing, Cape Town, 20-23 September 2005.

Parnham and Rispin. 2000. Residential Property Appraisal, Spon Press.

Pau Pedrón, A. 2002. "The Register as an Instrument of Security in Property Transactions." Sánchez Jordán, M.E. and A. Gambaro, Land Law in Comparative Perspective, pp. 8795. Kluwer Law International.

Reid, W., S. Laird, C. Meyer, R. Gámez, A. Sittenfeld, D. Janzen, M. Gollin and C. Juma. 1993. Biodiversity Prospecting: Using Genetic Resources for Sustainable Development. World Resources Institute. 
da Rocha Vianna, H. 2005. "Objectives and Possible Elements of an International Regime, and its Nature." Paper presented at the International Expert Workshop on Access to Genetic Resources and Benefit Sharing, Cape Town, 20-23 September 2005.

Romstad, E. and G. Stokstad. 2005. "Valuation of Genetic Resources." Study provided by the Norwegian Council of Genetic Resources, www.genressurser.no.

Rosenthal, J.P. 2006. "Politics, Culture, and Governance in the Development of Prior Informed Consent in Indigenous Communities." Current Anthropology 47(1): 116.

Rosenthal, J.P., D. Beck, A. Bhat, J. Biswas, L. Brady, K. Bridbord, S. Collins, G. Cragg, J. Edwards, A. Fairfield, M. Gottlieb, L.A. Gschwind, Y. Hallock, R. Hawks, R. Hegyeli, G. Johnson, G.T. Keusch, E.E. Lyons, R. Miller, J. Rodman, J. Roskoski and D. Siegel-Causey. 1999. "Combining High Risk Science with Ambitious Social and Economic Goals." Pharmaceutical Biology 37, supplement. Swets \& Zeitlinger.

Rosenthal, J., "Measure to Ensure Compliance with CBD and Access Legislation." Presented at the International Expert Workshop on Access to Genetic Resources and Benefit-sharing, Cuernavaca, 24-27 October 2004.

Rosenthal, J.P. 1996. "Equitable Sharing of Biodiversity Benefits: Agreements on Genetic Resources." Investing in Biological Diversity: Proceedings of the Cairns Conference. OECD.

Ruiz, M. and I. Lapeña (eds.) 2007. A Moving Target: Genetic Resources and Options for Tracking and Monitoring their International Flows. IUCN Environmental Policy and Law Paper No. 67/3, The ABS Series.

Safrin, S. 1998. "Hyperownership in a Time of Biotechnological Promise: The International Conflict to Control the Building Blocks of Life." The American Journal of International Law 98: 641.
Sampath, P.G. 2004. "Intellectual Property Rights on Traditional Medicinal Knowledge - A ProgressOriented Perspective." The Journal of World Intellectual Property 7(5): 711737.

Scott, P.T. 2005. "User and provider country measures in the context of the international regime: Some thoughts and observations based on the experiences of the Uniform Biological Material Transfer Agreement Project." Presented at the International Expert Workshop on Access to Genetic Resources and Benefit Sharing, Cape Town, 20-23 September 2005.

Shany, V. 2003. The Competing Jurisdictions of International Courts and Tribunals. Oxford University Press.

Smith, A. and T. Young. 2006. "Innovative financial and incentive mechanisms for promoting the conservation of High Conservation Value Forests." Forest Stewardship Council.

Svarstad H. and S. S. Dhillion. 2000. "Responding to bioprospecting: Rejection or regulation?” In Svarstad and Dhillion (eds). Bioprospecting. Spartacus.

Swiderska, K. 2001. Stakeholder Participation in Policy on Access to Genetic Resources, Traditional Knowledge and Benefit Sharing. Case studies and recommendations. Biodiversity and Livelihoods Issues, No 4. IIED.

Tobin, B. 2004. "Certificates of Origin, Legal Provenance and Source: Mutually Exclusive or Complementary Elements of a Comprehensive Certification Scheme." International Expert Workshop on Access to Genetic Resources and Benefit Sharing: Record of Discussion, pp. 271277 at 275. CONABIO and Environment Canada.

Tosh, D. and W. Rayburn. 2006. Uniform Standards of Professional Appraisal Practice. 13th Ed. Dearborn Real Estate Education.

Tvedt, M.W. 2007. [Forthcoming] "The Disclosure Obligation in Norwegian Legislation: Is it Likely to Lead to Fair and Equitable Benefit Sharing?” 
Tvedt, M.W., S.J. Hiemstra, Drucker, N. Louwaars, K. Oldenbroek. 2007. Legal Aspects of Exchange, Use and Conservation of Farm Animal Genetic Resources. The Fridtjof Nansen Institute 1/2007.

Tvedt, M.W. 2006. "Elements for Legislation in User Countries to Meet the Fair and Equitable BenefitSharing Commitment." The Journal of World Intellectual Property 9(2): 189-212.

Tvedt, M.W. 2005. "How Will a Substantive Patent Law Treaty Affect the Public Domain for Genetic Resources and Biological Material?" The Journal of World Intellectual Property 8(3): 311-344.

UNCITRAL (undated) "commentary on the UN Convention on Contracts for the International Sale of Goods" and Travaux Préparatoires, available online in UNCITRAL's website: http://www.uncitral.org/uncitral/en/uncitral_texts/sale_goods/1980CISG_travaux .html.

UNU-IAS. 2003. User Measures - Options for Developing Measures in User Countries to Implement the Access and Benefit-Sharing Provisions of the Convention on Biological Diversity. UNU-IAS.

Vogel, J. 2007. "Reflecting Financial and other Incentives of the TMOIFGR: The Biodiversity Cartel.” Ruiz and Lapeña, (eds.), A Moving Target: Genetic Resources and Options for Monitoring their International Flows, ch. 3. IUCN Environmental Policy and Law Paper No. 67/3, The ABS Series.

Waldron. 1993. Printed in Chisum, D. S. N., Craig Allen \& Schwartz, Herbert F. \& Newman, Pauline \& Kieff, F. Scott (1998). Principles of Patent Law. New York, Foundation Press.
WIPO Study No. 3. WIPO Technical Study on Patent Disclosure Requirements Related to Genetic Resources and Traditional Knowledge. WIPO Publication No. 786(E).

Westerlund, L. 2001. Biotech Patents -Equivalency and Exclusions under European and U.S. Patent Law. Juridiska fakulteten vid Stockholms universitet.

Wolfe, T.A. and B. Zycher. 2005. Biotechnological and Pharmaceutical Research and Development Investment Under a Patent-Based Access and Benefit-Sharing Regime. Pacific Research Institute.

Young, T. 2006a. "An Analysis of Claims of Unauthorized Access and Misappropriation of Genetic Resources and Associated Traditional Knowledge," distributed at AHWG-ABS-4 as UNEP/CBD/WG-ABS/4/INF/6.

Young, T. 2005. "Summary Analysis: Legal Certainty for Users of Genetic Resources under Existing Access and Benefit-sharing (ABS) Legislation and Policy," distributed at AHWG-ABS-3 as UNEP/CBD/WGABS/3/INF10.

Young, T. 2007. Covering ABS: Addressing the Need for Sectoral, Geographical, Legal and International Integration in the ABS Regime. IUCN Environmental Policy and Law Paper No. 67/5, The ABS Series.

Young, T. 2004. [Unpublished]. An Examination of Environmental Certification Systems and Standards Development: IUCN Situation Analysis. (IUCN/III-C).

Young, T. 2006b. An Implementation Perspective on International Law of Genetic Resources: Incentive, Consistency and Effective Operation. Yearbook of International Environmental Law 15: 393 (anchor article). Oxford University Press. 
AUSTRALIA: Environment Protection and Conservation Regulations, 2000, Statutory Rules 2000 No 181, as amended (taking into account amendments up to SLI 2006 No 131, Parts 8A, 9, 10, and 17).

AUSTRALIA: Queensland Biodiscovery Act, Act No 19, 24 Aug 2004; and other documents available on the CBD's ABS Measures database through March 2007.

BRAZIL: Provisional Act No 2,186-16 implementing the CBD Articles 1, 8j, 10c, 15 and 16, (August 23, 2001).

COSTA RICA: Normas Generales para el Acceso a los Elementos y Recursos Genéticos y Bioquimicos de la Biodiversidad; Decreto No. 31 514, 2003, issued pursuant to the Organic Law on the Environment $\left(\mathrm{N}^{\circ}\right.$ 7554 of 4 Oct. 1995) $\$ \$ 46-47$; and the Biodiversity Law (N 7788 of 30 April 1998), $\$ 62$.

COSTA RICA: Estrategia Nacional de Biodiversidad, 1999. Accessed via the CHM's ABS Measures database.

EUROPEAN COMMISSION: EU Directive on Legal Protection of Biotechnological Inventions (EC/98/44).

EUROPEAN COMMISSION: EC 2003 "Communication from the Commission to the European Parliament and the Council, The implementation by the EC of the 'Bonn Guidelines' on access to genetic resources and benefit-sharing under the Convention on Biological Diversity," COM(2003) 821 final, Brussels, 23.12.2003.

EUROPEAN COMMISSION: EC 2002, "Second Report of the European Community to the Convention on Biological Diversity: Thematic Report on Access and Benefit Sharing" (CHM).

EUROPEAN COMMISSION: 2001. Regulation (EC) No 761/2001 allowing voluntary participation by organizations in a Community Eco-Management and Audit Scheme (EMAS).
JAPAN: METI/KBA. 2006. Guidelines for Access to Genetic Resources for Users in Japan, Ministry of Economy, Trade and Industry (adopted March 2005, published in English, 2006). Available online in English at http://www.mabs.jp/information/oshirase/pdf/iden_tebiki_e.pdf.

NETHERLANDS: State Secretary of Agriculture, (undated), Nature Management and Fisheries, Sources of Existence: Conservation and the Sustainable Use of Genetic Diversity. Available online at http://www.absfocalpoint.nl/documents/note_on_biodiversity_Comple te.pdf.

NORWAY: The first draft Nature Diversity Act, NOU 2004:28. Available online at http://www.regjeringen.no/nb/dep/md/NOU-2004-28.html?id= 388846.

NORWAY: Draft Marine Resources Act, NOU 2005:10. Available online at http://www.regjeringen.no/Rpub/NOU/20052005/010/PDFS/NOU20 0520050010000DDDPDFS.pdf.

UNITED STATES: The Lacey Act enacted as Pub. L. 97-79, Sec. 3, Nov. 16, 1981 (last amended 2003), codified in the US Code at 16 USC \$\$ 3371-3378. Available online at http://www.Thomas.gov.

UNITED STATES: Stolen Property Act (NSPA), codified as 18 U.S. Code $\$ \$ 2314$ and 2315. Available online at http://www.Thomas.gov.

UNITED STATES: Federal Technology Transfer Act of 1986 (FTTA), enacted 20 Oct. 1986 as Public Law No 99-502, codified at 15 US Code 2781, 3701 and 3710. Available online at http://www.Thomas.gov.

UNITED STATES: National Park Service, September 2006, Servicewide Benefits-Sharing - Draft Environmental Impact Statement, Department of the Interior, U.S. found online at http://parkplanning.nps .gov/document.cfm?parkId=442\&projectId=12515\&do cumentID=16763.

(Other laws cited can be found in the CBD database of ABS measures at http://www.cbd.int/information/abs-measures.shtml) 


\section{About the Authors:}

\section{Morten Walløe Tvedt}

Morten Walløe Tvedt is currently senior research fellow at the Fridtjof Nansen Institute (FNI) in Oslo, Norway, where he has published extensively in the field of intellectual property rights, the Convention on Biological Diversity and genetic resources. His main research area is the interplay between international agreements relevant for biological diversity and genetic resources and their implementation in developed and developing countries.

His latest work includes interdisciplinary studies of exchange, sustainable use and conservation of Animal Genetic Resources (AnGR) for the FAO and the Nordic Gene Bank for Farm Animals. This includes a study of how the current work for further harmonization of patent law globally will affect the management of genetic resources.

His doctoral thesis deals with the sui generis alternative for establishing intellectual property rights to plant varieties according to the TRIPS Agreement Article 27.3b.
His first assignment on biological diversity and genetic resources was in the interdisciplinary research project From Plants in the South to Medicines in the North in 1999, where he conducted a legal case-study of the Costa Rican implementation of the CBD.

Before taking up the position at the FNI he worked as an assistant lawyer at the law firm Hjort DA in Oslo. During this period of time he had consultancy work for the Norwegian Ministry of Environment in their work to draft a Nature Diversity Act which, among a number of biodiversity-related issues, deals with the right to genetic resources in Norway and access to these resources.

He has extensive teaching experience in law, and has written two text books in legal argumentation and legal analysis.

He is a Norwegian citizen, currently residing in Bahia, Brazil and in Norway. 



\section{About the Authors:}

\section{Tomme Rosanne Young}

Tomme Rosanne Young is currently an independent consultant on environmental law and policy and international mechanisms. She began her legal career in the United States, where she initially worked in commercial and property law, slowly evolving to address the complex interaction of such laws with environmental obligations of companies and individuals. In 1988, she co-authored a legal treatise on this interrelationship (Machlin and Young, 1988, Managing Environmental Risk in Real Estate and Business Transactions, The West Group, (updated annually) which remains a standard reference and practice guide in American environmental law. During her years in private practice as an attorney in the US, she represented commercial clients, government agencies, towns and cities, and private citizens in a variety of venues, including administrative permitting, inspections and compliance, transactional negotiations, and litigation. In the late 1980s she began to work outside the United States, representing some private clients, but primarily working with governmental, intergovernmental, private sector and civil society groups in developing practical solutions to legislative and transactional needs and controversies

Between the years of 1988 and 2000, her primary employment was as a consultant on national environmental and technical legislation, working primarily through UN organs, including FAO, UNDP and the GEF. In that capacity, she provided technical assistance to 24 developing countries and countries in transition and to three indigenous groups in the drafting of environmental laws and setting up regulatory systems. In several of these assignments, her work focused on the application of commercial and financial concepts and laws to environmental purposes, including the use of environmental and conservation trust funds, mortgage and fee systems, commercial permit systems, certification programs, compensation systems, incentives and other measures for these purposes.

After 2000, Ms Young served as the Senior Legal Officer at IUCN until April 2006. While she continued to provide national legislative advice and technical assistance working directly with governments of nine countries, her primary work has been in international law and policy, particularly in working with and through global and regional environmental and conservation instruments, and assisting in their implementation at the national level. Since 2003, she has also headed The ABS Project, under which this book has been published. Her first formal work on ABS began under a FAO project initiated in 1991, under which she researched the issue in detail, preparatory to developing a guide for FAO member countries in implementing the CBD. She is proud to say that her opinions on $\mathrm{ABS}$ issues have evolved since that initial work.

She is a United States citizen, currently residing in Bonn, Germany. 


\title{
Publications of the ABS Project
}

\section{EPLP No. 54}

Accessing Biodiversity and Sharing the Benefits: Lessons from Implementing the Convention on Biological Diversity Edited by Santiago Carrizosa, Stephen B. Brush, Brian D. Wright, Patrick E. McGuire, 2004

Also available in Chinese (2006)

EPLP No. 57

Explanatory Guide to the International Treaty on Plant Genetic Resources for Food and Agriculture Gerald Moore and Witold Tymowski, 2005

Also available in French (2007) and Spanish (2007)

\section{The ABS Series}

\section{EPLP 67, No. 1}

Addressing the Problems of Access: Protecting Sources, While Giving Users Certainty

Jorge Cabrera Medaglia and Christian López Silva, 2007

\section{EPLP 67, No. 2}

Beyond Access: Exploring Implementation of the Fair and Equitable Sharing Commitment in the CBD Morten Walløe Tvedt and Tomme Young, 2007

EPLP 67, No. 3

A Moving Target: Genetic Resources and Options for Tracking and Monitoring their International Flows Manuel Ruiz and Isabel Lapeña, editors, 2007

EPLP 67, No. 4

Contracting for ABS: The Legal and Scientific Implications of Bioprospecting Contracts

Shakeel Bhatti, Santiago Carrizosa, Patrick McGuire, Tomme Young, editors, 2007

\section{EPLP 67, No. 5}

Covering ABS: Addressing the Need for Sectoral, Geographical, Legal and International Integration in the ABS Regime, Tomme Young, editor, 2007

Translations of The ABS Series into French and Spanish are forthcoming. The project continues to seek funds and other support for translation of the books into other languages. Interested persons and organizations may contact the Environmental Law Centre for more information:

\author{
Daniel Klein, Legal Officer \\ IUCN Environmental Law Centre \\ Godesberger Allee 108-112 \\ 53175 Bonn \\ Germany \\ E-mail: daniel.klein@iucn.org
}

A wider range of publications from the Environmental Law Centre can be found online: http://www.iucn.org/themes/law/info04.html 

Email: elcsecretariat@iucn.org

Phone: ++49 2282692231

Fax: ++492282692 250 